\title{
Social Security Reform in Spain
}

by

\section{Pedro Sainz de Baranda}

Ph.D. Materials Science and Engineering

Rutgers University (1991)

Ingeniero de Minas

ETSIMO (Spain, 1986)

Submitted to the Alfred P. Sloan School of Management in Partial Fulfillment of the Requirements for the Degree of

\section{Master of Business Administration \\ at the}

\section{Massachusetts Institute of Technology \\ June 2001}

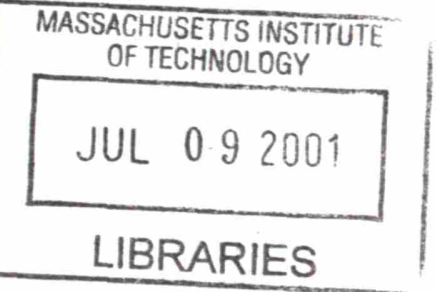

(C)2001 Pedro Sainz de Baranda. All rights reserved.

The author hereby grants MIT permission to reproduce and to distribute publicly paper and electronic copies of this thesis document in whole or in part.

Signature of Author:

$$
\begin{array}{r}
\text { Sloan School of Management } \\
\text { May 7, 2001 }
\end{array}
$$

Certified by:

Franco Modigliani Institute Professor Emeritus, Senior Lecturer Massachusetts Institute of Technology

Thesis Supervisor

Accepted by: 


\title{
Social Security Reform in Spain
}

by

\author{
Pedro Sainz de Baranda
}

Submitted to the Alfred P. Sloan School of Management on May 7, 2001 in Partial Fulfillment of the Requirements for the Degree of Master of Business Administration

\section{ABSTRACT}

The Spanish public pension system is currently based on the pay as you go (PAYGO) principle. This thesis examines the current structure of this public system and its financial viability in the face of expected demographic changes.

First, demographic and macroeconomic models were created extending out to 2050 and, based on them, the finances of the system were estimated assuming that the current regulations would remain largely unchanged. The simulations indicate that the system will show small surpluses for the next years followed by an alarming deterioration beyond 2020, mainly driven by demographic factors such as increasing life expectancy and the reduction in fertility rate observed in the last two decades. The baseline demographic and macroeconomic scenario results in a projected deficit of about $7 \%$ of GDP by 2045 . This outlook includes a reduction of unemployment and an increase in labor force participation within reasonable limits. It is also shown that high immigration, fertility and productivity growth, again, within reasonable limits, while improving the financial outlook, do not resolve the issue. Without significant reforms, the system will be faced with a reduction in benefits and/or an increase in the payroll-tax by the second quarter of this century.

The model is further used to test the effectiveness of potential reforms. We conclude that a permanent solution could be supported on three pillars:

1. The creation of a Pension Fund with the surpluses of the PAYGO system and a creative investment policy such as that recommended by Modigliani et al.

2. The contribution of the prospective surpluses from the unemployment system (INEM) to the fund during a transitory period.

3. Reforms in the pension calculating procedures that will foster participation in the labor force and eliminate some of the distortions introduced by the current system.

These reforms would maintain financial viability without having to raise the payroll-tax. Furthermore, the tax could be reduced gradually beyond 2045. Additionally, this reform would combine advantages from funded pension systems, such as deepening of the capital stock and consolidation of the financial markets, with those of PAYGO schemes, such as their redistributive aspects and "defined benefit" character.

Thesis Supervisor: Franco Modigliani

Title: $\quad$ Institute Professor Emeritus, Senior Lecturer 
Biographical Note:

Pedro Sainz de Baranda Riva joined the Sloan Fellows class of 2001 sponsored by United Technologies Corporation (UTC), where he was Manager of Advanced Technology at the Otis Elevator Company, a division of UTC. Prior to assuming this position he was a Principal Engineer at Otis for two years. Between 1993 and 1997 he worked at United Technologies Research Center, the central research organization for UTC, where he held positions of increasing responsibility ending up as General Manager of the Spanish operation. Prior to this, he worked as an engineer for an industrial construction firm in Spain.

He received a degree in Mining Engineering from the University of Oviedo (Spain) in 1986, graduating first in his class and receiving the "Outstanding Graduate Award" (Premio Extraordinario Fin de Carrera). He also holds a M.Sc. in Materials Science from Rutgers University (1988) and a Ph.D. in Ceramic Science and Engineering, also from Rutgers (1991).

Dr. Sainz de Baranda is a recipient of the 2000 George Mead Medal, the highest technical honor awarded by UTC. He is a member of the College of Mining Engineers in Spain as well as of the Fullbright Association (former scholarship recipients). A native of Spain, he is married and has three children.

\section{Acknowledgements:}

The author would like to acknowledge the sponsorship of United Technologies Corporation for this year at Sloan, as well as the insights and precious time of Franco Modigliani who was kind enough to guide this work. The author is also indebted to Juan Francisco Jimeno (FEDEA) for some useful discussions and materials. This work would not have been possible without the support of my wife Silvia. 


\section{TABLE OF CONTENTS}

Introduction

1. The Spanish Social Security system. 9

1.1. Background. 9

1.2. Description of the Social Security system. 9

1.3. The contributive protection system. 11

1.4. Evolution of the economics of the system up to the year 2000 . 17

2. Demographic data and projections. 19

2.1. Summary of recent demographic trends in Spain 19

2.2. Detailed demographic projections for Spain out to 2050 . 19

2.3. Results of the population model.

3. Macroeconomic and labor projections.

3.1. Recent trends and short-run projections. 39

3.2. Long-term projections.

4. Financial projections for the contributive programs of Social Security. 45

4.1. Income projections.

4.2. Expense projections.

4.3. Expected Social Security balance. Scenario analysis.

5. Social Security reform.

5.1. The need for Social Security reform. Recent proposals for Spain. 59

5.2. The Modigliani proposal for Social Security reform in the US. 61

5.3. Financial impact of potential reforms. The case of Spain. 62

$\begin{array}{lll}\text { 6. Conclusions and policy recommendations } & \mathbf{8 7}\end{array}$

\begin{tabular}{lr} 
7. & 91 \\
\hline
\end{tabular}

Appendix 1. Mortality projections.
95

Appendix 2. Fertility projections. 111

Appendix 3. The effect of the maxima for contributions and pensions. 117

Appendix 4. The real rate of return. 123 


\section{Introduction}

The public pension system, administered by the Social Security administration (Instituto Nacional de la Seguridad Social) is one of the pillars of the social protection system in Spain. This public pension system is currently funded as a pay-as-you-go (PAYGO) scheme, that is, current contributions from active workers (a payroll tax) are used to pay pensions for current retirees.

The scheme has come under increased financial pressure as a result of three trends:

- Increased generosity: There has been the political intent to increase pensions in real terms for those segments of society in greater need. Furthermore, the pension system has on occasion been used as an electoral weapon. This can also create a trend towards increasing generosity as political parties compete to outbid one another in the fight for the pensioner's votes.

- Deterioration in the labor markets: The large increase in the unemployment rate suffered in Spain during the eighties and nineties has eroded the payroll tax base below its theoretical potential.

- Demographic changes: An increase in the life expectancy combined with a dramatic decline in fertility rates since 1975 have made the old age dependency ratios (number of people retirement age divided by the people of working age) go up in the past years. The demographic expectations point towards further increases in this ratio which should result, everything else equal, in higher fiscal pressure on the existing wage base in order to maintain the pension commitments.

These trends, particularly the last one, are not unique to Spain and have been the subject of much scholarly and political debate in recent years. The future of the Spanish public pension system has spurred many debates and prompted many proposals for reform in recent years. Of particular importance have been the agreements of the Pacto de Toledo (1995) that have led to several positive reforms in the system. The economic expansion of the last half of the nineties has led to small surpluses for the Spanish public pension system and, in some circles, a potentially false sense of security for its financial viability.

The objective of this study is to assess the current and future health of the Spanish public pension system using the most recent data available for the year 2000 and, more importantly, to evaluate the impact of some potential reforms on the financial viability of the system.

To accomplish this, the work is divided into six sections. The first section includes a description of the Spanish public pension system (sistema contributivo de la Seguridad Social) including its financial performance over the last two decades. Sections two and three explore two of the key "exogenous" factors that can, and will, affect the future

\footnotetext{
${ }^{1}$ The macroeconomic outlook for the economy is not a truly exogenous factor. A successful reform of the public pension system can improve the output growth potential in the economy as discussed in Sections 5 and 6.
} 
financial outlook of the public pension system, namely the demographic projections and the macroeconomic evolution for the country. Section four outlines detailed financial projections for each of the main existing programs within the system. This section also includes an assessment of the sensitivity of these financial projections to changes in the demographic and macroeconomic outlook.

Section five presents the analysis of the impact of potential reforms on the financial outlook of the system. Those evaluated include two potential reforms that were widely discussed among policy makers, employers and unions at the time this thesis was written. These are the implementation of flexible retirement after age 64 and the extension of the number of years used to calculate the retirement pension from the last 15 prior to retirement to the last 35. This section also includes a brief description of a reform proposal put forward by Modigliani et al. for the United States and examines in detail its applicability to the Spanish social security system, both by itself and in combination with additional reforms to the PAYGO system currently in place. Finally section six summarizes the main findings and puts forward some policy recommendations that, if successfully implemented, should allow the Spanish social security system to meet its obligations to current and future retirees without raising the payroll tax to current or future workers. Furthermore, the simulations of the reformed system included in section five suggest that the payroll-tax could be substantially decreased, particularly after 2045 . 


\section{The Spanish Social Security system.}

\subsection{Background.}

The Social Security system in Spain has its roots in social protection policies started at the turn of the century. Reference 1 provides a good summary of the development of the social protection schemes in Spain.

The current system is anchored in the Constitution of 1978, which tasks the State with providing a public Social Security System for all citizens that will guarantee certain services as well as provide monetary contributions in case of necessity.

The future of the pension system was the subject of flagrant electoral manipulations during the campaign of 1993. This, combined with the notorious deterioration of the Social Security finances during the recession of that same year, triggered a multi-party discussion to reach an agreement that would meet two key objectives:

a) Provide a consensus path to guarantee the future of the pension system in Spain

b) Avoid the partisan use of the pension system as an electoral weapon. This can be especially dangerous to the viability of the system, as parties overbid for the votes of the pensioners.

The result of this discussion was the so-called "Pacto de Toledo", that resulted in the Ley de Consolidación y Regularización del Sistema de Seguridad Social, in July 1997. The reforms introduced were steps in the right direction and have shaped some of the current characteristics of the system as described next.

\subsection{Description of the Social Security system.}

The Social Security system in Spain provides three major types of protection/services:

- Monetary payments:

Contributive payments: Contributive pensions, temporary disability and maternity benefits. Earned as a result of contributions to the Social Security system during the active years of the worker and dependent on his/her contributive history.

Non- contributive payments. Intended to maintain a minimum living standard for all citizens in need. Include complements to pensions below certain levels and other monetary payments.

- Universal Health Care protection.

- Social Services: Social assistance programs for disfavored groups such as the disabled or the elderly.

It has therefore two main components, a contributive component (represented by the contributive pensions), and a universal component to which every citizen is entitled regardless of his or her contributive history.

Figure 1 below shows the evolution in nominal terms of the expenses for the different types of protection

Similarly, there are two main sources of funds:

- Contributions from the workers in the program (details below).

- Government transfers from the general budget (taxation).

Figure 2 shows the evolution in nominal terms of the sources of funds. 


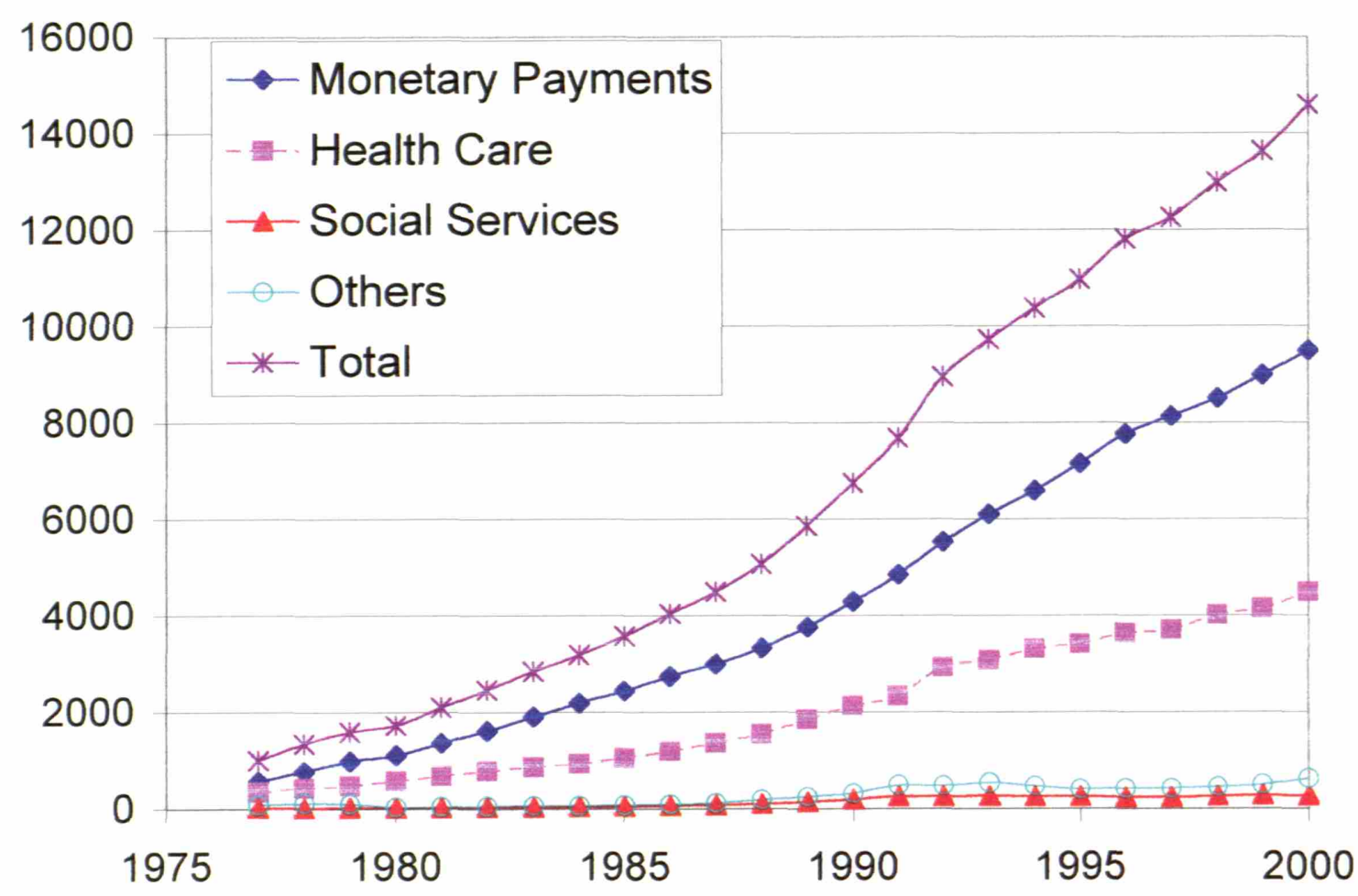

Figure 1. Evolution of Social Security expenses in Spain, in billion Pesetas. (Ref 3)

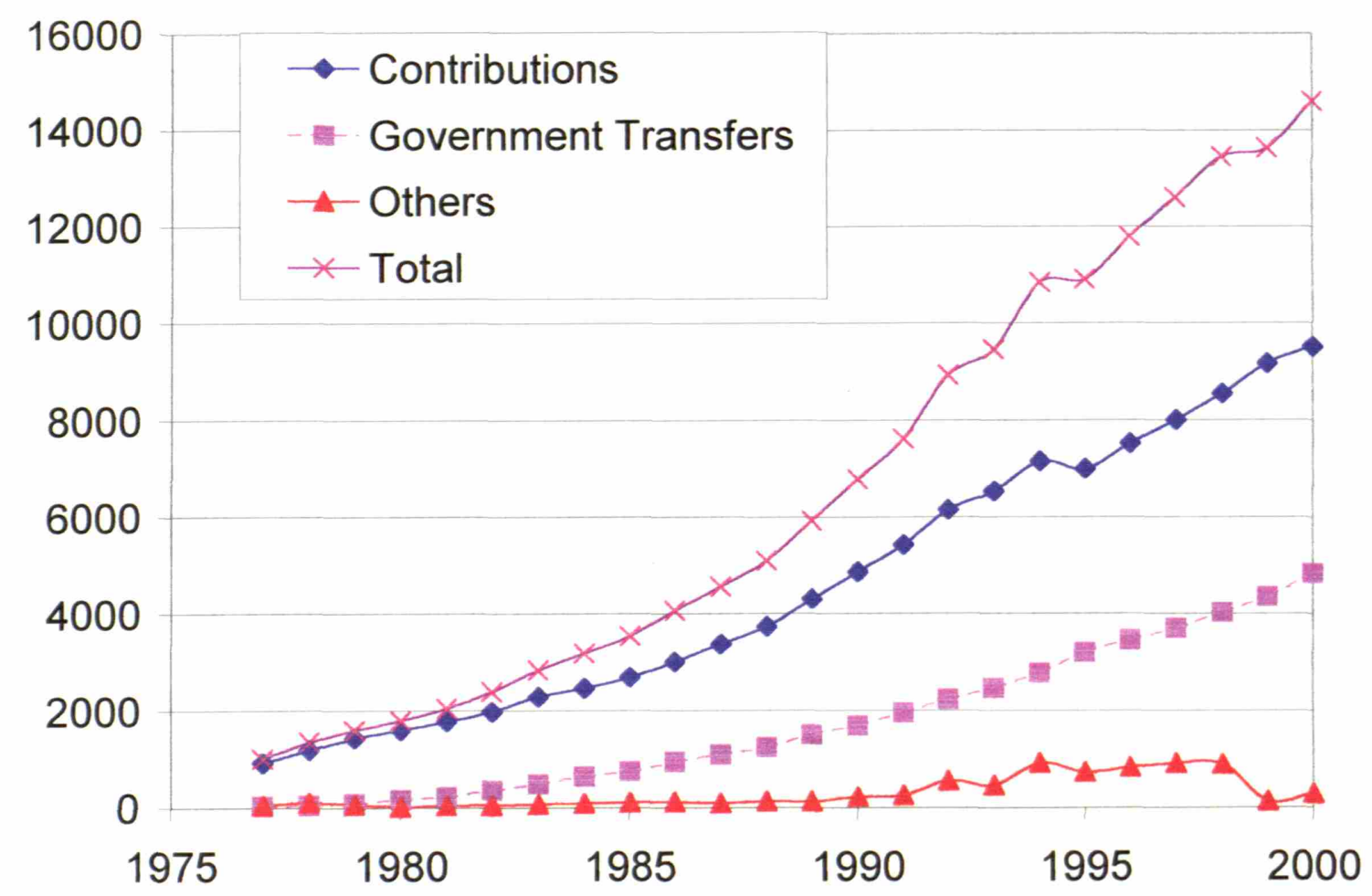

Figure 2. Evolution of Social Security revenues in Spain, in billion Pesetas. (Ref 3) 
The contributive and non-contributive pensions are managed by the INSS (Instituto Nacional de la Seguridad Social), Health services by the Instituto Nacional de la Salud and social services by the Instituto Nacional de Servicios Sociales. In order to introduce "solidarity" the finances are managed jointly for all services by the Tesorería General de la Seguridad Social. This "solidarity" resulted for years in the application of surpluses in the contributive pension system to finance the non-contributive (universal) programs.

Since the reform of 1997, the government is moving towards a clarification of the funding sources. Health care and non-contributive pensions will tend to be supported by government transfers (general taxation) while the contributive benefits, including pensions will be funded by the contributions. This change, however, was not fully implemented until the year 2000, and part of the surpluses of the pension system in the nineties were used to fund health care costs. Only in 2000 have surpluses from the pension system been allocated to a "Pension Fund".

This work will focus on the contributive protection system only. As is the case in all the EU countries, the public contributive pension system is based on the pay as you go (PAYG) principle by which contributions from active workers are used to fund the current pensions.

\subsection{The contributive protection system.}

The Social Security system has different schemes depending on the field of activity of the worker. The most common one is the General Scheme that covers most of the workers that are not self-employed. There are however several "Special Schemes" for groups that were deemed to need special protective actions. The ones currently in existence are:

- Special Scheme for self-employed workers

- Special Scheme for Farmers (Land workers)

- Special Scheme for Coal Miners.

- Special Scheme for Sea Workers.

- Special Scheme for Domestic Helpers

The rules for these special schemes are slightly different than those in the General Scheme. Table 1 documents some important parameters for each scheme for 2000.

Table 1. The Social Security schemes in 2000.

\begin{tabular}{|l|c|c|c|c|c|c|}
\cline { 2 - 7 } \multicolumn{1}{c|}{} & General & Self-employed & Farmers & Coal mining & Sea & Domestic \\
\hline Number of Pensions in 2000 & $4,182,856$ & 873,546 & $1,578,215$ & 75,358 & 129,296 & 205,289 \\
\hline Variation vs 1999 & $2.0 \%$ & $3.0 \%$ & $-0.5 \%$ & $-0.7 \%$ & $1.0 \%$ & $-0.1 \%$ \\
\hline Paid (million Pts) & $5,671,552$ & 691,170 & $1,244,064$ & 149,042 & 160,002 & 156,163 \\
\hline Variation vs 1999 & $6.1 \%$ & $7.8 \%$ & $3.1 \%$ & $5.1 \%$ & $5.5 \%$ & $4.0 \%$ \\
\hline \% of pensions paid & $70.3 \%$ & $8.6 \%$ & $15.4 \%$ & $1.9 \%$ & $2.0 \%$ & $2.0 \%$ \\
\hline Active workers per pension & 2.66 & 2.81 & 0.65 & 0.25 & 0.68 & 0.72 \\
\hline Contributions (million Pts) & $7,488,868$ & $1,049,844$ & 201,936 & 27,714 & 46,431 & 33,906 \\
\hline \% Contributions & $84.6 \%$ & $11.9 \%$ & $2.3 \%$ & $0.3 \%$ & $0.5 \%$ & $0.4 \%$ \\
\hline
\end{tabular}

Source: Ref. 3. From 2000 Social Security Budget

Figure 3 shows the evolution of the relative weight of the pension payments made under the different schemes. 


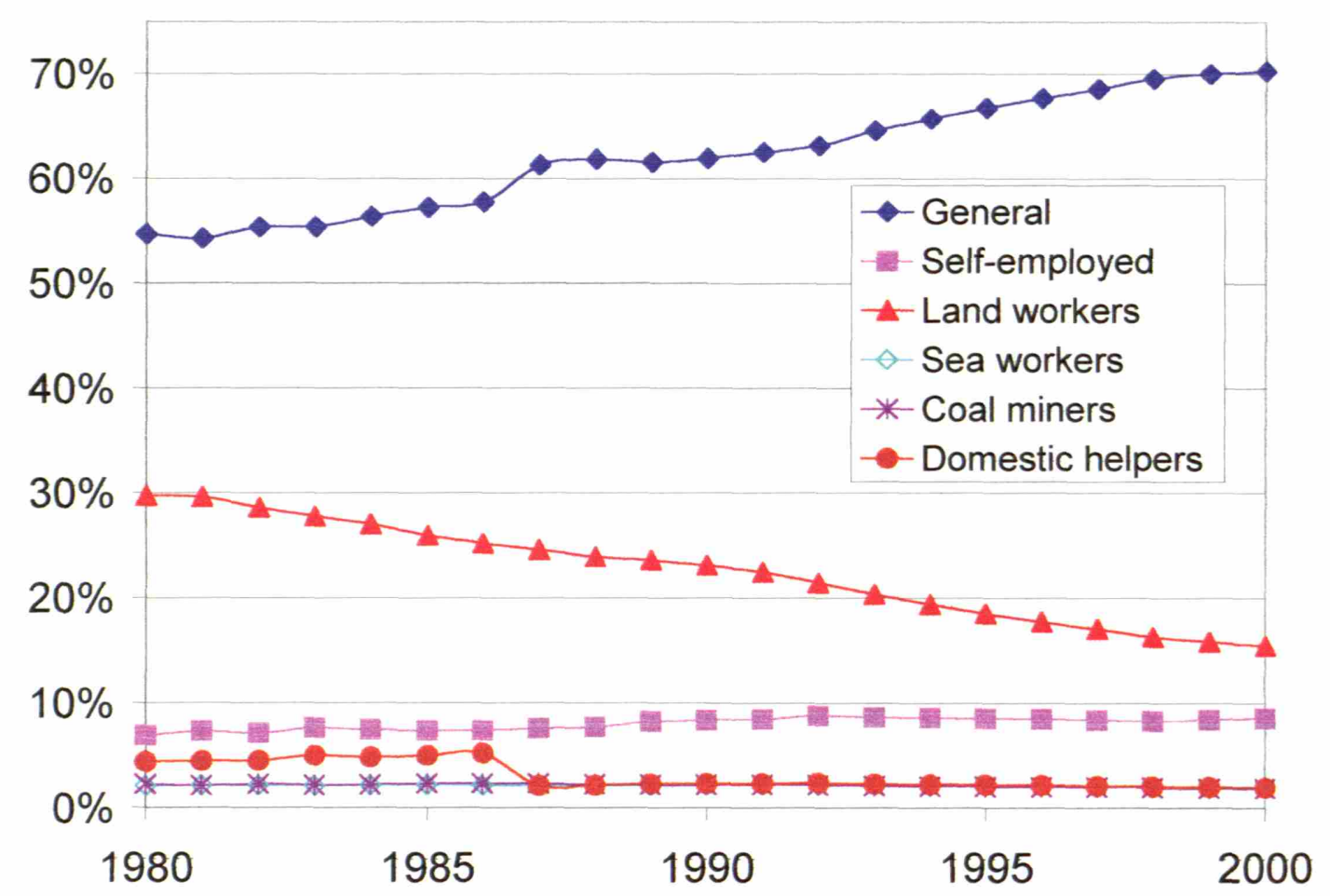

Figure 3. Weight of each scheme on the pension payments since 1980. (Ref. 3)

The weight of the special schemes for sea workers and coal miners is very small and declining. Given the ratio of active workers to pensioners shown in Table 1, the weight is expected to decline further. The Farmers scheme represents about $15 \%$ of the pensions paid in monetary terms, but only $0.3 \%$ of the income from contributions. The trend in pensions paid, the low number of active workers per pension and the changes in the Spanish economy suggest that the relative economic importance of this scheme will decline steadily.

The general scheme and the scheme for self-employed workers will be the prevalent ones in the future. As far as pensions are concerned, the contributions and rights gained in both schemes are rather similar. Besides, the legislature (2) has recommended the progressive merger of the different schemes into the conditions of the general scheme. The description that follows focuses on the conditions of the general scheme.

A detailed description of all the rules and regulations relative to the functioning of all the schemes can be found in reference 4 . The main features are summarized below for the general scheme. 


\subsubsection{Contributions.}

The contributions to the Social Security system are calculated as a percentage of the "Contribution Regulatory Base" (CRB).

The CRB is equivalent to the gross salary received by the employee, not including the contribution to the Social Security system made by the Company. There is a maximum and a minimum CRB established every year. Currently, these maximum and minimum vary depending on the "professional category" of the worker. However, there is a trend towards a convergence in the maximum and minimum for all workers. The minimum tends typically to the minimum wage increased by $1 / 6$. The maximum currently ranges from 369,750 to $407,790 \mathrm{Pts} / \mathrm{month}$ depending on the "professional category". These minimum and maximum are intended to be adjusted yearly by the CPI. However the minimum RB has grown faster than the CPI as the minimum wage has.

Table 2 shows the payments that must be made to the Social Security system.

Table 2. Payments made to the Social Security system (\% of CRB). (General Scheme)

\begin{tabular}{|l|c|c|l|}
\cline { 2 - 4 } \multicolumn{1}{c|}{} & \multicolumn{1}{c|}{ Employer } & Employee & \multicolumn{1}{c|}{ Purpose } \\
\hline General Contingencies & 23.6 & 4.7 & Contributive pensions \\
\hline Jobsite Accidents & Varies with job & 0 & Temporary disability \\
\hline Unemployment & 6.0 & 1.55 & Fund subsidies for unemployed workers \\
\hline FOGASA & 0.4 & 0 & Pay salary and severance in bankruptcies \\
\hline Training & 0.6 & 0.1 & Fund training programs for workers in need \\
\hline
\end{tabular}

Of these, only the first two are managed by the contributive programs of the Social Security. The other three are managed by independent entities that have focused on fighting unemployment and supporting unemployed workers. The Instituto Nacional de Empleo (INEM), an independent entity, pays the general contingencies contributions of those unemployed workers that have the right to perceive a contributive unemployment subsidy.

Table 3 details the amounts received by the Social Security from each of these two categories, as well as the total for the last decade. The contributions for general contingencies represent over $90 \%$ of the funding for the contributive programs.

Table 3 . Payments to Social Security for contributive programs. (million Pts, nominal)

\begin{tabular}{|r|r|r|l|}
\hline Year & General Contingencies & Jobsite Accidents & Total \\
\hline 1990 & $4,485,068$ & 375,690 & $4,860,758$ \\
\hline 1991 & $5,011,356$ & 409,529 & $5,420,885$ \\
\hline 1992 & $5,705,366$ & 436,334 & $6,141,700$ \\
\hline 1993 & $6,062,477$ & 428,204 & $6,490,681$ \\
\hline 1994 & $6,700,202$ & 446,649 & $7,146,851$ \\
\hline 1995 & $6,508,350$ & 471,742 & $6,980,092$ \\
\hline 1996 & $6,983,919$ & 529,306 & $7,513,225$ \\
\hline 1997 & $7,430,028$ & 563,356 & $7,993,384$ \\
\hline 1998 & $7,932,944$ & 607,180 & $8,540,124$ \\
\hline 1999 & $8,482,664$ & 583,100 & $9,065,764$ \\
\hline 2000 & $8,848,679$ & 651,080 & $9,499,759$ \\
\hline
\end{tabular}

Source Ref. 3. The latest figures for 1999 showed a total contribution income of 9,155 bPts and for 2000 , the estimate based on data up to November showed income of $9,900 \mathrm{bPts}$ 
1.3.2 Contributive payment programs. (See References 3 and 4 for full details)

Workers that contribute to Social Security gain title to the following contributive programs:

a) Contributive pensions: Retirement

Permanent disability

Survivors: Spouse

Children

Family support

b) Temporary disability. (A result of accident or illness, related or not to work activity)

c) Maternity leave.

Table 4 and Figure 4 illustrate the monetary weight of these programs.

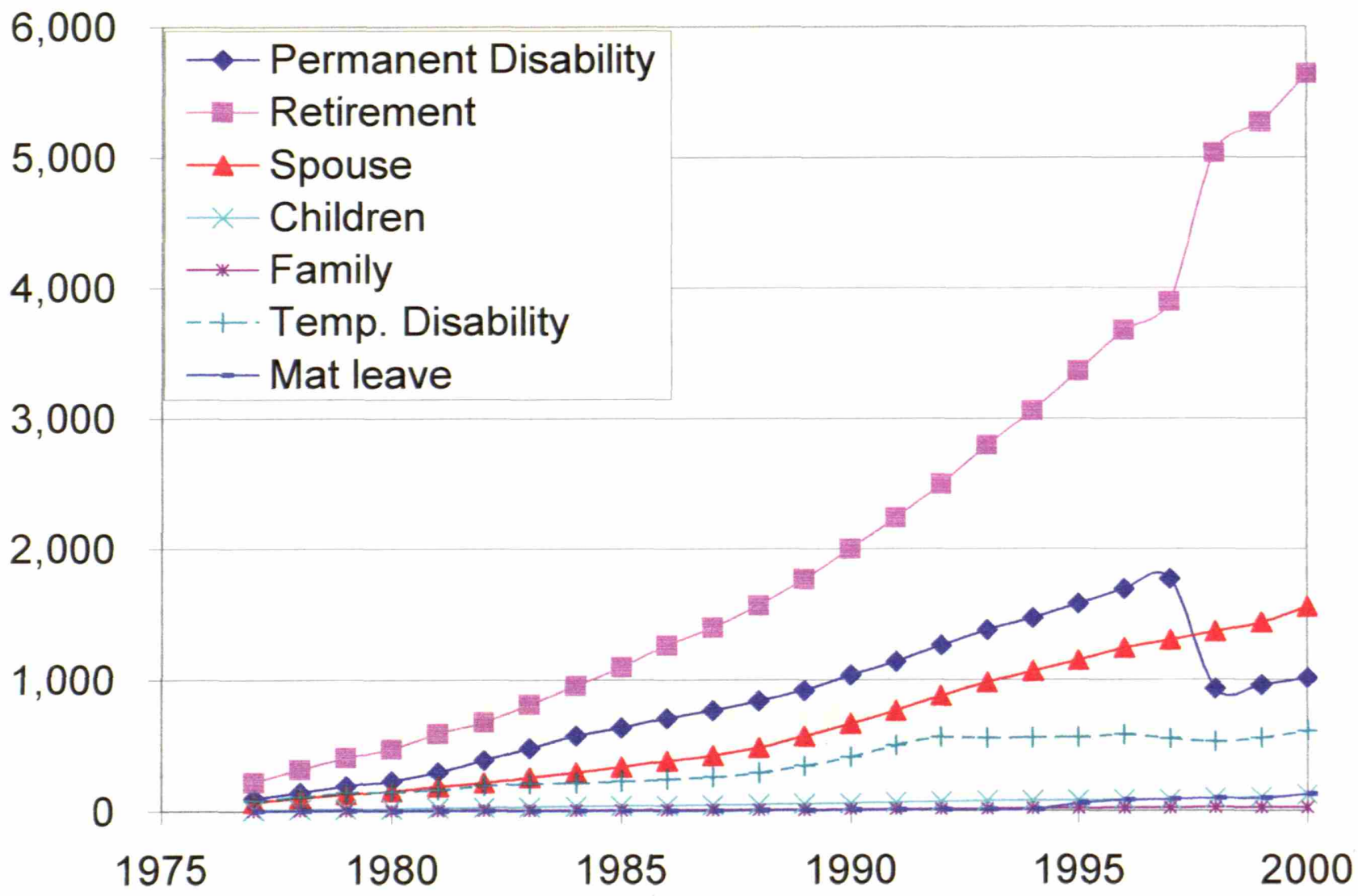

Figure 4. Benefits paid on the different contributive programs since 1977. In billion nominal Pts. (Ref. 3) 
Table 4. Benefits paid on the different contributive programs. (In billion nominal Pts)

\begin{tabular}{|c|c|c|c|c|c|c|c|c|c|c|}
\hline & \multicolumn{6}{|c|}{ CONTRIBUTIVE PENSIONS } & & \\
\hline Year & $\begin{array}{l}\text { Permanent } \\
\text { Disability }\end{array}$ & Retirement & Spouse & Children & Family & Total & $\begin{array}{c}\text { Temp. } \\
\text { Disability }\end{array}$ & $\begin{array}{l}\text { Mat. } \\
\text { leave }\end{array}$ & Other & Total \\
\hline 1977 & 98 & 219 & 67 & 9 & 1 & 394 & 81 & 0 & 15 & 490 \\
\hline 1978 & 141 & 317 & 100 & 13 & 2 & 573 & 111 & 0 & 14 & 698 \\
\hline 1979 & 192 & 408 & 130 & 16 & 3 & 749 & 142 & 0 & 13 & 904 \\
\hline 1980 & 230 & 472 & 151 & 19 & 3 & 875 & 148 & 0 & 8 & 1031 \\
\hline 1981 & 299 & 593 & 187 & 24 & 4 & 1,107 & 164 & 0 & 9 & 1280 \\
\hline 1982 & 390 & 680 & 215 & 28 & 5 & 1,318 & 195 & 0 & 9 & 1522 \\
\hline 1983 & 479 & 817 & 257 & 32 & 6 & 1,591 & 211 & 0 & 10 & 1812 \\
\hline 1984 & 576 & 956 & 295 & 37 & 7 & 1,870 & 214 & 0 & 10 & 2094 \\
\hline 1985 & 638 & 1,099 & 336 & 40 & 7 & 2,120 & 225 & 0 & 9 & 2354 \\
\hline 1986 & 708 & 1,265 & 382 & 45 & 8 & 2,408 & 241 & 0 & 9 & 2658 \\
\hline 1987 & 770 & 1,398 & 423 & 47 & 9 & 2,647 & 261 & 이 & 9 & 2917 \\
\hline 1988 & 841 & 1,567 & 483 & 51 & 9 & 2,951 & 291 & 2 & 10 & 3254 \\
\hline 1989 & 923 & 1,768 & 572 & 55 & 10 & 3,329 & 345 & 4 & 10 & 3688 \\
\hline 1990 & 1,037 & 2,001 & 669 & 61 & 12 & 3,781 & 414 & 6 & 12 & 4213 \\
\hline 1991 & 1,140 & 2,238 & 766 & 66 & 13 & 4,223 & 502 & 8 & 13 & 4746 \\
\hline 1992 & 1,263 & 2,496 & 877 & 71 & 14 & 4,721 & 565 & 9 & 15 & 5310 \\
\hline 1993 & 1,379 & 2,794 & 982 & 77 & 16 & 5,249 & 557 & 9 & 17 & 5832 \\
\hline 1994 & 1,470 & 3,058 & 1,062 & 79 & 19 & 5,688 & 561 & 9 & 16 & 6274 \\
\hline 1995 & 1,580 & 3,360 & 1,147 & 83 & 20 & 6,190 & 562 & 55 & 15 & 6822 \\
\hline 1996 & 1,695 & 3,673 & 1,241 & 87 & 22 & 6,717 & 585 & 80 & 15 & 7397 \\
\hline 1997 & 1,772 & 3,894 & 1,301 & 89 & 23 & 7,078 & 552 & 89 & 19 & 7738 \\
\hline $1998\left(^{*}\right)$ & 930 & 5,034 & 1,368 & 97 & 24 & 7,453 & 526 & 94 & 19 & 8092 \\
\hline 1999 & 959 & 5,269 & 1,436 & 108 & 25 & 7,796 & 555 & 94 & 22 & 8467 \\
\hline 2000 & 1013 & 5,640 & 1,556 & 122 & 26 & 8,357 & 610 & 125 & 24 & 9116 \\
\hline
\end{tabular}

(*) From 1998, permanent disability pensions for people over 65 are considered retirement pensions

Clearly, the retirement pension program and the surviving spouse program are the most significant ones. They are also the programs that will be most affected by the demographic changes expected during the coming decades. For full details on all the contributive programs can be found in references 3 and 4 . A brief description of the rules currently governing the two key programs follow.

\subsubsection{Retirement pensions:}

Requisites:

Must have paid the legal contributions to the Social Security for at least 15 years.

Must be 65 years old and stop any professional activities.

Amount paid:

There are 14 payments per year, each calculated as a percentage of the "Pension Regulatory Base" (PRB). The PRB is calculated (starting January 1, 2002) as:

$$
P R B=\frac{\sum_{i=1}^{24} C R B_{i}^{n}+\sum_{i=24}^{180} C R B_{i}^{r}}{210}
$$


Where $C R B_{i}^{n}$ is the contribution regulatory base for the $\mathrm{i}^{\text {th }}$ month before retirement in nominal terms (not adjusted for inflation), and $C R B_{i}^{r}$ is an equivalent term but adjusted by the CPI up to the $24^{\text {th }}$ moth prior to retirement.

Since the CRB is roughly the monthly gross salary, on an annual basis, 14x PRB would be $100 \%$ of the gross salary if this had been constant for the last 180 months and there was no inflation in the previous two years. Real salary increases (decreases) during the past 15 years and inflation (deflation) in the last two would make the PRB to last salary ratio lower (higher) than $100 \%$.

The pension becomes $100 \%$ of the PRB for people with 35 years of contributions or greater. It decreases at a rate of $2 \%$ /year of contribution down to $80 \%$ of PRB for people with 25 years of contribution and then at a rate of $3 \% /$ year of contribution down to $50 \%$ of the PRB for people with 15 years of contributions.

Note: Currently, workers that were contributive members to some specific programs before January 1, 1967 have an option to retire early; starting at 60 . The people that so choose will get an $8 \%$ reduction of their pension per year left for them to turn 65 .

\subsubsection{Surviving spouse pensions:}

Requisites:

Surviving spouses of pensioners or active workers with certain contribution profiles (4). Amount paid:

14 payments per year, each $45 \%$ of the "Pension Regulatory Base" (PRB). The PRB is the PRB for the pensioner or, for active workers:

$$
P R B=\frac{\sum_{i=1}^{24} C R B_{i}^{n}}{28}
$$

\subsubsection{Indexing.}

All existing pensions are indexed to the CPI.

Its is worth noting that the indexing to the CPI is done in relation to the CPI forecast, and should be adjusted at years end to reflect the actual CPI. However, only when the CPI is higher than the forecast have the pensions been revised. The government has lacked the political courage to adjust to the low side when the CPI was below expectations.

There has also been a political intent to increase the purchasing power of the minimum pensions and thus these (and the minimum salary to which they are to some extent indexed) have grown faster than the CPI. (Reference 1).

\subsubsection{Maximum and minimum pensions:}

The total pension received for all concepts cannot exceed 4,255,440 Pts/year (4). Therefore, for people contributing at the maximum level, the replacement rate drops to $87 \%$.

There are also minimums depending on the type of pension and the personal circumstances of the pensioner (4).

\subsubsection{An open wound. Minimum pensions.}

When a pensioner has earned a pension through the contributive system that is below a minimum established by law, the Social Security system pays a complement to increase his/her income up to a level that allows a decent subsistence. Although a respectable, an even desirable, policy, this is clearly a non-contributive benefit, and so was recognized at the agreements of the "Pacto de Toledo". Nonetheless, this benefit is still being financed from the contributions, rather than by government transfers from the general budget. 
Table 5. Shows the financial impact of this benefit and the sources of funds for it. In 1999 , approximately $52 \%$ of these funds went to retirement pensions and $44 \%$ to surviving spouse pensions.

Table 5. The complements for minimum pension and the sources of financing. (Billion nominal Pts.)

\begin{tabular}{|c|c|c|c|}
\hline Year & Gov. Transfers & Contributions & Total \\
\hline 1989 & 249.01 & 105.52 & $\mathbf{3 5 4 . 5 3}$ \\
\hline 1990 & 228.80 & 183.29 & $\mathbf{4 1 2 . 0 9}$ \\
\hline 1991 & 212.39 & 252.18 & $\mathbf{4 6 4 . 5 7}$ \\
\hline 1992 & 221.01 & 298.33 & $\mathbf{5 1 9 . 3 4}$ \\
\hline 1993 & 214.20 & 326.40 & $\mathbf{5 4 0 . 6 0}$ \\
\hline 1994 & 214.00 & 345.30 & $\mathbf{5 5 9 . 3 0}$ \\
\hline 1995 & 232.04 & 336.85 & $\mathbf{5 6 8 . 8 9}$ \\
\hline 1996 & 232.04 & 372.45 & $\mathbf{6 0 4 . 4 9}$ \\
\hline 1997 & 16.00 & 592.11 & $\mathbf{6 0 8 . 1 1}$ \\
\hline 1998 & 16.00 & 596.60 & $\mathbf{6 1 2 . 6 0}$ \\
\hline 1999 & 16.29 & 599.29 & $\mathbf{6 1 5 . 5 8}$ \\
\hline 2000 & 16.29 & 604.96 & $\mathbf{6 2 1 . 2 5}$ \\
\hline
\end{tabular}

1.4. Evolution of the economics of the system up to the year 2000.

Table 6 shows the financial evolution of the contributive programs in Spain isolated (in as much as has been possible) from the overall Social Security finances. ${ }^{2}$

The income from worker contributions have been quite steady at around $9.5-10 \%$ of GDP, while the cost of the contributive programs has increased steadily from about $7 \%$ to $9-10 \%$ of GDP in the period as a result of improved coverage and deteriorated demographics.

Note that the contributive system of the Social Security has always produced surpluses (except for a short period in 1995 and 1996 after the payroll tax was lowered one percentage point). However, these surpluses have always been used to fund other noncontributive programs. The first exception could be the year 2000, when part of the surplus may be allocated to the "Pension Reserve Fund".

The situation is even more favorable when the finances are analyzed assuming that the non-contributive complements for minimum pensions are funded out of the general budget and not out of contributions. In this case, the surplus would have been of about $1 \%$ of GDP for the past few years. .

\footnotetext{
${ }^{2}$ Note: A portion of the management expenses of Social Security has been allocated to the contributive programs. Management expenses for the contributive system were a total of about $3.7 \%$ of the contributions, of which half involves management of the temporary disability benefits. The trend has been for a management cost of $2.1 \%$ of the paid amounts for pensions and $27 \%$ of the paid amounts for temporary disability. (Reference 3 )
} 


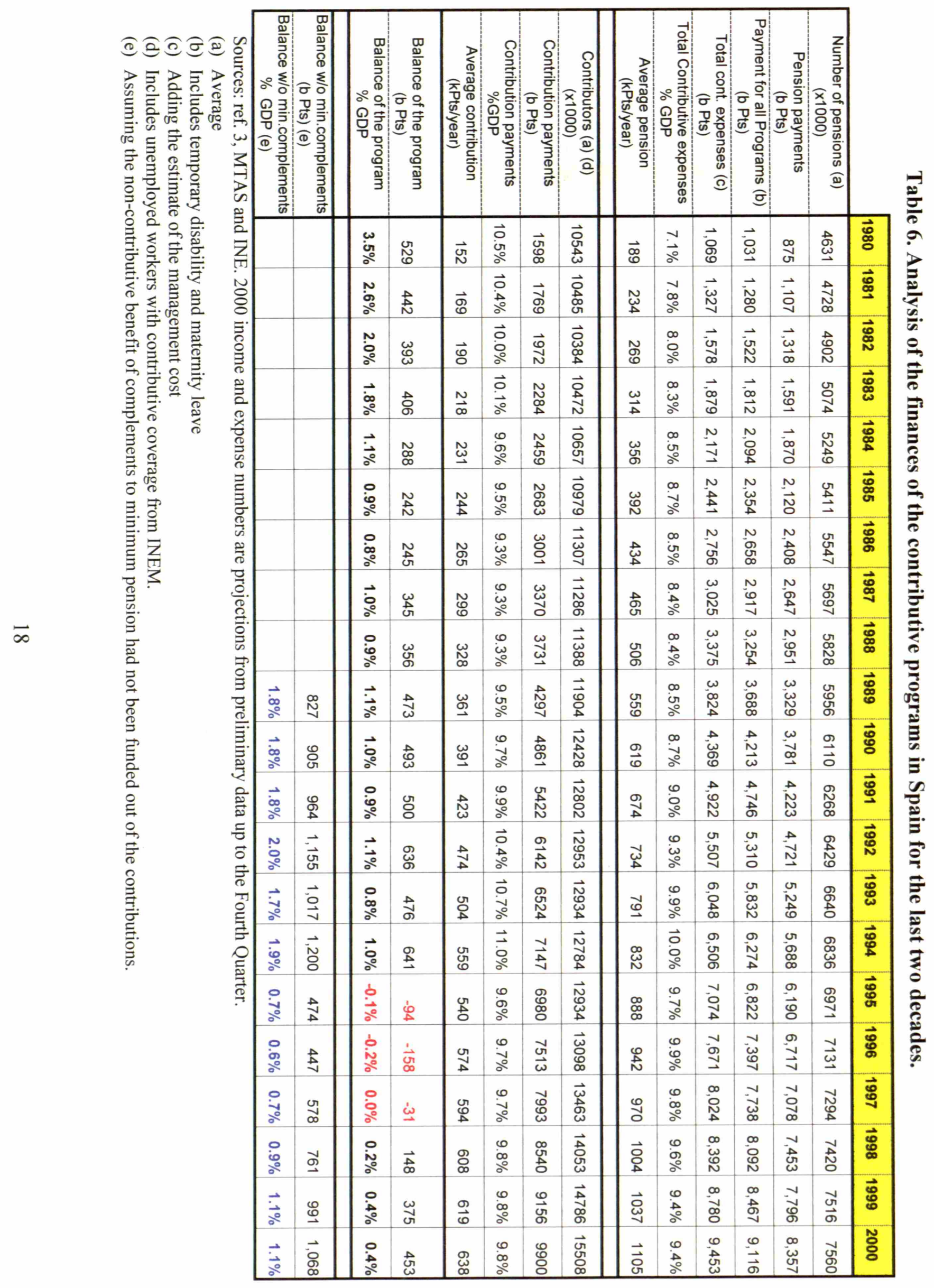




\section{Demographic data and projections.}

\subsection{Summary of recent demographic trends in Spain}

The key source for demographic data in Spain is the Instituto Nacional de Estadística (INE). The latest published data, at the time this work was written, were the census of 1991(5), the review of the municipal listings in 1996 (6) and the new municipal listings in 1998(7). Table 7 summarizes some of the key figures for the population in Spain in the last decades.

Table 7. Population in Spain. Some key recent historical data.

\begin{tabular}{|l|l|l|l|l|l|}
\cline { 2 - 6 } \multicolumn{1}{c|}{} & \multicolumn{1}{c|}{$\mathbf{1 9 7 1}$} & \multicolumn{1}{c|}{$\mathbf{1 9 8 1}$} & \multicolumn{1}{c|}{$\mathbf{1 9 9 1}$} & \multicolumn{1}{c|}{ May 1996 } & Jan 1998 \\
\hline Total Population & $\mathbf{3 4 2 1 6 2 7 4}$ & $\mathbf{3 7 7 4 1 4 6 0}$ & $\mathbf{3 8 9 1 9 9 1 0}$ & $\mathbf{3 9 6 6 9 3 8 5}$ & $\mathbf{3 9 8 5 2 6 5 2}$ \\
\hline $0-15$ years & 10076820 & 10271646 & $\mathbf{8 1 0 3 7 0 8}$ & 6930284 & 6570530 \\
\hline 15-64 years & 20799873 & 23196732 & 25387404 & 26542607 & 26778356 \\
\hline$>64$ years & 3339581 & 4273082 & 5428798 & 6196494 & 6503766 \\
\hline Youth dependency ratio $(*)$ & $48.4 \%$ & $44.3 \%$ & $31.9 \%$ & $26.1 \%$ & $24.5 \%$ \\
\hline$>64$ dependency ratio $(* *)$ & $16.1 \%$ & $18.4 \%$ & $21.4 \%$ & $23.3 \%$ & $24.3 \%$ \\
\hline Total dependency ratio & $64.5 \%$ & $62.7 \%$ & $53.3 \%$ & $49.5 \%$ & $48.8 \%$ \\
\hline
\end{tabular}

(*) Ratio of population under 16 to population between 16 and 64

(**) Ratio of population over 64 to population between 16 and 64

The trends are clear and consistent with observations in other European countries:

a) A reduction in the fertility rate has resulted in fewer births and a significant reduction in the youth dependency ratio in the 80 s and 90 s.

b) An increase in the life expectancy has resulted in increases in the old age dependency ratio.

Both factors combined result in rapid aging of the population of Spain in the past few decades. These issues will be discussed in more detail below to support the construction of the demographic models used to predict future population changes in Spain.

\subsection{Detailed demographic projections for Spain out to 2050.}

The number of pensioners depends strongly on the number of people over the retirement age in the country. Demographic projections are, therefore essential in estimating the future structure of the pension system. This section presents the methodology used to make such projections as well as the results obtained.

There are some published projections for the population of Spain out into the XXI century. The main ones are published by the INE (5), based on the Census of 1991 and by Juan Antonio Fernández Cordón, from the Consejo Superior de Investigaciones Científicas. This latter author published data based on the 1991 census (8) as well as updated projections based on the 1998 municipal listings (9).

This latter forecast, used for the analysis of the Spanish pension system included in references 10 and 11 is currently the best available in the literature.

We will develop a demographic forecast for Spain using the same methodology that is outlined in references 5 and 9 . This is done in order to obtain data with the necessary granularity to evaluate the impact of policy recommendations and to be able to have flexibility in assessing the impact of different possible demographic evolutions on the future of the pension system. 
The projections, will be based on a known starting population and independent forecasts of the three components of the population change, deaths, births and migrations; all of them based on recent data from Spain and trends from comparable countries.

\subsubsection{Starting population:}

The latest official data, from 1998, were used as the basis to reconstruct the starting population. However as noted in (9), these data are inconsistent with the birth and death data published by INE for the years preceding the census. The discrepancies are particularly significant for children ages 0 and 1 on January 11998 . For this reason, these numbers have been adjusted based on the birth and death data for 1996 and 1997, which are deemed more reliable. This results in an increase in the population ages 0 and 1 (and thus the total population) of a little over 129,000 , bringing the total starting population to $39,981,895$.

Table 8 details the starting population used for the projections by gender and age.

\subsubsection{Mortality.}

One of the most dramatic impacts on the population structure has come from the reduction in mortality rates. In 1900, the life expectancy at birth in Spain was 34.8 years, while in 1997 was 74.9 for men and 81.9 for women, clearly among the highest in the world. Figure 5 shows the evolution of the life expectancy at birth for both men and women since 1900, together with the projections used in this study.

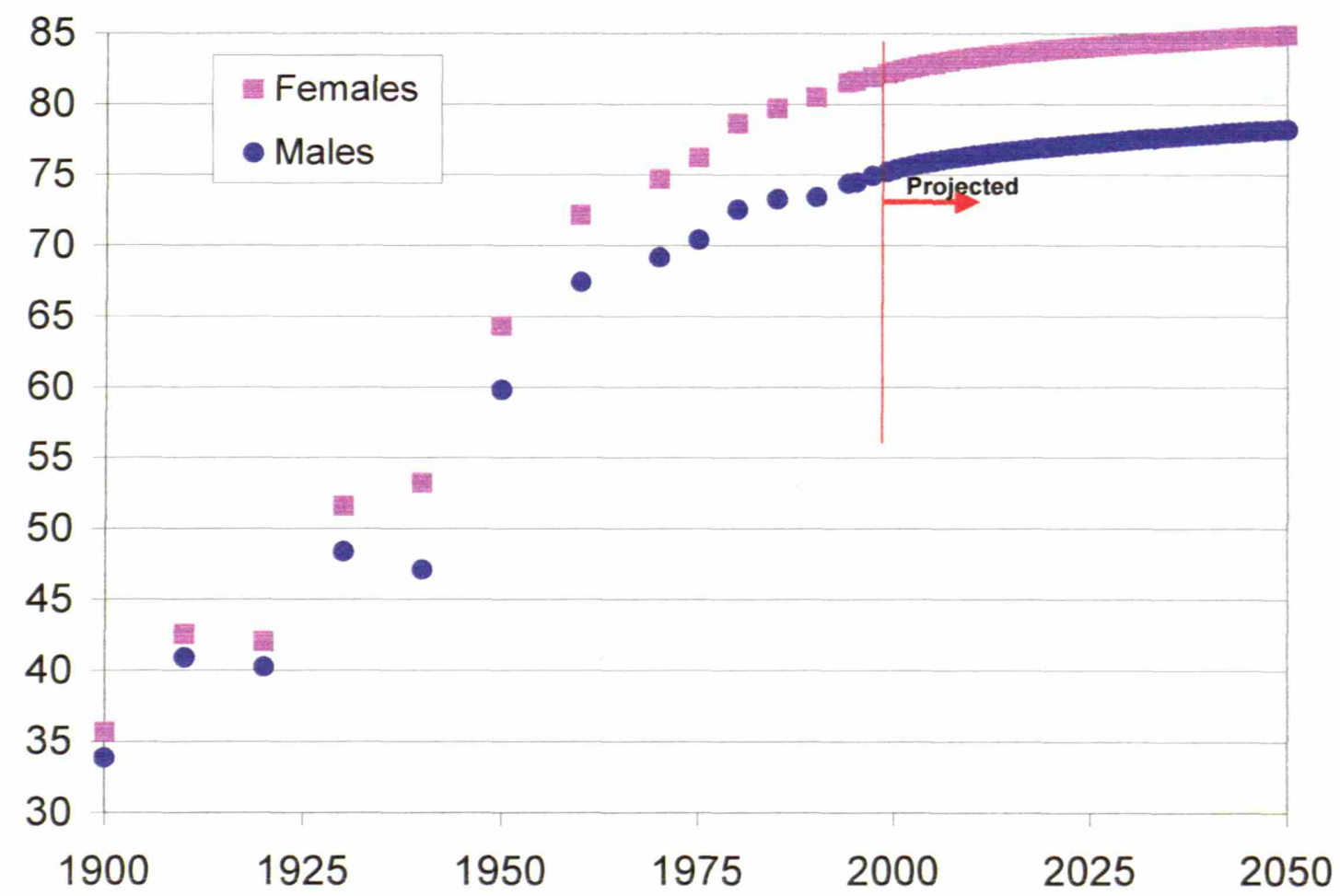

Figure 5. Evolution of life expectancy in Spain.

(Historical data from www.ine.es/prensa/npot3.htm INE projections from this work.) 
Table 8. Starting population.

\begin{tabular}{|c|c|c|c|c|c|c|c|}
\hline Age & Males & Females & Total & Age & Males & Females & Total \\
\hline 0 & 189,063 & 178,116 & 367,179 & 51 & 225,803 & 230,988 & 456,791 \\
\hline 1 & 185,431 & 175,006 & 360,437 & 52 & 239,130 & 245,667 & 484,797 \\
\hline 2 & 184,719 & 175,135 & 359,854 & 53 & 226,625 & 233,442 & 460,067 \\
\hline 3 & 188,074 & 178,615 & 366,689 & 54 & 225,357 & 231,105 & 456,462 \\
\hline 4 & 197,288 & 186,779 & 384,067 & 55 & 195,448 & 200,952 & 396,400 \\
\hline 5 & 205,367 & 195,432 & 400,799 & 56 & 180,091 & 184,964 & 365,055 \\
\hline 6 & 205,140 & 194,050 & 399,190 & 57 & 223,405 & 232,632 & 456,037 \\
\hline 7 & 209,531 & 198,948 & 408,479 & 58 & 146,721 & 158,244 & 4,965 \\
\hline 8 & 214,159 & 203,209 & 417,368 & 59 & 168,503 & 180,388 & 8,891 \\
\hline 9 & 216,514 & 205,156 & 421,670 & 60 & 190,269 & 204,207 & 4,476 \\
\hline 10 & 216,298 & 204,617 & 420,915 & 61 & 209,853 & 232,000 & 441,853 \\
\hline 11 & 222,720 & 211,753 & 434,473 & 62 & 204,559 & 223,018 & 427,577 \\
\hline 12 & 231,952 & 220,259 & 452,211 & 63 & 203,150 & 223,344 & 494 \\
\hline 13 & 247,498 & 235,391 & 482,889 & 64 & 210,177 & 231,971 &, 148 \\
\hline 14 & 254,228 & 241,920 & 496,148 & 65 & 207,257 & 230,726 & 437,983 \\
\hline 15 & 270,635 & 256,770 & 527,405 & 66 & 197,145 & 220,493 & 417,638 \\
\hline 16 & 287,412 & 272,608 & 560,020 & 67 & 196,018 & 226,232 & 422,250 \\
\hline 17 & 301,365 & 287,460 & 588,825 & 68 & 183,379 & 213,793 & 397,172 \\
\hline 18 & 312,628 & 297,910 & 610,538 & 69 & 179,331 & 213,562 & 392,893 \\
\hline 19 & 330,753 & 314,591 & 645,344 & 70 & 165,867 & 199,273 & 365,140 \\
\hline 20 & 336,785 & 320,533 & 657,318 & 71 & 164,194 & 200,748 & 364,942 \\
\hline 21 & 345,682 & 331,906 & 677,588 & 72 & 151,517 & 191,136 & 342,653 \\
\hline 22 & 346,846 & 332,595 & 679,441 & 73 & 145,132 & 187,203 & 332,335 \\
\hline 23 & 343,607 & 331,215 & 674,822 & 74 & 137,351 & 178,441 & 315,792 \\
\hline 24 & 338,470 & 325,469 & 663,939 & 75 & 129,109 & 177,664 & 306,773 \\
\hline 25 & 337,307 & 325,879 & 663 & 76 & 118,719 & 158,770 & 277,489 \\
\hline 26 & 333,078 & 321,791 & 654,869 & 77 & 101,328 & 153,241 & 254,569 \\
\hline 27 & 329,037 & 319,469 & & 78 & 82,755 & 129,955 & 212,710 \\
\hline 28 & 326,634 & 318,488 & 645 & 79 & 75,877 & 127,277 & 203,154 \\
\hline 29 & 324,779 & 318,237 & 643,016 & 80 & 68,166 & 116,668 & 184,834 \\
\hline 30 & 329,605 & 324,345 & 653,950 & 81 & 62,198 & 109,097 & 171,295 \\
\hline 31 & 326,916 & 320,991 & 647,907 & 82 & 57,408 & 104,000 & 161,408 \\
\hline 32 & 325,486 & 322,486 & 647,972 & 83 & 51,736 & 98,319 & 150,055 \\
\hline 33 & 331,881 & 329,323 & 661,204 & 84 & 45,919 & 88,774 & 134,693 \\
\hline 34 & 319,124 & 315,075 & 634,199 & 85 & 40,561 & 81,921 & 122,482 \\
\hline 35 & 308,209 & 306,796 & 615,005 & 86 & 34,293 & 70,112 & 104,405 \\
\hline 36 & 302,533 & 302,679 & 605,212 & 87 & 29,136 & 63,609 & 92,745 \\
\hline 37 & 306,671 & 306,845 & 613,516 & 88 & 23,771 & 51,927 & 75,698 \\
\hline 38 & 300,049 & 300,305 & 600,354 & 89 & 19,482 & 43,128 & 62,610 \\
\hline 39 & 294,975 & 295,549 & 590,524 & 90 & 14,775 & 35,234 & 50,009 \\
\hline 40 & 289,565 & 290,929 & 580,494 & 91 & 11,164 & 28,343 & $\mathbf{3 9 , 5 0 7}$ \\
\hline 41 & 271,023 & 272,083 & 543,106 & 92 & 8,714 & 22,603 & 31,317 \\
\hline 42 & 264,185 & 266,038 & 530,223 & 93 & 6,025 & 16,763 & 22,788 \\
\hline 43 & 252,864 & 255,543 & $\mathbf{5 0 8 , 4 0 7}$ & 94 & 4,529 & 12,746 & 17,275 \\
\hline 44 & 255,984 & 256,255 & 512,239 & 95 & 3,224 & 9,616 & 12,840 \\
\hline 45 & 257,224 & 256,402 & 513,626 & 96 & 2,148 & 6,142 & 8,290 \\
\hline 46 & 239,940 & 240,788 & 480,728 & 97 & 2,194 & 5,435 & 7,629 \\
\hline 47 & 236,227 & 236,877 & 473,104 & 98 & 1,597 & 3,298 & 4,895 \\
\hline 48 & 245,770 & 249,374 & 495,144 & 99 & 470 & 1,540 & 2,010 \\
\hline 49 & 258,374 & 262,528 & 520,902 & 100 & 788 & 2,700 & 3,488 \\
\hline 50 & 236,433 & 239,560 & 475,993 & Total & $19, \mathbf{5 5 8}, \mathbf{4 0 6}$ & $20,423,489$ & 81,895 \\
\hline
\end{tabular}

Sources: 1998 municipal listings. Ages 0 and 1 modified from official birth and infant mortality data (INE) 
Mortality in Spain has been at the level of developed countries for the last three to four decades, but despite being at such a low level, it has continued to decrease in the recent years. Figure 6 shows the death rates, or Probability of death (POD), recorded for Spain by gender and simple age.
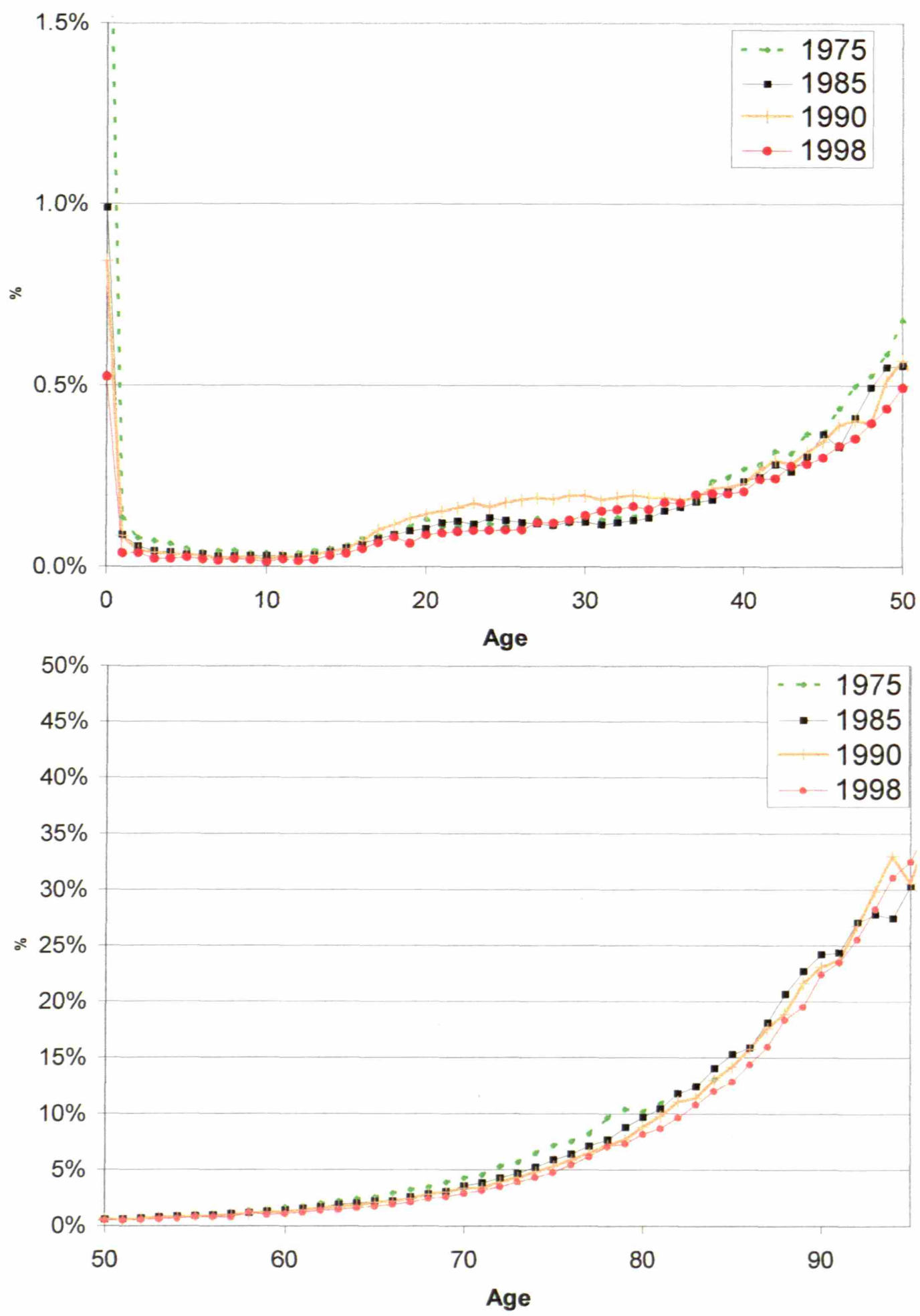

Figure 6.a. Probability of death for Spanish males. (Based on deaths and population data from INE) 

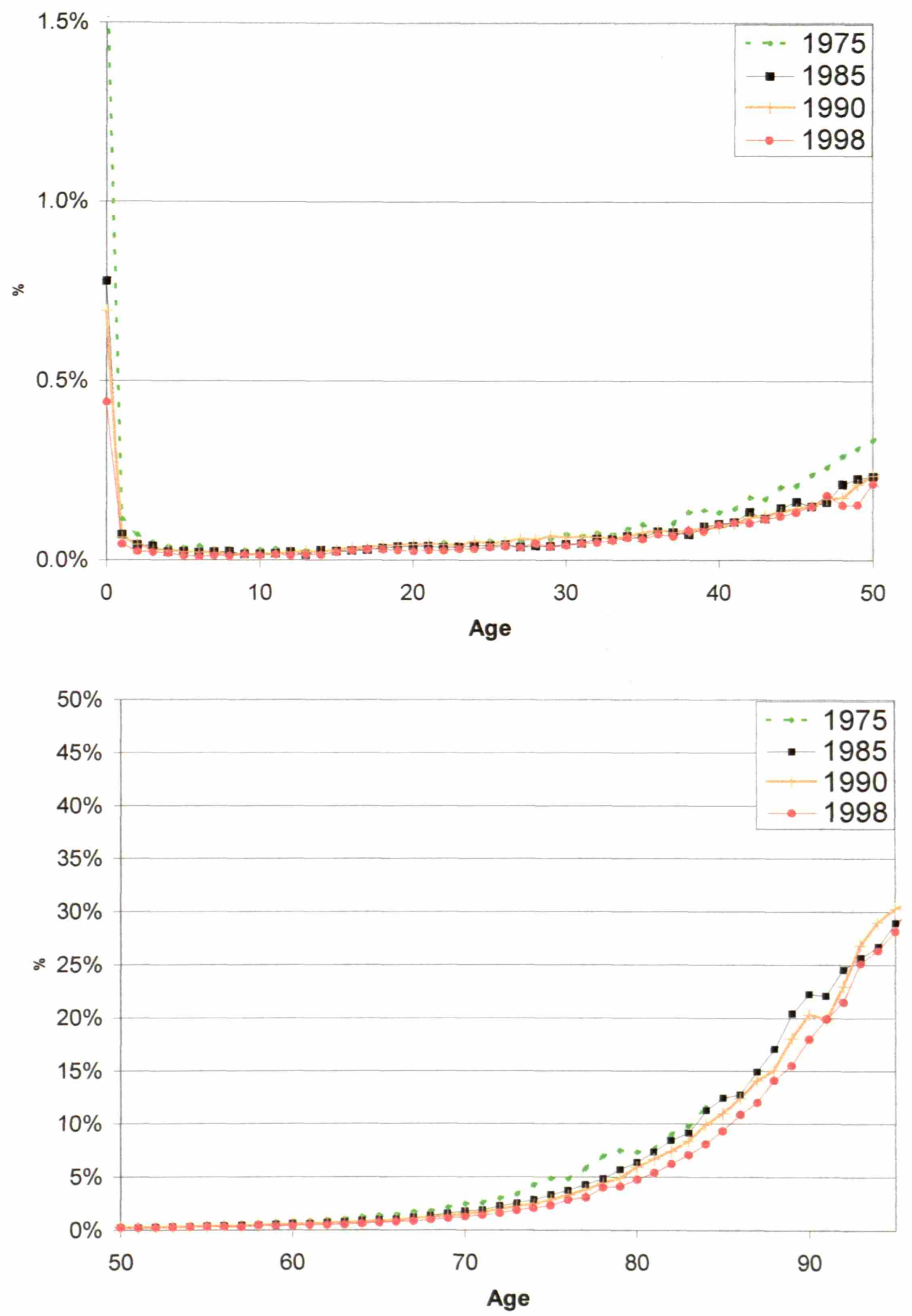

Figure 6.b. Probability of death for

Spanish females. (Based on data from INE) 
The data in Figure 6 suggests some general trends:

1. The probability of death has been steadily decreasing for almost all ages since 1975

2. The decrease in infant mortality has been particularly strong.

3. One exception have been males ages 18 through 35 , which showed a trend towards higher probability of death during the late $80 \mathrm{~s}$ and early $90 \mathrm{~s}$. The causes for such an increase were AIDS, traffic-accidents and drug-addiction (5). However, the data for the late nineties suggests that the trend is receding.

4. Women have a lower probability of death at al ages

\subsubsection{Mortality projections:}

In order to estimate future life expectancies and probabilities of death, the existing data for the POD at each age for males and females was projected into the future using some of the guidelines presented in reference 5. Appendix 1 describes the method in more detail. It suffice to say here, that as a general rule the projections assume that the positive trends continue into the future albeit at a slowing improvement rate. The projections provide the probability of death for each year and simple age up to 2050, as needed to estimate the death rates and age profile of the deceased for each of the projected years. The life expectancy estimated from the baseline projections is documented in Table 9.

Table 9. Projected Life Expectancy at Birth.

\begin{tabular}{|c|c|c|c|c|c|}
\hline Year & Males & Females & Year & Males & Females \\
\hline 1999 & 75.20 & 82.15 & 2025 & 77.20 & 84.03 \\
\hline 2000 & 75.35 & 82.30 & 2026 & 77.24 & 84.07 \\
\hline 2001 & 75.51 & 82.44 & 2027 & 77.29 & 84.11 \\
\hline 2002 & 75.63 & 82.56 & 2028 & 77.33 & 84.15 \\
\hline 2003 & 75.74 & 82.67 & 2029 & 77.38 & 84.18 \\
\hline 2004 & 75.84 & 82.77 & 2030 & 77.43 & 84.22 \\
\hline 2005 & 75.94 & 82.88 & 2031 & 77.47 & 84.26 \\
\hline 2006 & 76.03 & 82.97 & 2032 & 77.51 & 84.29 \\
\hline 2007 & 76.12 & 83.06 & 2033 & 77.56 & 84.33 \\
\hline 2008 & 76.20 & 83.15 & 2034 & 77.60 & 84.36 \\
\hline 2009 & 76.27 & 83.21 & 2035 & 77.64 & 84.40 \\
\hline 2010 & 76.34 & 83.28 & 2036 & 77.68 & 84.43 \\
\hline 2011 & 76.41 & 83.34 & 2037 & 77.72 & 84.47 \\
\hline 2012 & 76.49 & 83.40 & 2038 & 77.76 & 84.50 \\
\hline 2013 & 76.56 & 83.46 & 2039 & 77.80 & 84.54 \\
\hline 2014 & 76.61 & 83.53 & 2040 & 77.84 & 84.57 \\
\hline 2015 & 76.67 & 83.58 & 2041 & 77.88 & 84.61 \\
\hline 2016 & 76.73 & 83.63 & 2042 & 77.92 & 84.64 \\
\hline 2017 & 76.79 & 83.69 & 2043 & 77.96 & 84.67 \\
\hline 2018 & 76.84 & 83.74 & 2044 & 78.00 & 84.71 \\
\hline 2019 & 76.90 & 83.79 & 2045 & 78.04 & 84.74 \\
\hline 2020 & 76.95 & 83.84 & 2046 & 78.07 & 84.77 \\
\hline 2021 & 77.00 & 83.88 & 2047 & 78.11 & 84.80 \\
\hline 2022 & 77.05 & 83.92 & 2048 & 78.15 & 84.84 \\
\hline 2023 & 77.10 & 83.96 & 2049 & 78.18 & 84.87 \\
\hline 2024 & 77.15 & 84.00 & 2050 & 78.22 & 84.90 \\
\hline
\end{tabular}


The life expectancy predictions are similar (somewhat lower for the later years of the projections) to those in reference 9 and higher than those in reference 5 . It should be noted, however that reference 5 failed to anticipate the improvement in life expectancy in the nineties that resulted from lower impact from traffic accidents, AIDS and drugaddiction. Figure 7 shows projected mortality curves for males and females.
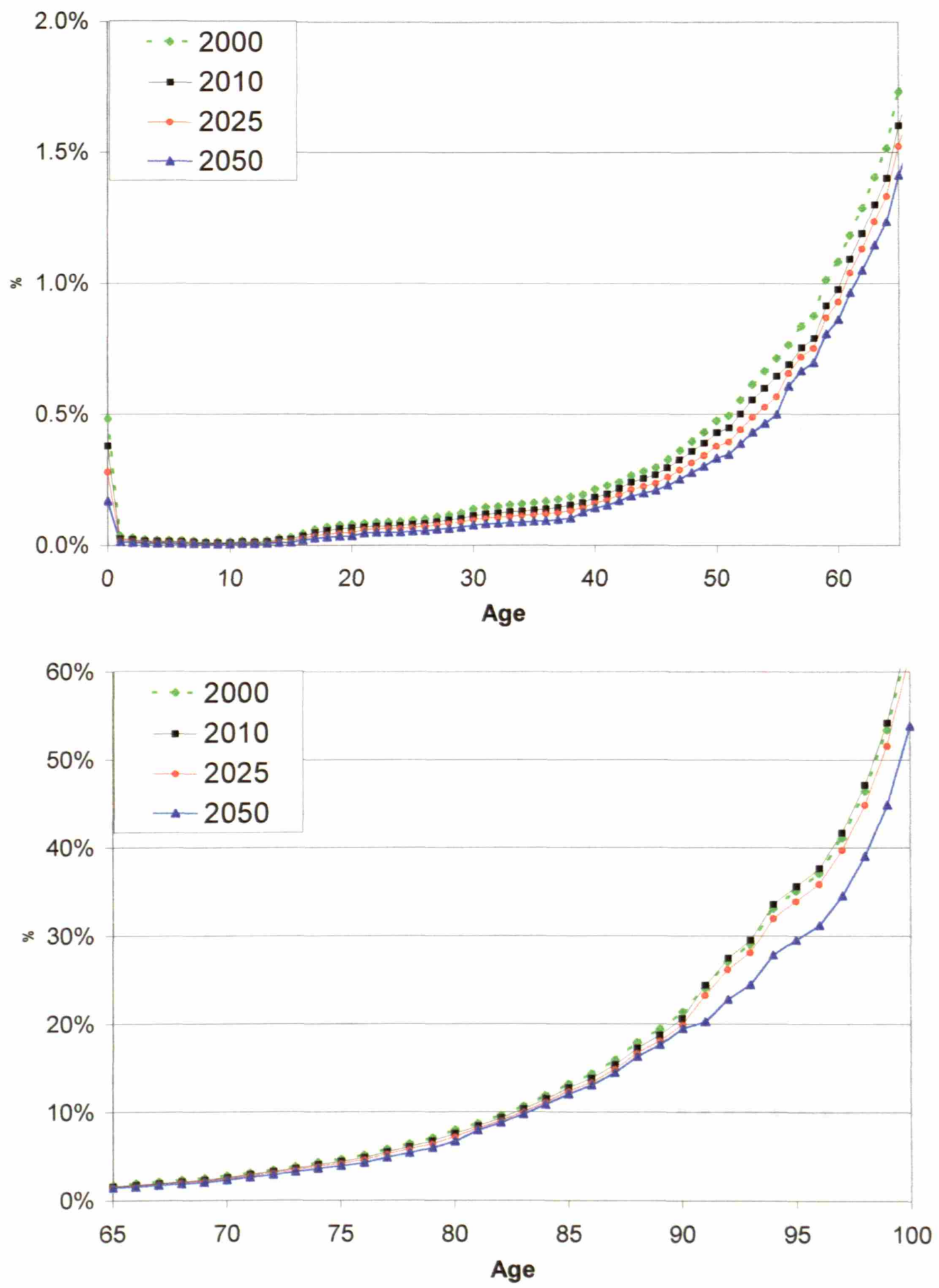

Figure 7.a. Projected probability of death for Spanish males. 

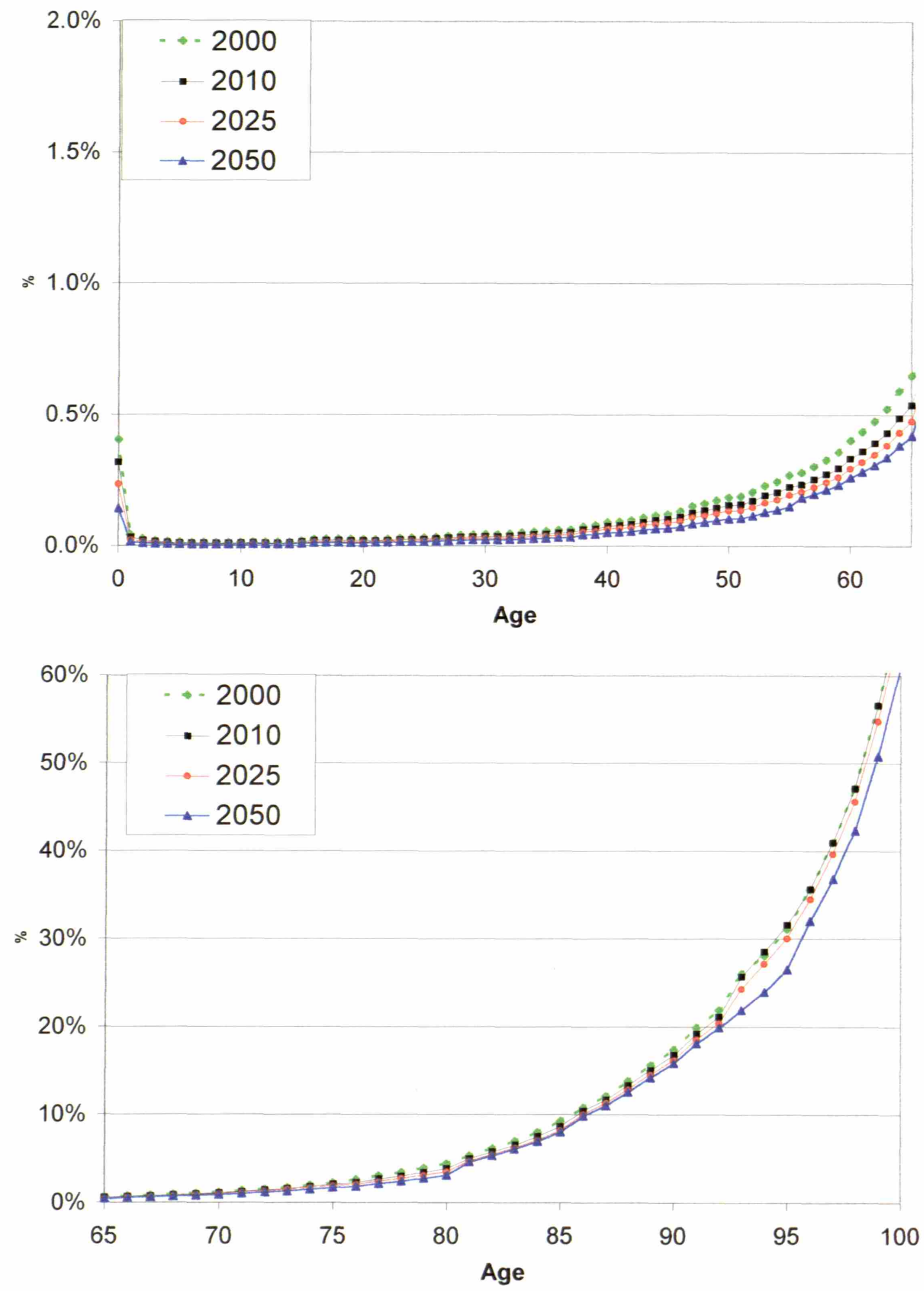

Figure 7.b. Projected probability of death for Spanish females. 


\subsubsection{Fertility.}

The change in fertility rates observed in Spain stating in 1977 has had a key influence in the demographic evolution and outlook for Spain. From 1977 to the present, Spain went from being one of the countries with the highest fertility rates in Europe to the lowest. Figure 8 shows the evolution of the average number of children per woman in EU countries since 1971, together with the projections used in this study.

Figure 9 shows the evolution of the average maternity age in EU countries since 1971.

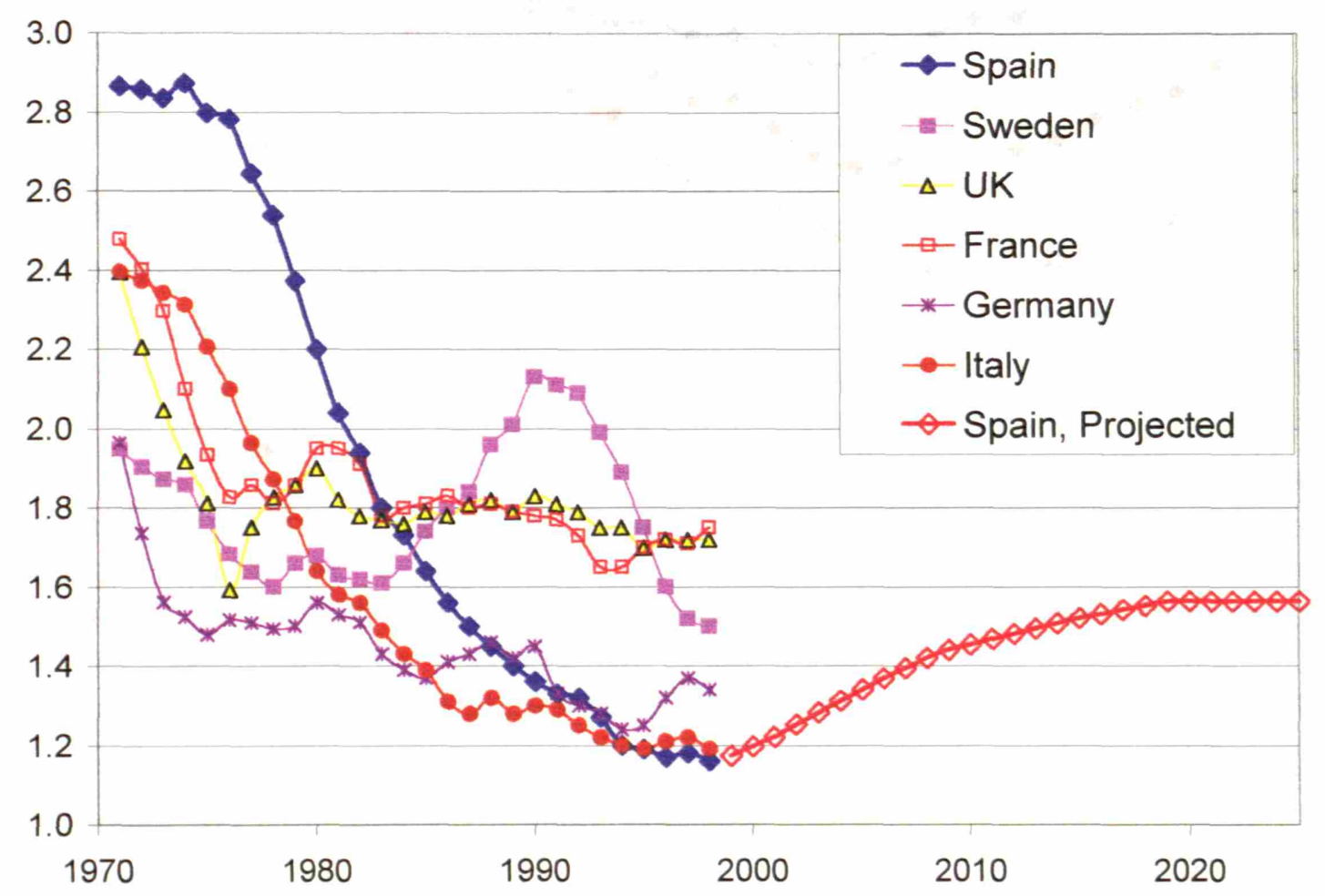

Figure 8. Average number of children per woman in some EU countries.

The data in the figures suggests the following trends:

1. Southern countries have had a later but more dramatic decrease in the fertility rates within the EU, having reached the lowest levels ever seen in the EU.

2. The average maternity age in Spain has been increasing significantly in recent years and has become one of the highest in the EU.

Several economic and sociological reasons have been put forward to explain this trends, a detailed analysis of which is beyond the scope of this work. The increasing participation of the woman in the labor market, together with the high unemployment rates have made women less amenable to interrupt their careers to bear children. The extended educational period and the need for a solid economic base to raise children have contributed to a delay in the maternity age. 


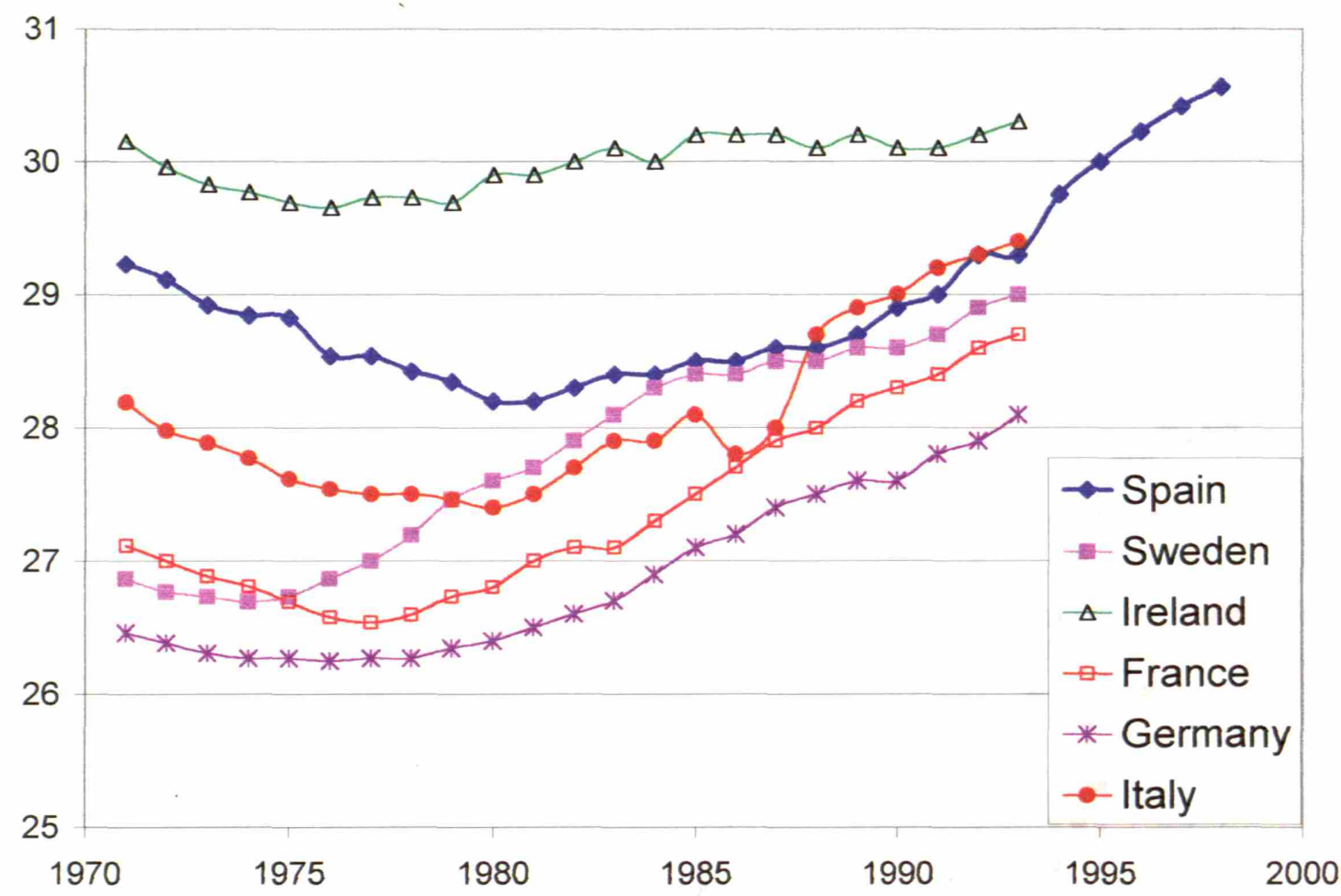

Figure 9. Average maternity age in some EU countries.

Figure 10 shows the fertility rates for Spanish women in the recent past, by simple age.

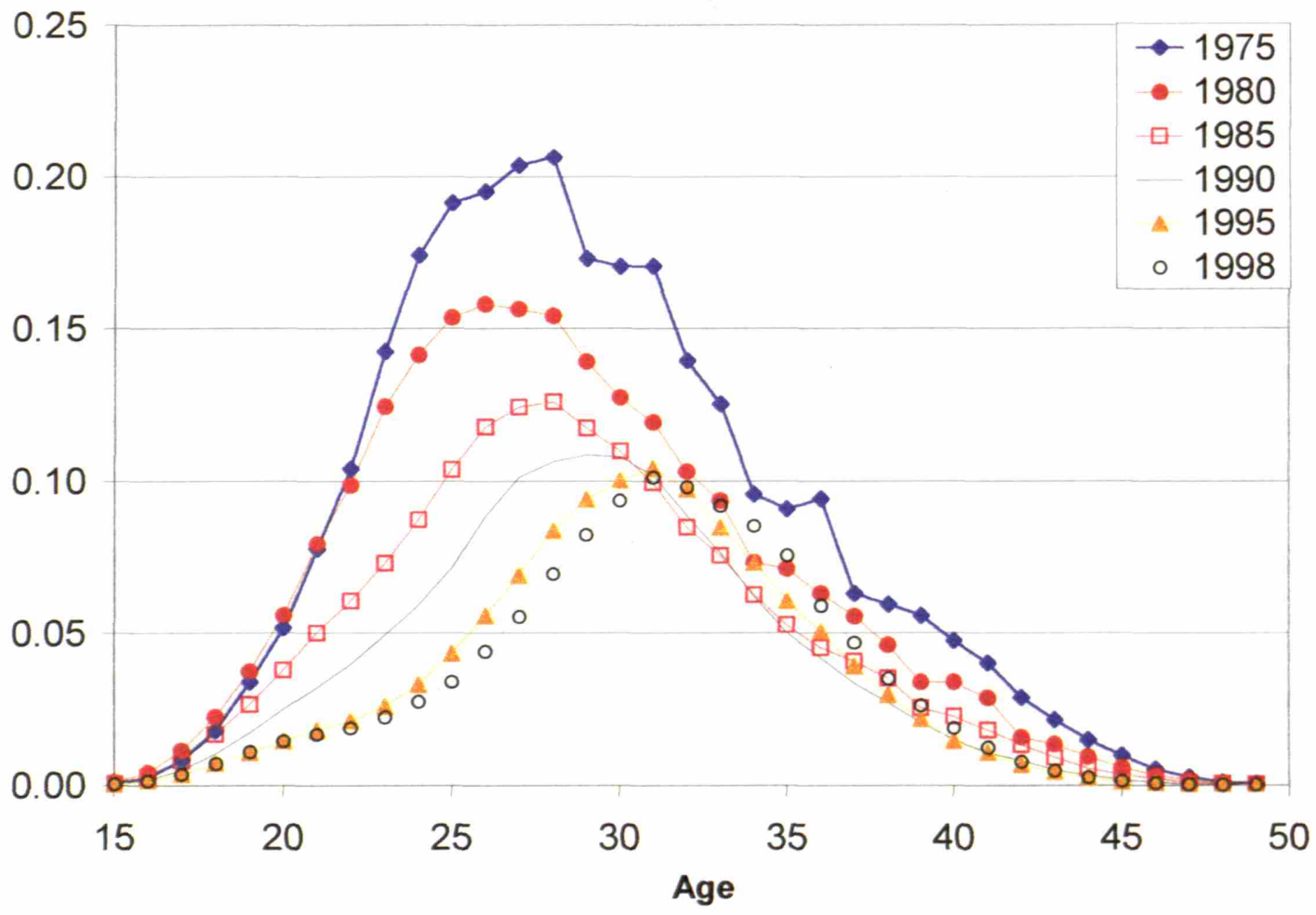

Figure 10. Fertility rate evolution since 1975 for Spain. (Based on births and population data from INE) 


\subsubsection{Fertility projections:}

The number of births in a year can be calculated by multiplying the fertility rate for a given age (as illustrated by the fertility rate curve, such as the one shown in Figure 10) times the number of women in that age group.

In order to estimate future birth rates, the fertility rates at each age for females ages 15 to 49 was projected into the future using some of the guidelines presented in references 5 and 9 . The number of births by gender is calculated by applying a ratio of male to female births of 1.07 . The observed ratio has been very close to this number for all the data examined since 1975.

Forecasting the behavior of fertility rates in Spain is not easy given the diverse factors that can influence it. An attempt is made here based on past data and the evolution observed in other EU countries. References 5 and 9 are used throughout this section, as well as data from INE and Eurostat. The guidelines followed for the extrapolation were:

a) Teenage fertility rates, as well as fertility rates for women 42 and older have shown a clear decrease in the recent past and are projected to continue at their current low levels. Better education and contraceptive methods, will help move pregnancies away from ages that are either socially (teenagers) or health-wise undesirable.

b) Fertility rates for women 23 to 30 had been steadily declining in recent years. The projection moving forward is that these rates will see a recovery in the decade of 2000-2010 as a result of the better economic and labor conditions. This recovery is more significant for the older segment in this group.

c) The fertility rates for women 31 to 41 had increased in the nineties. The projection moving forward is that this trend will continue for the next decade.

d) Beyond 2020, the rates are assumed constant.

e) The net effect is that the average motherhood age is projected to remain between 30 and 31 for the complete period.

Appendix 2 shows the projections, for the baseline scenario in more detail. This baseline projection calls for a recovery in the number of children per woman to 1.56 in 2020, remaining constant beyond that point (Figure 8). Projected fertility rate curves for this baseline scenario are shown in Figure 11.

Since the fertility figures have a very large impact on the influx of new individuals (more so than migrations), and are susceptible to large, rather sudden changes, it is worth establishing more than one scenario for the fertility projections. Two other scenarios are considered:

1. An optimistic scenario in which the recovery is higher and reaches 1.75 children per woman by 2020 and remains stable at this level going forward. The fertility rates in France and the UK have been at these levels lately and remained much more stable than that of Spain. One factor that could contribute to this recovery is the increasing weight of the immigrant population which has much higher fertility rates than the natives. 
2. A pessimistic scenario in which the expected recovery does not take place in the coming decade. A slight recovery happens starting 2010 and reaching only 1.35 children per woman by 2020 , remaining stable beyond that date.

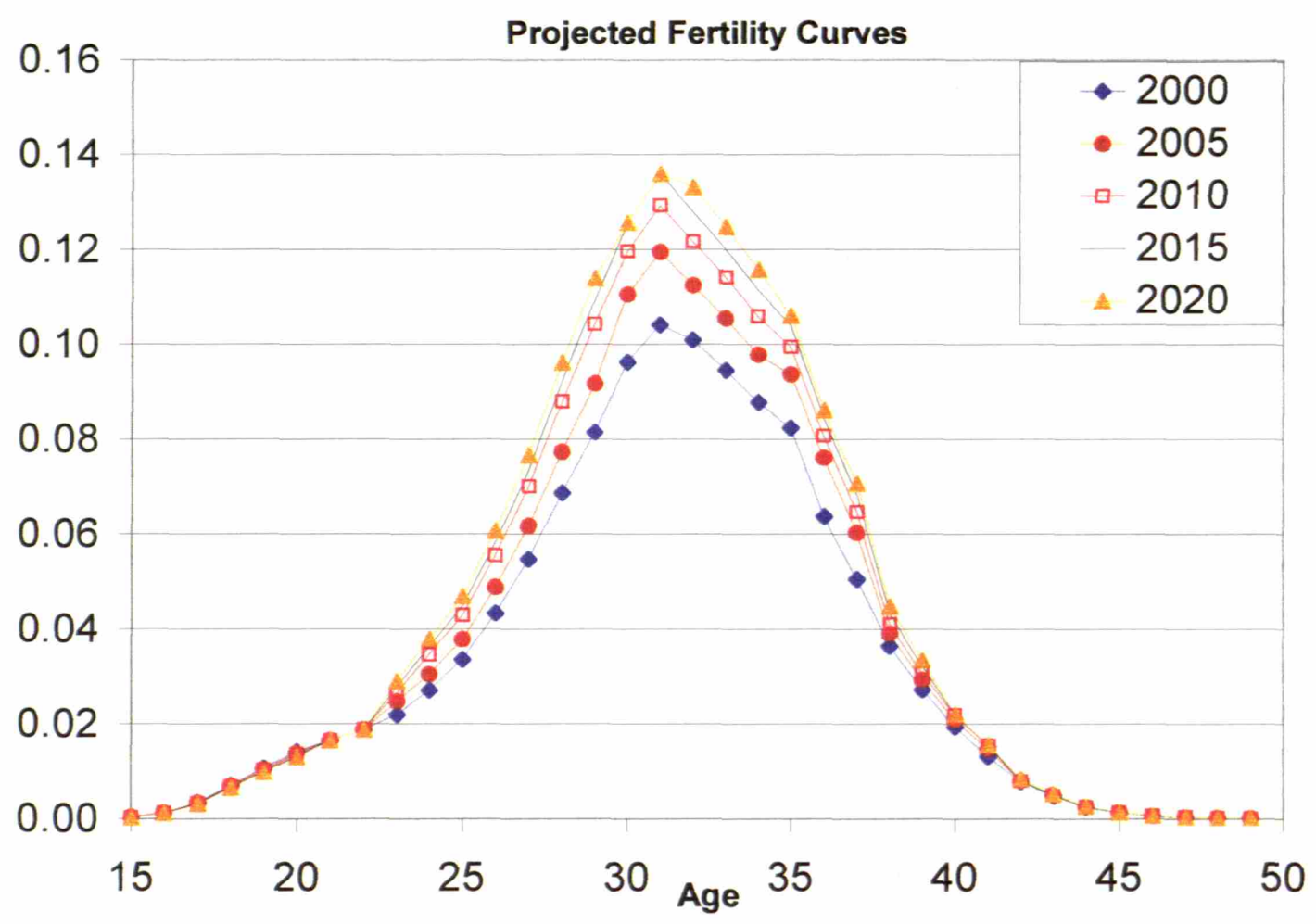

Figure 11. Projected fertility rates. Baseline scenario.

For the alternative scenarios, the shape of the projected fertility curves is not changed, just scaled up or down to yield the required average number of children per woman.

Table 10 shows the projected average number of children per woman in the baseline scenario and in the two additional scenarios outlined above.

Table 10. Projected average number of children per woman.

\begin{tabular}{|cccc|}
\hline Year & Baseline & Optimistic & Pessimistic \\
1999 & 1.17 & 1.18 & 1.17 \\
2000 & 1.20 & 1.21 & 1.17 \\
2001 & 1.22 & 1.25 & 1.17 \\
2002 & 1.25 & 1.29 & 1.17 \\
2003 & 1.28 & 1.34 & 1.17 \\
2004 & 1.31 & 1.38 & 1.17 \\
2005 & 1.34 & 1.42 & 1.17 \\
2006 & 1.37 & 1.46 & 1.17 \\
2007 & 1.39 & 1.50 & 1.17 \\
2008 & 1.42 & 1.54 & 1.17 \\
2009 & 1.44 & 1.57 & 1.17 \\
2010 & 1.45 & 1.59 & 1.18 \\
\hline
\end{tabular}

\begin{tabular}{|cccc|}
\hline Year & Baseline & Optimistic & Pessimistic \\
2011 & 1.47 & 1.61 & 1.19 \\
2012 & 1.48 & 1.63 & 1.22 \\
2013 & 1.49 & 1.65 & 1.24 \\
2014 & 1.51 & 1.67 & 1.27 \\
2015 & 1.52 & 1.69 & 1.29 \\
2016 & 1.53 & 1.70 & 1.32 \\
2017 & 1.54 & 1.72 & 1.33 \\
2018 & 1.55 & 1.73 & 1.34 \\
2019 & 1.56 & 1.75 & 1.35 \\
2020 & 1.56 & 1.75 & 1.35 \\
$>2020$ & & Constant & \\
\hline
\end{tabular}




\subsubsection{Migrations.}

Migrations have had a net positive contribution to the population of Spain for the last two decades. This contribution can be estimated by the influx of immigrants alone, as the outflow of Spanish residents has become negligible in recent years and is not projected to increase significantly.

The economic situation in western countries makes them attractive destinations for immigrants, and indeed, the number of immigrants into Spain has been climbing steadily in recent years, as illustrated in Figure 12.

The Spanish authorities currently establish a maximum of 30,000 immigrants per year. However, this number applies only to a limited number of countries and cannot affect the EU and Spaniards living abroad. This latter group has represented a net influx of 15 to 25,000 people a year in the last years. Furthermore, illegal immigration, not counted in the official statistics of Figure 12 has become commonplace in Spain. Recent "regularization" campaigns have brought to light thousands of immigrants, mainly from Africa and Latin America, previously unrecorded.

The first scenario for immigration is that the influx remains steady at about 35,000 per year, limited by the current policies. In a second scenario, the influx of immigrants continues to climb as the aging of the local population and the resulting labor shortages require it. In this second scenario, the influx remains at about 80,000 for the next decade climbing to 125,000 in 2010 and 150,000 per year from 2020 forward. This second scenario is intended to assess the potential impact of high immigration rates on the economics of the pension system. Table 11 summarizes the two immigration scenarios.

Table 11. Projected net immigration.

\begin{tabular}{|c|c|c|c|c|c|}
\hline Year & Baseline & Heavy Immigration & Year & Baseline & Heavy Immigration \\
\hline 1999 & 35,000 & 80,000 & 2011 & 35,000 & 125,000 \\
\hline 2000 & 35,000 & 80,000 & 2012 & 35,000 & 125,000 \\
\hline 2001 & 35,000 & 80,000 & 2013 & 35,000 & 125,000 \\
\hline 2002 & 35,000 & 80,000 & 2014 & 35,000 & 125,000 \\
\hline 2003 & 35,000 & 80,000 & 2015 & 35,000 & 125,000 \\
\hline 2004 & 35,000 & 80,000 & 2016 & 35,000 & 125,000 \\
\hline 2005 & 35,000 & 80,000 & 2017 & 35,000 & 125,000 \\
\hline 2006 & 35,000 & 80,000 & 2018 & 35,000 & 125,000 \\
\hline 2007 & 35,000 & 80,000 & 2019 & 35,000 & 125,000 \\
\hline 2008 & 35,000 & 80,000 & 2020 & 35,000 & 150,000 \\
\hline 2009 & 35,000 & 80,000 & $>2020$ & & Constant \\
\hline 2010 & 35,000 & 125,000 & & & \\
\hline
\end{tabular}

In order to carry out the population projections, the immigrants must be distributed into age and gender groups.

The age distribution has been derived from the data presented in reference 5 and is illustrated in Figure 13. The distribution has been remarkably constant with time, with a disproportionate number of immigrants being of working age. Inflows observed at or near the retirement age have been disregarded, as these people (often retirees from other EU countries or Spaniards coming back after retirement) are typically not a burden for the Spanish pension system.

As far as the gender distribution, the number of men and women immigrants has been rather similar (5), and thus assumed equal in the projections. 


\section{Immigration Trends}

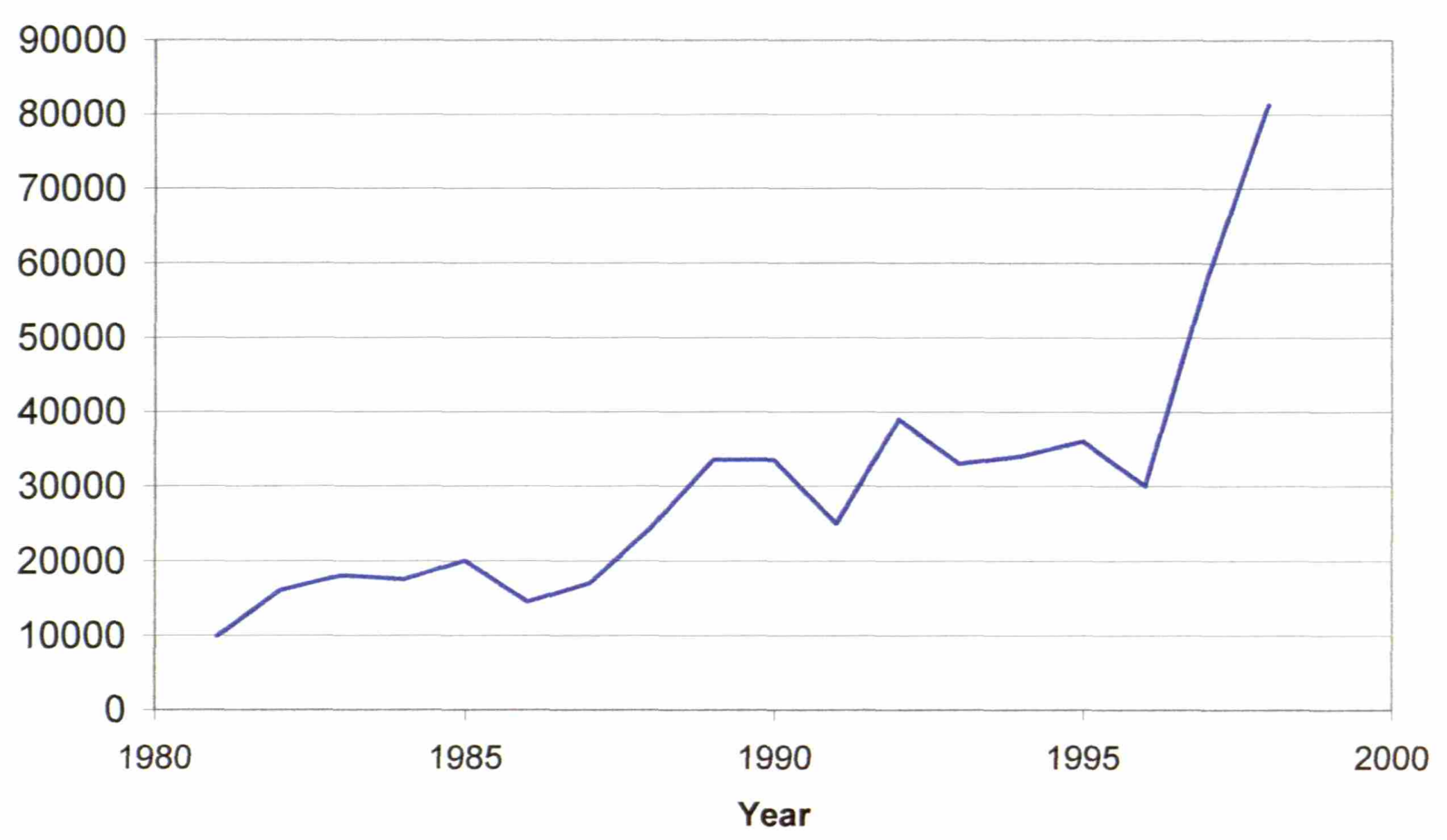

Figure 12. Immigration into Spain since 1981.

\section{Immigration Age Profile}

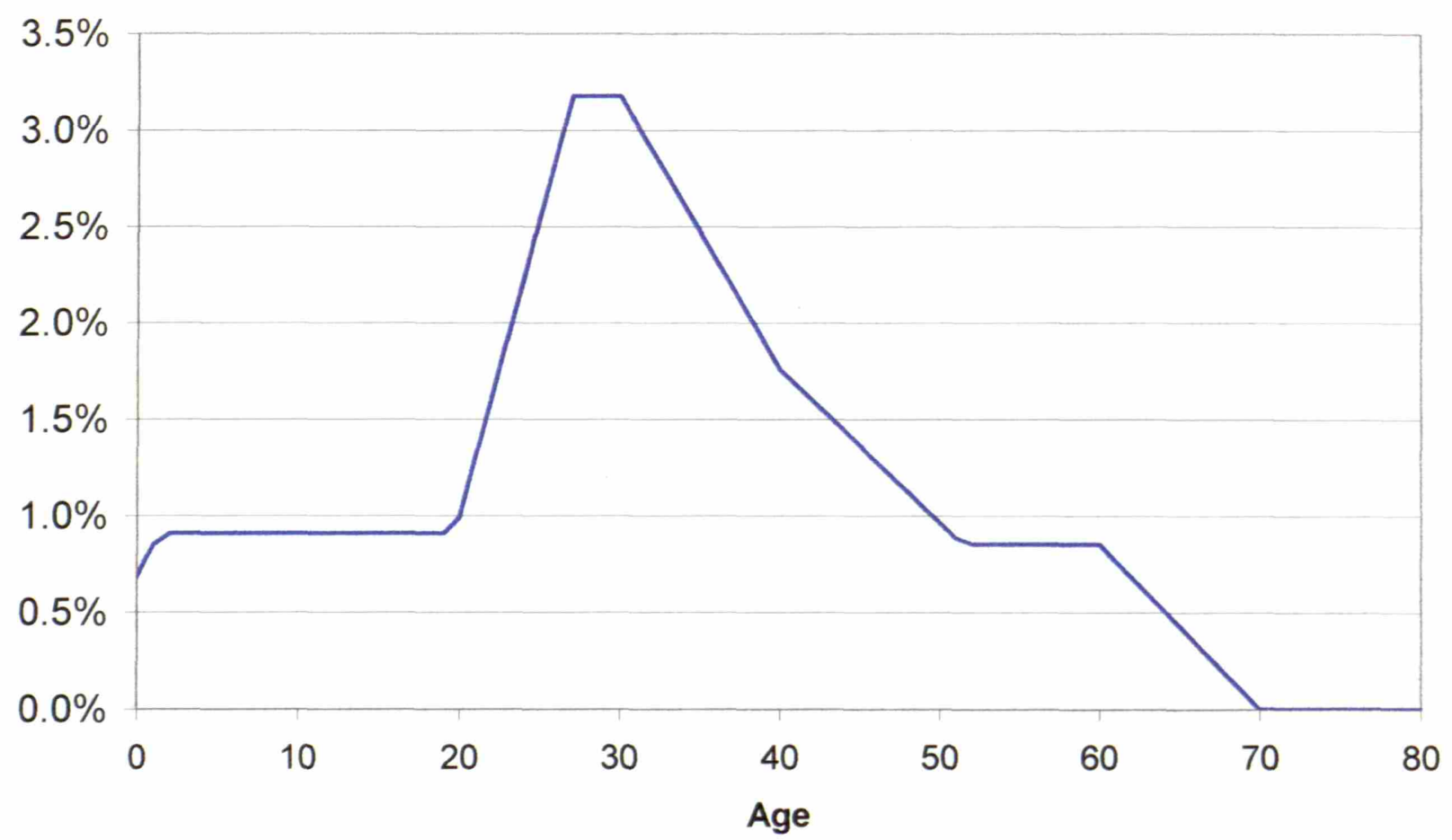

Figure 13. Typical age profile for the immigrants. (Based on data from ref. 5) 


\subsection{Results of the population model.}

With the four elements described in the previous section: starting population, probabilities of death, fertility rates and migrations, the population can be projected forward by simple age and gender as follows:

$$
\begin{gathered}
F_{i}^{y}=\left\{\begin{array}{c}
\left(\frac{m_{0}^{y-1}}{2}+0.485 \sum_{j=15}^{49} f_{j}^{y-1} F_{j}^{y-1}\left(1-q_{0}^{y-1}\right), i=0\right. \\
\left(F_{i-1}^{y-1}+\frac{m_{i}^{y-1}}{2}\right)\left(1-\frac{q_{i}^{y-1}+q_{i-1}^{y-1}}{2}\right), i>0
\end{array}\right\} \\
M_{i}^{y}=\left\{\begin{array}{c}
\left(\frac{m_{0}^{y-1}}{2}+0.515 \sum_{j=15}^{49} f_{j}^{y-1} F_{j}^{y-1}\left(1-p_{0}^{y-1}\right), i=0\right. \\
\left(M_{i-1}^{y-1}+\frac{m_{i}^{y-1}}{2}\right)\left(1-\frac{p_{i}^{y-1}+p_{i-1}^{y-1}}{2}\right), i>0
\end{array}\right\}
\end{gathered}
$$

Where:

$F_{i}{ }^{y}$ is the number of females age $\mathrm{i}$ living in year y (January 1$)$.

$M_{i}^{y}$ is the number of males age i living in year y (January 1 ).

$m_{i}^{y}$ is the number of immigrants age $\mathrm{i}$ entering in year $\mathrm{y}$.

$f_{i}^{y}$ is the fertility rate for females age $\mathrm{i}$ in year $\mathrm{y}$.

$q_{i}^{y}$ is the probability of death for females age $\mathrm{i}$ in year $\mathrm{y}$.

$p_{i}^{y}$ is the probability of death for males age $\mathrm{i}$ in year $\mathrm{y}$.

The projection hypothesis have been grouped into four demographic scenarios:

1. Baseline. Uses the baseline fertility rate projection (a recovery in the number of children per woman to 1.56 in 2020) with a constant immigration stream of 35,000 people per year, as determined by current immigration policy.

2. Pessimistic. Uses the pessimistic fertility scenario (expected recovery does not take place in the coming decade; a slight recovery happens starting 2010 and reaching only 1.35 children per woman by 2020) with the baseline immigration scenario.

3. High fertility. Uses the optimistic fertility scenario (in which the recovery is higher and reaches 1.75 children per woman by 2020) with the baseline immigration scenario.

4. Optimistic. Uses the optimistic fertility scenario (in which the recovery is higher and reaches 1.75 children per woman by 2020) with the higher immigration model (in which the inflow starts at about 80,000 per year and grows to 150,000 by 2020). 
Figures 14 through 17 show the evolution of the total population in Spain, the percentage of the population over 65 , the old-age dependency ratio $(>65 / 16-64)$ and the youth dependency ratio $(0-15 / 15-64)$ projected out to 2050 for each of the scenarios.

The total population tends to grow in the short run for all scenarios, however, the long term outlook is very different. For the baseline scenario, the population continues to grow slowly out to 2015, where it peaks at about 40.7 million. From then on, the low birth rate starts to take its toll as the numerous current middle-agers reach older age without adequate replacement. The population decreases at an increasing rate out to 2050 where it is down to 35.3 million. The pessimistic scenario, with even lower birth rates, the population peaks at about 40.2 million in 2006 and drops from there down to 32.2 million in 2050 , almost a $20 \%$ drop from the current levels. The higher fertility scenario extends the population expansion out to 2017 , whet it peaks at 41.1 million, and then decreases at a lower rate than the previous scenarios down to 37.5 million in 2050. Finally, the optimistic scenario, that adds higher immigration to higher fertility, shows a steady population increase out to 2030 , with a plateau around 43.2 million extending out to the end of the projected period.

The old age dependency ratio and the \% of population over 65 show a different behavior. The changes are small and quite similar for all scenarios out to about 2015. Beyond this time, both parameters increase at a faster pace for all scenarios. The dependency rates double by 2050 even for the most optimistic population scenario.

The youth dependency ratio does not see such large swings. It remains rather stable for the baseline scenario, decreases slightly for the pessimistic scenario and increases for the two high fertility scenarios.

As expected, the most dramatic effect stems from the aging of the population, itself a consequence of the extended life expectancies and low fertility rates. The old-age dependency ratio gets to alarming levels at the end of the projected period. Increasing over $130 \%$ for the baseline scenario and $100 \%$ for the most optimistic one.

It can be argued that projections out to 2050 are unreliable and this can certainly be true. However, demographic projections tend to be quite robust, at least for the old age population. It must be noticed that the retirees of 2050 are already born.

Table 12 summarizes some key demographic parameters derived from the four scenarios. 


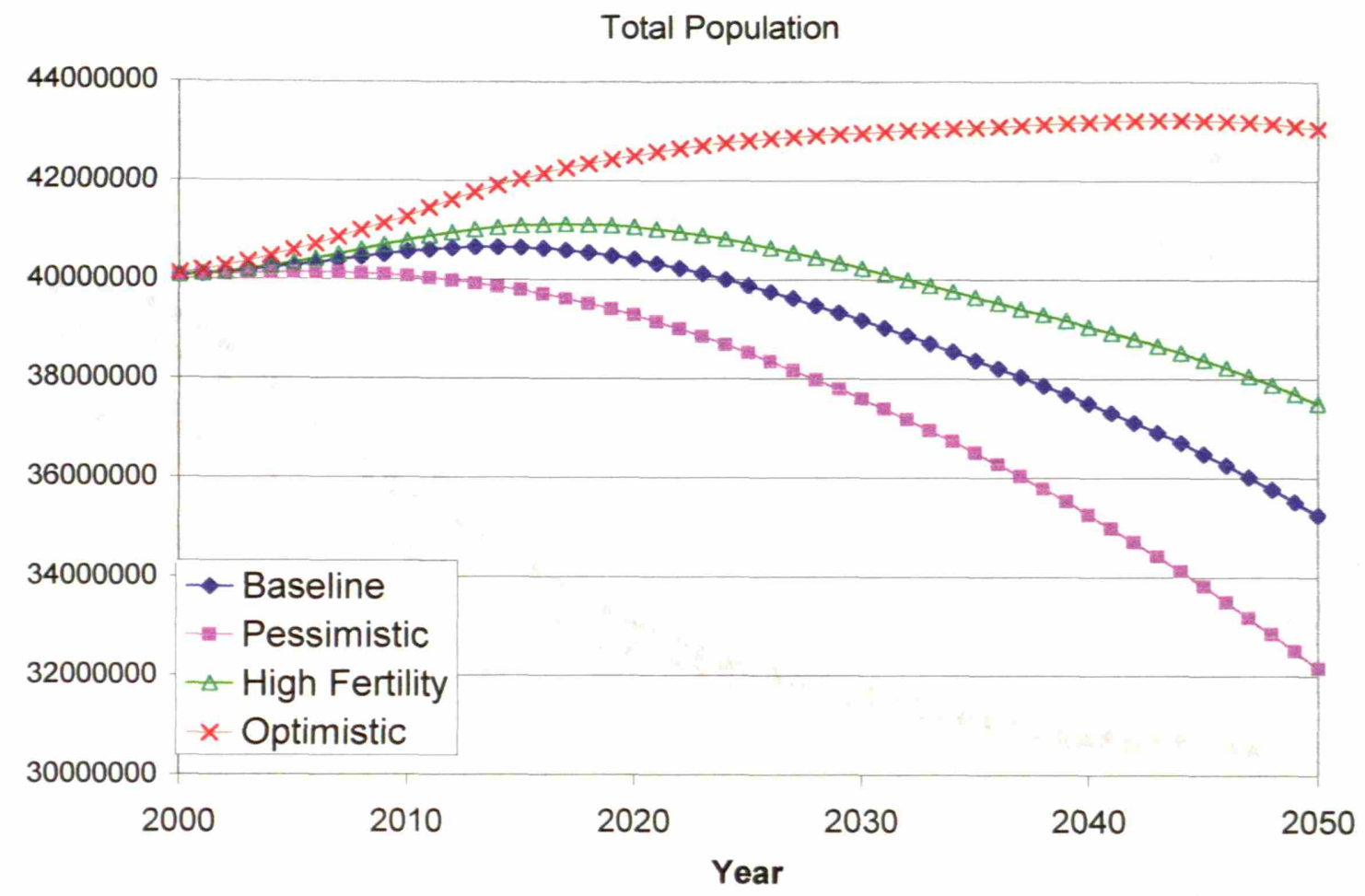

Figure 14. The total population of Spain projected out to 2050; four scenarios.

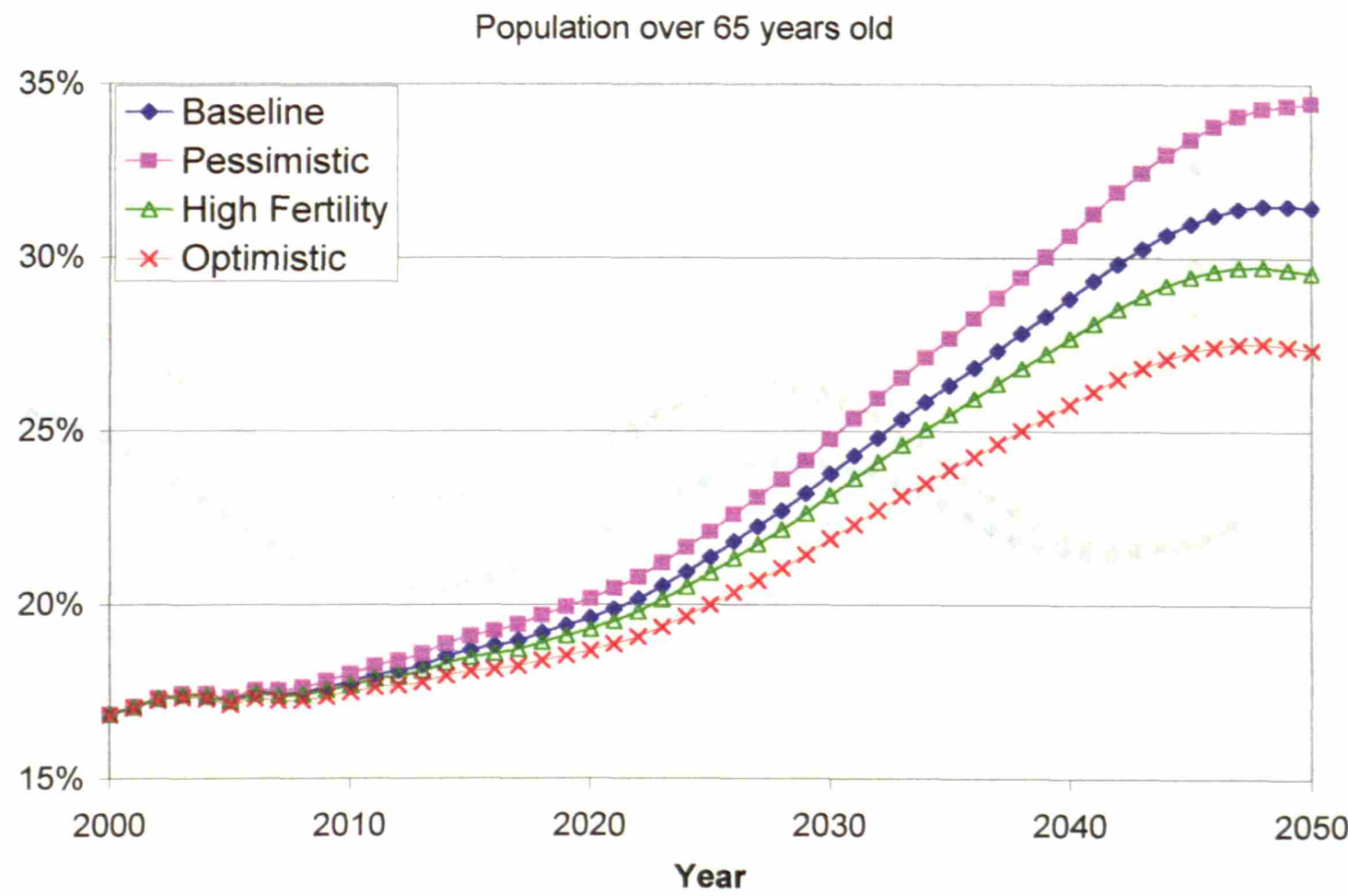

Figure 15. Percentage of people over 65 in Spain projected out to 2050; four scenarios. 
Old Age Dependency Ratio

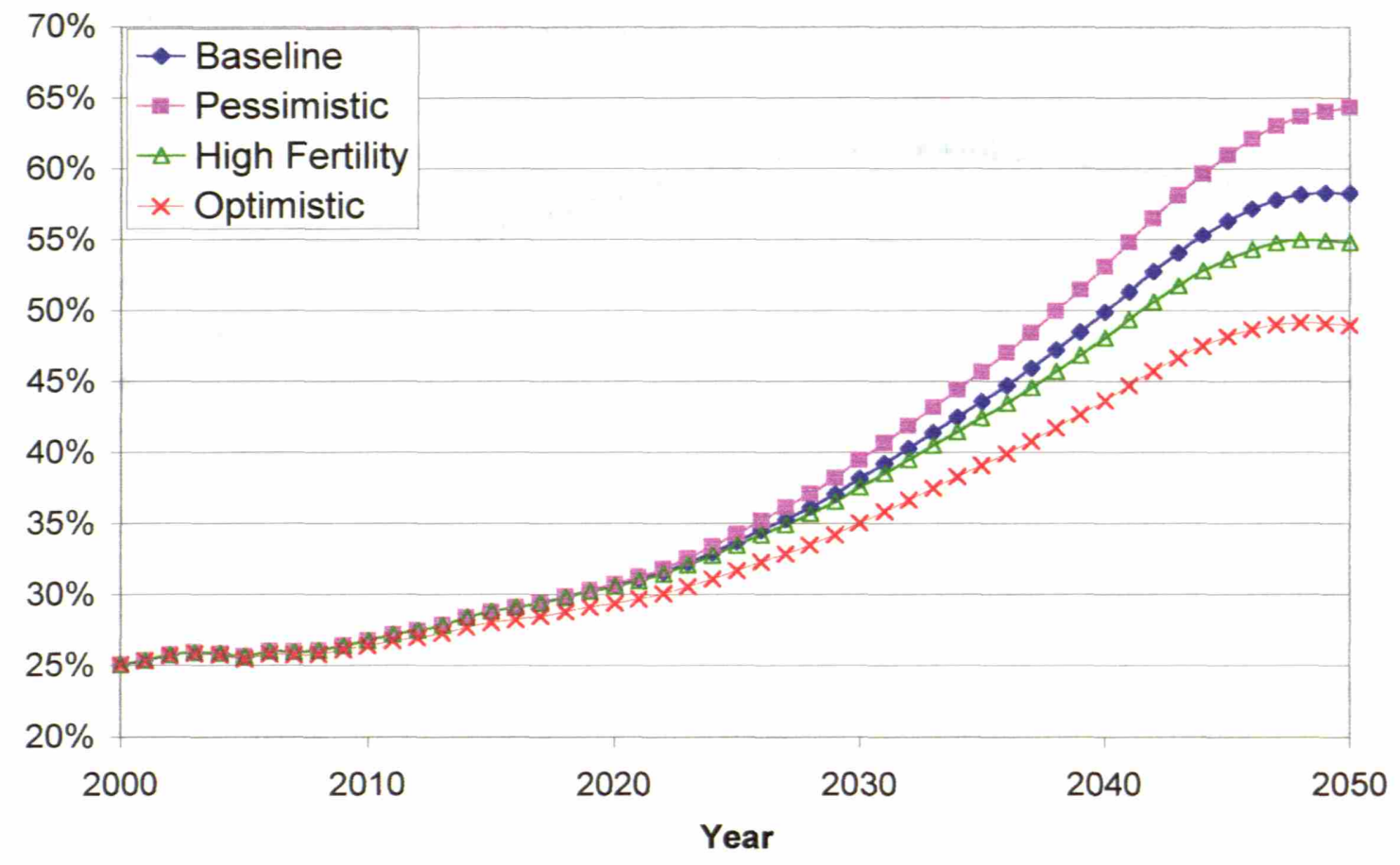

Figure 16. Over 65 dependency ratio for Spain projected out to 2050; four scenarios.

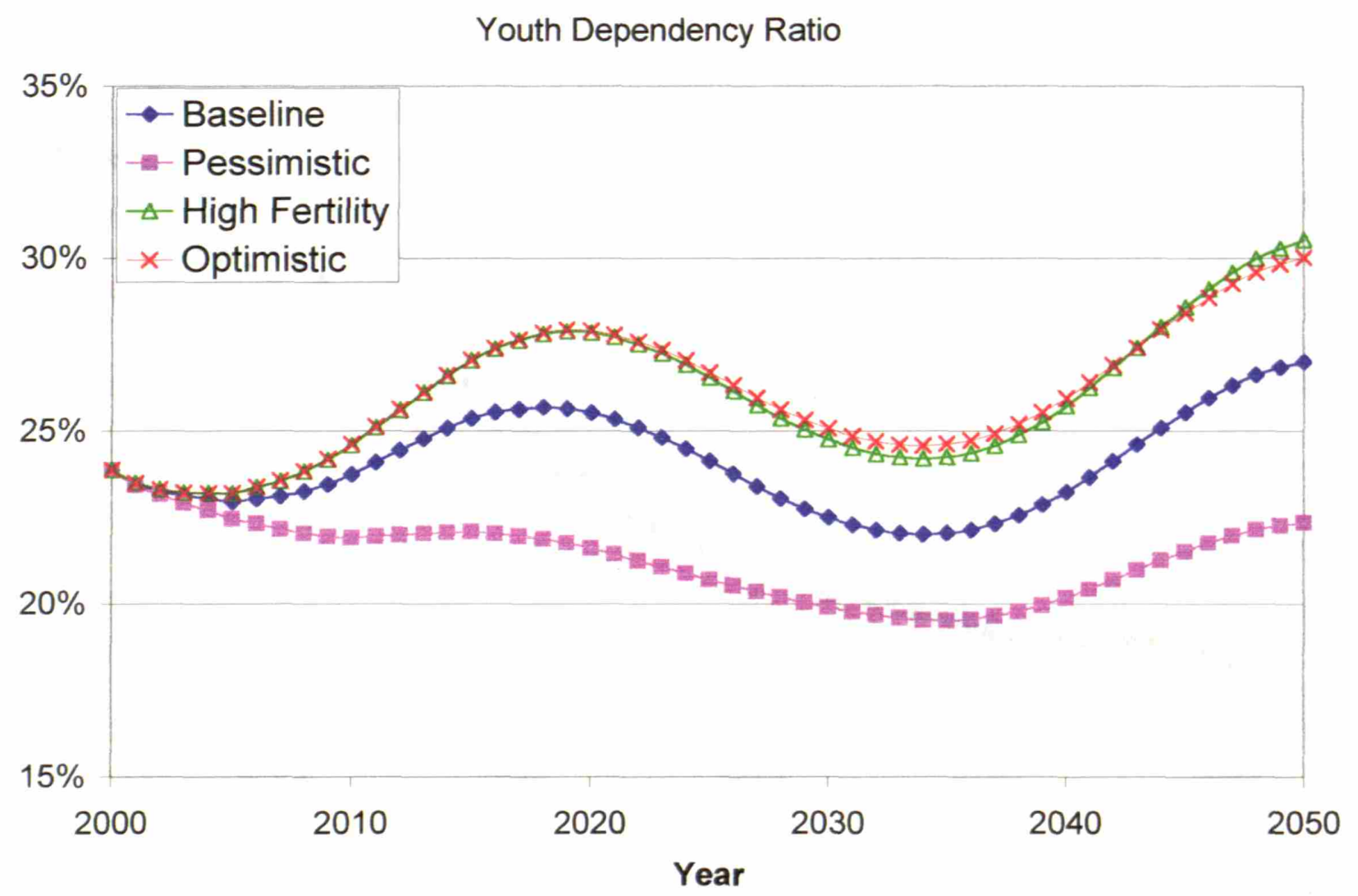

Figure 17. Youth dependency ratio for Spain projected out to 2050; four scenarios. 
Table 12. Population in Spain. Key parameters for the four projection scenarios.

\begin{tabular}{|l|r|r|r|r|r|r|}
\cline { 2 - 7 } \multicolumn{1}{c|}{} & \multicolumn{1}{c|}{$\mathbf{2 0 0 0}$} & \multicolumn{1}{c|}{$\mathbf{2 0 1 0}$} & \multicolumn{1}{c|}{$\mathbf{2 0 2 0}$} & \multicolumn{1}{c|}{$\mathbf{2 0 3 0}$} & \multicolumn{1}{c|}{$\mathbf{2 0 4 0}$} & \multicolumn{1}{c|}{$\mathbf{2 0 5 0}$} \\
\hline Total Population & 40078836 & 40559003 & 40408110 & 39177560 & 37493055 & 35245036 \\
\hline $0-15$ years & 6425164 & 6397306 & 6607112 & 5486159 & 5032696 & 5138880 \\
\hline $15-64$ years & 26906656 & 26951288 & 25878767 & 24381627 & 21657512 & 19023811 \\
\hline$>64$ years & 6747016 & 7210409 & 7922231 & 9309774 & 10802847 & 11082345 \\
\hline$\%>64$ & $16.8 \%$ & $17.8 \%$ & $19.6 \%$ & $23.8 \%$ & $28.8 \%$ & $31.4 \%$ \\
\hline Youth dependency ratio $(*)$ & $23.9 \%$ & $23.7 \%$ & $25.5 \%$ & $22.5 \%$ & $23.2 \%$ & $27.0 \%$ \\
\hline$>64$ dependency ratio $(* *)$ & $25.1 \%$ & $26.8 \%$ & $30.6 \%$ & $38.2 \%$ & $49.9 \%$ & $58.3 \%$ \\
\hline Total dependency ratio & $49.0 \%$ & $50.5 \%$ & $56.1 \%$ & $60.7 \%$ & $73.1 \%$ & $85.3 \%$ \\
\hline
\end{tabular}

\begin{tabular}{|l|r|r|r|r|r|r|}
\cline { 2 - 7 } \multicolumn{1}{c|}{} & \multicolumn{1}{c|}{$\mathbf{2 0 0 0}$} & \multicolumn{1}{c|}{$\mathbf{2 0 1 0}$} & \multicolumn{1}{c|}{$\mathbf{2 0 2 0}$} & \multicolumn{1}{c|}{$\mathbf{2 0 3 0}$} & \multicolumn{1}{c|}{$\mathbf{2 0 4 0}$} & \multicolumn{1}{c|}{$\mathbf{2 0 5 0}$} \\
\hline Total Population & 40076870 & 40068063 & 39280400 & 37589176 & 35257650 & 32168678 \\
\hline $0-15$ years & 6423198 & 5906366 & 5571809 & 4695860 & 4105136 & 3853823 \\
\hline $15-64$ years & 26906656 & 26951288 & 25786360 & 23583542 & 20349667 & 17232510 \\
\hline$>64$ years & 6747016 & 7210409 & 7922231 & 9309774 & 10802847 & 11082345 \\
\hline$\%>64$ & $16.8 \%$ & $18.0 \%$ & $20.2 \%$ & $24.8 \%$ & $30.6 \%$ & $34.5 \%$ \\
\hline Youth dependency ratio $(*)$ & $23.9 \%$ & $21.9 \%$ & $21.6 \%$ & $19.9 \%$ & $20.2 \%$ & $22.4 \%$ \\
\hline$>64$ dependency ratio $(* *)$ & $25.1 \%$ & $26.8 \%$ & $30.7 \%$ & $39.5 \%$ & $53.1 \%$ & $64.3 \%$ \\
\hline Total dependency ratio & $48.9 \%$ & $48.7 \%$ & $52.3 \%$ & $59.4 \%$ & $73.3 \%$ & $86.7 \%$ \\
\hline
\end{tabular}

\begin{tabular}{|l|r|r|r|r|r|r|}
\cline { 2 - 7 } \multicolumn{1}{c|}{} & \multicolumn{1}{c|}{$\mathbf{2 0 0 0}$} & \multicolumn{1}{c|}{$\mathbf{2 0 1 0}$} & \multicolumn{1}{c|}{$\mathbf{2 0 2 0}$} & \multicolumn{1}{c|}{$\mathbf{2 0 3 0}$} & \multicolumn{1}{c|}{$\mathbf{2 0 4 0}$} & \multicolumn{1}{c|}{$\mathbf{2 0 5 0}$} \\
\hline Total Population & 40079765 & 40790933 & 41063966 & 40224563 & 39051103 & 37497485 \\
\hline 0 -15 years & 6426093 & 6629236 & 7219308 & 6135282 & 5778603 & 6177190 \\
\hline $15-64$ years & 26906656 & 26951288 & 25922427 & 24779507 & 22469653 & 20237950 \\
\hline$>64$ years & 6747016 & 7210409 & 7922231 & 9309774 & 10802847 & 11082345 \\
\hline$\%>64$ & $16.8 \%$ & $17.7 \%$ & $19.3 \%$ & $23.1 \%$ & $27.7 \%$ & $29.6 \%$ \\
\hline Youth dependency ratio $(*)$ & $23.9 \%$ & $24.6 \%$ & $27.8 \%$ & $24.8 \%$ & $25.7 \%$ & $30.5 \%$ \\
\hline$>64$ dependency ratio $(* *)$ & $25.1 \%$ & $26.8 \%$ & $30.6 \%$ & $37.6 \%$ & $48.1 \%$ & $54.8 \%$ \\
\hline Total dependency ratio & $49.0 \%$ & $51.4 \%$ & $58.4 \%$ & $62.3 \%$ & $73.8 \%$ & $85.3 \%$ \\
\hline
\end{tabular}

\begin{tabular}{|l|r|r|r|r|r|r|}
\cline { 2 - 7 } \multicolumn{1}{c|}{} & \multicolumn{1}{c|}{$\mathbf{2 0 0 0}$} & \multicolumn{1}{c|}{$\mathbf{2 0 1 0}$} & \multicolumn{1}{c|}{$\mathbf{2 0 2 0}$} & \multicolumn{1}{c|}{$\mathbf{2 0 3 0}$} & \multicolumn{1}{c|}{$\mathbf{2 0 4 0}$} & \multicolumn{1}{c|}{$\mathbf{2 0 5 0}$} \\
\hline d) Optimistic Sc. & 40119200 & 41270614 & 42494463 & 42956514 & 43171331 & 43042222 \\
\hline 0 -15 years & 6432929 & 6728735 & 7538272 & 6726335 & 6602131 & 7221366 \\
\hline $15-64$ years & 26939255 & 27331470 & 27021424 & 26829092 & 25451530 & 24052603 \\
\hline$>64$ years & 6747016 & 7210409 & 7934767 & 9401087 & 11117670 & 11768253 \\
\hline$\%>64$ & $16.8 \%$ & $17.5 \%$ & $18.7 \%$ & $21.9 \%$ & $25.8 \%$ & $27.3 \%$ \\
\hline Youth dependency ratio $(*)$ & $23.9 \%$ & $24.6 \%$ & $27.9 \%$ & $25.1 \%$ & $25.9 \%$ & $30.0 \%$ \\
\hline$>64$ dependency ratio $(* *)$ & $25.0 \%$ & $26.4 \%$ & $29.4 \%$ & $35.0 \%$ & $43.7 \%$ & $48.9 \%$ \\
\hline Total dependency ratio & $48.9 \%$ & $51.0 \%$ & $57.3 \%$ & $60.1 \%$ & $69.6 \%$ & $79.0 \%$ \\
\hline
\end{tabular}

$\left({ }^{*}\right)$ Ratio of population under 16 to population between 16 and 64

(**) Ratio of population over 64 to population between 16 and 64 


\section{Macroeconomic and labor projections.}

\subsection{Recent trends and short-run projections.}

The health of the Spanish Economy has improved significantly in recent years. Fiscal restraint has been exercised to meet the requirements to be part of Stage 3 of the European Monetary Union. This has brought fiscal deficits from about 7\% of GDP in the early nineties to near balance today (fiscal balance is targeted for 2001). Qualifying for the monetary Union, coupled with the better fiscal outlook, has driven faster output growth and a sharp decline in interest rates and inflation that further strengthened the fiscal outlook. (12).

Reference 13 contains the short run (2000-2004) projections for the Spanish Economy published he Ministry of Economy. Figure 18 illustrates the trends in GDP growth and CPI variation for the past years together with the short run outlook from reference 13 .

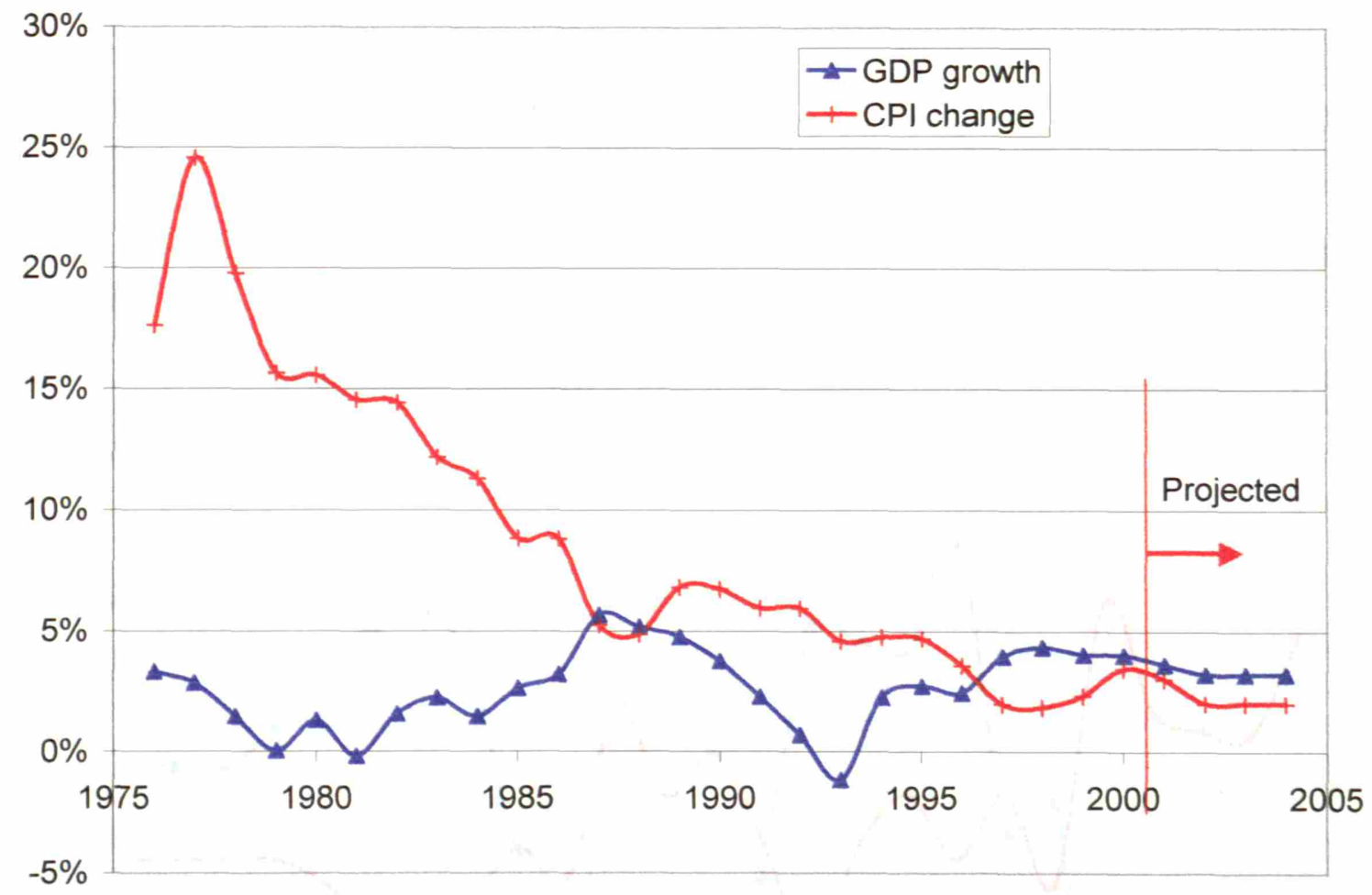

Figure 18. GDP Growth and CPI, 1977-2004. (Source INE and Ministerio de Economía)

The debt to GDP ratio has also been steadily declining as a result of the fiscal discipline observed by the Spanish authorities. The current outlook calls for a reduction in the debt to GDP ratio to about $50 \%$ by 2004 . Figure 19 illustrates the recent evolution of this ratio and the short-run government projections. The central government outlook includes a small Social Security surplus in each of the four years included in the forecast.

The recent expansive cycle in the economy has been mainly driven by job creation as shown in Figure 20. Productivity growth (measured as the difference between GDP growth and job creation) has remained at modest levels around $0.5-1.2 \%$ since 1995 . The government projections call for a yearly productivity growth of $1.1 \%$ out to 2004 . 


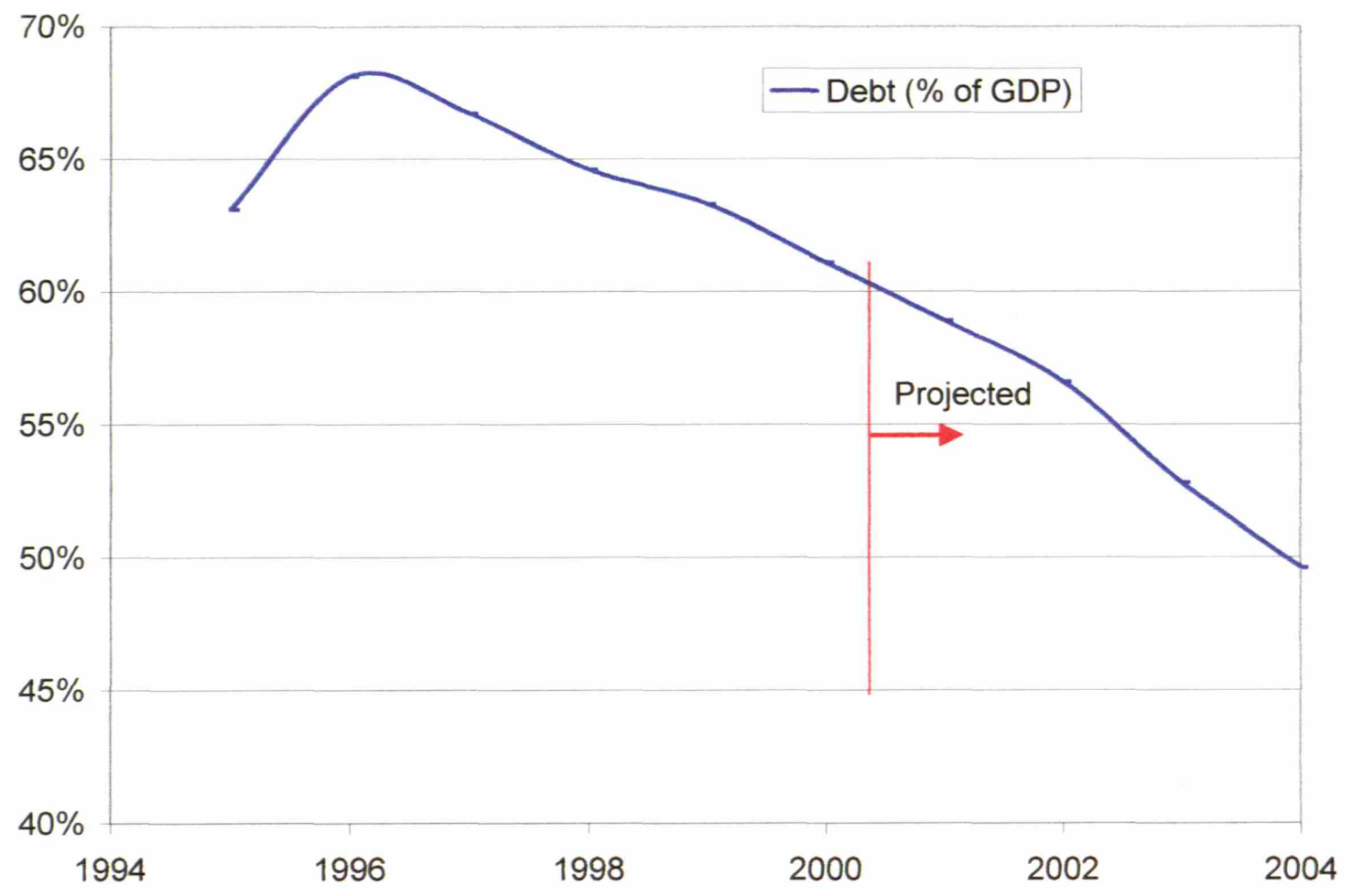

Figure 19. Debt to GDP ratio. Recent trends and short-run outlook. (Source: refs 12 and 13)

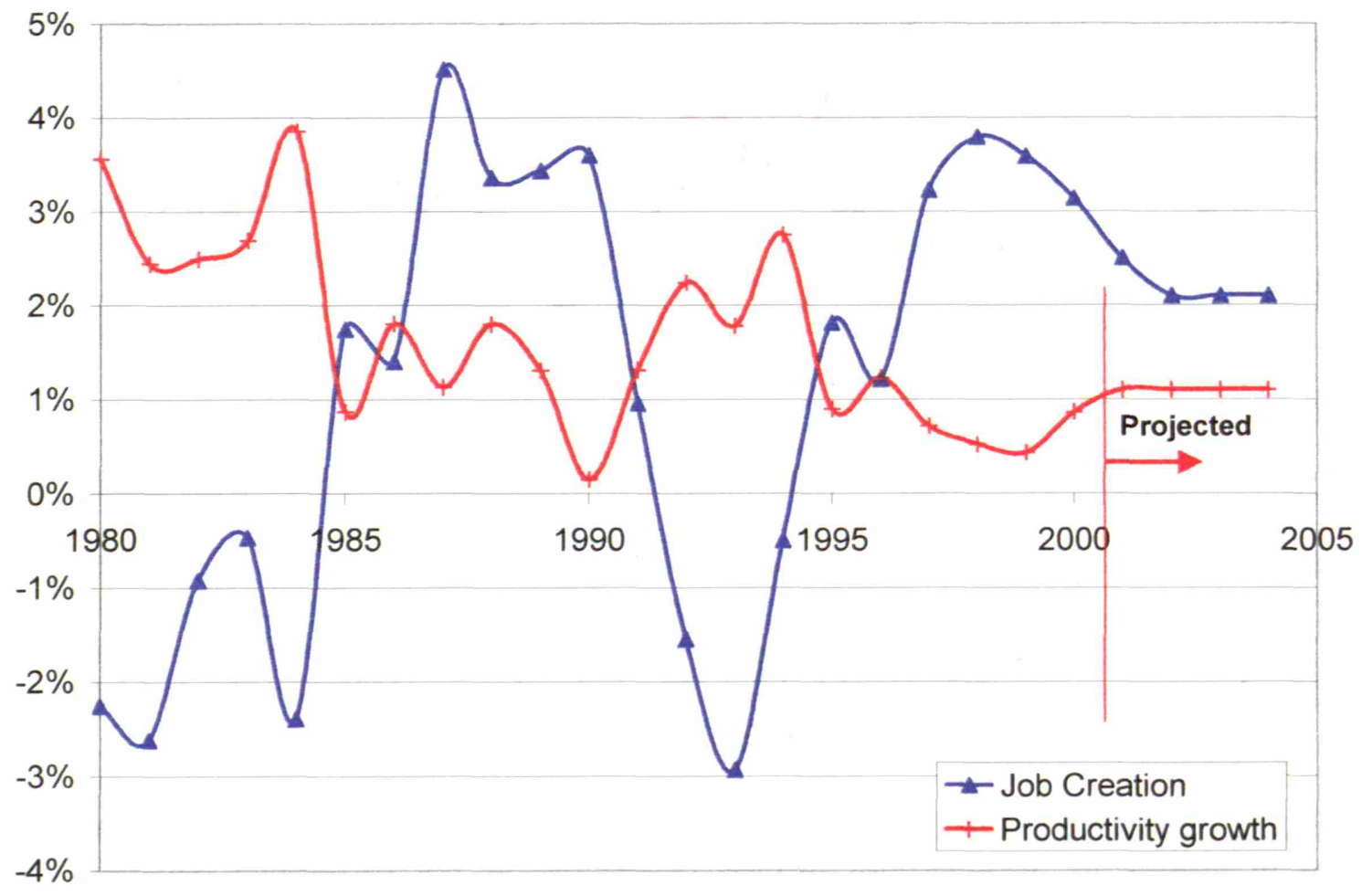

Figure 20. Job Creation and Productivity growth in Spain. Recent trends and short-run outlook. (Sources INE and ref 13) 
The occupied labor force in Spain has been rather low in relation to its working age population on two major accounts: High unemployment and low labor force participation.

Spain has been notorious for the degradation in the labor market since the late 1970s; with the highest unemployment rate of any EU country for much of the past two decades. The rate has been coming down very fast in the last few years. Figure 21 illustrates the recent data and the forecast for the near future. Nevertheless, there is still room for further reduction, down to the $4-5 \%$ level, although this may require additional structural reforms.

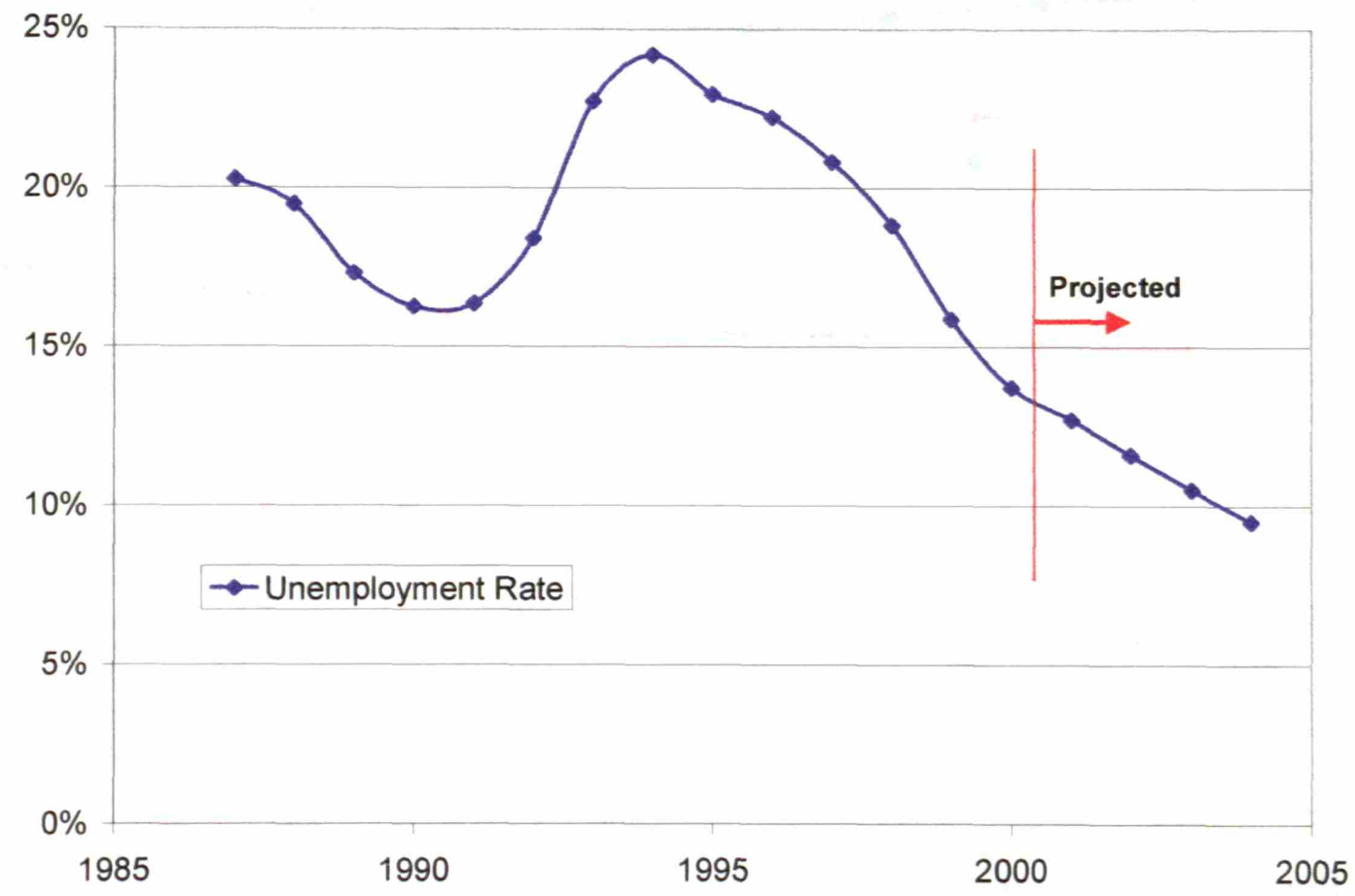

Figure 21. Unemployment rate in Spain. Recent trends and short-run outlook. (Sources INE-EPA and ref 13)

The participation rate, that is, the ratio of the active people (Those working or unemployed but actively seeking a job) to the total population available to work (16-64, or of a given age and gender group when so specified), has been rather low for Spain in the last years. However, it has been a recovering since 1995 as a result of the expansive economic cycle and the increasing participation of women in the labor force. Figure 22 illustrates the variations in the participation rates for the total population ages 16-64 as well as the figure for both genders. Note the steady recovery of the female participation rates.

A closer look at the age and gender breakdown of the participation rates (Table 13) shows that the opportunities for improvement lie mainly in the female rates, still far from those found in Scandinavian countries (particularly for ages 25-64), and for older men. In the latter segment, early retirement programs have resulted in a drop of almost $17 \%$ since 1980. There is opportunity for recovery for younger men also, however, given the longer study period, the rates of 1980 are difficult to recover. 
Table 13. Participation Rates by Age and Gender.

\begin{tabular}{|l|cccccc|}
\cline { 2 - 7 } \multicolumn{1}{c|}{} & \multicolumn{3}{c|}{ Men } & \multicolumn{3}{c|}{ Women } \\
\cline { 2 - 7 } \multicolumn{1}{c|}{} & $16-24$ & $25-54$ & $55-64$ & $16-24$ & $25-54$ & $55-64$ \\
Spain (1980) & $70.8 \%$ & $95.6 \%$ & $77.6 \%$ & $49.4 \%$ & $30.2 \%$ & $21.9 \%$ \\
Sweden (1995) & $50.1 \%$ & $90.6 \%$ & $70.4 \%$ & $49.9 \%$ & $86.2 \%$ & $63.4 \%$ \\
EU(1995) & $52.4 \%$ & $92.4 \%$ & $52.3 \%$ & $43.8 \%$ & $68.7 \%$ & $27.9 \%$ \\
Spain (2000) & $\mathbf{5 1 . 8 \%}$ & $\mathbf{9 2 . 8 \%}$ & $\mathbf{6 0 . 0} \%$ & $\mathbf{4 3 . 0} \%$ & $\mathbf{6 2 . 2} \%$ & $\mathbf{2 2 . 4} \%$ \\
\hline
\end{tabular}

Source EPA and reference 15.

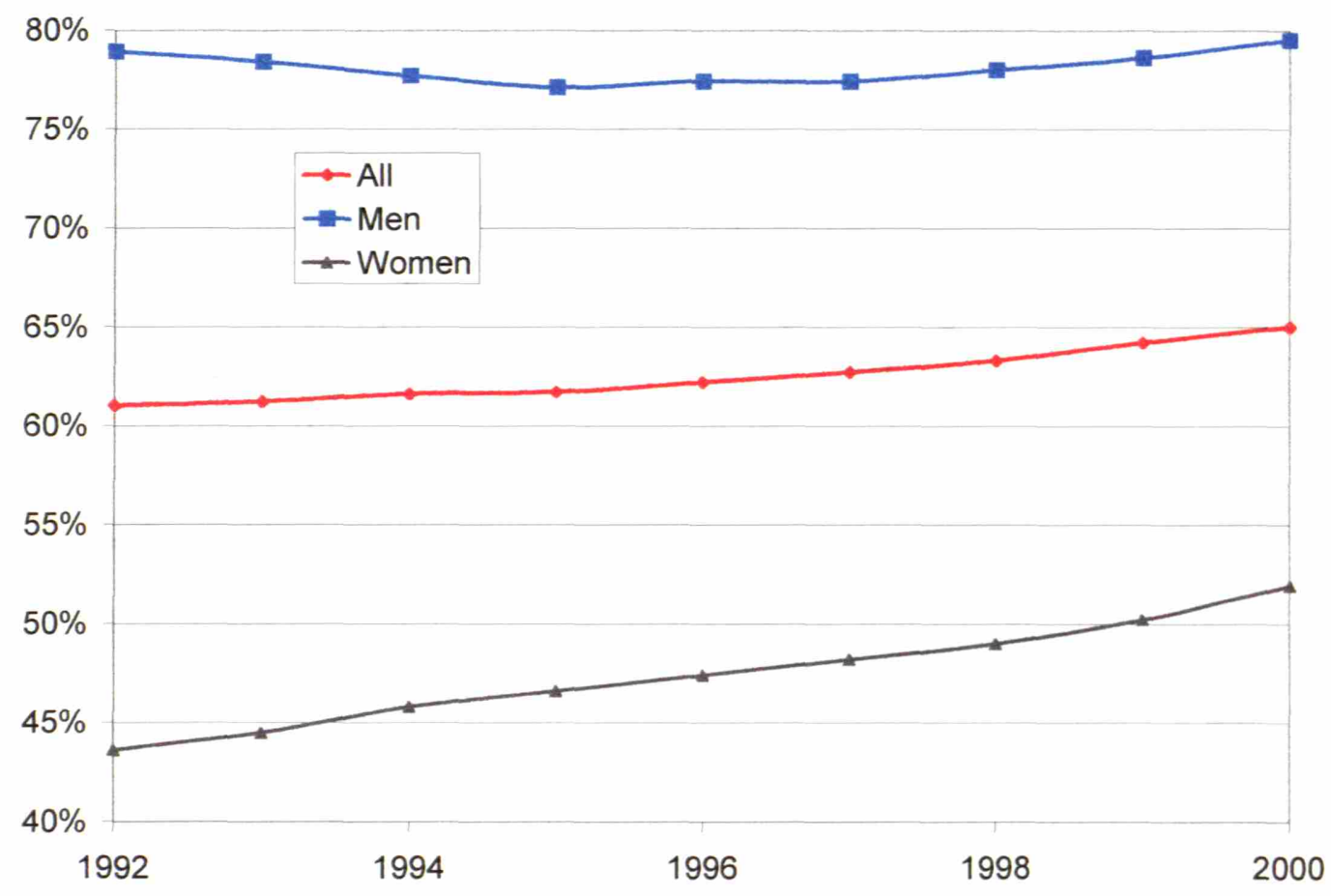

Figure 22. Evolution of the participation rates in the nineties. (Sources INE-EPA)

\subsection{Long-term projections.}

Projecting the evolution of the economy over a 50-year period with accuracy is an impossible task. In order to assess the major trends to be expected in the evolution of the finances of the Social Security system, we will carry out a simulation for a potential central path (no business cycles) for the economy. The outlook for the short run will be the one forecasted by the government (see reference 13).

Beyond 2004, the central scenario used is developed as follows:

- Assume a more modest rate of output growth of $2.5 \%$ starting at 2005 .

- Inflation is kept at $2 \%$

- The government maintains fiscal balance outside of Social Security beyond 2003. Small deficits of $-.3 \%$ of GDP in 2001 and $-.1 \%$ of GDP in 2002 are anticipated not considering the Social Security surplus.

- The number of jobs grows as $1.4 \%$ a year during the initial period until the unemployment rate reaches a minimum rate $(5 \%$ taken here as the figure for structural unemployment).

- Productivity growth is taken initially as $1.1 \%$, the same figure used for the short run outlook. As the labor supply becomes tighter (decreasing unemployment), the rate of 
productivity growth increases up to a maximum of $1.5 \%$ /year. The GDP growth adapts to the new rate of growth of productivity and jobs.

- Finally, in order to calculate the active population (and thus the unemployment rates) the Labor Force Participation Rates (LFPR) are projected forward from their current levels.

\section{Projecting LFPR:}

Figure 23 approximates the current participation rates of the Spanish labor force by age and gender and also shows the future state of the LFPR. The main changes expected are:

- The progressive increase in LFPR for men over 55 as a result of the phasing out of the early retirement provisions currently in effect and also predicting a more restrained use of early retirement to solve social problems. The end state for men is reached at around 2011.

- Increasing the LFPR of women over 30 , getting closer to that already found in Nordic countries. The end state for men is reached at around 2030.

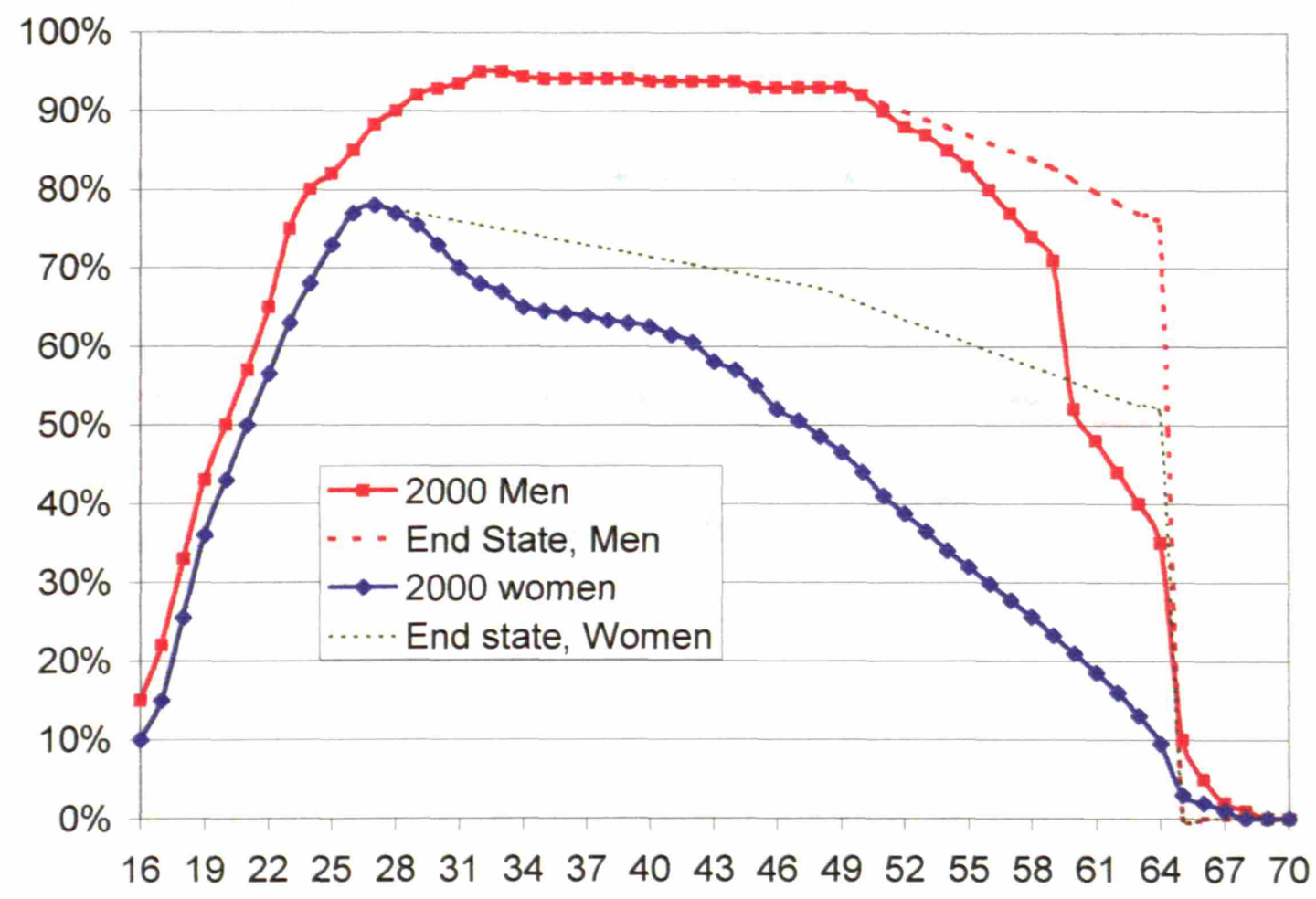

Figure 23. LFPR in 2000 and projected levels. (Sources for 2000 data INE-EPA, ref 16)

The active population is calculated by simple age and gender as: $A_{i}^{y}=A M_{i}^{y}+A M_{i}^{y}$ with

$$
A F_{i}^{y}=\sum_{j=16}^{65} P R F_{j}^{y} \frac{\left(F_{j}^{y}+F_{j}^{y+1}\right)}{2} \quad A M_{i}^{y}=\sum_{j=16}^{65} P R M_{j}^{y} \frac{\left(M_{j}^{y}+M_{j}^{y+1}\right)}{2}
$$

Where:

$A_{i}^{y}$ is the average active population of age $\mathrm{i}$ living in year $\mathrm{y}$.

$A F_{i}^{y}$ is the average number of active females of age i living in year $\mathrm{y}$. 
$A M_{i}^{y}$ is the average number of active males age $\mathrm{i}$ living in year $\mathrm{y}$.

$P R F_{i}^{y}$ is the participation rate of females age $\mathrm{i}$ living in year $\mathrm{y}$.

$P R M_{i}^{y}$ is the participation rate of males age $\mathrm{i}$ living in year $\mathrm{y}$.

$F_{i}{ }^{y}$ is the number of females age i living in year y (January 1), (See Chapter 2.3).

$M_{i}^{y}$ is the number of males age i living in year y (January 1), (See Chapter 2.3)

Figure 24 shows some key parameters of the Economy as projected forward for the baseline population scenario outlined in Chapter 2.3 and the central macroeconomic scenario.

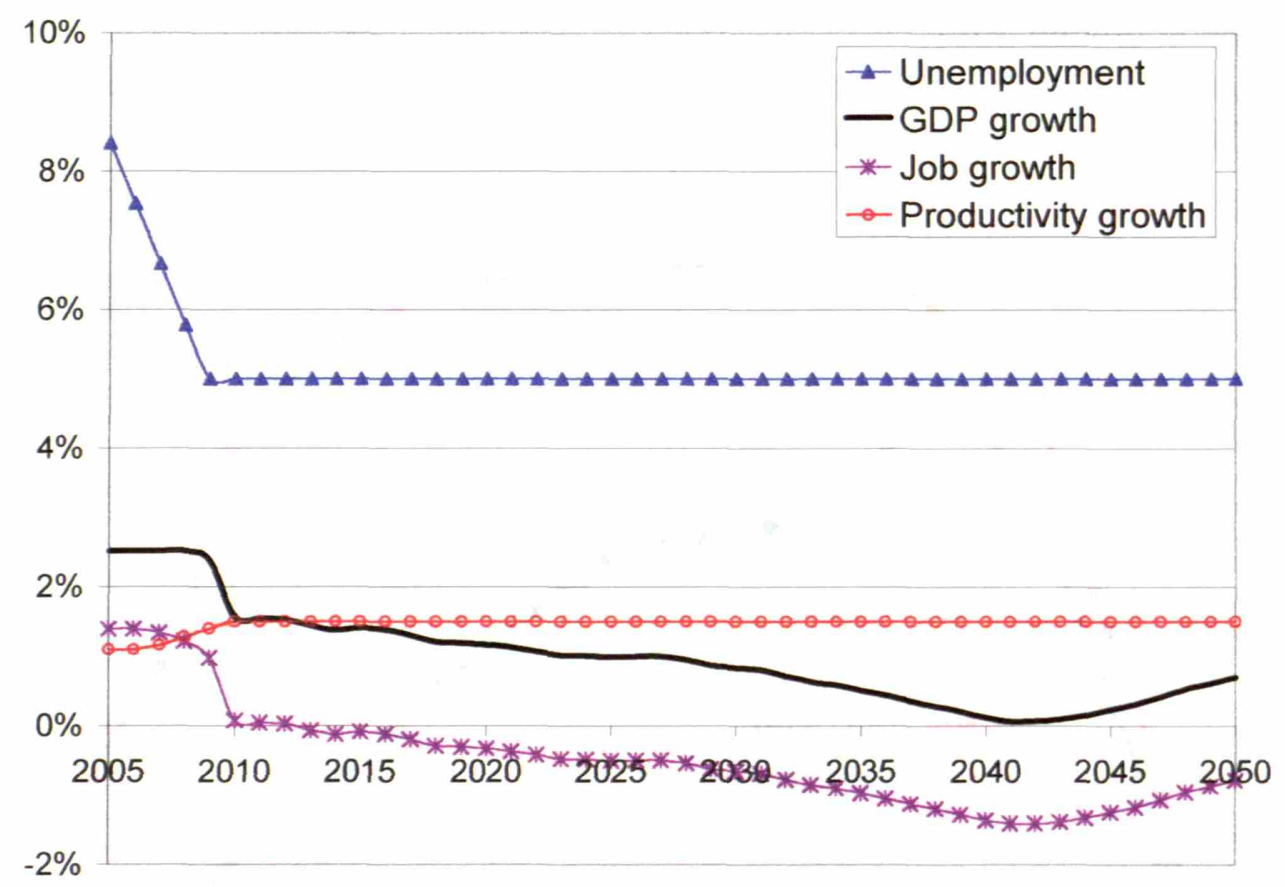

Figure 24. Economic parameters as projected for our baseline scenario.

The following observations can help understand the chart:

The economy continues to generate jobs and taking up the slack provided by the unemployment until around 2008, when the structural unemployment rate is reached. From that point on, lack of available workers constrains GDP growth despite the increase in productivity growth to $1.5 \%$ /year. The rate of job creation becomes negative driven by the reduction in population ages 16-64. In 2030 (the date at which we arbitrarily set the convergence to the final LFPR) the problems gets worse as there is no further improvement in participation rates.

The macroeconomic outlook is therefore highly dependent on the demographic outlook and the evolution of LFPR, as labor shortages could start constraining output growth this decade. Figure 24 shows the outlook for the baseline demographic scenario. Simulations ran for other demographic scenarios showed that even for the most optimistic one, full employment is reached by 2010 (with growth at $2.5 \%$ and productivity growth at $1.1 \%$ ). 


\section{Financial projections for the contributive programs of Social Security.}

The income and expenses of the contributive programs of the Social Security system will be projected forward into 2050 in order to get a rough estimation of the financial viability of the system as currently constructed. The demographic scenarios developed in Chapter 2.3 and the macroeconomic scenario described in Chapter 3.2 are taken as the basis for the projection. It will be assumed that salaries increase in real terms as productivity. The non-linear growth of contributions and new pensions with salaries, resulting from the maximum contributions and maximum pensions, will be disregarded initially. An attempt to quantify this effect is included at the end of this chapter.

\subsection{Income projections.}

There are two sources of income:

- A payroll tax (Contributions for General Contingencies and Jobsite Accidents).

- The returns on the "Pension Fund". The returns will be a function of the total capital accumulation and the investment policy. They are non existent in the current PAYGO system and will be discussed in the following chapter.

To estimate the future contribution income, it will be assumed that contributions will increase with real wages (productivity), inflation and total jobs in the economy as:

$$
C^{y}=C^{y-1}\left(1+q^{y}\right)\left(1+n^{y}\right)\left(1+\pi^{y}\right)
$$

Where: $C^{y}$ is the contribution (nominal) collected in year $\mathrm{y}$, and $q^{y}, n^{y}, \pi^{y}$ are the productivity growth, job growth and inflation for year $\mathrm{y}$.

Figure 25 shows the real contribution income and that calculated by (1), staring in 1980 and taking real data for inflation, job growth and productivity growth. The match is good.

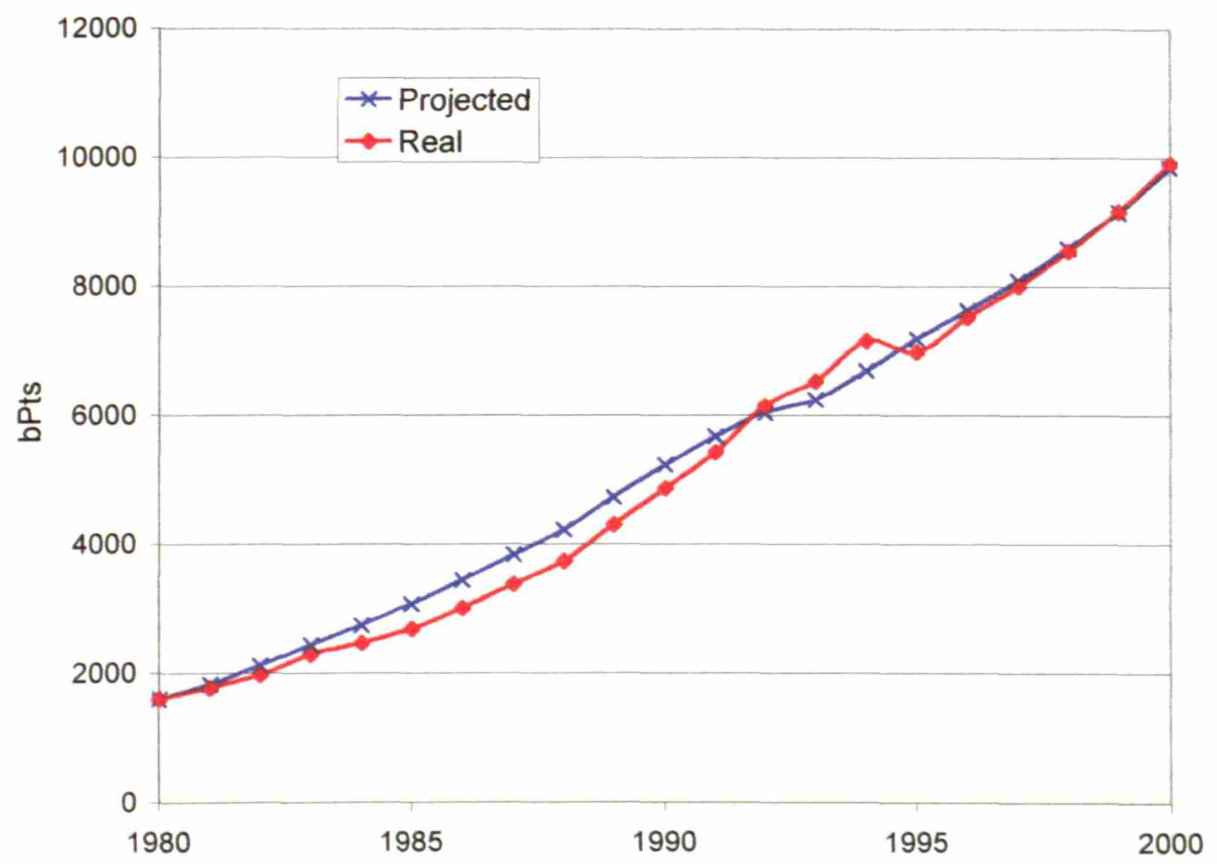

Figure 25. Comparison between real contributions and those estimated using (1).

With these assumptions, the contributions to GDP ratio remains constant at $9.8 \%$ throughout the projection period. 


\subsection{Expense projections.}

Projecting expenses is a much more complex matter, and it is bound to have significant inaccuracies given the number of parameters that can affect its evolution. The approach presented in this chapter is to project the expenses for each of the contributive programs described in Section 1.3 individually, with a management cost added over this amount in proportion similar to that observed in the past. The projection will be based mainly on demographic factors, activity parameters and the projected evolution of salaries. A more detailed description of the projection method used for each program follows.

\subsubsection{Retirement pensions.}

This is the most important program and the one most affected by the expected demographic changes. The first problem faced lies with the determination of the number of contributors that will be entitled to retirement pensions. There is information available about the number of contributors for each of the past years. However, this number exceeds the number of total occupied people from EPA despite the fact that this statistic includes the workers of government agencies that do not participate in Social Security Programs (Clases Pasivas del Estado).

We will use the number of employed workers contributing to Social Security as the starting point. The number of contributors is assumed to grow at the same rate as job creation as forecasted in the macroeconomic outlook. We then add to this number an estimate of the number of unemployed workers receiving contributive unemployment subsidies from INEM (about 15\% of the total EPA unemployed in the past few years).

In order to forecast future pension expenses, detailed information on the contribution history of current workers would be needed. This information was not available to us. A simplified approach was used to calculate future pension outlays as described below:

$$
R^{y}=\sum_{i} P_{f}(R)_{i}^{y} A_{f}(R)_{i}^{y}+\sum_{i} P_{m}(R)_{i}^{y} A_{m}(R)_{i}^{y} \quad \text { where: }
$$

$R^{y}$ is the total expenditure in Retirement pensions in year $\mathrm{y}$.

$P_{f}(R)_{i}^{y}$ is the number of Retirement pensions for females age $\mathrm{i}$ living in year $\mathrm{y}$.

$P_{m}(R)_{i}^{y}$ is the number of Retirement pensions for males age i living in year $\mathrm{y}$.

$A_{f}(R)_{i}^{y}$ is the average Retirement pension for females age $\mathrm{i}$ living in year $\mathrm{y}$.

$A_{m}(R)_{i}^{y}$ is the average Retirement pension for males age $\mathrm{i}$ living in year $\mathrm{y}$.

The number of pensions and average amounts are estimated as follows for females:

$$
\begin{gathered}
P_{f}(R)_{i}^{y}=P_{f}(R)_{i-1}^{y-1}\left(1-q_{i}^{y}\right)+N_{f}(R)_{i}^{y} \\
A_{f}(R)_{i}^{y}=\frac{\left(A_{f}(R)_{i-1}^{y-1}\left(1+\pi^{y}\right)\left(P_{f}(R)_{i-1}^{y-1}\left(1-q_{i}^{y}\right)\right)+N_{f}(R)_{i}^{y} A N_{f}(R)_{i}^{y}\right)}{P_{f}(R)_{i}^{y}}
\end{gathered}
$$

$N_{f}(R)_{i}^{y}$ is the number of new retirement pensions awarded to females age $\mathrm{i}$ in year $\mathrm{y}$. $A N_{f}(R)_{i}^{y}$ is the average new retirement pension awarded to a female age $\mathrm{i}$ in year $\mathrm{y}$. And totally symmetrical formulas for males. 
The initial distribution of the number of retirement pensions, and their average amount by age and gender is available through the "Anuario de Estadisticas Laborales" at Www.mtas.es

New retirement pensions are considered as follows:

Initially, all active contributors over age 59 that turn inactive the following year (except those that go into permanent disability) are considered to have retired. At age 65, all permanent disability pensioners join the pool of retirement pensioners. The activity rates described in section 3.2 are set in a way that by 2012 virtually all retirements take place at 65 . Note that by that time the possibility to retire at 60-64 given the laws in place in January 2001 would have expired.

The average pension for new retirees awarded in 2000 (both genders) was of the order of 1.5 million Pts. (1.74 million for the general scheme). However, this includes a significant number (about $35 \%$ ) of people taking early retirement and getting a reduction in the pension they would perceive had they retired at 65 . Using the figures for early retirees available from www.mtas.es the average new pension awarded for a person retiring at 65 in 2000 was estimated to be $1.69 \mathrm{mPts}$, and smaller for those taking early retirement. No distinction was made between the new pensions awarded by gender. This can introduce a bias upward as women who have had historically significantly lower pensions have a higher life expectancy than men do.

The average pension for future years is calculated assuming that the carry-over pensions from the previous year are updated by inflation, while the newly awarded pensions increase in real terms as productivity:

$$
A N(R)_{i}^{y}=A N(R)_{i-1}^{y-1}\left(1+\pi^{y}\right)\left(1+q^{y}\right)
$$

Figure 31 shows the projected path of the expenses from the Retirement Pensions Program in the baseline demographic scenario. Initially, the expenses are expected to fall from about $5.6 \%$ of GP in 2000 to a minimum of $4.8 \%$ of GDP around 2009 . This could be explained by the reduction in early retirement pension expenses and the fact that the generation born during, or shortly after the Civil War, which is not numerous, reaches retirement age in this coming decade. The expenses climb steadily from there until they reach over $12 \%$ of GDP toward the end of the projection period. This is a result of the rapid increase in the old-age dependency ratio.

\subsubsection{Surviving spouse pensions.}

This program represents the second largest expense for the contributive system with $2,027,193$ pensions at the end of 2000 and a total expense in pensions of approximately 1,560 bPts. The pension expense under this program will be affected by demographics and the evolution of wages, but in a different manner than retirement pensions. The improved life expectancy will tend to increase the number of pensions, but tamed by the fact that the contributors originating the rights will also tend to live longer.

In order to estimate the evolution of the expenses associated with this program we took as the starting point the current distribution of pensions (number and average by age and gender) available from www.mtas.er and were projected forward as described below.

Using the POD data derived in chapter 2.2, the probability of a man or woman of a given age becoming a widow/er can be estimated. Multiplying these probabilities by the 
population distribution, an estimation of the number of widow/er/s can be made. The "coverage" ratio (pensions divided by estimated widow/er/s) is about $75 \%$ for women and $25 \%$ for men. This is not due to the larger life expectancy of women, as this is already accounted by the projected numbers of widow/er/s. The reason for this difference is most likely the lower participation rates of women. The most numerous age groups women (65-79) have slightly higher "coverages" of about $82 \%$.

The future number of surviving spouse pensions was projected by estimation the total number of widow/er/s expected each year and applying a coverage rate for women which was $75 \%$ initially, growing to $82 \%$ by 2020 and staying at that level from then on (mature system). For men, the coverage rate was assumed to increase steadily from $25 \%$ in 2000 to $42 \%$ in 2050 as the new cohort of women with higher participation rates, generating surviving spouse pension rights, reaches older ages.

The average pension in 2000 was $773 \mathrm{kPts}$, the average new pension was $794 \mathrm{kPts}$ in 1999, and approximately 5\% of the pensioners exited the program during 1998 and 1999.

To complete the financial projections, it was assumed that $5 \%$ of the pensioners exited the program each year and were replaced by a new number of pensioners sufficient to reach the total number calculated as described in the previous paragraph. The new pensions are assumed to grow at the same rate as the average retirement pension, given that most spouse pensions generate from pensioners rather than active workers.

Table 14 shows the projected path of the expenses from the Surviving Spouse Program in the baseline demographic scenario. Initially, the expenses are expected to fall slightly from about $1.54 \%$ of GDP in 2000 to a minimum of $1.48 \%$ of GDP around 2008 and then increase steadily until about $2.64 \%$ of GDP in 2050 . The general trend is similar to that of the retirement pension plan, but with smaller relative changes over the period.

\subsubsection{Permanent disability pensions.}

Starting with the distribution of pensioners and their average pension by age (information available in Ref. 3 and Www.mtas.es) the expenses are projected forward as follows:

$$
P D^{y}=\sum_{i} P(P D)_{i}^{y} A(P D)_{i}^{y} \text { with, }
$$

$P D^{y}$ is the total expenditure in Permanent Disability pensions in year y.

$P(P D)_{i}^{y}$ is the number of PD pensions for people age i living in year $\mathrm{y}$.

$A(P D)_{i}^{y}$ is the average permanent disability pension for pensioners age $\mathrm{i}$ living in year $\mathrm{y}$.

$$
\begin{gathered}
P(P D)_{i}^{y}=P(P D)_{i-1}^{y-1}\left(1-p_{i}^{y}\right)+P D R_{i}^{y} A_{i}^{y} \\
A(P D)_{i}^{y}=\frac{\left(A(P D)_{i-1}^{y-1}\left(1+\pi^{y}\right)\left(P(P D)_{i-1}^{y-1}\left(1-p_{i}^{y}\right)\right)+P D R_{i}^{y} A_{i}^{y} A N(P D)_{i}^{y}\right)}{P(P D)_{i}^{y}}
\end{gathered}
$$

Where $P D R_{i}^{y}$ is the Permanent disability rate for people age $\mathrm{i}$ living in year $\mathrm{y}$, and $A N(P D)_{i}^{y}$ is the average new permanent disability pension awarded in year $\mathrm{y}$.

This approach estimates the number of people exiting the program (through death or turning 65) and those who will enter the program (new disability pensions). The average pension is calculated assuming that the carry-over pensions from the previous year are 
updated by inflation, while the newly awarded pensions increase in real terms as productivity:

$$
A N(P D)_{i}^{y}=A N(P D)_{i-1}^{y-1}\left(1+\pi^{y}\right)\left(1+q^{y}\right)
$$

The permanent disability program is not sensitive to the old-age dependency ratio. Indeed, when a worker with a disability pension turns 65 that pension is considered a retirement pension. This program will see the effect of two trends:

1. The lowering of the disability ratios (ratio of new disability pensions to total contributors) resulting from better practices in the jobsite, lower weight of sectors with higher ratios relative to the general scheme, and more importantly, measures to control fraud. Figure 26 shows the evolution of this parameter over the recent past (Ref. 3) and the projection used in this section.

2. The pressure on those ratios that can be expected from the aging of the active population that will result from the demographic effects and the increased participation rates (particularly for women) near the retirement age. See Figure 27 for a plot of the disability ratios as a function of age.

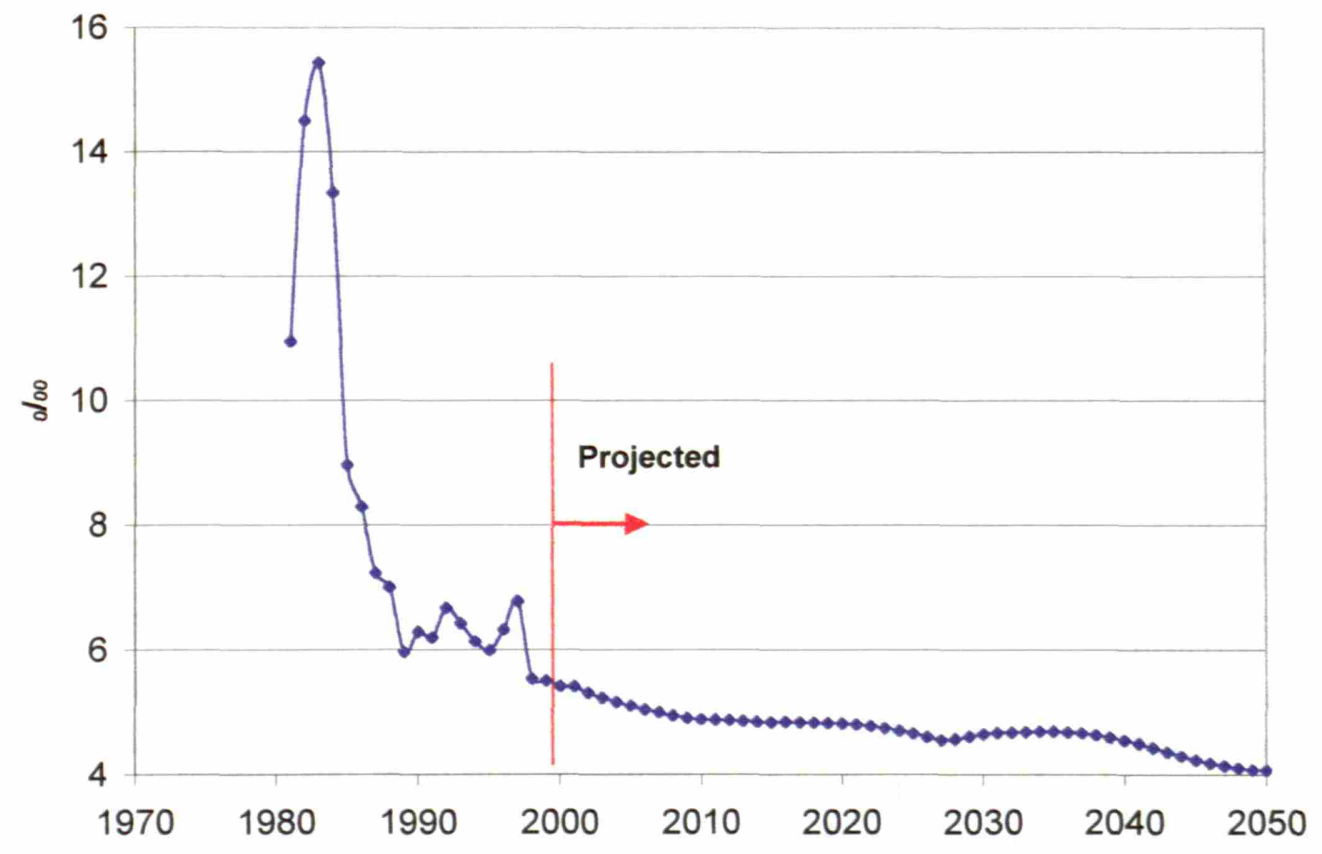

Figure 26. Permanent Disability ratio and its evolution over time. (Past data from ref. 3)

These values are still rather high, especially for the older working ages. Note that a person starting work in his/her twenties would have a probability of receiving a disability pension at age 64 of the order of $40 \%$ !. Unfortunately, full series as in Figure 3 were not available for many consecutive years. In order to project the evolution of the program, it will be assumed that the general age-distribution of the permanent disability ratio is as in Figure 3 . The disability ratios by age improve gradually until they reach $50 \%$ of the 1998 levels by 2030 and remain constant from there on. The net result is that the overall disability ratio decreases very slowly until it reaches approximately $4 \%$ in 2050 . The aging of the workforce offsets the foreseeable gains in disability ratios for most of the forecasted period. 


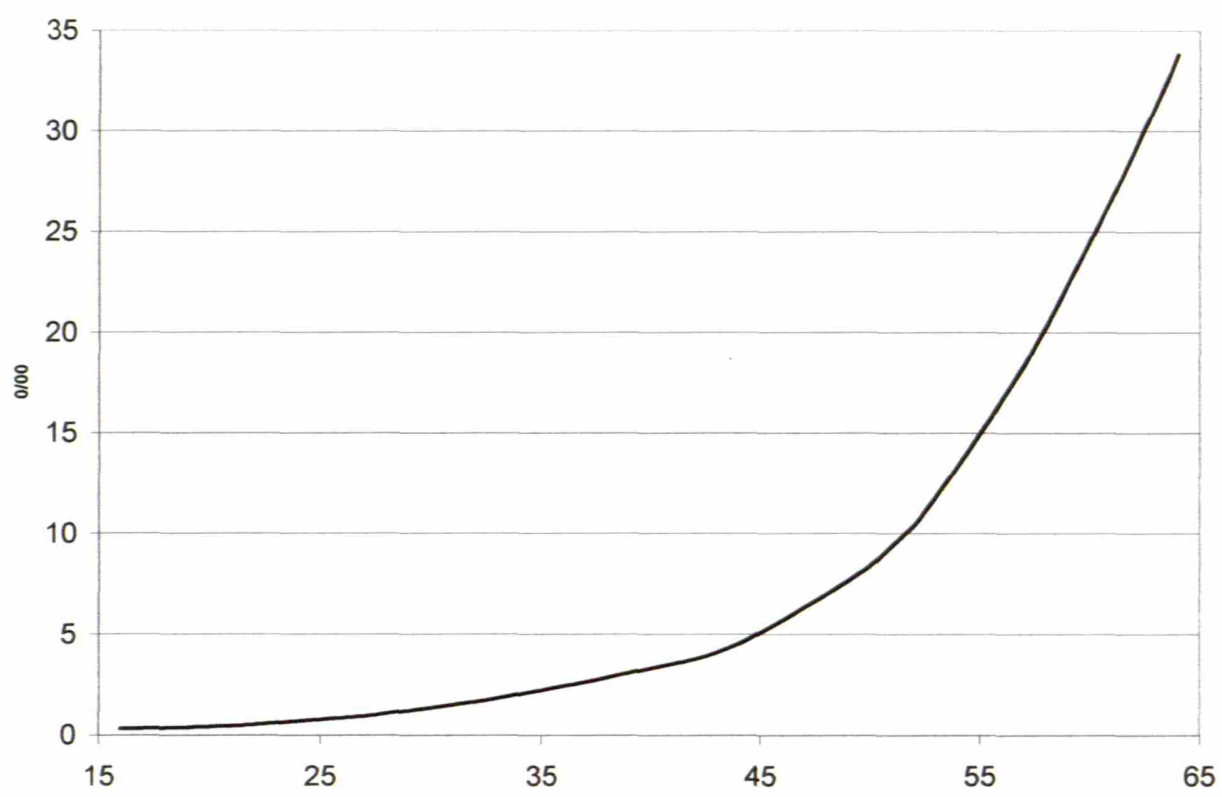

Figure 27. Permanent Disability ratio as a function of age, 1998. (From data in ref. 3)

Table 14 shows the projected path of the expenses from the permanent disability Program. A slight increase from 1.03\% to $1.16 \%$ of GDP in 2020 is expected initially as a result of the aging of the working population followed by a decline to about $0.8 \%$ of GDP at the end of the forecasted period as the disability ratios decrease.

This program can be very sensitive to these disability ratios. If the disability ratios by age remain as shown in Figure 27, the cost of the program can balloon to above $1.8 \%$ of GDP between 2030 and 2040 and stay above $1.5 \%$ since 2018 .

\subsubsection{Surviving children pensions.}

This program represented a relatively modest expense of 122 bPts $(0.12 \%$ of GDP) in 2000. The total number of pensions was 260,684 at the end of 2000 . The pension expense under this program will be affected by demographics in a very different manner than retirement pensions.

Given the low weight of this program in the total expenses, to estimate the number of pensions going forward, we have simply assumed it will be proportional to the population below 21 weighted by the current "coverage". The coverage is the ratio between the total number of pensions and people in the age group and was calculated based on the data in reference 3 and the population data presented in chapter 2 .

The average pension in 2000 was $464 \mathrm{kPts}$, the average new pension was $441 \mathrm{kPts}$ in 1999, and approximately 7\% of the pensioners exited the program during 1998 and 1999.

To complete the financial projections, it was assumed that $7 \%$ of the pensioners exited the program each year and were replaced by a new number of pensioners sufficient to reach the total number calculated as described in the previous paragraph. The new pensions are assumed to grow yearly, in real terms, with productivity.

Table 14 shows the projected path of the expenses from the Surviving Children Program in the baseline demographic scenario. Initially, the expenses are expected to fall steadily from about $0.12 \%$ of GP in 2000 to a range between 0.07 and $0.08 \%$ of GDP by 2009 remaining roughly in that rage throughout the projected period. This decrease reflects the evolution of the young population. 


\subsubsection{Surviving family support pensions.}

These pensions are intended to protect surviving family dependents other than spouse or children that lived with a contributing worker or pensioner and have no other pensions or economic means. This program represented a modest expense of $25.9 \mathrm{bPts}(0.026 \%$ of GDP) in 2000 . The program has been within a relatively narrow range of GDP in the last decade (Figure 28), with a slight decreasing trend in recent years. Population aging may tend to increase the expenses, as most of the pensions are paid today to elder women. However, the increased coverage expected from the other pension programs will tend to reduce it.

Given the low weight of this program in the total expenses, it will be simply assumed that the expenses associated with this pension will remain constant at $0.025 \%$ of GDP throughout the projection period.

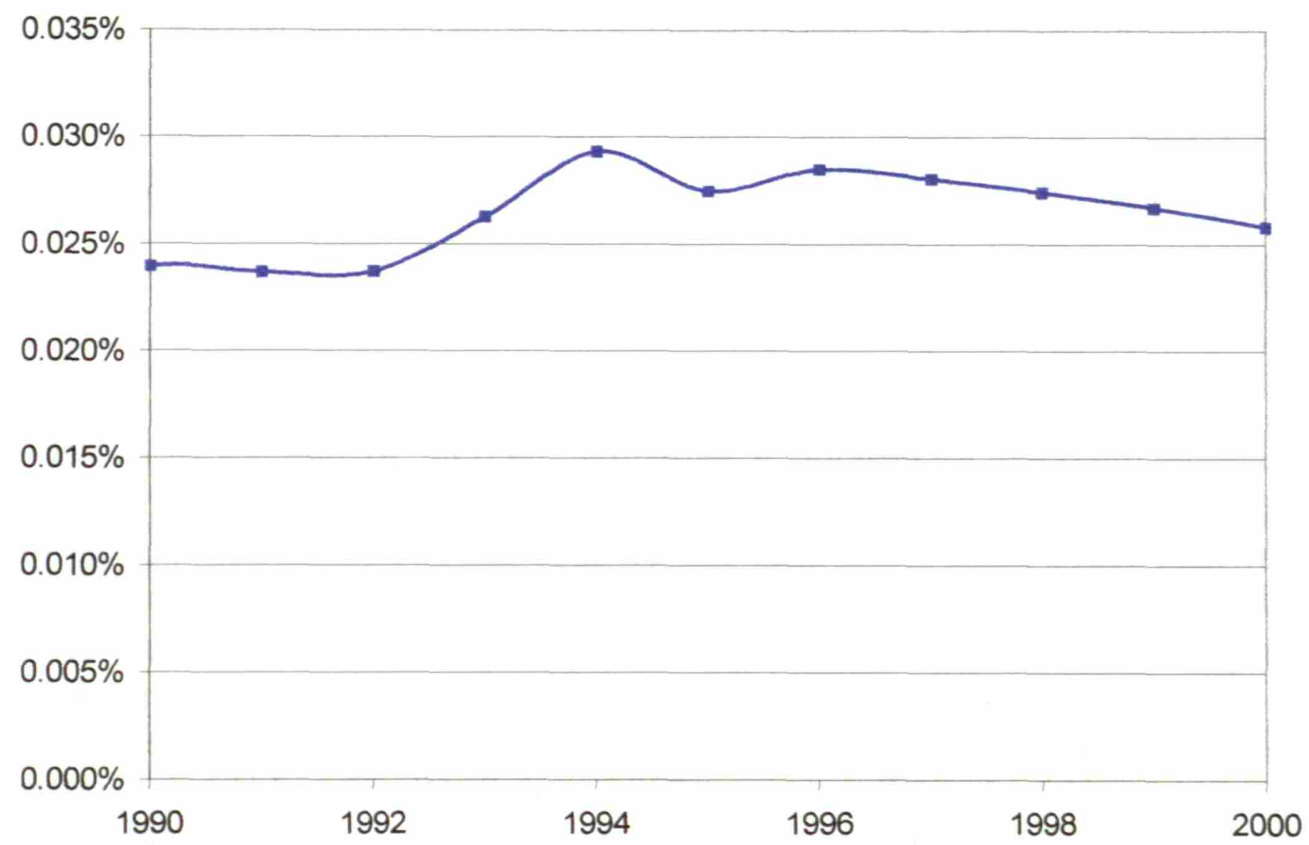

Figure 28. Family support pension expense as \% of GDP. (Sources: ref. 3 and www.mtas.es

\subsubsection{Temporary disability pensions.}

This program is intended to provide a substitute income to workers contributing to Social Security that are unable to work as a result of an accident or illness, related or not to work activity. The subsidy is limited to a year (with limited extension capabilities) and requires medical examinations. Ceteris paribus, the expenses associated with the program should scale with the contributions (and with salaries and GDP if we accept a linear relation between salaries and contributions). Figure 29 below shows the evolution of the expense as a $\%$ of GDP. The tendency to decrease observed in past years can be attributed (3) to better health and safety conditions as well as better control of fraud. In the projections made for this program, it is assumed that this trend to decrease will continue albeit at a slower pace, as shown in Figure 29. 


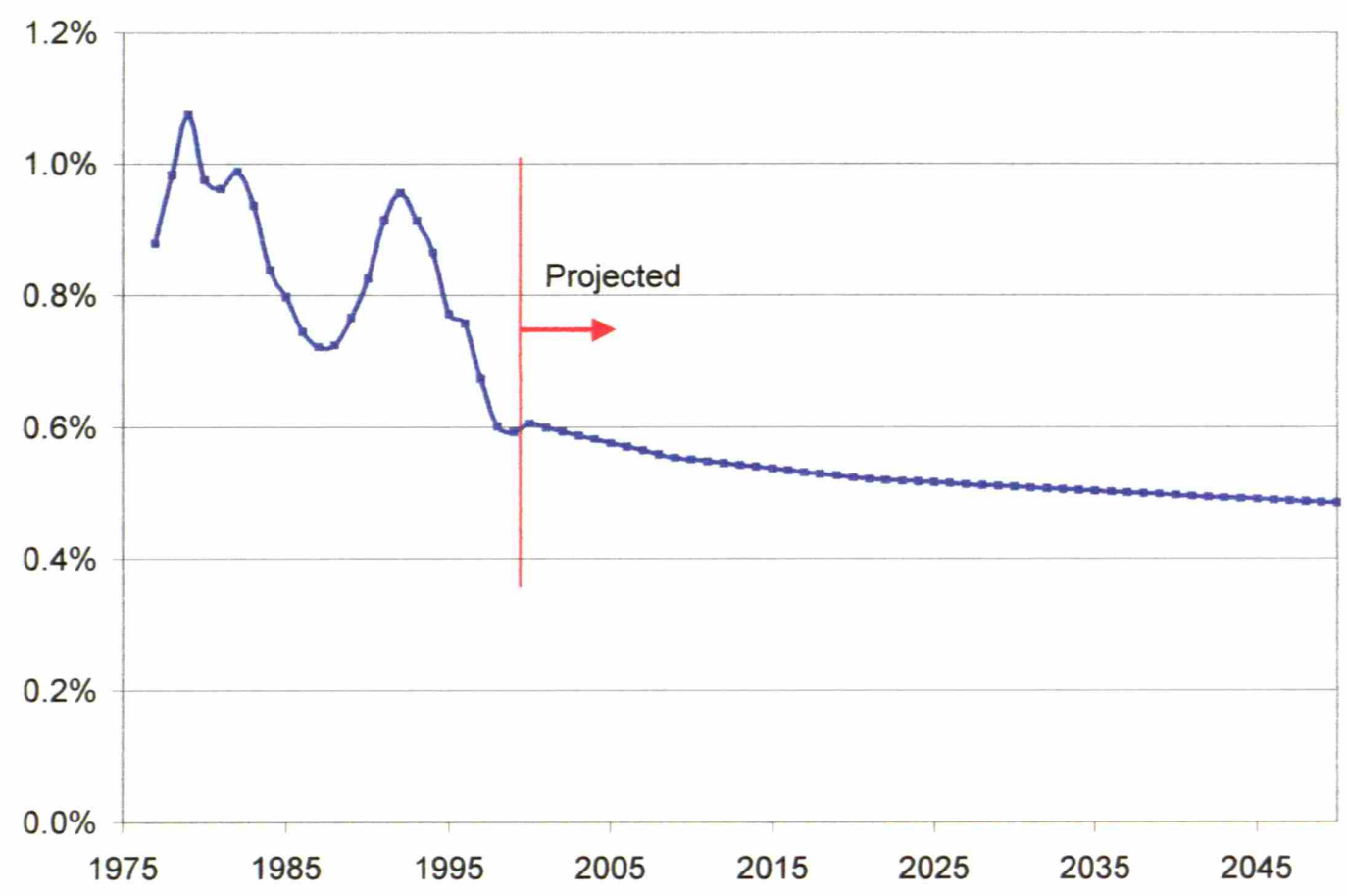

Figure 29. Temporary disability pension expense as \% of GDP in recent years and projections to 2050. (Sources for past data: ref. 3 and WwW.mtas.es)

\subsubsection{Maternity leave.}

This program is intended to provide a substitute income to parents of either gender contributing to Social Security that during a period of time (typically not to exceed 16 total weeks) take leave from work after the birth or adoption of a child. This program represented an expense of $0.12 \%$ of GDP in 2000 . In projecting the expense associated with this program forward it is assumed that the expense scales with the number of births in the year and the total contributions. With this projection, the expense in relation to the GDP will increase steadily from $0.12 \%$ in 2000 to $0.14 \%$ in 2008 and then decrease. It remains at about $0,1 \%$ of GDP between 2025 and 2050. This behavior reflects the number of births and is quite sensitive to the fertility scenario selected for the demographic outlook.

\subsubsection{Other contributive programs and management expenses.}

There are a number of other much smaller contributive programs that have represented, combined, only $0.024 \%$ of GDP. For simplicity, it will be assumed that the expenses associated with these other programs remain a constant fraction of GDP.

Regarding the management expenses incurred in the contributive programs of the Social Security system, it will also be assumed that they remain, in relative terms, at a level that is similar to the current conditions. Management expenses were estimated to be approximately $3.7 \%$ of all pensions paid in 2000 , broken down as $27 \%$ of the paid amounts for temporary disability plus $2.1 \%$ of all other pensions paid.

\subsubsection{Complements for minimum pensions.}

The calculations above include complements for minimum pensions. As mentioned in a previous chapter, these complements are non-contributive, and thus should be financed by government transfers from the general budget.

Figure 30 shows the evolution of this expense over the past years together with our projections. The projected expenses were evaluated as follows: 
- Starting with the data for 1999 as reflected in Table 14 (from reference 3).

- The pensions with a right for minimum for the retirement and spouse programs were distributed by age and gender in a way proportional to the distribution of all pensions (including those w/o complements).

- Exits from the program were calculated base on the probabilities of death for those pensioners in the retirement and spouse programs.

- The relative number of new pensions with complements and the monetary amount of said complement were estimated assuming a uniform distribution of complements with a width double the average complement. The generating salaries grow in real terms with productivity while the minimum pensions remain unchanged in real terms.

- For the retirement program, we have assumed that the number of new pensions requiring complements will decrease faster and be essentially 0 by 2011 , when early retirement will be phased out and the employment rate will be much higher, leading to longer contribution histories and thus higher accrued rights.

- Programs other than retirement and spouse, with much lower relative importance, were assumed to remain a constant fraction of the total minimum expenses.

Table 14. Structure of the complement to minimum pensions. 1999

\begin{tabular}{|lccccc|}
\cline { 2 - 6 } \multicolumn{1}{c|}{} & Retirement & Spouse & Children & Family & Perm. Disab. \\
\hline Pensions with complements & $1,418,084$ & 862,653 & 111,761 & 19,774 & 27,719 \\
Average complement paid (kpts/month) & 15.926 & 22.139 & 7.329 & 10.230 & 10.084 \\
$\%$ new pensions with complement & 23.45 & 40.35 & 35.79 & 33.51 & 1.71 \\
Average complement for new pensions (kpts/month) & 14.7 & 20.2 & 5.6 & 3.5 & 16 \\
Minimum Pension $(*)(\mathrm{kpts} /$ month) & 57 & 57 & 17 & 17 & 57 \\
\hline
\end{tabular}

$(*)$ Varies with the personal circumstances of the pensioner (3). Selected most frequent case

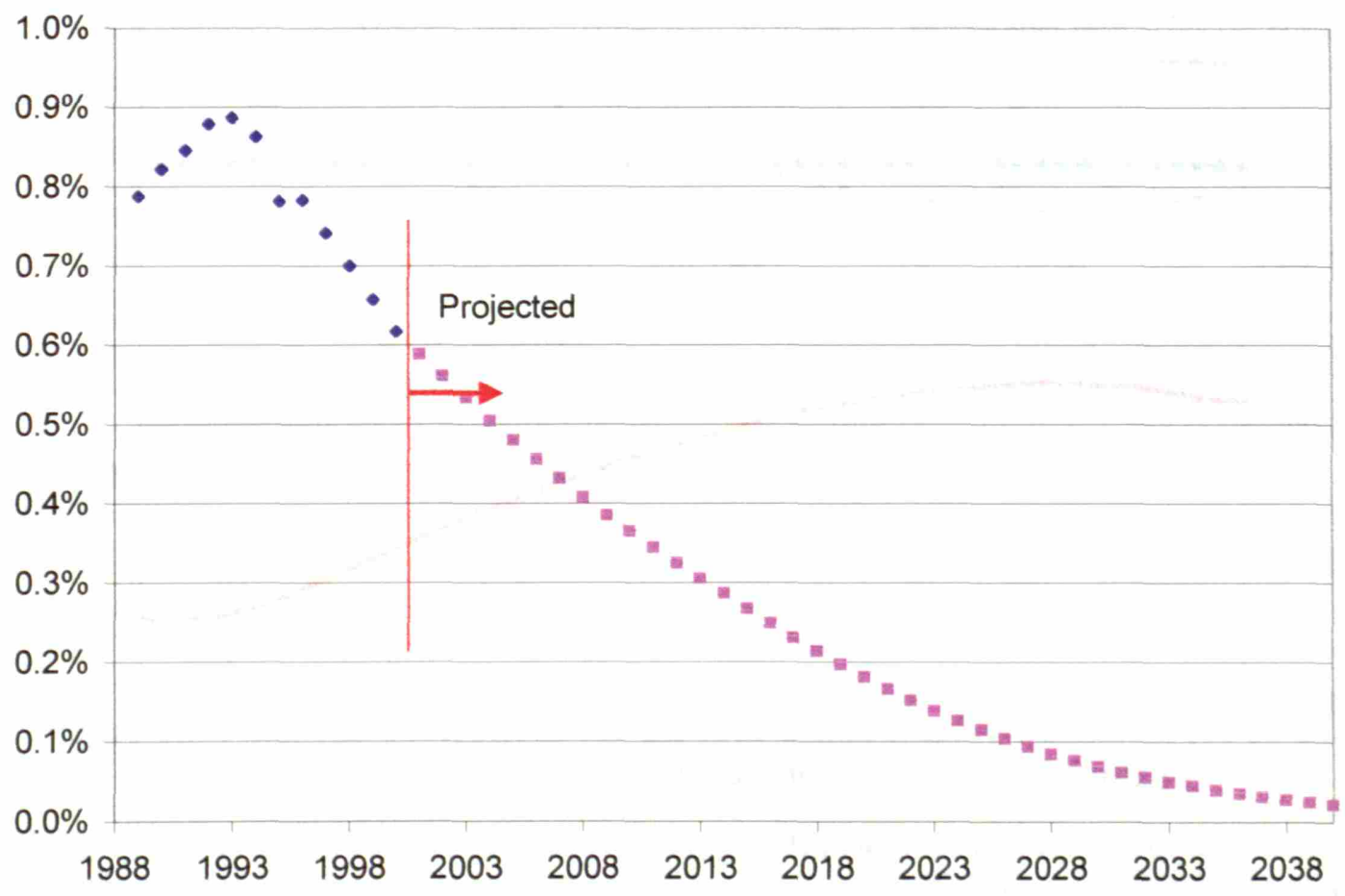

Figure 30. Complement for minimum pensions. Recent data and projections (\% of GDP) 


\subsection{Expected Social Security balance. Scenario analysis.}

Following the methodology outlined in the previous section, the financial projections for the contributive portion of the Spanish Social Security system were calculated for the baseline case and several alternative scenarios.

\subsubsection{Baseline scenario.}

Table 15 and Figure 31 show the projections for the baseline demographic and macroeconomic scenarios outlined in previous chapters. The balance includes the assumption that the complements for minimum pensions are financed out of general taxation.

Table 15. Financial Projections for the Baseline Demographic Scenario (\% of GDP)

\begin{tabular}{|c|c|c|c|c|c|c|c|c|c|c|c|}
\hline Year & Contr & $\begin{array}{l}\text { Permanent } \\
\text { Disability }\end{array}$ & Retir & Spouse & Children & $\begin{array}{c}\text { Temp. } \\
\text { Disability }\end{array}$ & $\begin{array}{c}\text { Mat. } \\
\text { Leave }\end{array}$ & Manz & $\begin{array}{l}\text { Comp. } \\
\text { minimur }\end{array}$ & $\begin{array}{l}\text { Total } \\
\text { Expense }\end{array}$ & Balan \\
\hline 2000 & $9.8 \%$ & $1.00 \%$ & $5.6 \%$ & $1.5 \%$ & $0.12 \%$ & $0.61 \%$ & $0.12 \%$ & $0.34 \%$ & $0.62 \%$ & $8.8 \%$ & $1.1 \%$ \\
\hline 2005 & $9.8 \%$ & $1.07 \%$ & $5.0 \%$ & $1.5 \%$ & $0.09 \%$ & $0.58 \%$ & $0.14 \%$ & $0.32 \%$ & $0.48 \%$ & $8.2 \%$ & $1.6 \%$ \\
\hline 2010 & $9.8 \%$ & $1.11 \%$ & $4.8 \%$ & $1.5 \%$ & $0.08 \%$ & $0.55 \%$ & $0.14 \%$ & $0.31 \%$ & $0.36 \%$ & $8.1 \%$ & $1.7 \%$ \\
\hline 2015 & $9.8 \%$ & $1.14 \%$ & $5.0 \%$ & $1.5 \%$ & $0.07 \%$ & $0.54 \%$ & $0.13 \%$ & $0.31 \%$ & $0.27 \%$ & $8.5 \%$ & $1.3 \%$ \\
\hline 2020 & $9.8 \%$ & $1.16 \%$ & $5.6 \%$ & $1.6 \%$ & $0.08 \%$ & $0.52 \%$ & $0.11 \%$ & $0.32 \%$ & $0.18 \%$ & $9.2 \%$ & $0.6 \%$ \\
\hline 2025 & $9.8 \%$ & $1.12 \%$ & $6.5 \%$ & $1.7 \%$ & $0.08 \%$ & $0.52 \%$ & $0.10 \%$ & $0.34 \%$ & $0.11 \%$ & $10.2 \%$ & $-0.4 \%$ \\
\hline 2030 & $9.8 \%$ & $1.04 \%$ & $7.7 \%$ & $1.8 \%$ & $0.08 \%$ & $0.51 \%$ & $0.10 \%$ & $0.36 \%$ & $0.07 \%$ & $11.6 \%$ & $-1.7 \%$ \\
\hline 2035 & $9.8 \%$ & $0.99 \%$ & $9.0 \%$ & $2.0 \%$ & $0.07 \%$ & $0.50 \%$ & $0.10 \%$ & $0.39 \%$ & $0.04 \%$ & $13.1 \%$ & $-3.3 \%$ \\
\hline 2040 & $9.8 \%$ & $0.93 \%$ & $10.5 \%$ & $2.3 \%$ & $0.07 \%$ & $0.50 \%$ & $0.11 \%$ & $0.43 \%$ & $0.02 \%$ & $14.8 \%$ & $-5.0 \%$ \\
\hline 2045 & $9.8 \%$ & $0.84 \%$ & $12.0 \%$ & $2.5 \%$ & $0.07 \%$ & $0.49 \%$ & $0.10 \%$ & $0.46 \%$ & $0.01 \%$ & $16.5 \%$ & $-6.6 \%$ \\
\hline 2050 & $9.8 \%$ & $\mathbf{0 . 8 0} \%$ & $12.3 \%$ & $2.7 \%$ & $0.07 \%$ & $0.48 \%$ & $0.09 \%$ & $0.47 \%$ & $0.00 \%$ & $16.9 \%$ & $-7.1 \%$ \\
\hline
\end{tabular}

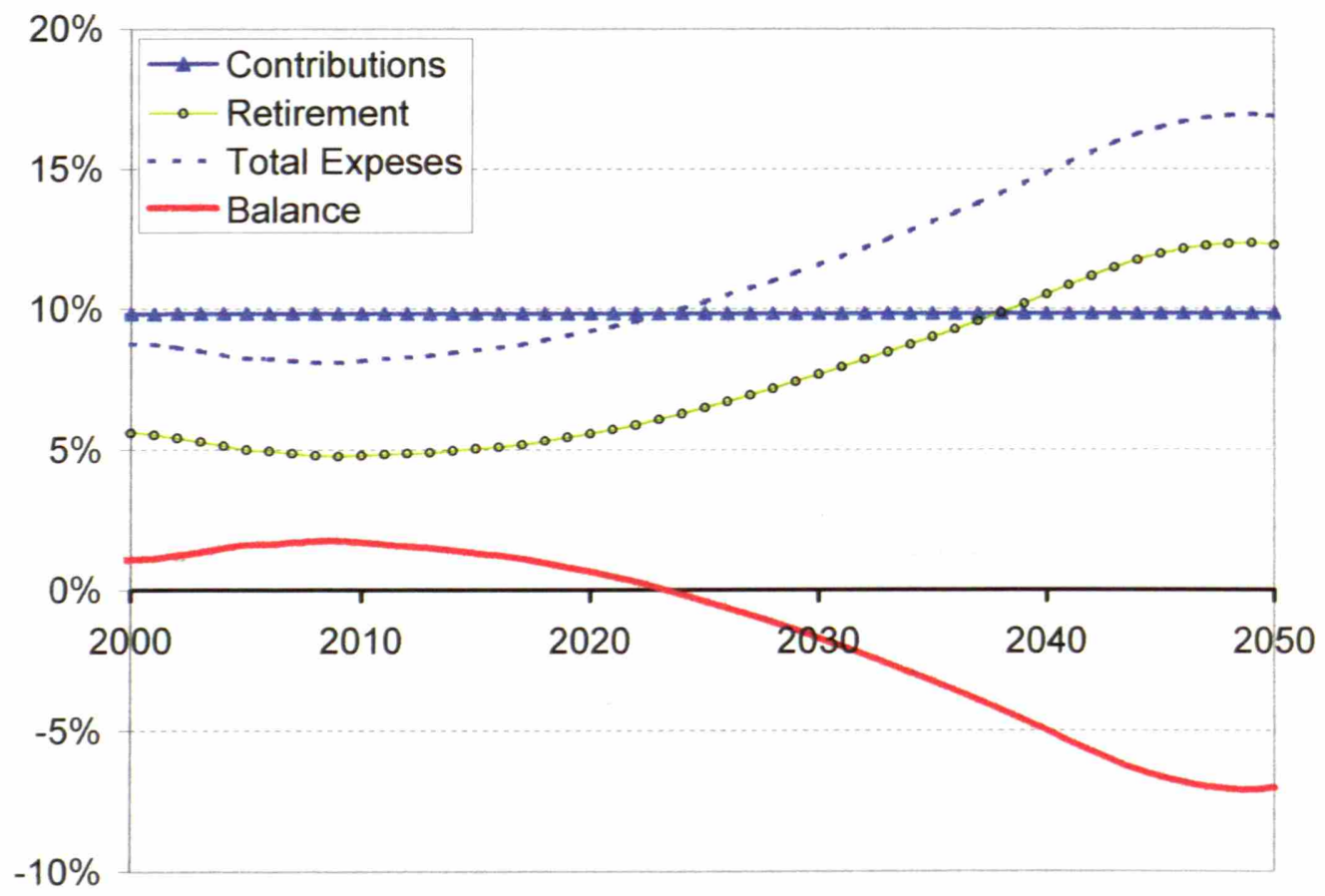

Figure 31. Financial Projections for the Baseline Demographic Scenario (\% of GDP)

The system is expected to have a surplus up to the decade of 2020 . The surplus peaks at about $1.7 \%$ of GDP around 2009 mainly as a result of a decrease in the weight of the retirement pension program. The increase in the old dependency ratio will drive the program into large deficits, over $7 \%$ of GDP, towards the end of the projected period. 


\subsubsection{Alternative demographic scenarios.}

To assess the potential impact of demographic changes on the finances of the Social Security system, similar calculations were run using the three alternative demographic scenarios outlined in section 2.3. Figure 32 compares the expected balances under those scenarios to the baseline.

All the projections share a similar pattern, with small surpluses initially and significant deficits towards the end of the projection period.

The short run analysis is not affected by changes in fertility as neither retirement liabilities nor the working age population would be affected until the cohort born in this decade reaches working age. However, changes in fertility do affect the deficits anticipated toward the end of the projection period, as the new cohorts reach working age and sustain higher (or lower) level of output (GDP) and contributions to finance the pensions of the large retired population. In particular, the lower fertility scenario results in alarming deficits exceeding $8 \%$ of GDP toward the end of the projection period.

Only the optimistic demographic scenario (in which a large flow of immigrants is accepted and integrated immediately into the labor force starting in 2000) shows a significant impact on the projections starting around 2015. However, this is not a very plausible scenario and could create a number of other social problems. Moreover, the overall trend remains unchanged even in this scenario.

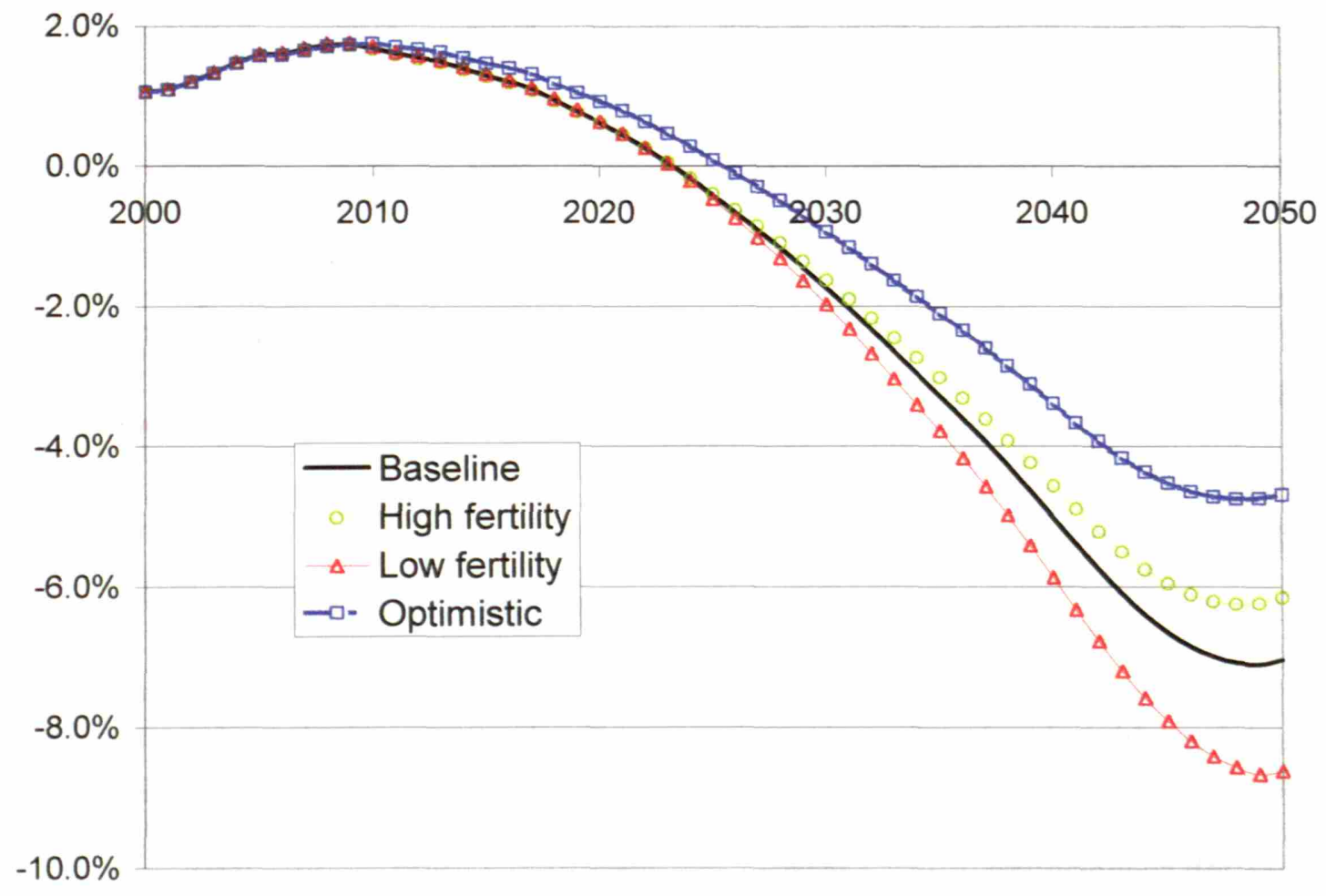

Figure 32. Financial Projections for the four Demographic Scenarios ( $\%$ of GDP) 


\subsubsection{The effect of output growth.}

To evaluate the impact of output growth of the projected Social Security finances, two additional macroeconomic scenarios were run using the baseline demographic scenario.

- Low growth: productivity grows at a lower rate of $0.85 \%$ per year throughout the period. Output growth is $2 \%$ starting in 2002 and remains at that level until labor shortages start to restrict growth.

- High growth: Productivity grows at a much faster rate of $2 \%$ per year throughout the projected period. Output growth is initially 3.2\% starting in 2001 and remains at that level until labor shortages start to restrict growth.

Figure 33 compares the balance expected under these two growth scenarios to the baseline growth scenario.

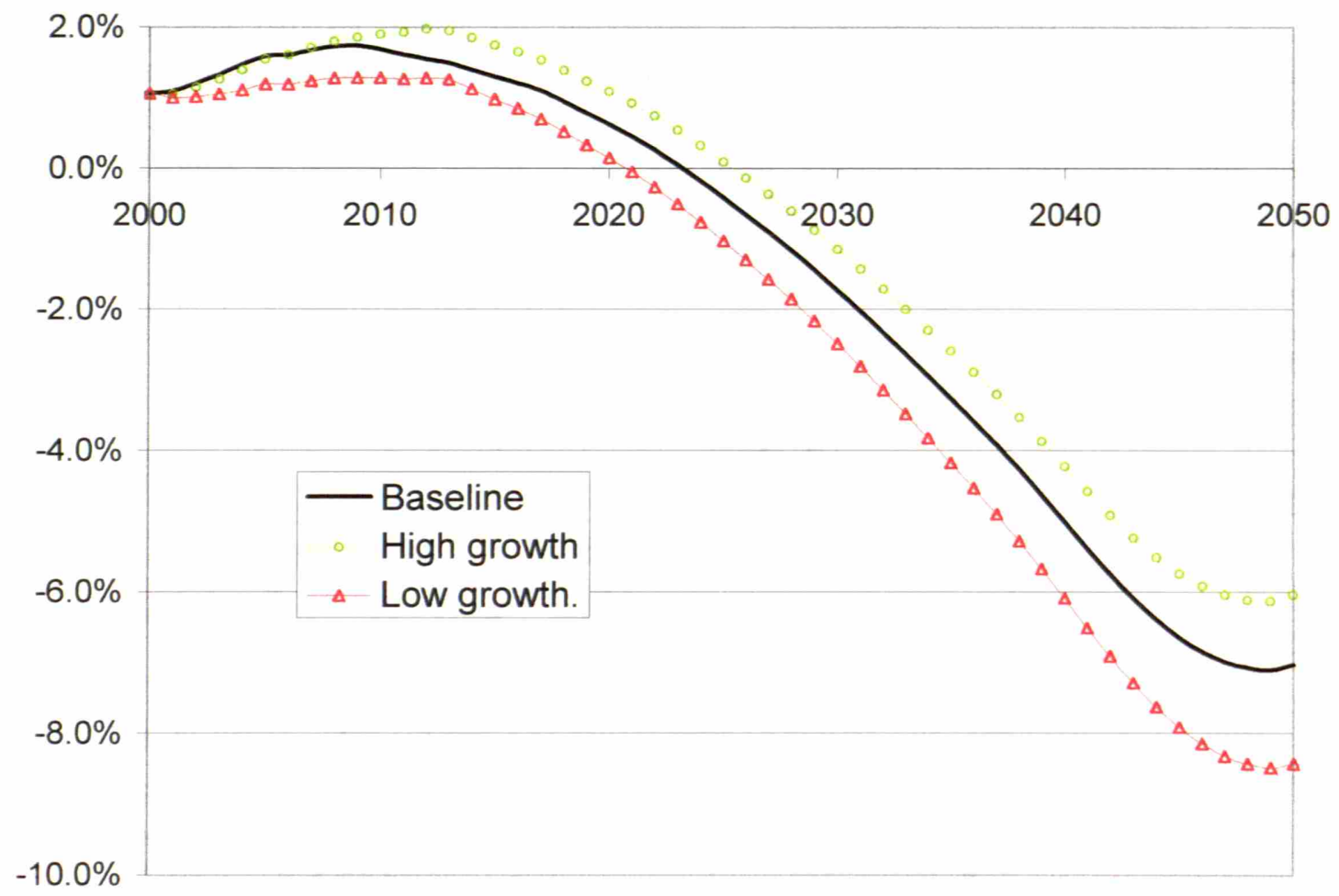

Figure 33. Financial Projections for 3 growth scenarios ( $\%$ of GDP)

Output growth has a large impact on the finances of the current system. However, even with sustained high levels of productivity growth, the system is bound to run into a financial crisis in the decade of the 20s. If productivity growth is lower than expected, the crisis can become quite severe, with deficits exceeding $8 \%$ of GDP forecasted for the lower growth scenario. 


\subsubsection{The effect of the maximum pensions and contributions.}

The non-linear growth of contributions and new pensions with salaries that results from the existence of maximum contributions and pensions has not been considered in the previous calculation. Appendix 3 describes the methodology used to obtain a rough estimation of the impact of this non-linearity. The results are shown in Table 16 and Figure 34 for the baseline population scenario. The main effects observed are:

- The contributions decline steadily over the period from $9.8 \%$ to about $7.7 \%$ by 2050 .

- The impact on the expected balance is modest. The expected surpluses for the next 20 years are reduced between 0.2 and $0.4 \%$ of GDP. The deficits shrink by about $0.4 \%$ of GDP towards the end of the period, possibly a result of the lower replacement rates for pensioners that contribute at or near the maximum limit.

This estimation suggests that the effect of the non-linearity is significant in terms of the weight of the Social Security Programs in the National Economy, but only modest in terms of the expected balance of the program.

Table 16. Financial Projections estimating the impact of non-linearity ( $\%$ of GDP)

\begin{tabular}{|c|c|c|c|c|c|c|c|c|c|c|c|}
\hline & & $\begin{array}{l}\text { Permanent } \\
\text { Disability }\end{array}$ & & & Children & $\begin{array}{c}\text { Temp. } \\
\text { Disability }\end{array}$ & $\begin{array}{l}\text { Mat. } \\
\text { Leave }\end{array}$ & Manag. & $\begin{array}{l}\text { Comp. } \\
\text { minimun }\end{array}$ & $\begin{array}{c}\text { Total } \\
\text { Expense }\end{array}$ & Balance \\
\hline 2000 & $9.8 \%$ & $1.00 \%$ & $5.6 \%$ & $1.5 \%$ & $0.12 \%$ & $0.61 \%$ & $0.12 \%$ & $0.34 \%$ & $0.62 \%$ & $8.8 \%$ & $1.1 \%$ \\
\hline 2005 & $9.7 \%$ & $1.07 \%$ & $5.0 \%$ & $1.5 \%$ & $0.09 \%$ & $0.57 \%$ & $0.14 \%$ & $0.32 \%$ & $0.48 \%$ & $8.2 \%$ & $1.5 \%$ \\
\hline 2010 & $9.6 \%$ & $1.10 \%$ & $4.8 \%$ & $1.5 \%$ & $0.08 \%$ & $0.54 \%$ & $0.14 \%$ & $0.30 \%$ & $0.36 \%$ & $8.1 \%$ & $1.5 \%$ \\
\hline 2015 & $9.4 \%$ & $1.12 \%$ & $5.0 \%$ & $1.5 \%$ & $0.07 \%$ & $0.51 \%$ & $0.12 \%$ & $0.30 \%$ & $0.27 \%$ & $8.4 \%$ & $1.0 \%$ \\
\hline 2020 & $9.2 \%$ & $1.12 \%$ & $5.4 \%$ & $1.6 \%$ & $0.08 \%$ & $0.49 \%$ & $0.10 \%$ & $0.31 \%$ & $0.18 \%$ & $8.9 \%$ & $0.3 \%$ \\
\hline 2025 & $9.0 \%$ & $1.06 \%$ & $6.2 \%$ & $1.6 \%$ & $0.08 \%$ & $0.47 \%$ & $0.09 \%$ & $0.32 \%$ & $0.11 \%$ & $9.8 \%$ & $-0.8 \%$ \\
\hline 2030 & $8.8 \%$ & $0.97 \%$ & $7.2 \%$ & $1.8 \%$ & $0.07 \%$ & $0.45 \%$ & $0.09 \%$ & $0.33 \%$ & $0.07 \%$ & $10.8 \%$ & $-2.1 \%$ \\
\hline 2035 & $8.5 \%$ & $0.90 \%$ & $8.2 \%$ & $1.9 \%$ & $0.06 \%$ & $0.44 \%$ & $0.09 \%$ & $0.35 \%$ & $0.04 \%$ & $12.0 \%$ & $-3.5 \%$ \\
\hline 2040 & $8.3 \%$ & $0.82 \%$ & $9.4 \%$ & $2.1 \%$ & $0.06 \%$ & $0.42 \%$ & $0.09 \%$ & $0.37 \%$ & $0.02 \%$ & $13.3 \%$ & $-5.0 \%$ \\
\hline 2045 & $8.0 \%$ & $0.72 \%$ & $10.4 \%$ & $2.3 \%$ & $0.06 \%$ & $0.40 \%$ & $0.08 \%$ & $0.39 \%$ & $0.01 \%$ & $14.4 \%$ & $-6.4 \%$ \\
\hline 2050 & $7.7 \%$ & $0.66 \%$ & $10.4 \%$ & $2.4 \%$ & $0.06 \%$ & $0.38 \%$ & $0.07 \%$ & $\mathbf{0 . 3 9 \%}$ & $0.00 \%$ & $14.4 \%$ & $-6.6 \%$ \\
\hline
\end{tabular}

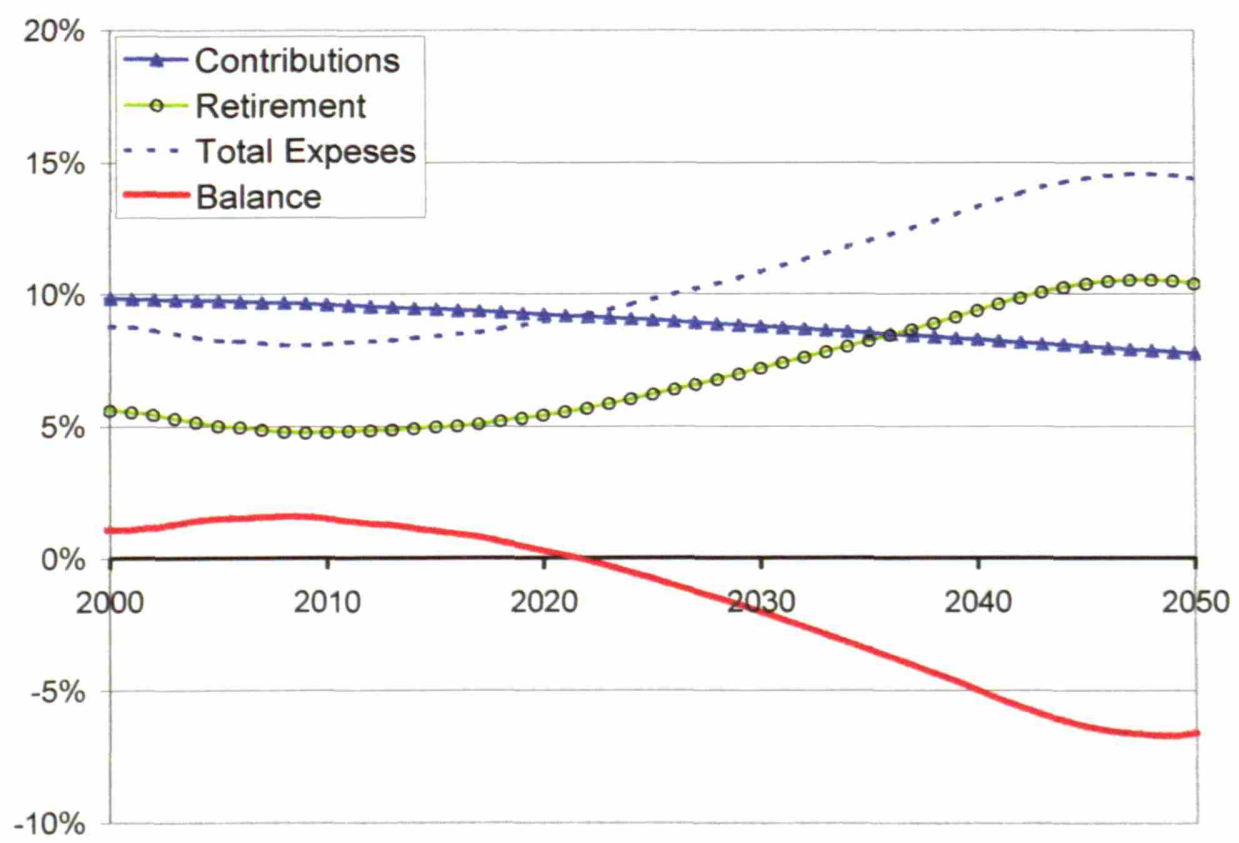

Figure 34. Financial Projections estimating the impact of non-linearity. Baseline Demographic Scenario, (\% of GDP) 


\section{Social Security reform.}

5.1. The need for Social Security reform. Recent proposals for Spain.

The projections outlined in the previous chapter follow a pattern that is somewhat similar to those found in recent studies $(11,12)$. A small difference being the higher expected surplus for the first years of the $\mathrm{XXI}^{\mathrm{st}}$ century, probably resulting from the good economic performance of Spain in 2000 as well as from the non-inclusion in our calculations of the complements to minimum pensions as a contributive expense.

The alarming deterioration expected beyond 2020, driven by demographic factors, has been the subject of extensive debates. For countries in the European Monetary Union, the restriction on fiscal deficits would make financing an imbalance in the contributive system of Social Security of 7\% of GDP a very difficult endeavor. The most likely options would be to reduce the imbalance through a rise in contributions or a cut in benefits.

Many proposals have been put forward to reform Social Security in Spain, for the most part, they can be grouped into two general categories:

a) Maintaining the current PAYGO system and insuring its financial viability by increasing contributions or reducing expenditures. This is the path currently selected by the Spanish authorities. Among the potential ways to increase the contribution revenue, the following are often cited:

- Reduce unemployment rates

- Increase participation rates, particularly for women.

- Increase the payroll tax above its current levels.

The first two are already included in our model, but fail to prevent the problem, although they certainly reduce it. Our forecasts would be even more negative if the unemployment rates and female participation rates were to remain at current levels. Raising contributions to fund pensions will increase the fiscal burden on labor making the country less attractive for both labor and capital investments.

The proposals cited to reduce the expenditures typically entail a reduction in benefits from its current level, some are:

- Increase the number of years of contribution used to calculate pension.

- Increase the penalty for early retirement or shorter contributive history.

- Postpone the retirement age.

- Foster part-time retirement at ages over 65.

Increasing the number of years used to calculate the pension can reduce the expenditures and eliminate some potential contributive distortions. Increasing the retirement age, or making it more flexible appears to be a reasonable approach, particularly taking into consideration that people tend to join the labor force at a later age, retain good health also into a later age and jobs tend to require less physical effort. Some of these measures can be used in conjunction with other reforms, such as the one proposed below, to ensure the viability of the pension system. At the time this thesis was written, the Spanish government had reached an initial agreement with unions and employers to allow workers to continue active at ages over 65, exempt from Social Security contributions, and receiving a pension proportional to their inactive time (if they remain as part time workers). The government was also proposing to increase the years of contribution used 
to calculate pension from 15 to 35 , a measure that was generating strong opposition from the unions. The potential impact of these reforms on the financial outlook of the contributive programs of Social Security is discussed in section 5.3 below.

b) Converting to a mixed PAYGO-funded system. This position has been defended convincingly by economists at FEDEA (see for instance references 10 and 11).

In funded pension systems, current contributions are not used to pay current pensions, but invested in interest-yielding assets that accumulate until the worker retires. At retirement, the contributions and accumulated interest starts to be repaid to the worker in the form of an annuity. These systems are widely acknowledged to offer some advantages:

- Higher returns resulting in a lower burden on labor for the same benefits. This holds if the return on invested assets is higher than the growth in wages (or GDP if wages grow with productivity). This is true for most countries.

- Increases savings rate and can thus result in a deeper capital stock and higher output per capita. The improvement in economic welfare (consumption per capita) with a funded system would occur if the economy has a level of capital below the "Golden Rule". The condition is similar to that outlined in the previous bullet: return on capital higher than rate of GDP growth.

- Incentivates labor force participation at all ages. This also increases output.

- The financial balance of a funded system is less sensitive to variables such as population growth, productivity growth etc... (17).

- Keeps the pension system further out of the political arena avoiding overpromising and the temptation to use eventual surpluses to fund other programs.

- Tends to strengthen the local financial markets.

Among the disadvantages cited, the most relevant are:

- Eliminates redistribution mechanisms currently existent under the PAYGO scheme.

- Uncertainty about the future pension benefit. Funded systems are typically "defined contribution" in which the worker knows the contributions that must be made, but not the pension received. The pension will typically depend on the performance of the capital markets and the choice of investments. PAYGO schemes are typically "defined benefit" in which the worker knows the pension entitlement as a function of his/her contributive history. Funded schemes result in a transfer of the investment risk to the worker.

- High administration costs. Individual pension fund accounts are more expensive to manage. These costs can have a significant impact on the potential returns.

- Pension Funds can distort corporate governance, particularly if they are state controlled.

- Transition costs. Going from PAYGO to fully funded schemes entails financing the unfunded liabilities of the existing PAYGO system. This reduces consumption today and introduces not only financial problems, but issues of intergenerational equity.

The advocates of a mixed system in Spain indicated that the PAYGO portion of the pension scheme can be taken as an investment in human capital, to complement the investment in physical capital of the funded portion. They also propose determining the relative weight of each program as a function of the returns to human and physical capital, thus achieving a socially beneficial portfolio diversification $(11,15)$. 


\subsection{The Modigliani proposal for Social Security reform in the US.}

Very recently, Franco Modigliani et al have proposed an alternative reform path that tries to combine the advantages of the PAYGO system with those of the fully funded system (17). In this section we will briefly present the fundamentals of the plan for the US, drawing heavily from reference 17 , and in the next section we will evaluate the applicability of this approach to the case of Spain.

The proposed reform relies on the gradual transition from the current PAYGO scheme to a mixed scheme including a large fund invested in a common portfolio (not individual accounts). The transition would be made easier in the USA by:

- The (transitory) current and prospective Social Security surplus and the Federal budget surplus, already pledged to Social Security. These constitute the initial contributions to build the Trust Fund (TF).

- An imaginative investment policy for the TF which aims for the highest return consistent with long run stability and with proper concern for minimizing the role of government in financial markets.

The investment policy proposed is to invest all the fund's resources in a single, highly diversified portfolio consisting of a share of the total US market portfolio. This reduces management cost and leaves no discretion to politicians or bureaucrats. In order to ensure that the real return is fixed, they propose a swap contract, between Social Security and the Treasury. Under this contract, the pension system would exchange the (uncertain) return derived from its market portfolio for a payment by the Treasury of a fixed real return, on the order of $5 \%$, safely below the expected (before tax) real market return.

This approach transfers the investment risk to the US government in exchange for the spread between the guaranteed real return and the slightly higher (before taxes) expected return. The authors contend that the government is in a position to absorb this risk because of its size and indefinite life as well as its ability to spread the risk across a given cohort and over a large number of cohorts. More important, it should be prepared to undertake the role of insurer of last resort in consideration of the externality that would come from given their citizens the peace of mind that comes with guaranteed pensions.

Note that this solution can combine several advantages of PAYGO and funded systems:

- Higher returns resulting in a lower burden on labor for the same benefits. This in turn is expected to reduce some of the labor market distortions induced by high payroll taxes.

- Increase the savings rate and can thus result in higher output per capita and economic welfare (consumption per capita). Note that the US economy has a level of capital below the "Golden Rule".

- The financial health of the pension system will become less sensitive to demographic and productivity changes.

- Maintain the redistribution mechanisms currently existent under the PAYGO scheme.

- Maintain the "defined benefit" character, thus limiting individual risk.

- Low administration costs compared to systems based on individual accounts. 
At least during the long transition period, pension benefits will be calculated using rules similar to the current PAYGO system, therefore, some of the distortions introduced by these rules would still be operating unless the rules themselves are changed.

Regarding the issue of governance, the authors propose the creation of a prestigious independent board to oversee the limited management required by the fund. Managing the fund passively reduces the risk of political manipulation. However, as the TF grows to be a larger share of the capital market, the management and valuation functions will be left to the owners of a declining fraction of capital.

\subsection{Financial impact of potential reforms. The case of Spain.}

\subsubsection{Modification of the PAYGO rules}

\subsubsection{Implementing a more flexible retirement age policy.}

There appears to be an ample consensus among workers, employers and the government about the desirability of implementing a more flexible retirement age policy. The details of the policy are not known at the time this thesis was written; however, some guidelines have been published in the press. To estimate the impact of this policy on the finances of the Social Security system, we made the following assumptions:

- The contributions remain unchanged from the baseline scenario, as those who choose to continue in the labor force after 65 will be exempt from contributing.

- Assumed that the participation rate at ages 65-69 is half of that observed at $64(50 \%$ of the people active at 64 choose to retire)

- Assumed that those who chose to continue in the labor force do so on a part time basis and devote $50 \%$ of their time to work, (50\% occupation rate).

- The pension paid to the active workers of age 65-69 will be proportional to what they would receive had they retired at 65 multiplied by (1- occupation rate). The pension received at ages 70 and over is not affected.

The result is an increase in the total available labor force, which has a positive impact of GDP, and a reduction the pensions paid to those workers ages 65-69 that remain active. Table 17 and Figure 37 summarize the results.

Table 17. Financial Projections. Estimations with flexile retirement age. (\% of GDP)

\begin{tabular}{|c|c|c|c|c|c|c|c|c|c|c|c|}
\hline Year & Contrib & $\begin{array}{l}\text { Permanent } \\
\text { Disability }\end{array}$ & tirement & Spouse & Children & $\begin{array}{c}\text { Temp. } \\
\text { Disability }\end{array}$ & $\begin{array}{l}\text { Mat. } \\
\text { Leave }\end{array}$ & Manag. & $\begin{array}{l}\text { Comp. } \\
\text { minimum }\end{array}$ & $\begin{array}{c}\text { Total } \\
\text { Expense }\end{array}$ & Balance \\
\hline 2000 & $9.8 \%$ & $1.00 \%$ & $5.6 \%$ & $1.5 \%$ & $0.12 \%$ & $0.61 \%$ & $0.12 \%$ & $0.34 \%$ & $0.62 \%$ & $8.8 \%$ & $1.1 \%$ \\
\hline 2005 & $9.8 \%$ & $1.07 \%$ & $4.9 \%$ & $1.5 \%$ & & $0.58 \%$ & $0.14 \%$ & $0.32 \%$ & $0.48 \%$ & $8.1 \%$ & $1.7 \%$ \\
\hline 2010 & $9.8 \%$ & $1.11 \%$ & $4.6 \%$ & $1.5 \%$ & $0.08 \%$ & $0.55 \%$ & $0.14 \%$ & $0.30 \%$ & $0.36 \%$ & $7.9 \%$ & $1.9 \%$ \\
\hline 2015 & $9.7 \%$ & $1.13 \%$ & $4.7 \%$ & $1.5 \%$ & $0.07 \%$ & $0.53 \%$ & $0.13 \%$ & $0.30 \%$ & $0.27 \%$ & $8.2 \%$ & $1.6 \%$ \\
\hline 2020 & $9.7 \%$ & & $5.1 \%$ & $1.6 \%$ & $0.08 \%$ & $0.52 \%$ & $0.11 \%$ & $0.31 \%$ & $0.18 \%$ & $8.7 \%$ & $1.0 \%$ \\
\hline 2025 & $9.7 \%$ & & & $1.6 \%$ & & & $0.10 \%$ & $0.32 \%$ & $0.11 \%$ & $9.6 \%$ & $0.1 \%$ \\
\hline 2030 & $9.6 \%$ & & & $1.8 \%$ & & & $0.10 \%$ & $4 \%$ & $7 \%$ & $10.7 \%$ & $-1.1 \%$ \\
\hline 035 & $9.6 \%$ & & & $2.0 \%$ & $0.07 \%$ & 0.4 & $0.10 \%$ & $7 \%$ & & $12.1 \%$ & $-2.5 \%$ \\
\hline 040 & $9.6 \%$ & $1 \%$ & $9.5 \%$ & $2.2 \%$ & $0.06 \%$ & $0.48 \%$ & $0.10 \%$ & $0 \%$ & & $13.7 \%$ & $-4.1 \%$ \\
\hline 2045 & $9.6 \%$ & $0.82 \%$ & $10.9 \%$ & $2.4 \%$ & $0.07 \%$ & $0.48 \%$ & $0.10 \%$ & $0.43 \%$ & $1 \%$ & $15.2 \%$ & $-5.7 \%$ \\
\hline 2050 & $9.6 \%$ & $0.78 \%$ & $11.4 \%$ & $2.6 \%$ & $0.07 \%$ & $0.47 \%$ & $0.09 \%$ & $0.44 \%$ & $0.00 \%$ & $15.9 \%$ & $-6.3 \%$ \\
\hline
\end{tabular}

This estimation suggests such a policy would have a positive effect on the finances of the Social Security system. This effect grows during the projected period, from $0.2 \%$ of GDP 
in 2010 to almost $1 \%$ of GDP around 2045, but the overall trend towards large deficits near the end of the projection period is not reversed. This policy, while clearly a step in the right direction, will by itself be insufficient to ensure the financial viability of the Social Security system.

Note that the projection period for this and other simulations in this section was extended beyond 2050 using the same demographic and macroeconomic criteria used before 2050 . Of course the confidence in the projections beyond 2050 is even lower than up to that year, however, the extended projections will be useful for the discussions.

\subsubsection{Extending the contribution years used to calculate the pension.}

Another proposal currently under debate is to extend the number of years used to calculate the pension from the current 15 to 35 . The supporters of this reform typically argue that indexing the pension to the complete contributive history of the pensioner is a more fair and logical thing to do, and that it would eliminate the incentive to report lower salaries in earlier years and higher salaries closer to the retirement age. Opposition to the measure is likely to stem from the fact that this policy represents a significant decrease in average benefits as will be shown below.

To estimate the financial impact of this reform on the Social Security System, we proceeded as follows:

- Estimated the changes of the salary levels with age from data published by INE (www.ine.es) The changes are illustrated in Figure 35.

- The shape of this distribution was assumed constant. That is, salaries increase in real terms as productivity across the age spectrum.

- The number of contributive years used to calculate the base pension was increased by one year each year staring in 2006 until 2025, when it reached 35 years. It was kept constant beyond that point.

- Let us define the replacement rate as the ratio between the last salary and the first pension. This rate was estimated as follows:

$$
R_{r}^{i}=\frac{S^{i}+S^{i-1}+\sum_{j=i-2}^{n} S^{j} \frac{C P I^{i-2}}{C P I^{j}}}{n S^{i}}
$$

Where $R_{r}^{i}$ is the replacement rate for those retired in year i, $S^{i}$ is the salary in year $\mathrm{i}, \mathrm{n}$ is the number of years used to calculate the pension. The salaries, beginning with year three and earlier are adjusted for inflation (CPI). The results for the replacement rates when maintaining the current policy of 15 years and the gradual increase to 35 starting in 2006 are reported in Figure 36. Historical data for inflation and wage increase are used up to 2000 and the projections from our baseline scenario beyond that time.

- The reduction in the retirement pensions triggers a decline in the surviving spouse pensions that are derived from pensioners. We have adjusted our model to prevent this. In effect this is equivalent to increasing the replacement rate for surviving spouse pensions from $45 \%$ today to about $60 \%$ by 2035 to maintain the same coverage for widows/ers as they would have had with a 15 year calculation base for the pension. 


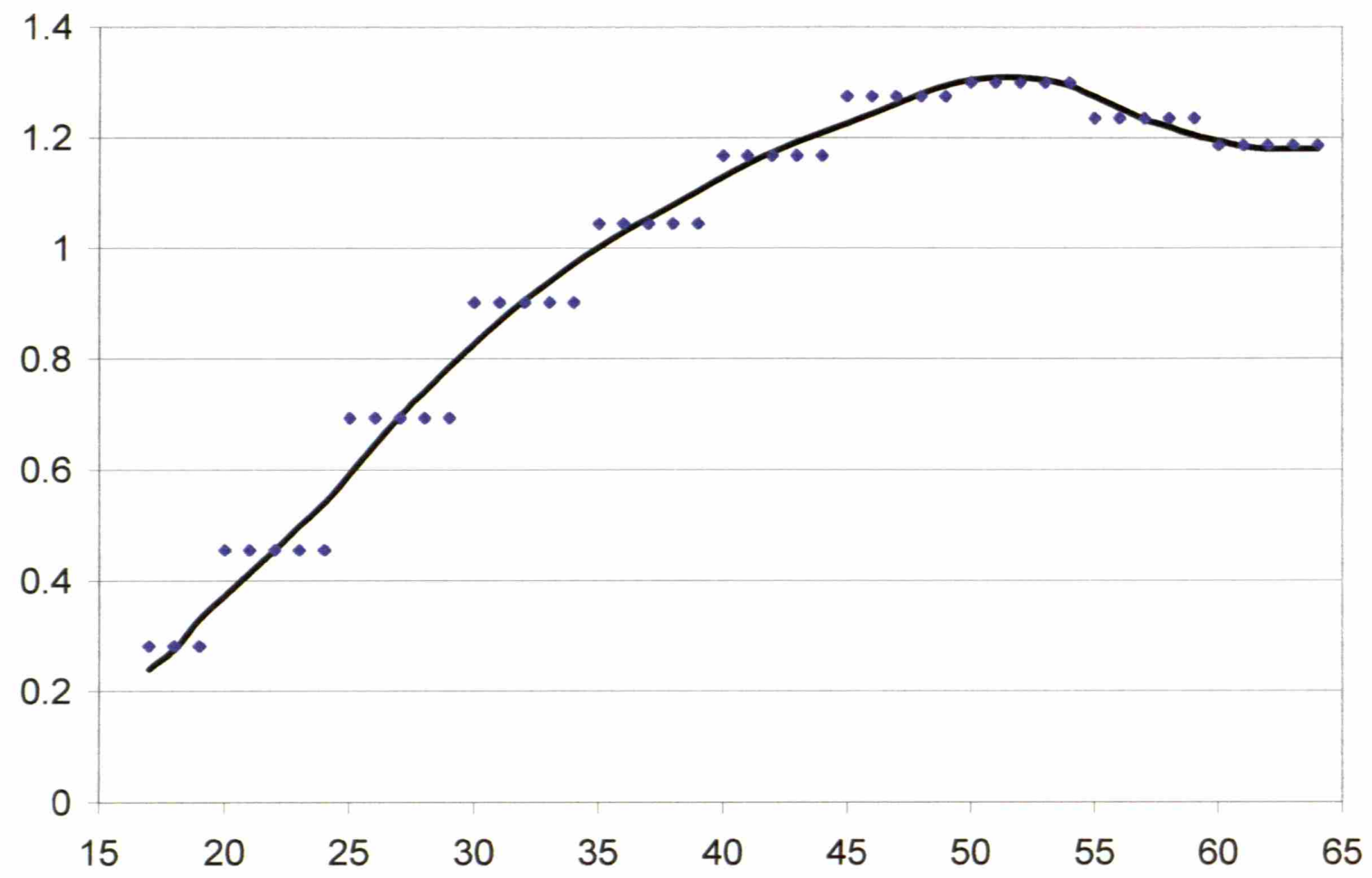

Figure 35. Age profile of salaries in Spain. (from data in www.ine.es

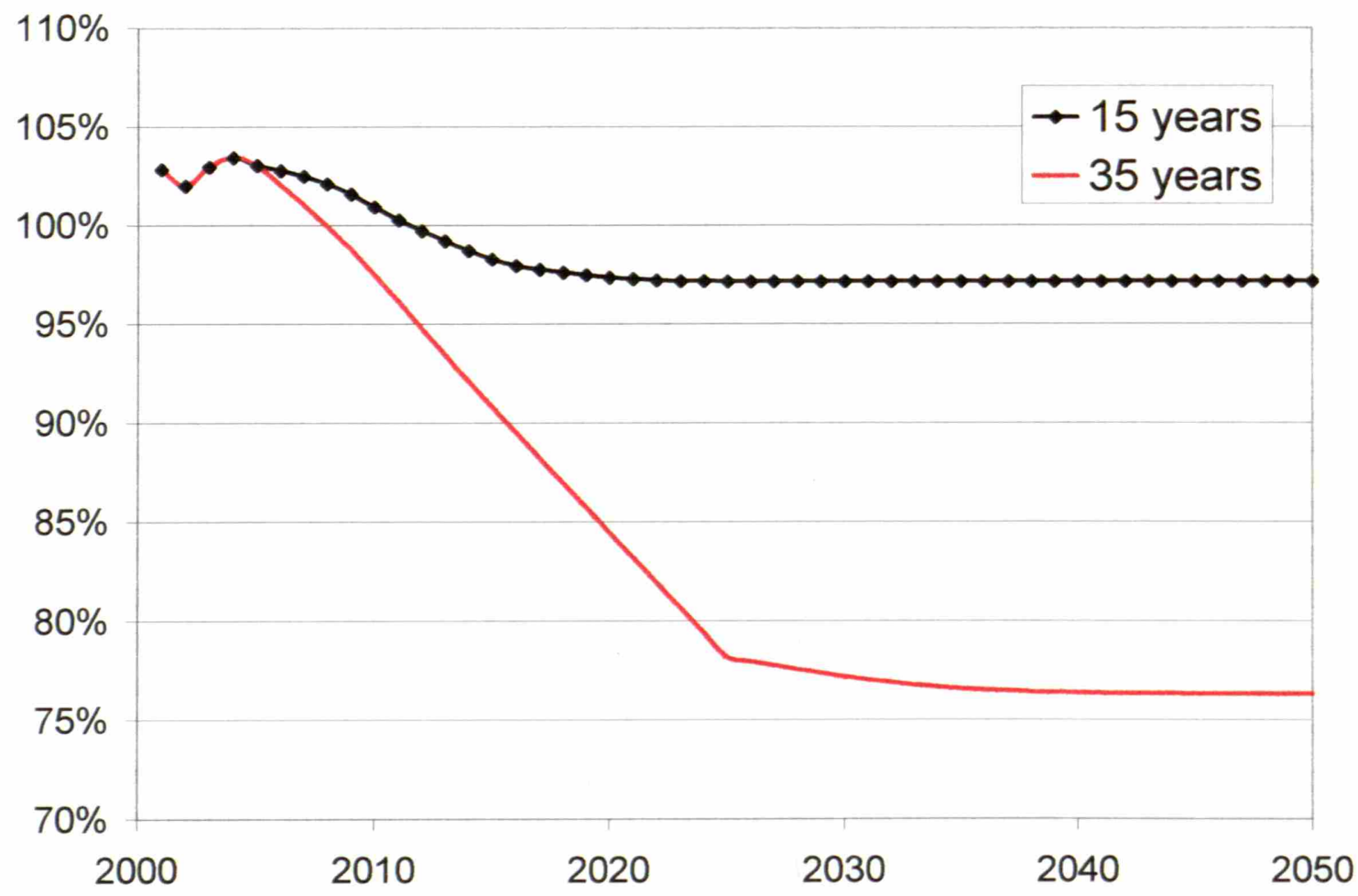

Figure 36. Variation of the replacement rate with time using 15 years to calculate the pension benefit and transitioning to 35 years starting in 2006. 
Figure 37 shows the impact of this reform on the finances of social security over the projection period. The projection period for this and other simulations in this section was extended beyond 2050 using the same demographic and macroeconomic criteria used before 2050. Of course the confidence in the projections beyond 2050 is even lower than up to that year, however, the extended projections will be useful for some of the simulations.

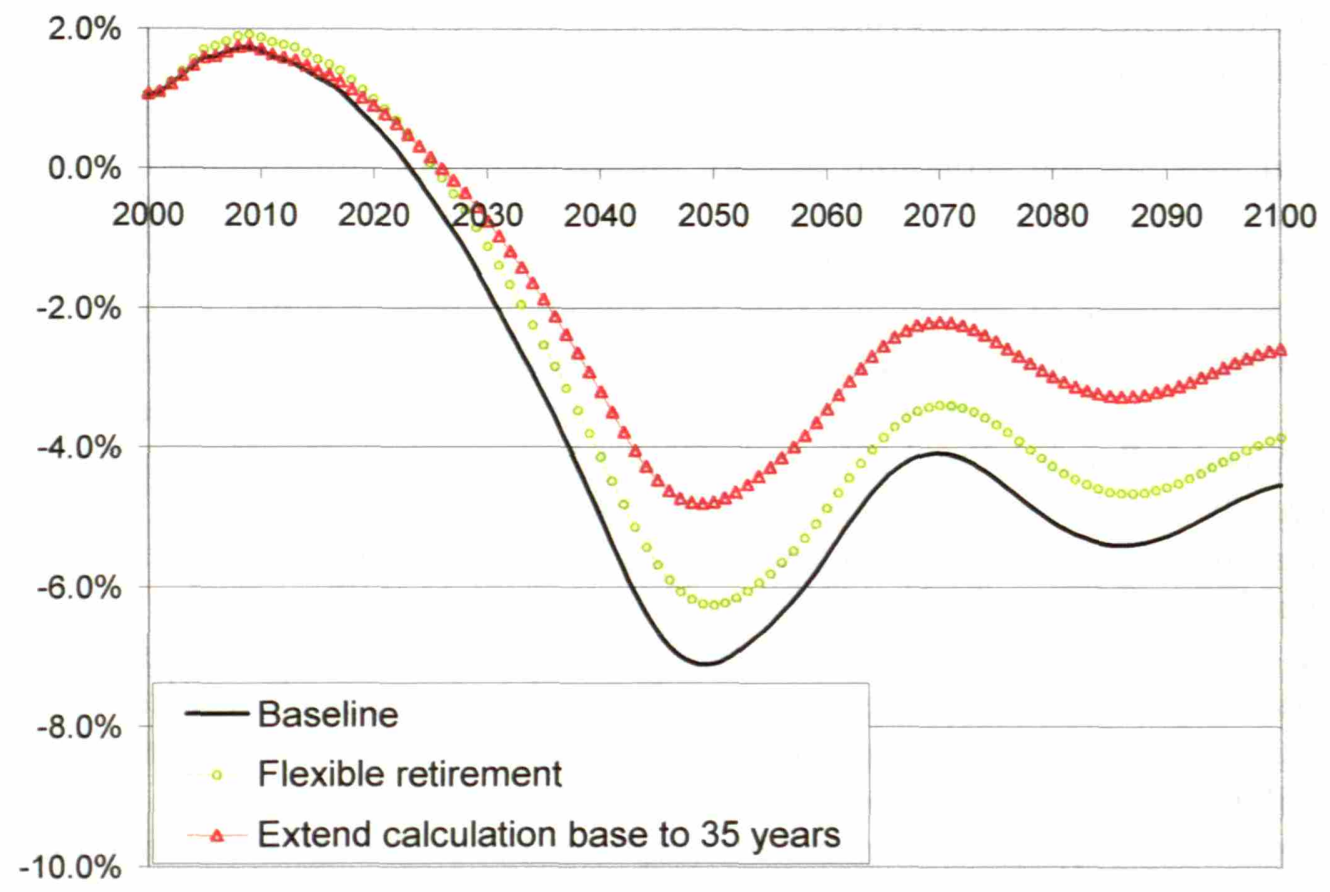

Figure 37. Financial Projections with the two PAYGO reforms discussed in this section (\% of GDP).

The impact of an increase in the contribution years used for the calculation of the retirement pension is substantial, particularly after 2025 when the transition is complete. Although this reform alone will be insufficient to ensure the financial viability of the pension system, it would significantly reduce the projected deficits by roughly $2 \%$ of GDP beyond 2045 .

However, this reform entails a substantial cut in benefits of about $20 \%$ compared to the current calculation method. Therefore, it may be difficult to implement from a political point of view, particularly while the system is running current surpluses as it is at present. On the positive side, the increase in the number of years used to calculate the PRB improves the equity of the system. Workers that become unemployed towards the end of their careers will see a smaller effect on their pensions, as their active years have a higher weight in the PRB. Also, highly educated (and paid) workers tend to see a steeper increase in their salaries with experience than less skilled workers. Therefore, the extension of the calculation period will affect the higher paid workers the most. An alternative could be to extend the number of years used to calculate the PRB, and thus make the system more equitable, and increase the replacement rate to compensate partially the decrease that results from such an extension. We will reexamine this issue in section 5.3.3.4. 


\subsubsection{Applicability of the Modigliani reform.}

The confluence of several factors makes a reform, such as that proposed by Modigliani et al. attractive for Spain:

- The need for a significant reform in the Social Security system to prevent it from sliding into a deep financial crisis in the middle decades of this century. Although this assertion is in itself not devoid of controversy (see for instance reference 19), our own projections strongly support it.

- The fact that the Spanish Economy has a capital level below the "Golden Rule" and could thus see the economic welfare improved by the implementation of a funded pension system. The Gross National savings rate is of the order of $22 \%$ in Spain and the Marginal Product of Capital is higher than the average observed rate of growth.

- The high degree of satisfaction with the current "defined benefit" system. This makes "privatization" of the pension system a very difficult political endeavor.

- The (transitory) current and prospective SS surplus can be used as the "embryo" of the Spanish Pension Fund (PF) to facilitate the transition. The Government budget is currently running small deficits, aiming for fiscal balance in 2001. Therefore, little contribution from the General taxation can be expected to the fund (unlike in the US). If needed, other sources could be tapped as discussed below.

- The Spanish capital markets are relatively underdeveloped. Figure 38 shows the market capitalization of listed Companies in Spain and other European countries, the US and Chile, a less developed country with a funded pension system. Also included are the sources of corporate financing. There appears to be ample opportunity for growth in the equity markets and for corporate bonds to desintermediate the banks as sources of corporate financing. The pension fund can foster the development of the Spanish financial markets.

One of the key issues is whether the expected Social Security surpluses, invested following the guidelines proposed by Modigliani et al, will be sufficient to finance the deficits projected for the middle years of this century. To explore this, several simulations were run using the baseline scenario described in the previous chapter. In these simulations, the initial Social Security surplus was accumulated in an interest-bearing fund. The interest generated by the fund constitutes a second source of income for Social Security. When the system runs a deficit, the assets accumulated in the fund are used to balance the system until the fund is drained. It is assumed that payroll taxes remain at a constant level throughout the period, unless otherwise stated. 
Market cap. (\% GDP)

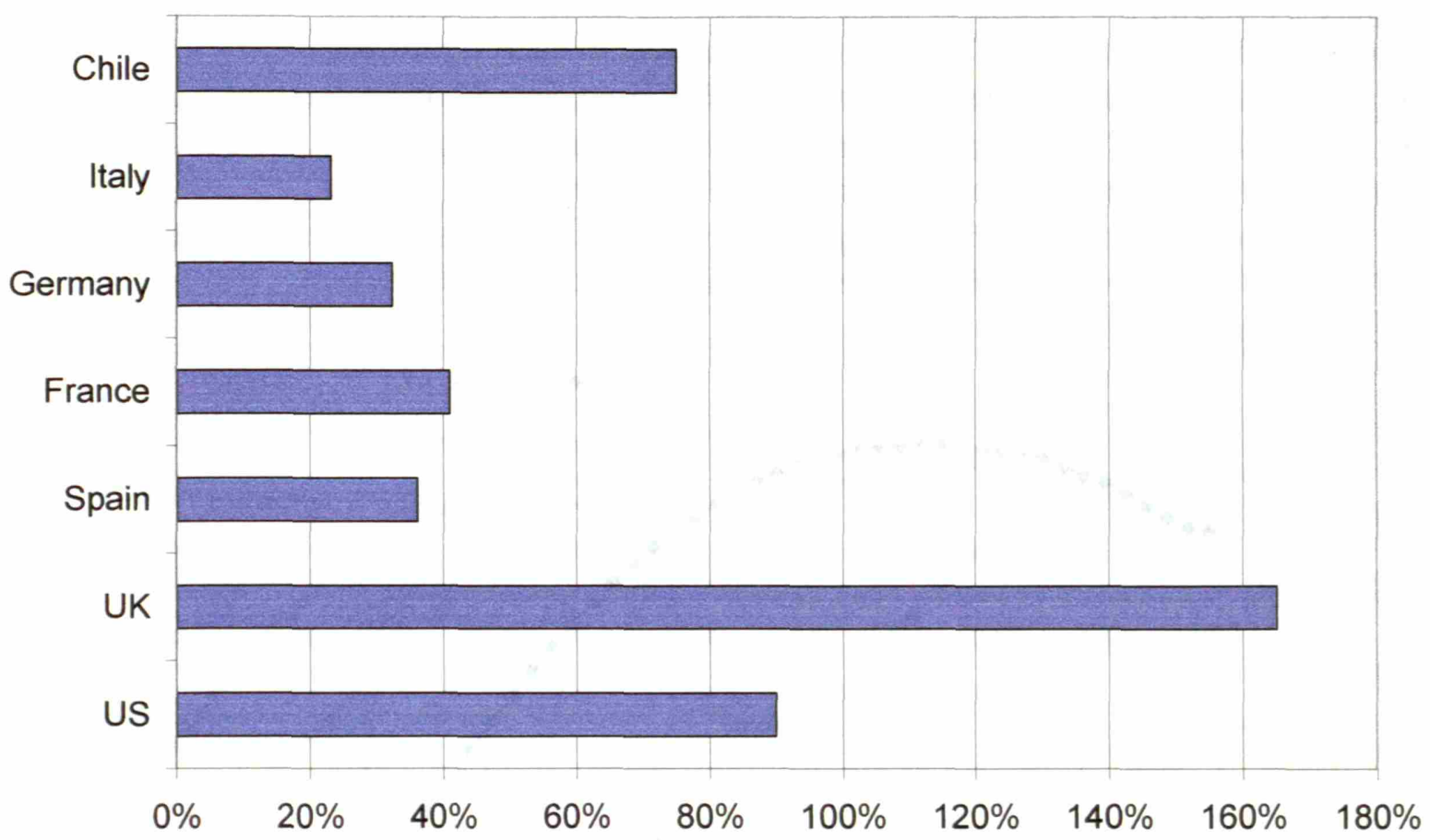

Figure 38.a. Market capitalization of publicly traded companies in selected countries (\% of GDP). (Source, Merrill Lynch, 1999)

\section{Sources of Corporate Financing}

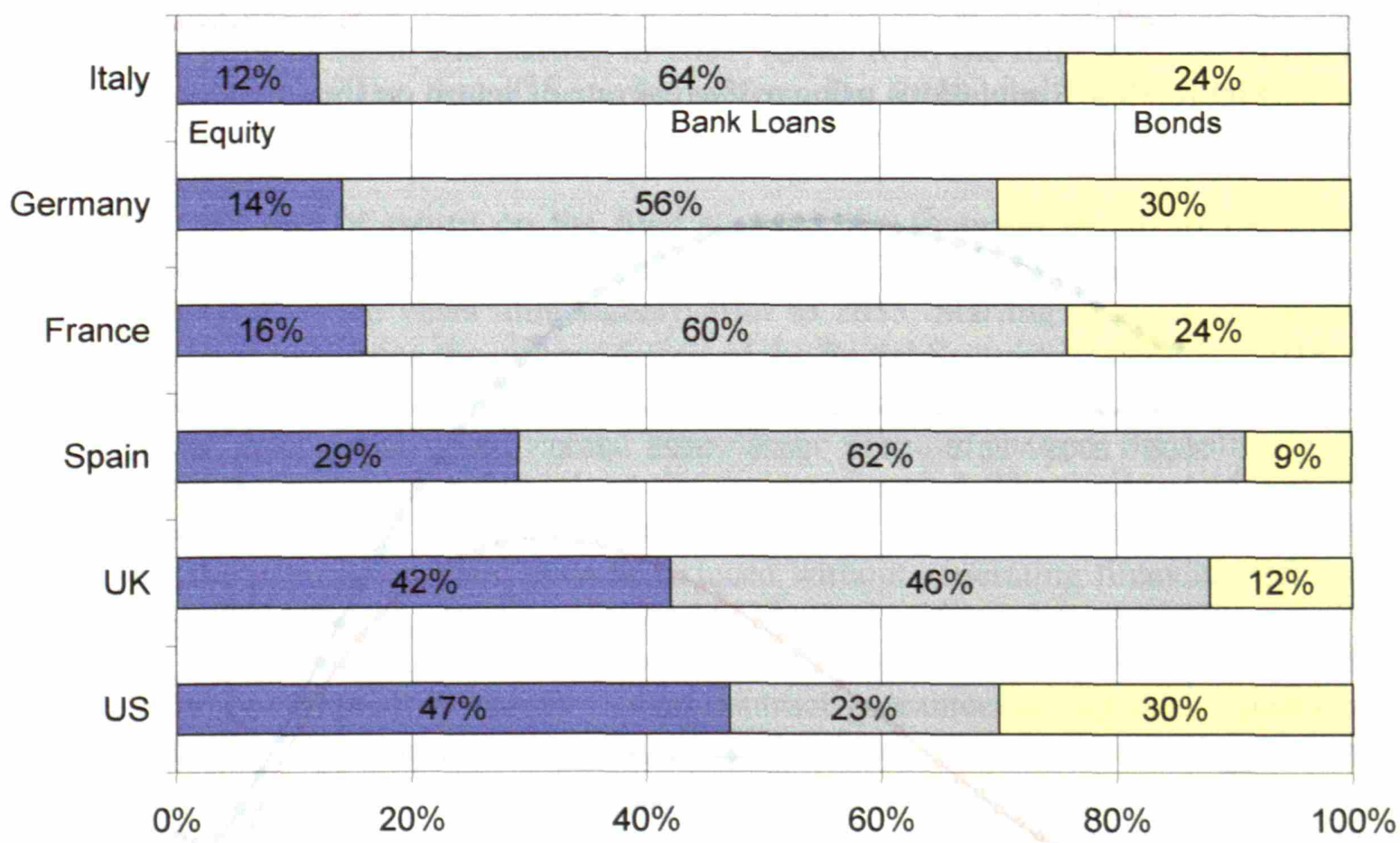

Figure 38.b. Sources of corporate financing. (Source, Merrill Lynch, 1999) 
Figure 39 shows the results of these simulations using a real rate of return on the fund's assets of $3 \%, 5 \%$ and $7 \%$. The three curves shown in each figure are:

- The total accumulated assets on the pension fund, as a \% of GDP (right scale).

- The balance of the Social Security system, when the interest on the fund's assets is added to the contributions as a second source of income.

- The need for external financing, which will be 0 for as long as the system runs a surplus or there are sufficient assets in the fund to cover the deficit.

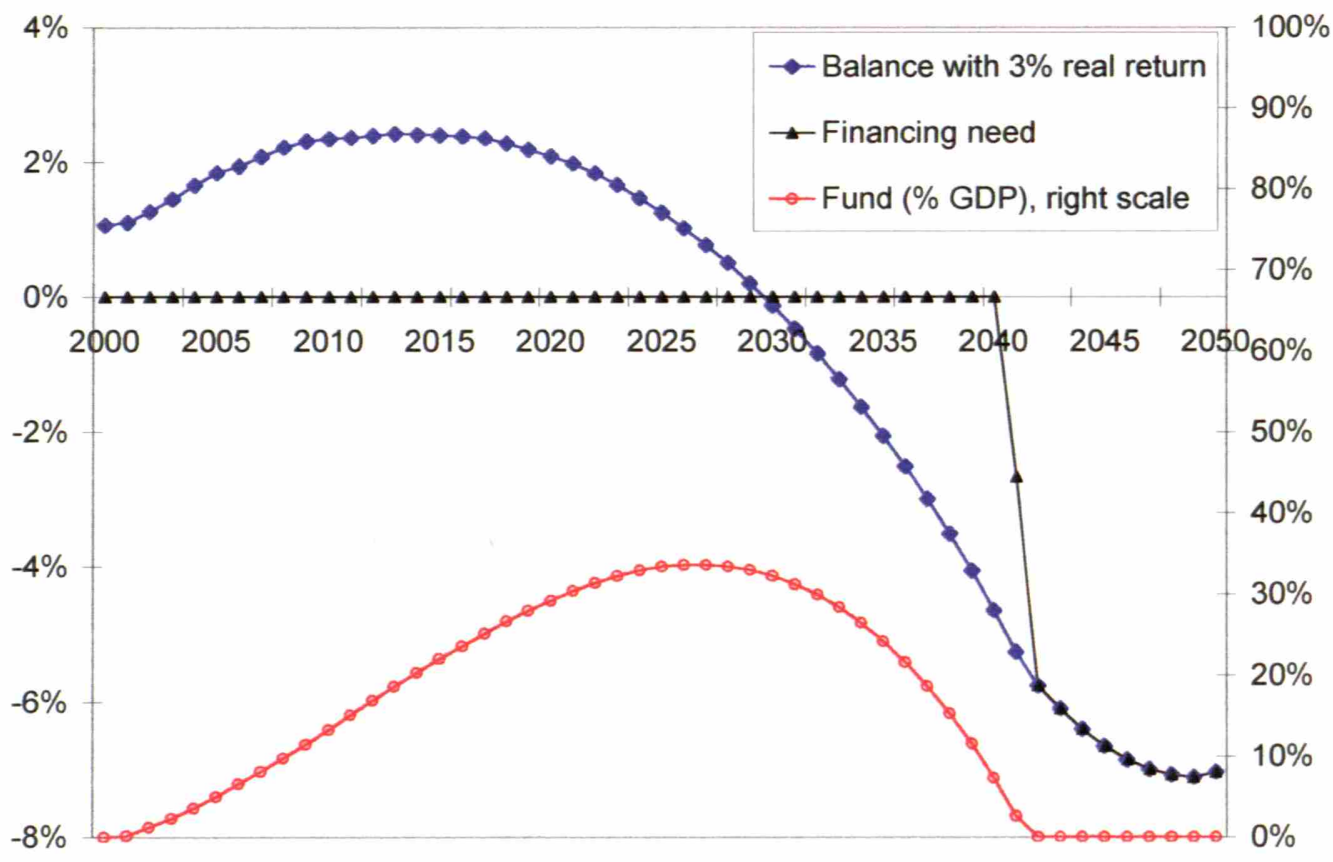

Figure 39.a. Simulations using a 3\% real rate of return on the funds' assets

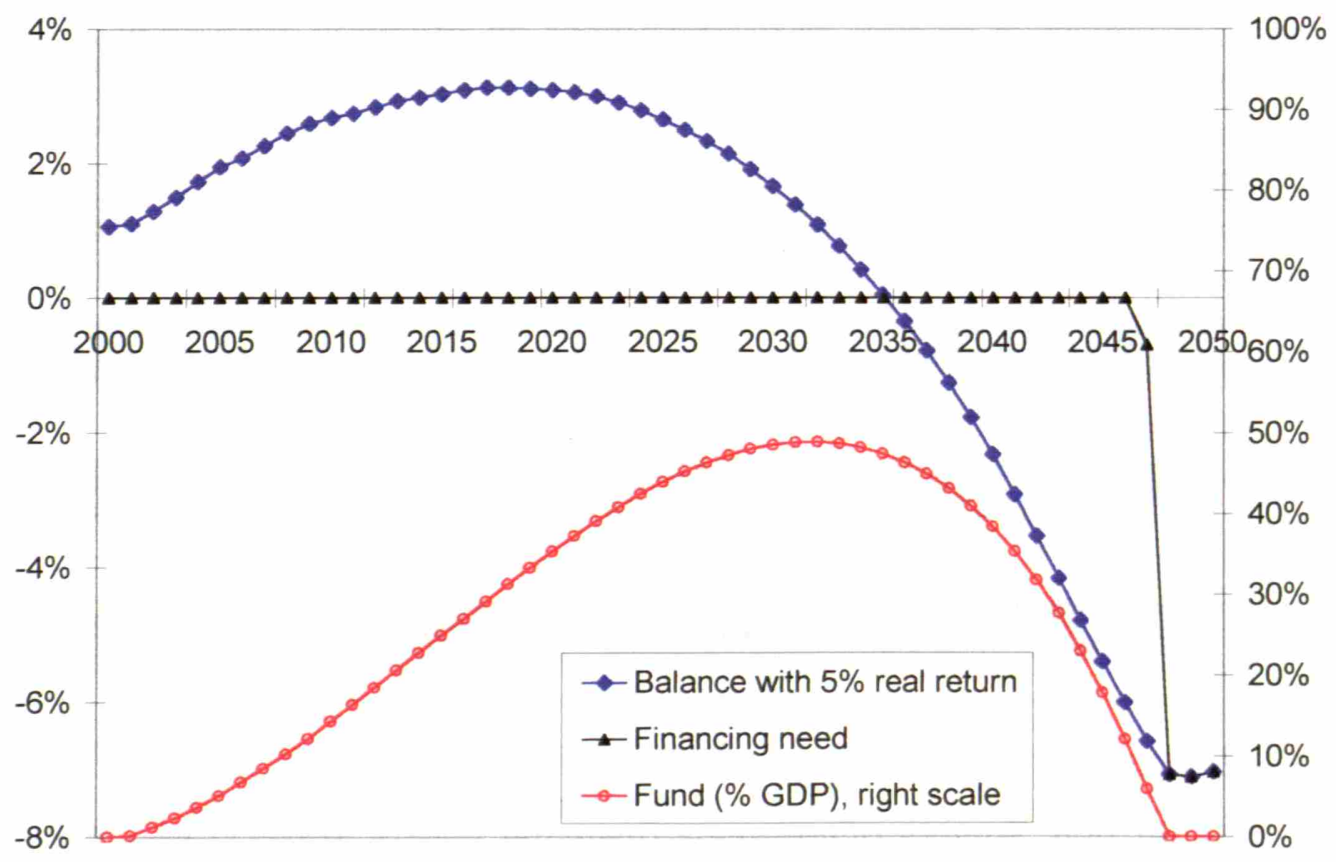

Figure 39.b. Simulations using a 5\% real rate of return on the funds' assets 


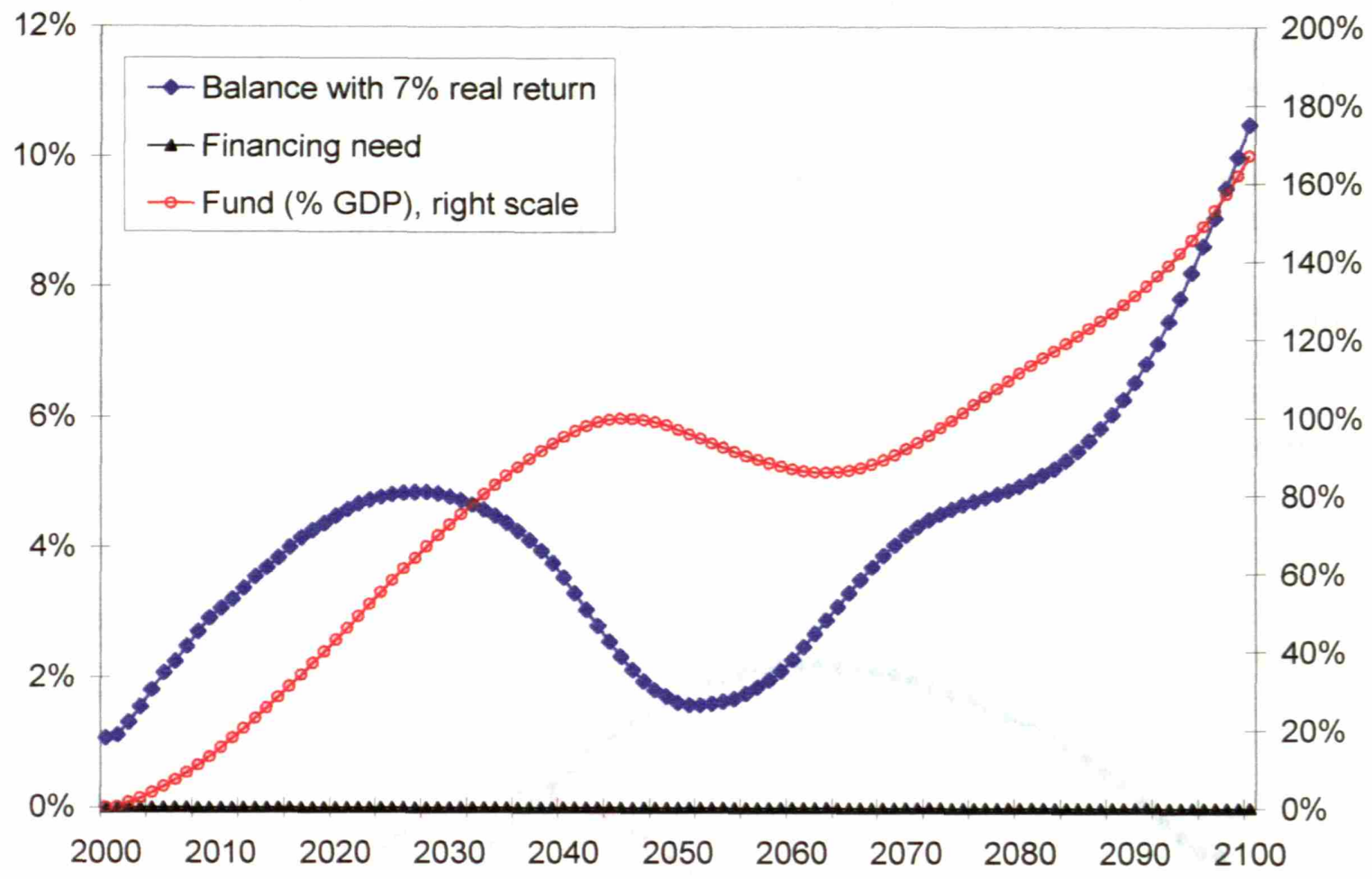

Figure 39.c. Simulations using a 7\% real rate of return on the funds' assets.

With a 3\% real rate of return on the fund's assets, the Social Security system remains in the black until 2030. The fund reaches a maximum of about $1 / 3$ of GDP in the years immediately prior to 2030 , and starting in 2031 , assets from the fund are used to finance the current deficit of the Social Security system. By 2040, the fund is drained and alternative financing sources are needed to cover the large deficits expected in the following decades.

With a $5 \%$ real rate of return on the fund's assets, the financial health of the system improves. Surpluses would continue out to about 2035. The fund reaches a maximum of about $1 / 2$ of GDP in the years immediately prior to 2035. Starting in 2036, assets from the fund are used to finance the current deficit of the Social Security system. By 2048, the fund is drained.

With a 7\% real rate of return on the fund's assets, the situation changes dramatically. The system would show surpluses throughout the projected period. The fund would make the system sustainable and no alternative financing sources are needed. The large surpluses suggest that the payroll tax could even be reduced without generating financial deficits in the Social Security system, but this cuts would only be significant beyond 2070 .

Although a real rate of return on capital of $7 \%$ is not wholly unreasonable, it leaves little spread for the government to accept a swap contract guaranteeing this rate. Appendix 4 includes some historical returns on equities and fixed income securities in Spain. A real rate of return of $5 \%$, similar to that proposed to Modigliani et al, is not deemed to be unreasonable. With this rate, the financial health of the system improves but the longterm viability of the system is not guaranteed. Additional reforms are required in conjunction with the creation of the Pension Fund. Three options are explored in the next 
paragraphs: flexible retirement over age 64 , extending the contribution years used to calculate the pension from 15 to 35 and contributing the expected surplus from the INEM (Employment Institute, financed through payroll taxes) to the pension fund.

\subsubsection{Combining a "Modigliani" type fund with additional reforms.}

\subsubsection{Introducing a flexible retirement age.}

One of the possible alternatives is to combine the creation of the fund with the implementation of a flexible retirement age. The impact of the flexible retirement age on the finances of the system (without the creation of the fund) was described in section 5.3.1. Figure 40 shows the results of a simulation in which those projections are combined with the creation of a fund yielding a real return of $5 \%$.

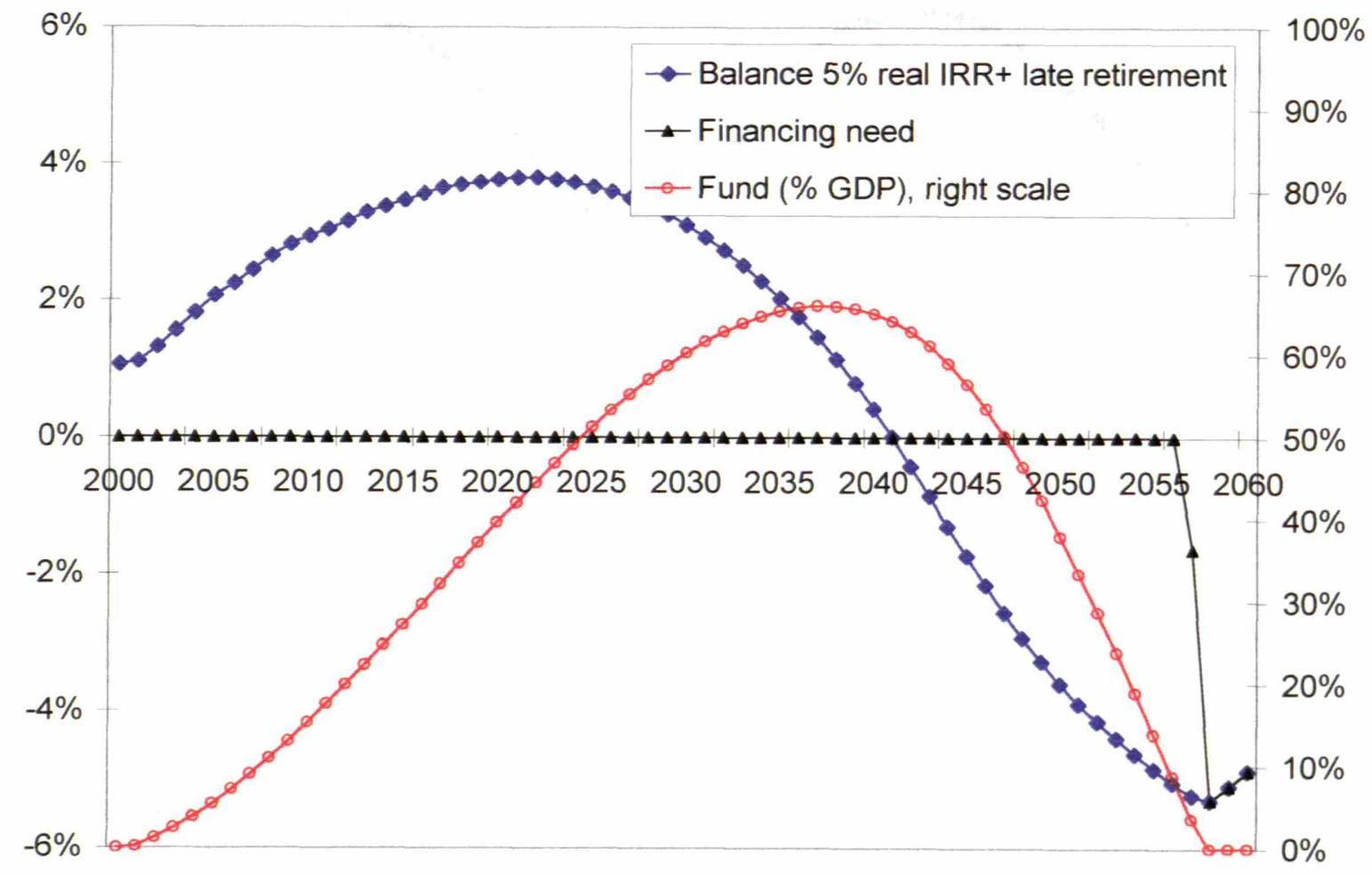

Figure 40. Simulation combining the implementation of a flexible retirement age with the creation of a fund yielding a real return of $5 \%$.

The combination of these two reforms improves the financial outlook of the system. Surpluses would continue out to 2042. The fund accumulates assets that reach a maximum of about $65 \%$ of GDP around 2040. Starting in 2042, assets from the fund are used to finance the current deficit of the Social Security system, which reaches over $4 \%$ of GDP around 2050. The fund is drained by the year 2055. Therefore, although a step in the right direction, this does not appear to be a sustainable long-term solution. 


\subsubsection{Contributing the surpluses from INEM to the pension fund.}

It should be remembered (Section 1.3.1) that in the general scheme wages are taxed, not only to finance the contributive programs of Social Security, but also to finance programs to fight unemployment and support unemployed workers. These taxes are a total of $8.65 \%$ of the CRB, $7 \%$ paid by the employer and $1.65 \%$ by the employee and fund programs managed by independent entities, primarily the Instituto Nacional de Empleo (INEM) that receives a payroll-tax of $8.25 \%$ and FOGASA with the other $0.4 \%$.

Table 18 summarizes the financing of INEM over the past few years as well as the budgets for 2000 and 2001.

Table 18. Summary of INEM finances as \% of GDP (Source: Ministerio de Hacienda \& INE)

\begin{tabular}{|c|r|r|r|r|r|}
\cline { 2 - 6 } \multicolumn{1}{c|}{} & \multicolumn{1}{c}{1997} & \multicolumn{1}{c}{1998} & 1999 & 2000 & \multicolumn{1}{c|}{2001} \\
\hline Government Transfers & $0.33 \%$ & $0.25 \%$ & $0.16 \%$ & $0.05 \%$ & $0.00 \%$ \\
\hline External Transfers & N/A & N/A & $0.12 \%$ & $0.11 \%$ & $0.10 \%$ \\
\hline Payroll taxes & $1.87 \%$ & $1.88 \%$ & $2.09 \%$ & $1.97 \%$ & $1.95 \%$ \\
\hline Total Income & $2.32 \%$ & $2.25 \%$ & $2.37 \%$ & $2.13 \%$ & $2.05 \%$ \\
\hline
\end{tabular}

\begin{tabular}{|c|r|r|r|r|r|}
\hline Subsidies & $1.83 \%$ & $1.71 \%$ & $1.44 \%$ & $1.33 \%$ & $1.28 \%$ \\
\hline Employment policies & $0.49 \%$ & $0.54 \%$ & $0.82 \%$ & $0.80 \%$ & $0.77 \%$ \\
\hline Total Expenses & $2.32 \%$ & $2.25 \%$ & $2.26 \%$ & $2.13 \%$ & $2.04 \%$ \\
\hline
\end{tabular}

The main source of financing is the payroll tax, that represents approximately $2 \%$ of GDP, and, as Social Security contributions, should remain a rather stable fraction of GDP for as long as the tax rules are not changed. Additionally, transfers from the general budget had to be used while the unemployment rate was high to supplement the payroll tax. These transfers have declined progressively and will be zero in 2001 . There is also a small transfer from the EU captured as external transfers in the table.

The main expense item is the subsidies paid to unemployed workers. However, this item has declined steadily as a fraction of GDP as the unemployment fell in the past years. The second item relates to programs to actively promote employment, such as training. This item has increased in weight as the reduction in unemployment rates freed up resources to invest in this type of programs.

Beyond 2001, it can be safely assumed that the income will remain approximately $2 \%$ of GDP for as long as the payroll tax is not changed. However, as the unemployment rate falls from the current level of over $13 \%$ to the steady state level of $5 \%$, the expenses should decrease substantially. To estimate that decrease we proceed as follows:

- We fitted a straight line to the past subsidy expense (\% GDP) as a function of the unemployment rate. This line was used to estimate the subsidy as a function of the future unemployment rates.

- The expense in programs to promote employment per unemployed worker is maintained constant at the level of 2001 throughout the projection period (in real terms).

With these simple assumptions, the surplus of INEM can be estimated. Figure 41 shows the results. There is a rapid increase in the surplus up to $1 \%$ of GDP around 2009, when "full employment" is reached. The surplus increases slightly from there up to almost $1.2 \%$ of GDP by 2050 . 


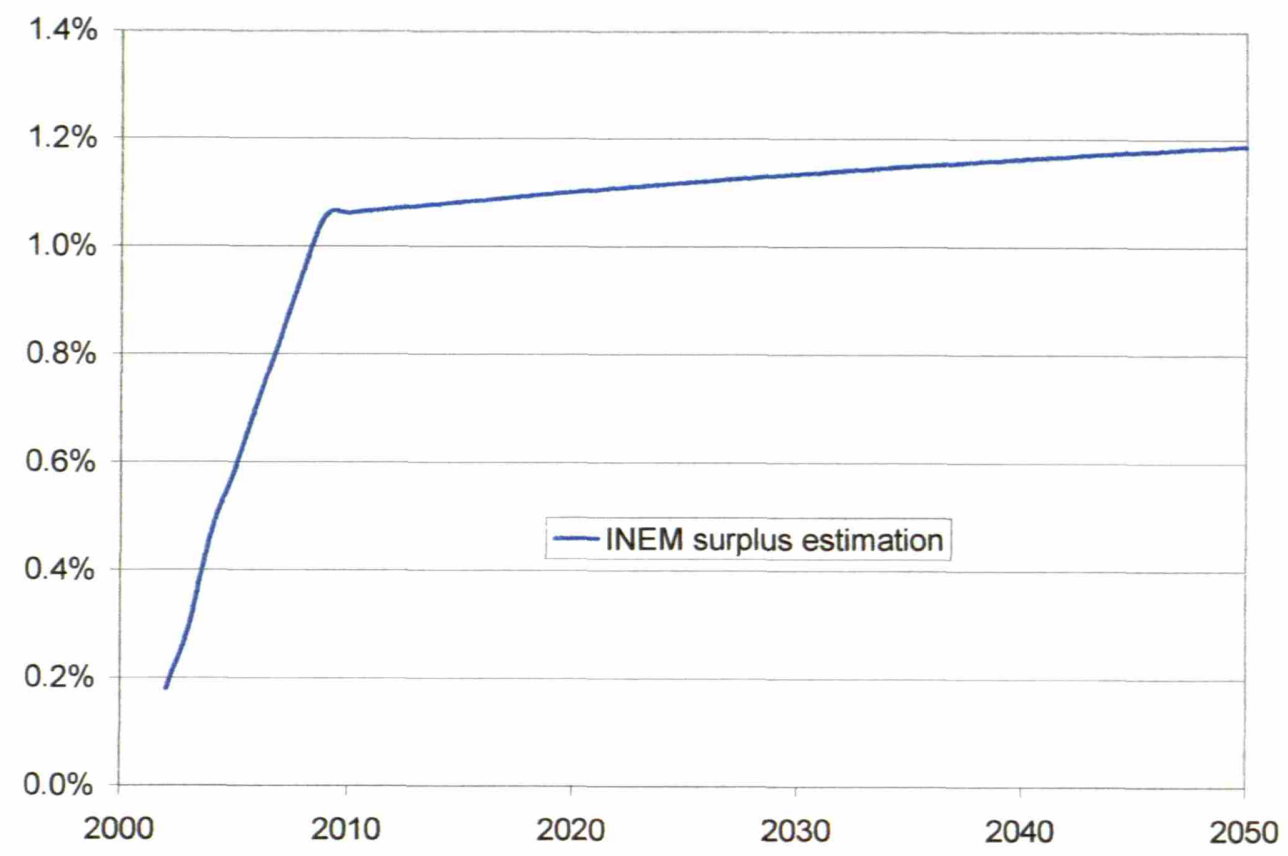

Figure 41. Estimation of the INEM surplus as \% of GDP.

As the economy approaches the state of shortage of labor, the expenses in unemployment related programs should decline sharply. This can be used to cut the payroll tax, clearly a desirable step. However, in the next simulations we will assume that the payroll-tax is not cut initially, but rather the surplus in INEM is contributed to the pension fund.

Two simulations were conducted. In the first one, the INEM surplus is added to the pension fund up to 2015. Subsequent surpluses in INEM would be trimmed through payroll-tax cuts. In the second one, the surplus continues to be added to the fund out to 2060 , and only after that year is the payroll tax cut. Figure 42 illustrates both simulations. When the contributions from the INEM surplus are stopped in 2015, the Social Security system runs current deficits starting around 2040 that reach 6\% of GDP around 2055. Around that same year, the fund is drained. If the INEM surplus contributions are kept up to 2060 , there is a current surplus for the period and the fund grows to about $120 \%$ of GDP. Under these circumstances, the system is financially viable.

It would appear that adding the INEM surplus to the pension fund for an extended period of time could prevent the anticipated financial crisis of the Social Security system. It would also mean postponing a reduction in the very high payroll-tax for decades. The effectiveness of this reform is also strongly dependent on the rapid reduction of unemployment to generate a significant surplus in INEM.

It should also be noted that in this, and all other simulations, the maximum in the fund (stock) to GDP ratio does not occur on the year the surplus (flow) is zero. It occurs when the surplus becomes a fraction of the existing stock equal to the growth of the economy in nominal terms. 


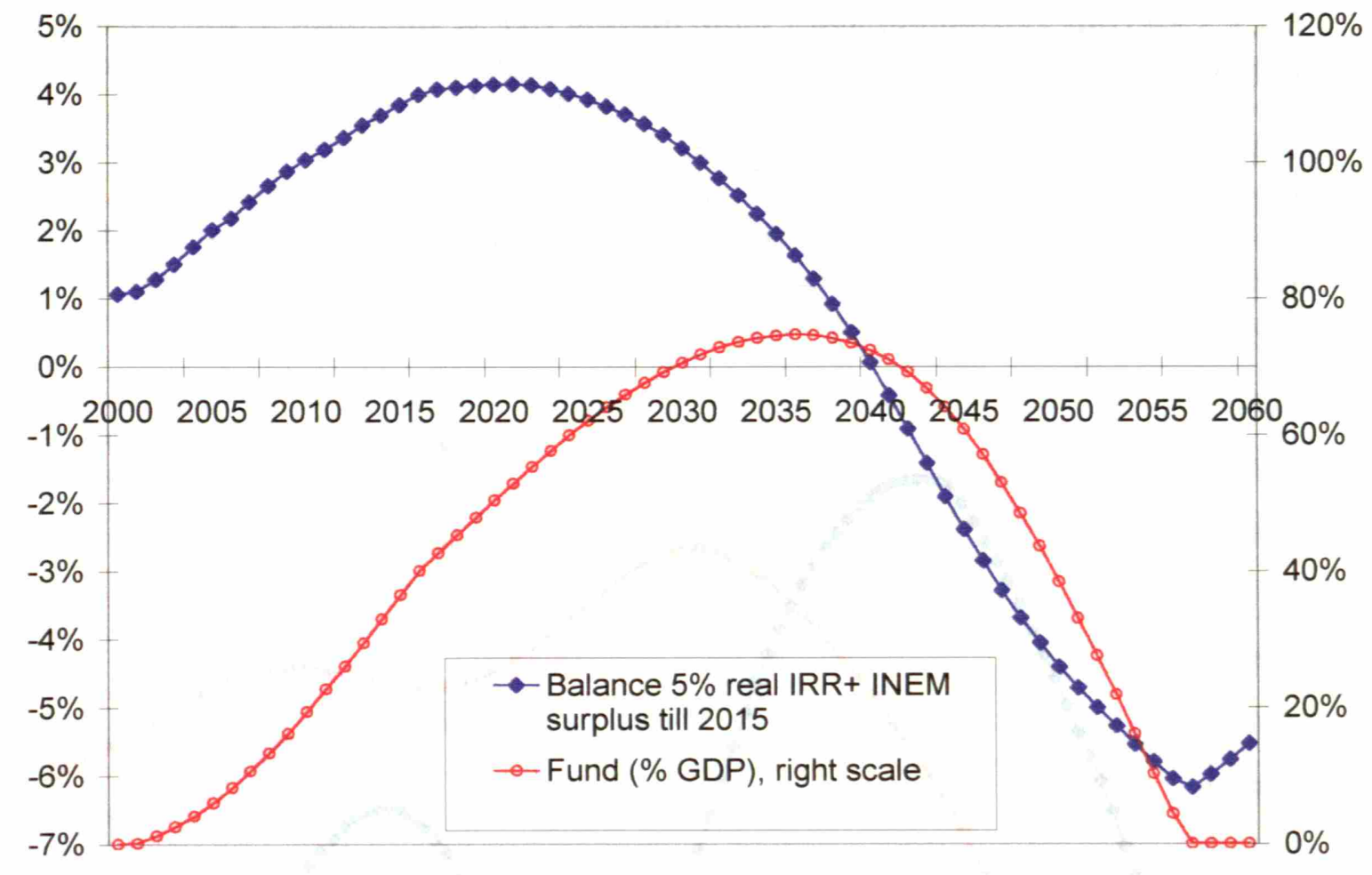

Figure 42.a. Simulation in which the INEM surplus up to 2015 is added to a pension fund yielding a real return of $5 \%$

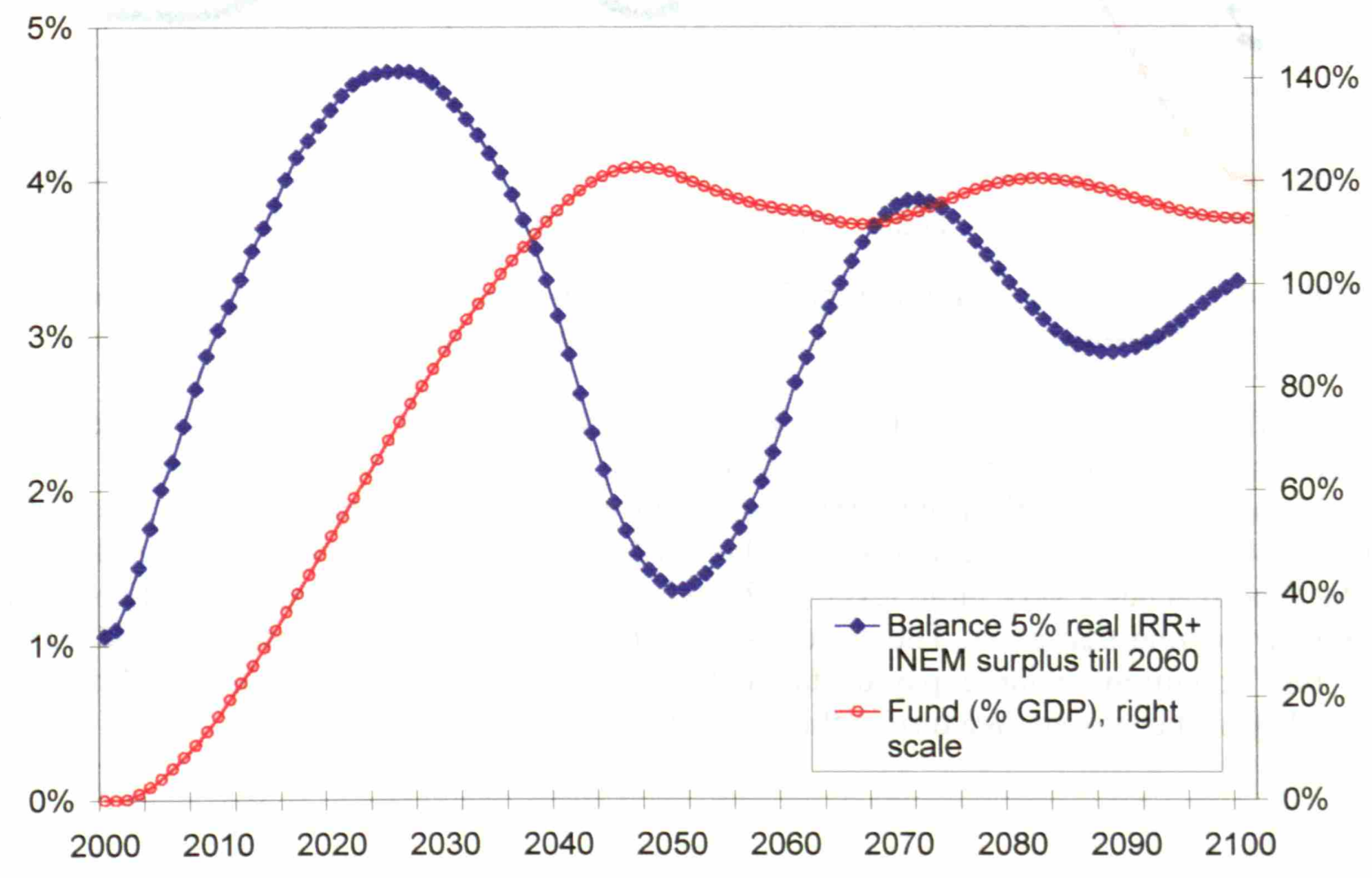

Figure 42.b. Simulation in which the INEM surplus up to 2060 is added to a pension fund yielding a real return of $5 \%$ 


\subsubsection{Flexible retirement age + contributing INEM surpluses to the pension fund.}

A more robust solution can be obtained by combining the introduction of flexible retirement policies with the contribution of INEM surpluses to the fund.

Figure 43 shows an additional simulation in which it is assumed that a flexible retirement policy is introduced and adopted as described earlier in section 5.3.1, plus the INEM surpluses are added to the fund up to 2021. The system runs current surpluses throughout the projection period. This approach would permit a reduction in the payroll-tax starting around 2020 while still ensuring the financial viability of the system.

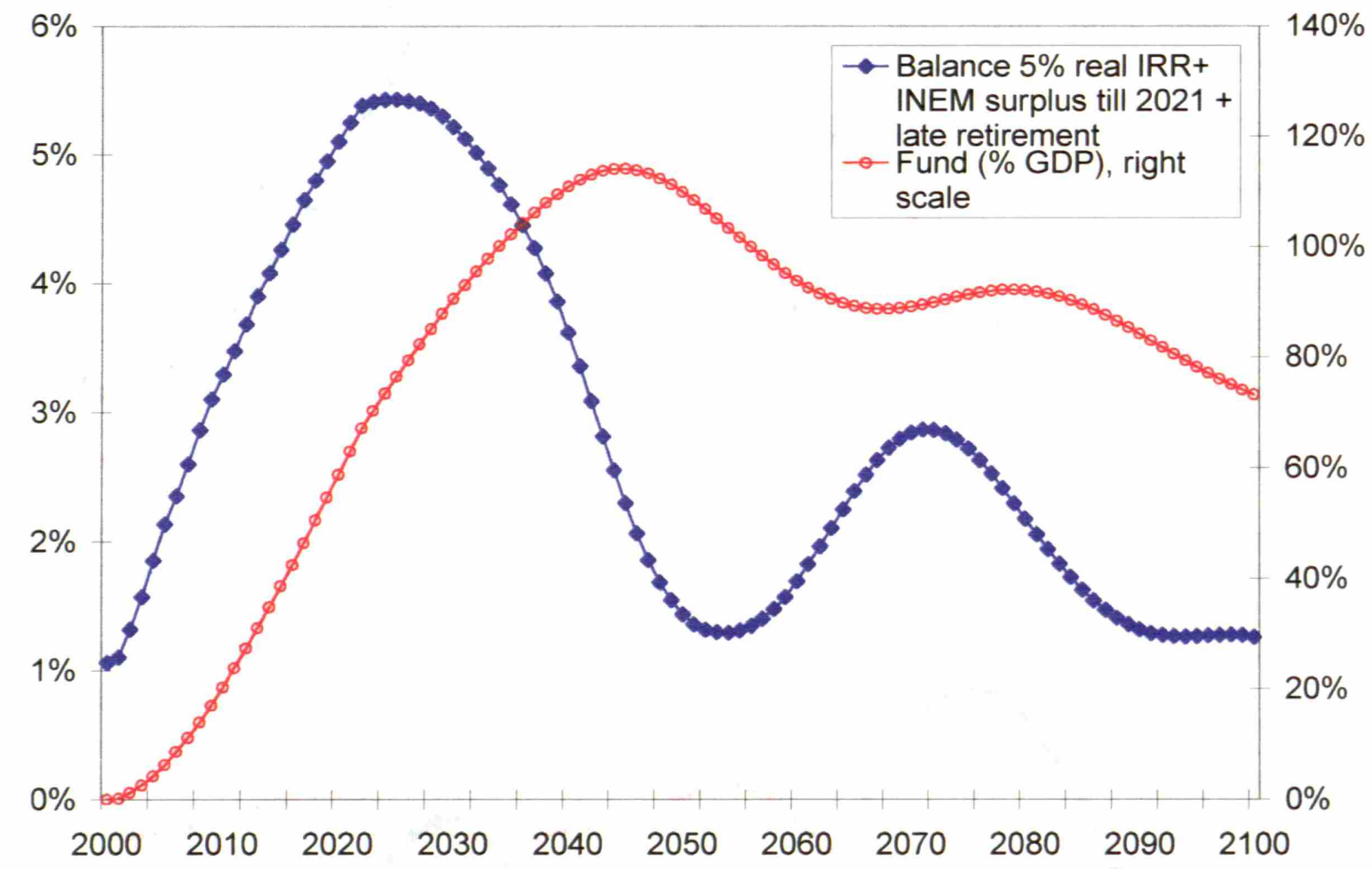

Figure 43. Simulation combining the implementation of a flexible retirement age, adding INEM surpluses up to 2021 to the pension fund yielding a real return of $5 \%$

A possible second path would be to continue the INEM surplus contributions to the fund, this would not only keep the current surpluses in the Social Security system, but would build the fund to a critical mass that would allow larger payroll-tax cuts at a later date. Figure 44 illustrates this scenario, with the INEM surpluses added to the fund until 2050. The fund reaches a very large level of about $200 \%$ of GDP by 2050 and would continue to grow beyond that point. The system shows increasing current surpluses beyond 2050 . In this condition, a large payroll-tax cut will still be compatible with the financial viability of the system. We turn to this point in section 5.3.3.5 below. 


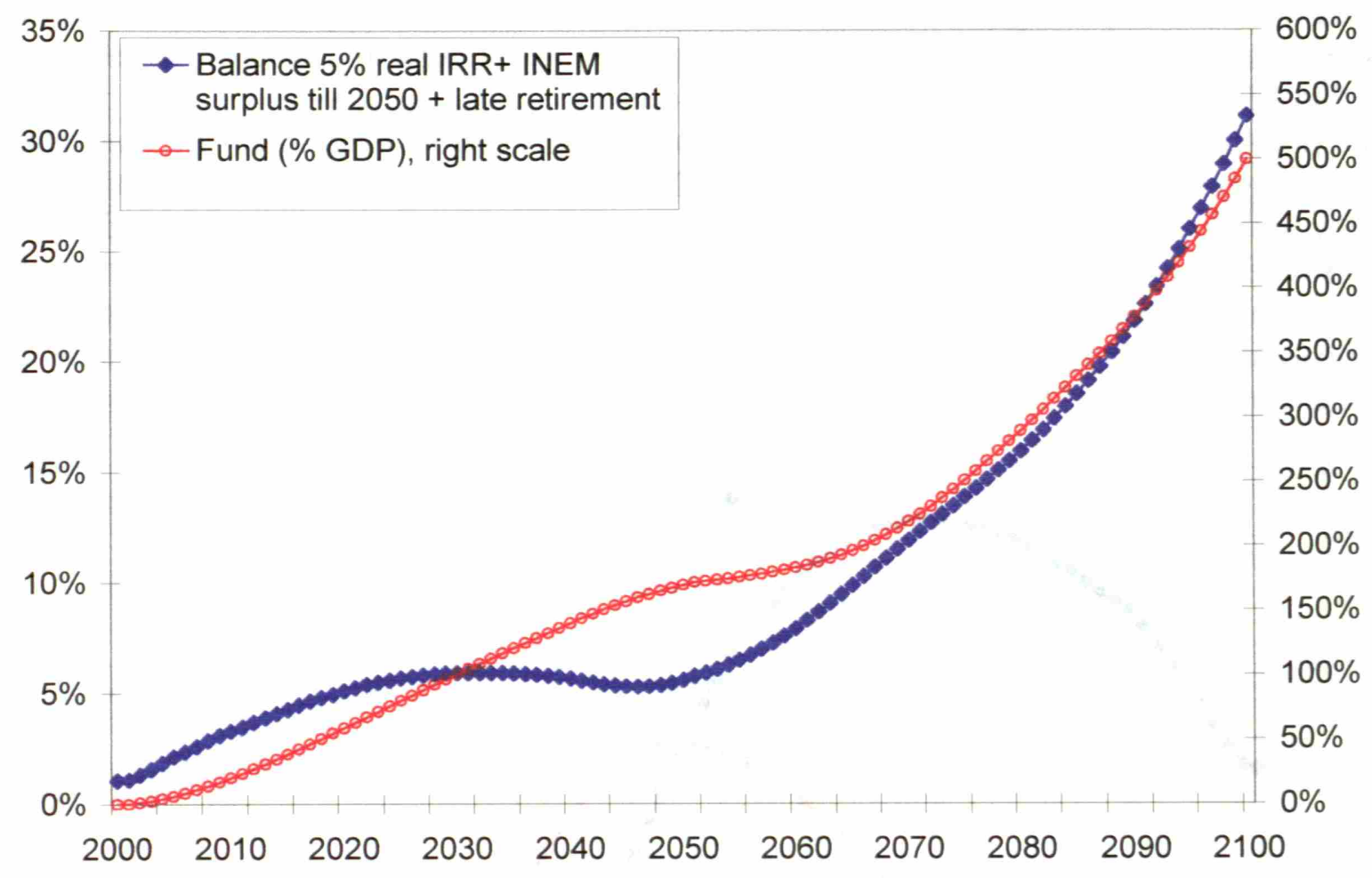

Figure 44. Simulation combining the implementation of a flexible retirement age, adding INEM surpluses up to 2050 to the pension fund yielding a real return of $5 \%$ 


\subsubsection{Extending the contribution years used to calculate the pension.}

Another reform package would be to combine the creation of the pension fund with the extension of the number of contribution years used to calculate the pension benefit from 15 to 35 as described in section 5.3.1.

Figure 45 shows an additional simulation combining these two reforms. The real return on the pension fund is assumed to be 5\%. The system runs current surpluses until 2045 . Beyond that time, current deficits drain the fund until its depletion around 2070. However, the improvement of the finances of the system is better than by combining the creation of the fund with a flexible retirement age policy (Figure 40). Therefore, it is apparent that adding the INEM surpluses to the fund for a period of time can ensure the financial viability of the system.

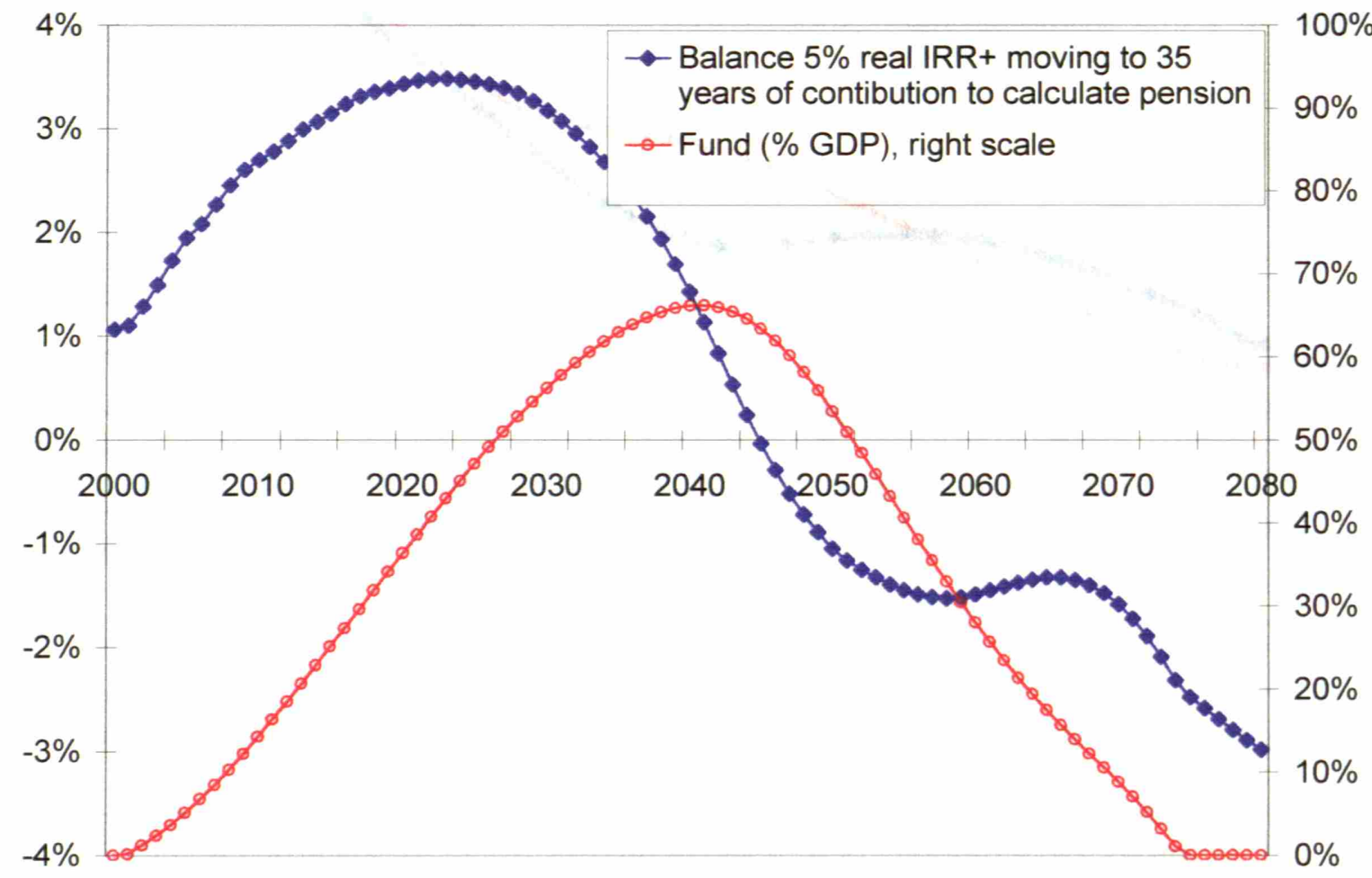

Figure 45. Simulation combining an increase in the contribution years used to calculate

the pension benefit from 15 to 35 with the creation of a pension fund yielding a real return of $5 \%$

One additional simulation, shown in Figure 46 included a combination of reforms:

- Creation of a pension fund yielding a real return of 5\%

- Contributing the social security surpluses and the INEM surpluses up to 2025 to the fund

- Flexible retirement age as in section 5.3.1

- Extending the calculation period for the PRB to 35 years as above, but changing the pension calculation method in such a way that the decline in the effective replacement rate is only one half of that estimated in Figure 36. 


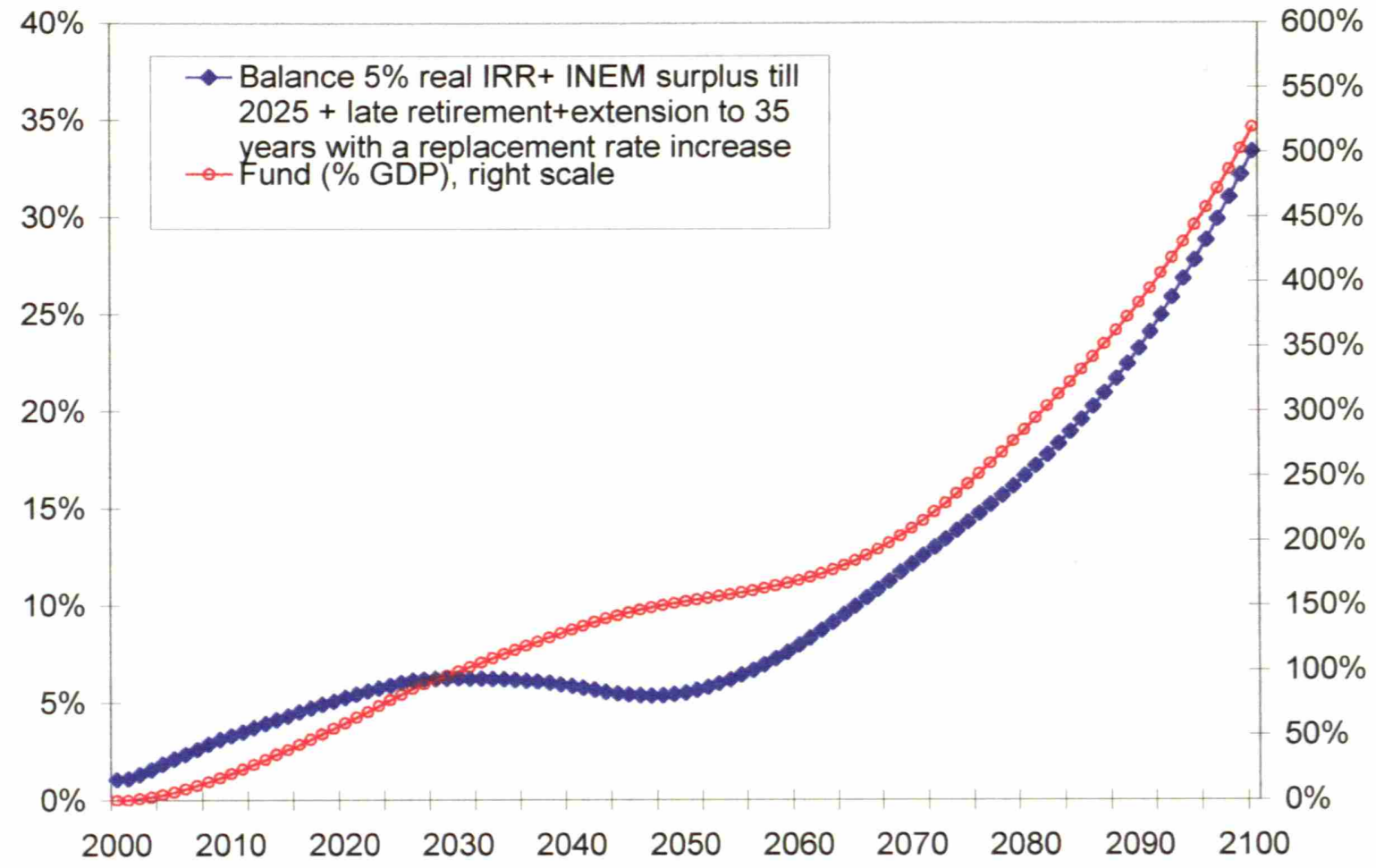

Figure 46. Simulation combining an increase in the contribution years used to calculate the PRB from 15 to 35 , a change in the pension to PRB ratio so as to partially compensate for the decline in replacement rate and a flexible retirement age. The resulting social security surpluses and the INEM surpluses up to 2025 are invested in a pension fund yielding a real return of $5 \%$

With this combination, not only are the payroll taxes cut in 2025 to trim the surplus in INEM, but the pension fund continues to grow and the system shows steady surpluses that increase rapidly after 2050. Therefore, additional payroll tax cuts could be implemented. The following section explores possible paths for the payroll tax cuts under some of the scenarios presented above. 


\subsubsection{Potential paths for payroll tax cuts.}

Of all the potential reforms explored in the previous sections, the most promising include a combination of three things:

- The creation of a Pension Fund with an investment policy such as that recommended by Modigliani et al. (reference 17). The current and future surpluses of Social Security will be transferred to the fund.

- The contribution of the prospective surpluses from INEM to the fund, at least for a transitory period.

- Reforms in the pension calculating procedures such as the implementation of a more flexible retirement age policy aimed at promoting later, not earlier, retirement and extending the years used to calculate the base pension from 15 to 35 . The latter would result in a significant decrease in pensions, that could be partly compensated by increasing the pension in relation to the PRB.

Figures 43 and 44 include the first two elements and a flexible retirement age (not the extension of the number of years used to calculate the PRB to 35). The difference stems from the fact that in figure 43, the payroll-tax is cut early (in 2021 to compensate for the INEM surplus), and as a consequence further payroll tax cuts are difficult to accommodate. In Figure 44, the first payroll-tax cuts occur later and the fund grows in such a way that deeper cuts can be effected.

This is one of the trade-offs faced in deciding the "right size" of the fund. Cutting payroll taxes early will result in a smaller fund (limiting further payroll tax cuts) and/or in a longer transition, while postponing the payroll tax can have the opposite long-term effect.

Figure 47 illustrates a potential path for the payroll tax for the baseline scenario introducing the combination of reforms described above with the exception of the extension in the number of years used to calculate the PRB. The cuts are aimed at keeping the fund's assets around $150 \%$ of GDP.

The "payroll tax level" curve shows the evolution of the required payroll tax in relation to current levels. Both the INEM (unemployment) and the Social Security portions of the payroll tax were used to calculate this ratio. That is, cuts in the unemployment or Social Security portions of the payroll tax result in a drop in the "payroll tax level" curve.

The tax remains unchanged up to 2040 when the first cut is introduced to reflect the lower INEM expenses (in other words, the INEM surplus is no longer added to the pension fund). By implementing a rather late cut, the fund grows to around $150 \%$ of GDP and subsequent cuts are possible. The payroll tax level could be reduced later on by $1 / 3$.

Figure 48 shows a similar graph for the case in which, in addition, the years to calculate the PRB are extended from 15 to 35 with an increase in the pension to PRB ratio to compensate partially for the effective decrease in the replacement rate (as in Figure 46). The payroll tax cuts can start earlier than in the previous case and be deeper given the lower expenses of the pension system that result from the extension in the number of years used to calculate the PRB. The payroll taxes are reduced by about $40 \%$ by the end of the projected period. 


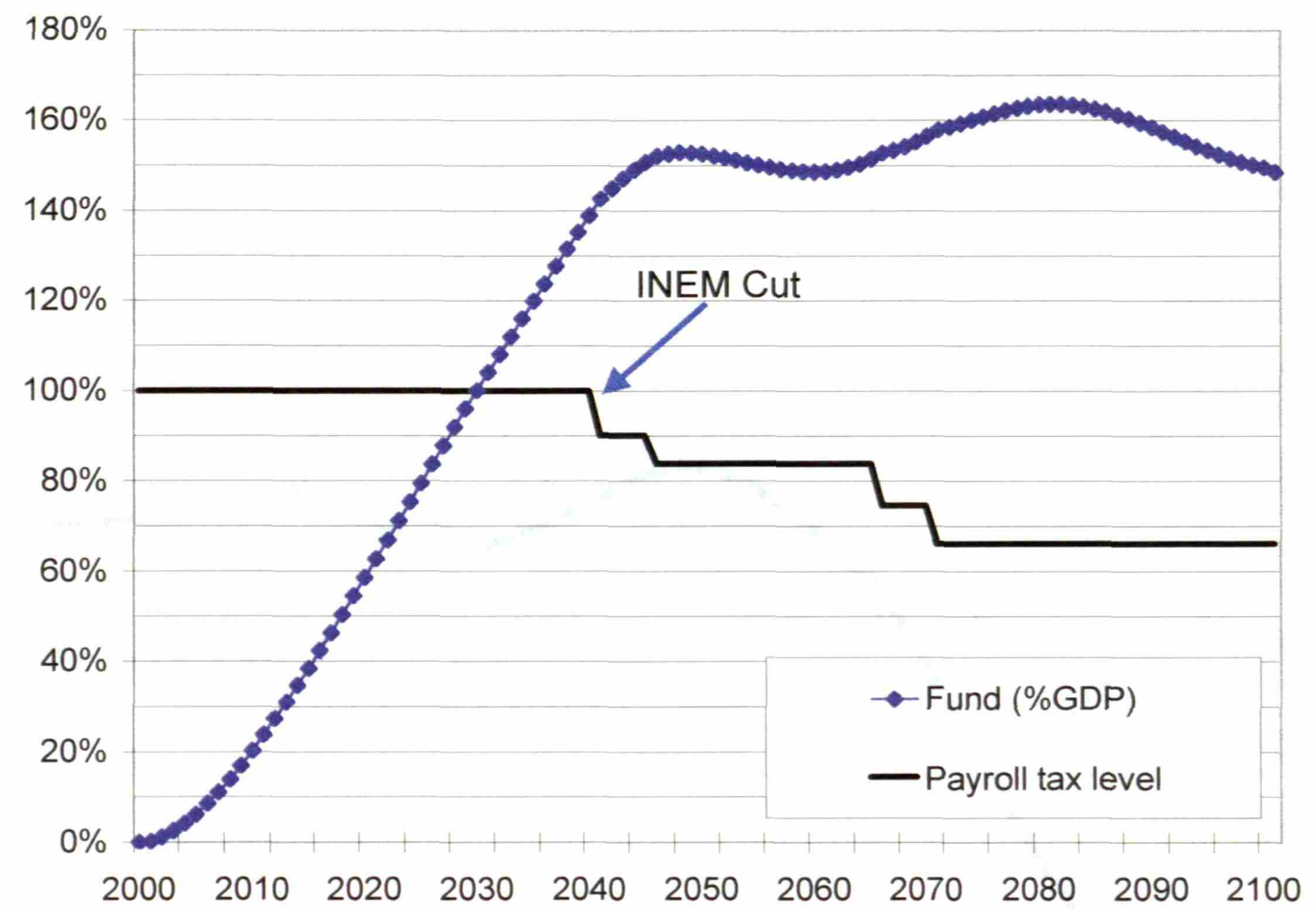

Figure 47. Potential path for payroll tax level with the implementation of a flexible retirement age and adding INEM surpluses up to 2040 to the pension fund yielding a real return of $5 \%$

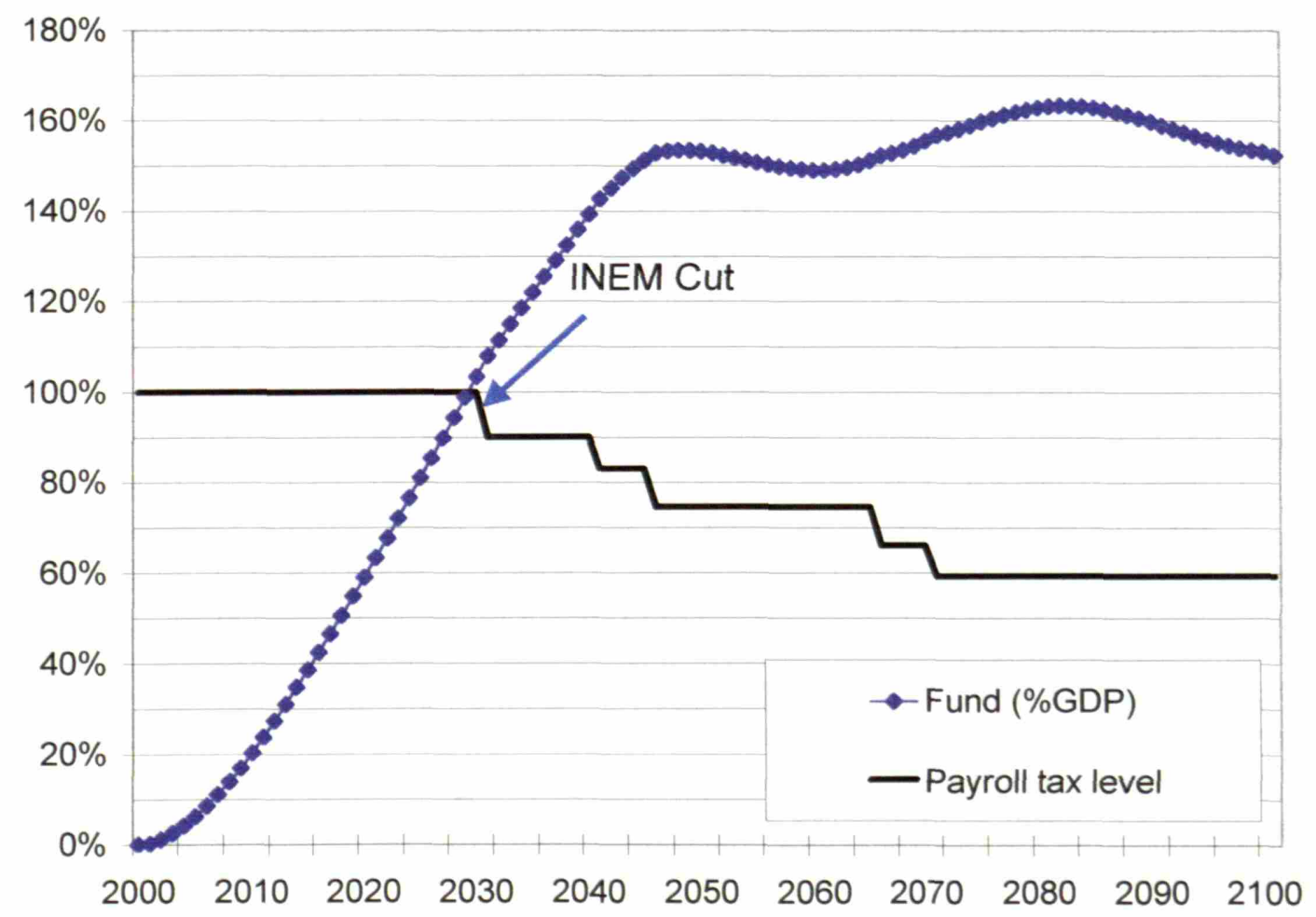

Figure 48. Potential path for payroll tax level for the case illustrated in Figure 46. 
Finally, Figure 49 shows an alternative path for the same reform package in which the first payroll tax cuts are implemented earlier and the fund is kept at a smaller size. As expected, this limits the possibility of deeper tax cuts later.

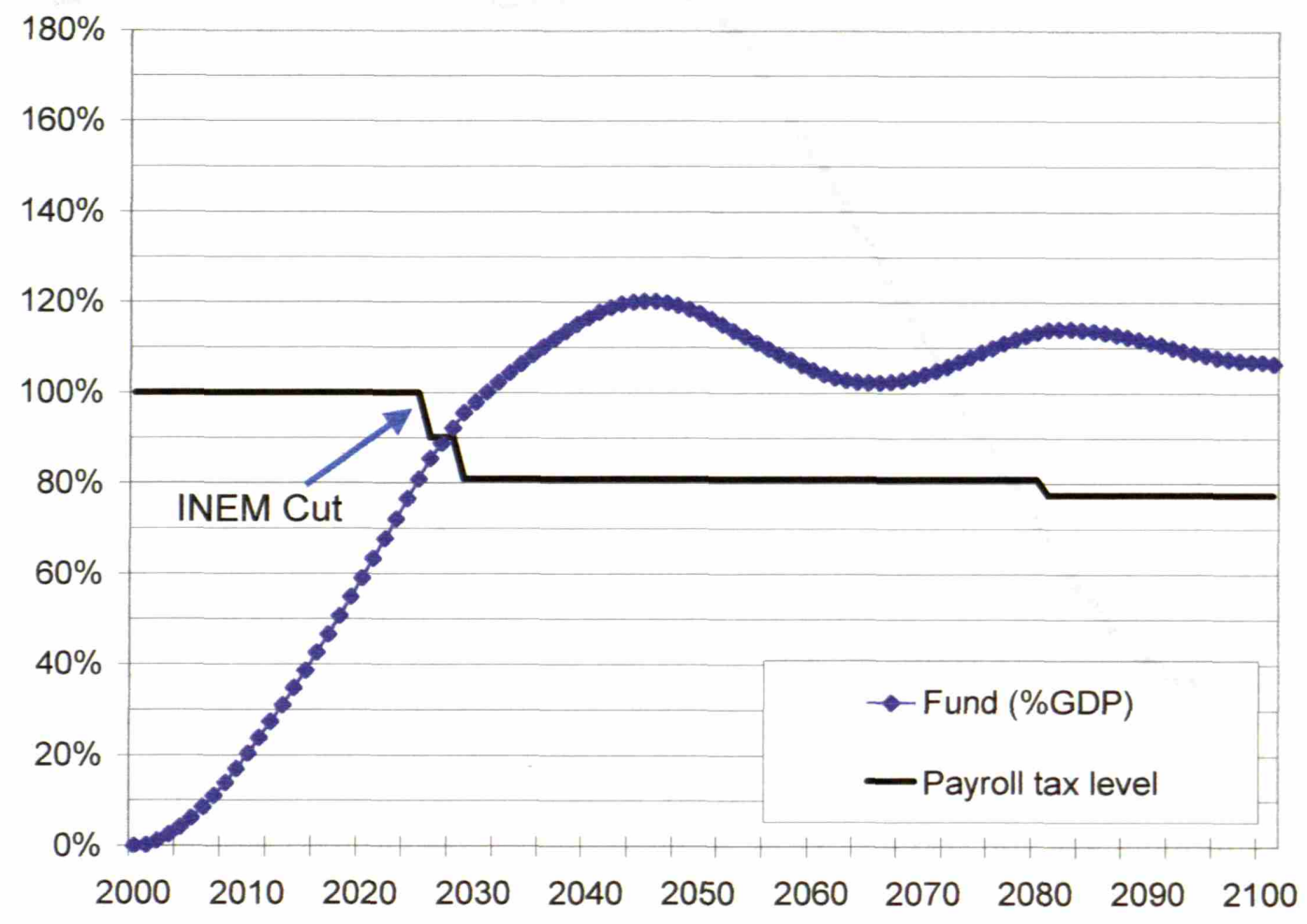

Figure 49. Alternative path for payroll tax level for the case illustrated in Figure 46. 


\subsubsection{Summary.}

The financial impact of the different reform options described in this section will be summarized here making emphasis on the implications for the payroll tax level endured by the workers. The analysis will focus on three years, 2001, the current status, 2050, representing the worst period projected in our models and 2085, more representative of a potential long run steady state.

The figures will be presented as a percentage of wages and not GDP. Wages are approximately $50 \%$ of GDP in the national accounts, this ratio remains constant in our model, as we assume that salaries increase with productivity. Therefore, the conversion is achieved simply multiplying times two.

The income and expenses of the Social Security and INEM programs are merged in this section, given a fuller representation of the potential impact of the increase in expenses in the contributive programs of Social Security and the decrease expected in the unemployment programs. The expenses for contributive programs in the Social Security system and for INEM programs (unemployment subsidies and programs to foster employability) are lumped together. The income is separated into two key sources: contributions (payroll taxes) and the return on the pension fund's assets, which will be non-zero only for those reform packages that include the creation of the pension fund.

The reform options have been grouped into six packages:

A. Baseline scenario: no reform implemented. The population and macroeconomic variables follow our baseline paths.

B. As in A but introducing a flexible retirement age. (See section 5.3.1.1 for details)

C. As in B but extended the number of years used to calculate the PRB from 15 to 35. This reform is coupled with a change in the pension to PRB ratio to compensate partially for the effective decrease in replacement rate. This is done in such a way that the decline in the effective replacement rate is only one half of that estimated in Figure 36.

D. As in B but creating a pension fund. The current and future surpluses from the social security system are contributed to the fund together with the INEM surpluses until 2040. Payroll tax cuts are aimed at keeping the fund's assets at around 1.5 times GDP. (This is the case described fully in Figure 47).

E. As in $\mathrm{C}$ but creating a pension fund. The current and future surpluses from the social security system are contributed to the fund together with the INEM surpluses until 2030. Payroll tax cuts are aimed at keeping the fund's assets at around 1.5 times GDP. (This is the case described fully in Figure 48).

F. As in E but introducing earlier payroll tax cuts that lead to a smaller fund with assets of around 100\% of GDP. (This is the case described fully in Figure 49).

Figure 50 summarizes the projections for package A. The small surpluses enjoyed now, of about $2.2 \%$ of wages (remember that we do not include the complements for minimum pensions as a contributive expense in our calculations), turn into a large deficit of $11.8 \%$ of wages by 2050 . The deficit is still large (8.4\% of wages) in 2085 . As discussed above, given the difficulty in running large fiscal deficits within the EMU, these deficits would likely be trimmed by decreasing the pensions, as increasing the payroll tax over the high current level would harm the competitiveness of the country. 


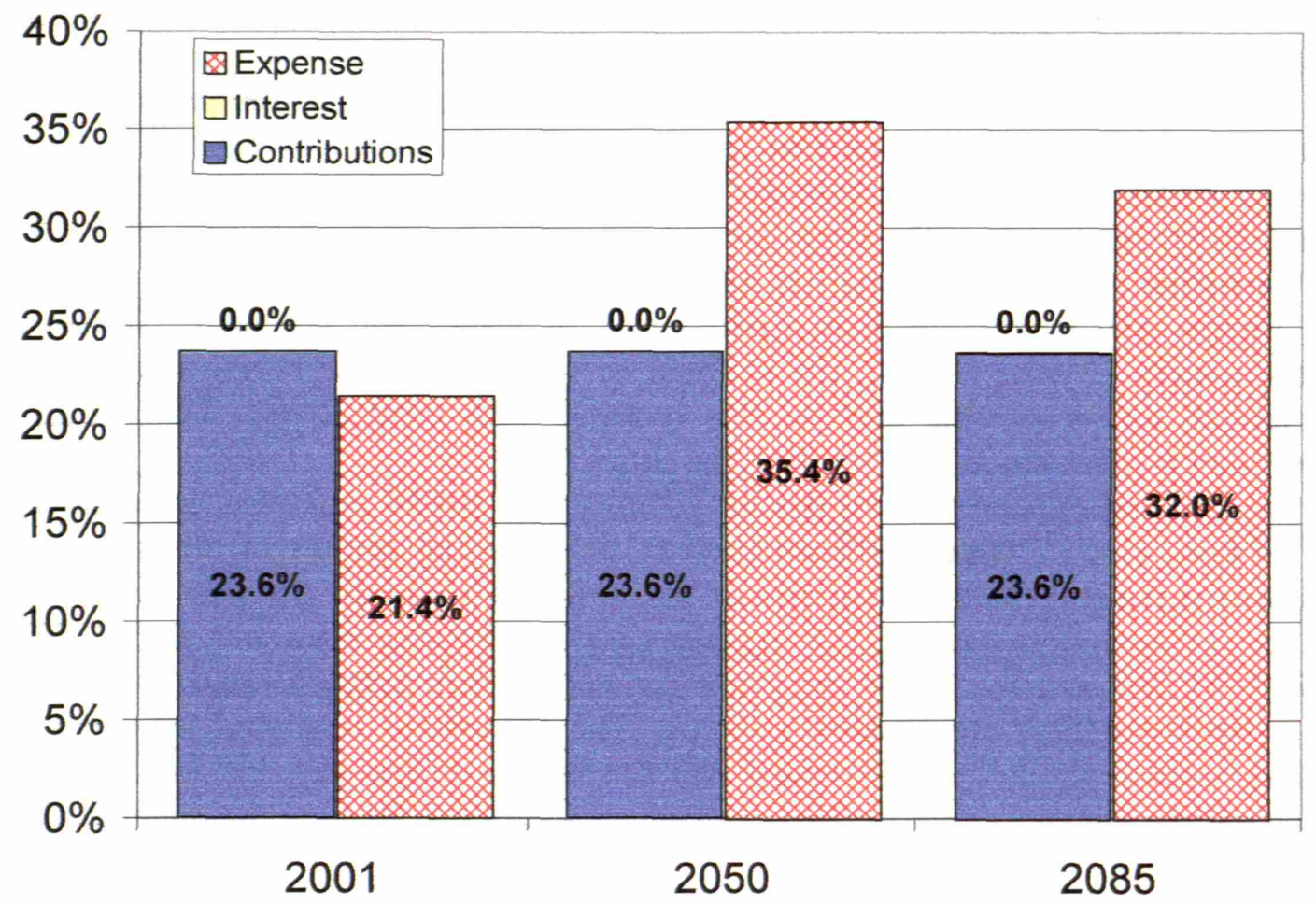

Figure 50. Summary financial projections for reform package A (in $\%$ of wages).

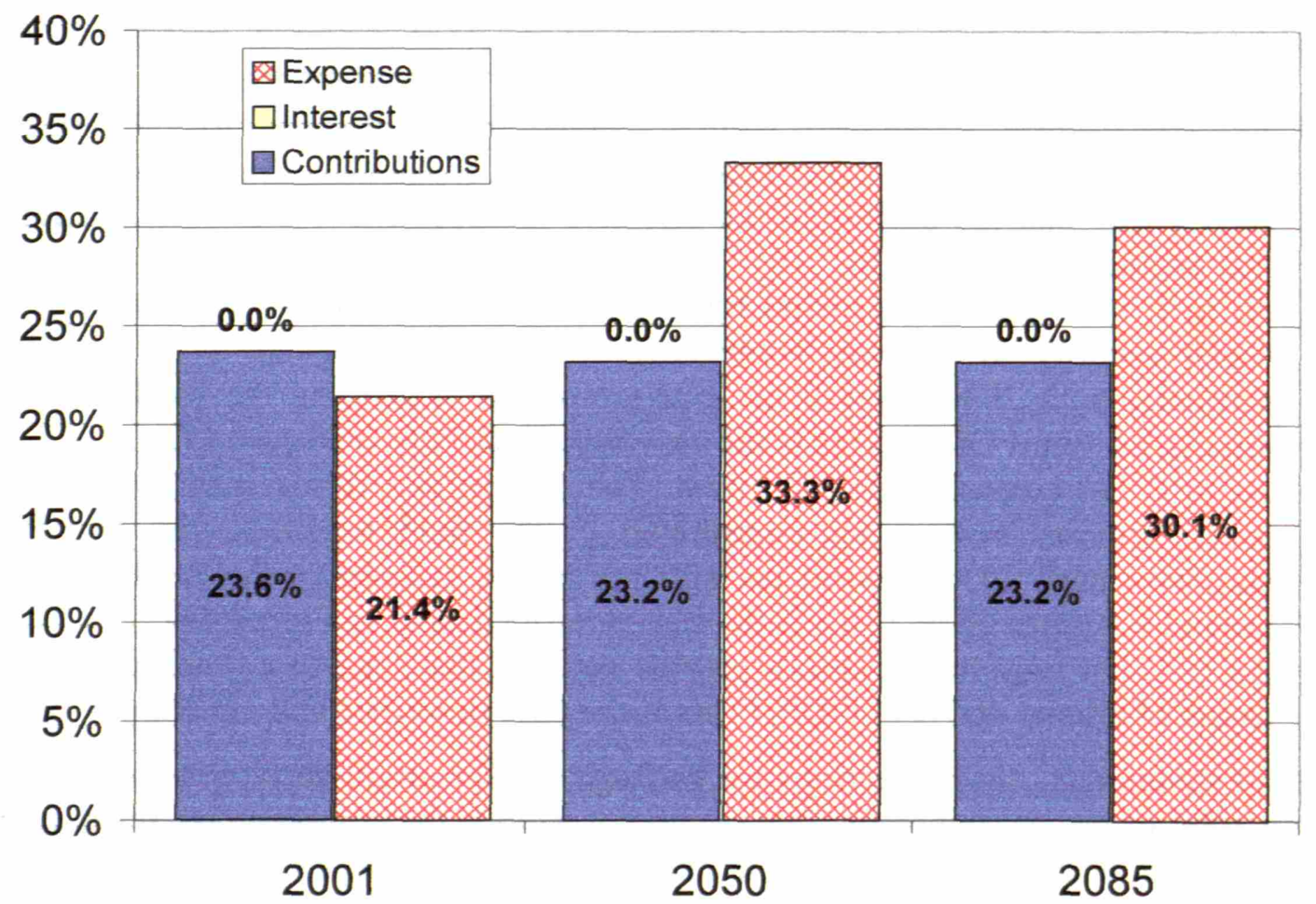

Figure 51. Summary financial projections for reform package B (in \% of wages). 
Figure 51 presents a similar projection for reform package B. The introduction of the flexible retirement package reduces the contributions slightly, as those workers ages 65 and over that choose to stay in the labor force are exempt from contributions. However, the impact on the expenses is even higher as the pension payments are also postponed. Overall, this reasonable reform improves the financial outlook of the system slightly, but does not ensure its viability. Large deficits (about $10 \%$ of wages) are still anticipated in the year 2050 .

Turning now to Figure 52, for reform package $\mathrm{C}$, it is apparent what would be the effect of adding the extension in the period used to calculate the PRB. The contributions are unaltered from case B, while the expenses drop further. However, even these two reforms combined fail to ensure the viability of the system. Rather large deficits ( $8 \%$ of wages) are still projected for 2050. It should also be noted that this reform may be more difficult to implement politically, as it can be perceived as an effective cut in the pension benefit.

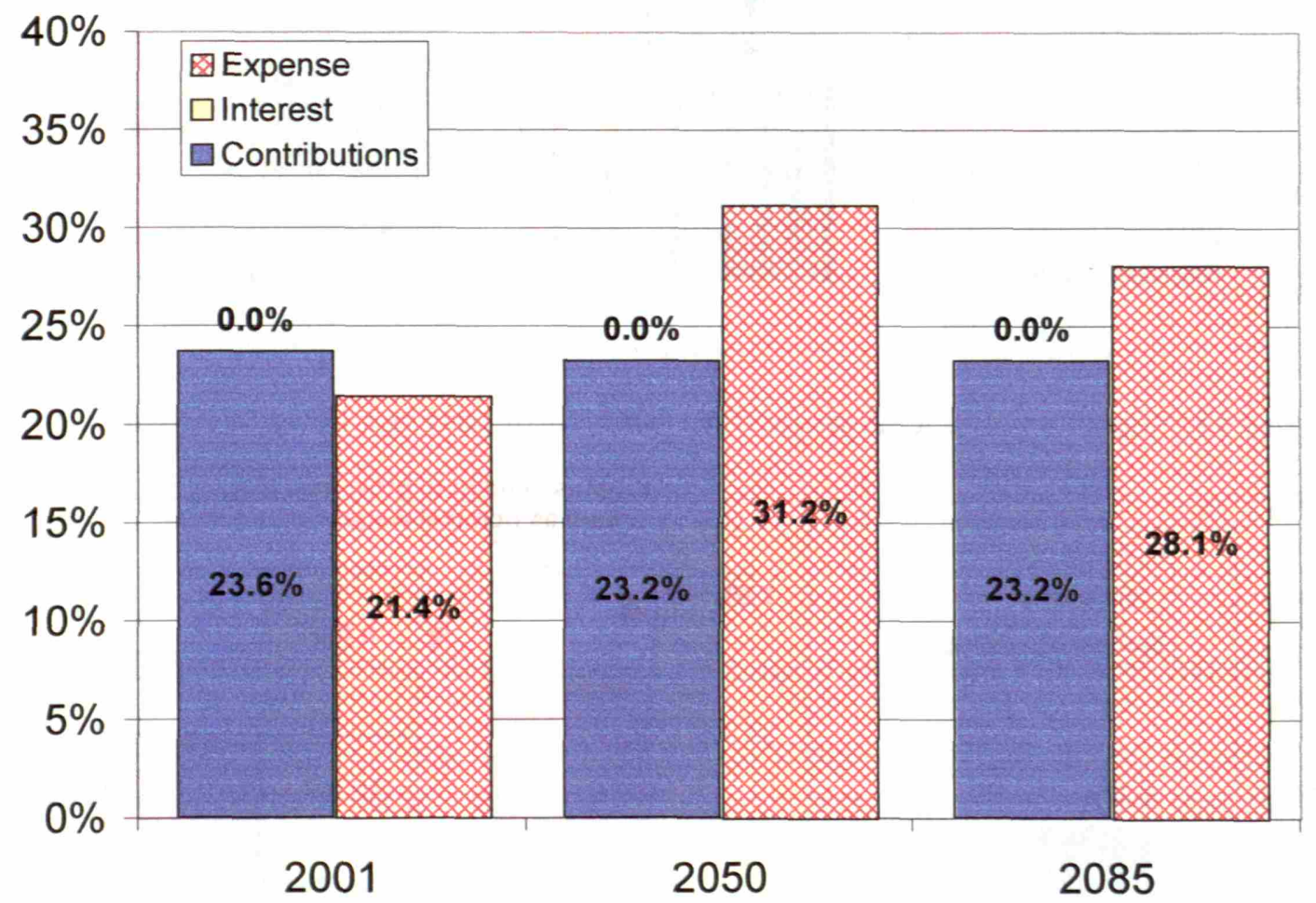

Figure 52. Summary financial projections for reform package C (in \% of wages).

Figures 53 and 54 present the projections for reform packages D and E. Both include the introduction of a pension fund (with a 5\% real rate of return) which is grown to levels around $150 \%$ of GDP, or three times wages. The situation changes dramatically. The interest returned by the fund becomes the larger source of income and allows the progressive reduction in the payroll tax, as reflected by the declining contribution income. The system maintains current surpluses that are needed to keep the fund growing roughly as nominal GDP (and wages). Also note that this is achieved without reducing the expenses relative to packages $\mathrm{B}$ and $\mathrm{C}$ respectively. Reform package $\mathrm{E}$, which includes the extension in the number of years used to calculate the PRB, and therefore a 
reduction in expenses, permits the implementation of earlier and deeper payroll tax cuts relative to reform package $\mathrm{D}$.

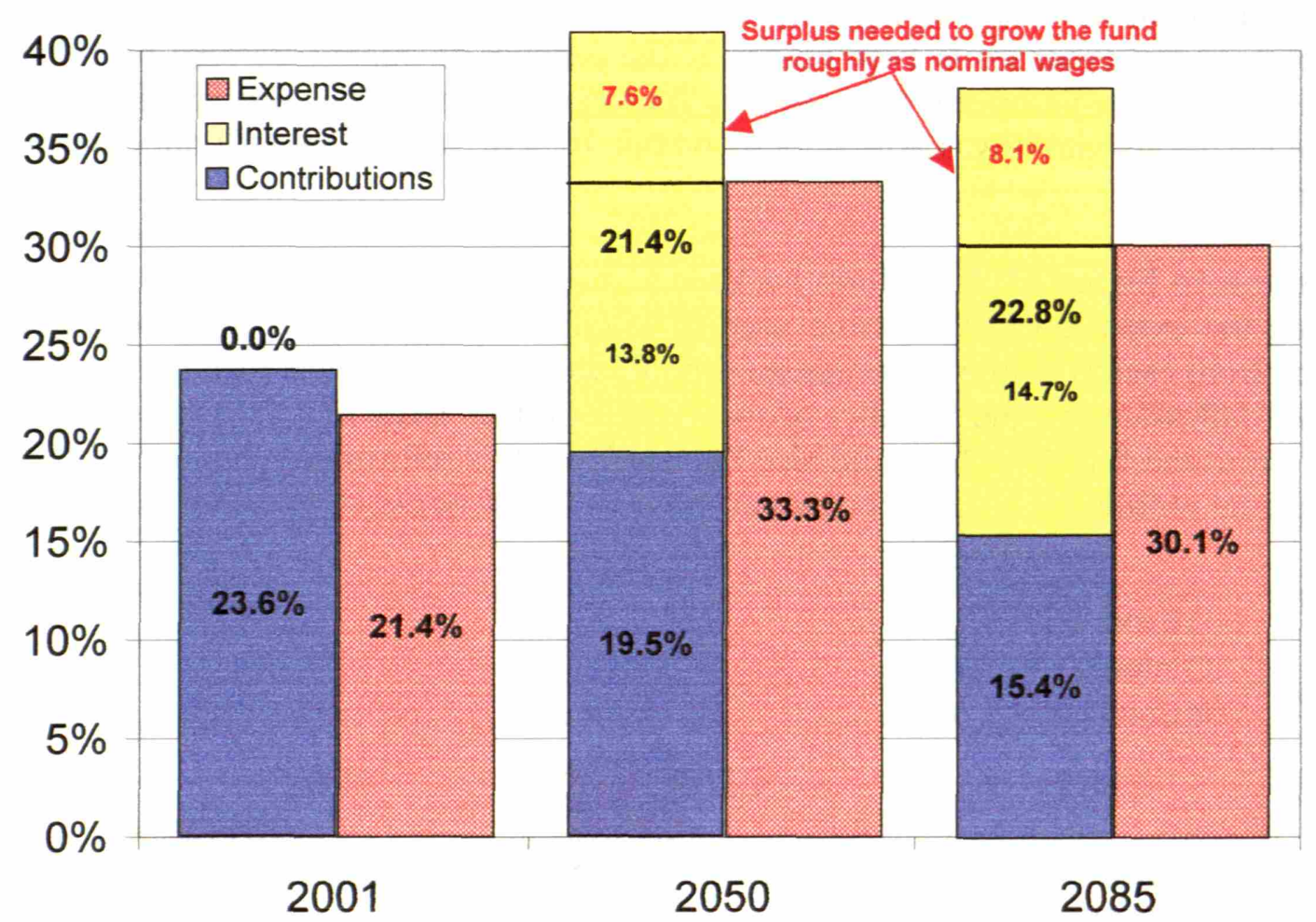

Figure 53. Summary financial projections for reform package D (in \% of wages).

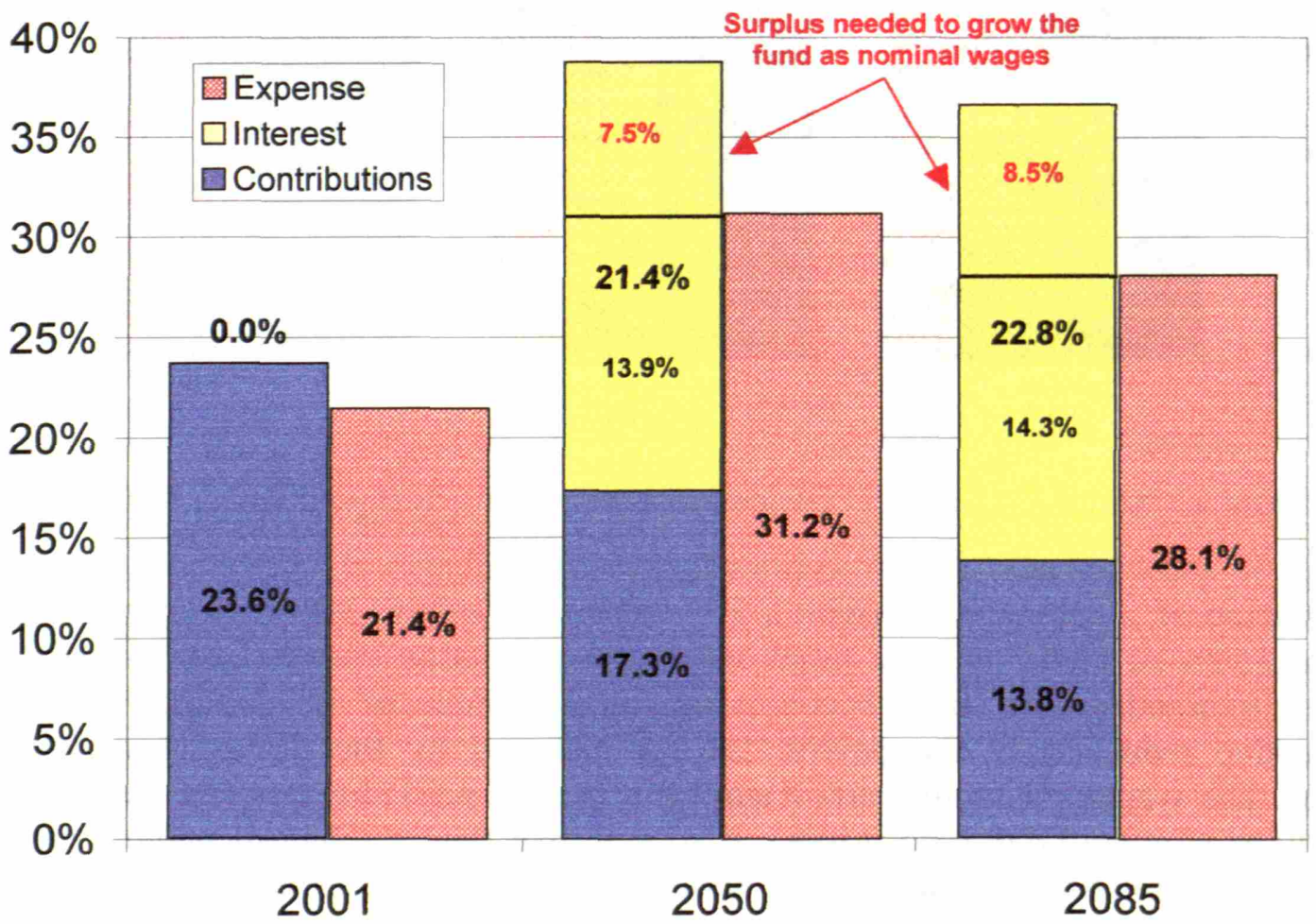

Figure 54. Summary financial projections for reform package $\mathrm{E}$ (in $\%$ of wages). 
Finally, Figure 55 presents similar projections for reform package F. The expenses do not change relative to package E. However, for this package earlier payroll taxes are implemented that maintain the fund at a lower level (100-120\% of GDP or two times wages). As a result, the interest income is smaller and the payroll tax cuts that can be effected later are not as deep, as shown by the larger weight of the contribution income as a $\%$ of wages. Again, the surpluses are needed to keep the fund growing approximately with nominal GDP and wages.

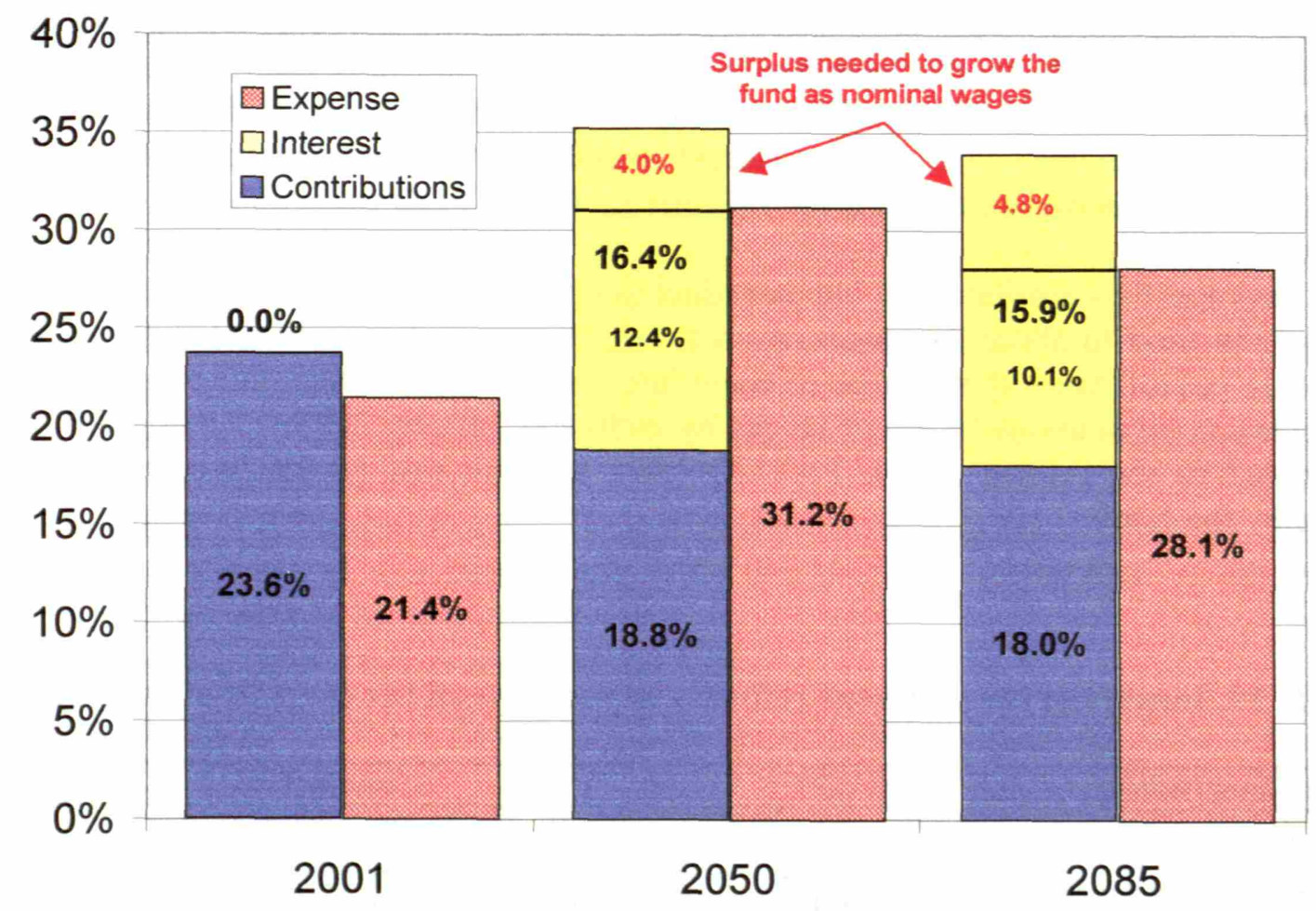

Figure 55. Summary financial projections for reform package F (in \% of wages).

Finally, Table 19 summarizes the payroll tax (as a percentage of wages) required to keep the system in balance under the different reform scenarios. Remember that the current payroll tax collections are about $23.6 \%$ of wages. Without reforms, the tax pressure on wages required to maintain the current level of benefits would have to in crease by over $12 \%$ in 2050 . The other option would be to cut pensions to reduce expenses.

The next two sets of reform packages are modifications of the current PAYGO system. The introduction of a flexible retirement age can reduce the required contributions in 2050 by about $2 \%$ of wages by reducing expenditures. The source of the reduction is the postponement of the initiation of pension payments for those workers ages 65 and over that choose to stay in the labor force. If, in addition, the number of years used to calculate the pension is extended from 15 to 35 (coupled with a change in the pension calculation method to partially offset the reduction in replacement rate), the required payroll tax is lowered by an additional $2 \%$ in 2050 . The reduction is derived again from a reduction in expenses. This reduction results from the effective decrease in the replacement rate for most pensions. 
The last three reform packages include the creation of a pension fund to which current and future surpluses of social security and INEM would be added and invested as described in previous sections. The creation of the fund is coupled with PAYGO reforms as those if packages $\mathrm{B}$ or $\mathrm{C}$.

For reform packages $\mathrm{D}$ and $\mathrm{E}$, the fund grows to approximately $150 \%$ of GDP (or $3 \mathrm{x}$ wages). The returns from this fund permit a large additional drop in payroll tax level. This drop is of the order of $14 \%$ of wages by 2050 (over and above the reductions resulting from PAYGO reforms).

Over the long run (2085), these packages can reduce the payroll tax level to less than half the level required to balance the system without reform. Of the more than $18 \%$ reduction in the payroll tax as a \% of wages that would result from package $\mathrm{E}$, the bulk of the reduction $(14.3 \%)$ is derived from the interest income provided by the fund. A smaller reduction of $4 \%$ is achieved through the reforms in the PAYGO rules aimed at reducing the expenses.

Reform package $\mathrm{F}$ is similar to $\mathrm{E}$ but introducing earlier payroll tax cuts that limit the growth of the fund to about $2 \mathrm{x}$ wages. As a result, the interest income is lower and the reduction in payroll taxes that can be effected later on is limited when compared to case E. The cuts can be of about $16.6 \%$ of wages by 2050 and $14 \%$ by 2085 . Of these, $4 \%$ can be attributed to the reform of the PAYGO rules and the rest to the interest income provided by the fund.

Table 19. Impact of the different reforms on the payroll tax (as a \% of wages)

\begin{tabular}{|c|c|c|c|}
\hline Reform Package & 2050 & 2085 & Comment \\
\hline A- No reform & $35.4 \%$ & $32.0 \%$ & Baseline \\
\hline B- Flexible retirement & $33.3 \%$ & $30.1 \%$ & Reduction in expenses by postponing some pension payments \\
\hline $\begin{array}{l}\text { C- As B plus use } 35 \text { years to } \\
\text { calculate pension }\end{array}$ & $31.2 \%$ & $28.1 \%$ & $\begin{array}{l}\begin{array}{c}\text { Further reduction in expenses by decreasing the replacement } \\
\text { rates for some pensions }\end{array} \\
\text {. }\end{array}$ \\
\hline D- As B plus creating a fund & $19.5 \%$ & $15.4 \%$ & $\begin{array}{c}\begin{array}{c}\text { The interest from the fund permits an additional large } \\
\text { decrease over and above reform package B }\end{array} \\
\end{array}$ \\
\hline E- As C plus creating a fund & $17.3 \%$ & $13.8 \%$ & $\begin{array}{c}\text { The interest from the fund permits an additional large } \\
\text { decrease over and above reform package } \mathrm{C}\end{array}$ \\
\hline $\begin{array}{l}\text { F- As E but with earlier } \\
\text { cuts/smaller fund }\end{array}$ & $18.8 \%$ & $18.0 \%$ & $\begin{array}{l}\text { The interest from the fund permits a decrease over and above } \\
\text { reform package } C \text {, but not as large as in the previous package } \\
\text { because of the smaller size of the fund }\end{array}$ \\
\hline
\end{tabular}




\section{Conclusions and policy recommendations}

After three years with small deficits in the mid-nineties, the contributive segment of the Spanish Social Security system (referred to as Social Security throughout the rest of this section) has enjoyed increasing surpluses. These are the result of the expansive economic cycle of the second half of the nineties and also partly due to the reforms implemented after the "Pacto de Toledo".

The expansive economic cycle has been characterized by intense job creation in Spain (Figure 20). The unemployment rate fell from almost $25 \%$ to below $14 \%$ today (Figure 21) despite an increase in labor force participation rates (Figure 22). This has expanded the income base for social security, currently financed through a payroll tax.

The reforms introduced following the "Pacto de Toledo" were also a step in the right direction, among these, the most relevant ones are:

- Clarification of the funding sources. Health care and non-contributive pensions will be supported by government transfers (general taxation) while the contributive benefits, including pensions will be funded by the contributions (payroll tax).

- Classification of the complements to minimum pensions as a non-contributive benefit.

- Extension of the number of contribution years used to calculate the retirement pension benefit from 8 to 15 .

- Creation of a Pension Reserve Fund with the current surpluses. However, this fund is intended more as a means to adjust for the business cycles than as an alternative source of income for Social Security.

- Indexation of existing pensions to the CPI.

Positive as they have been, these reforms are insufficient to ensure the long term financial viability of Social Security. The current PAYGO system will, according to our baseline simulations, run small current surpluses over the next two decades and then start generating increasing current deficits that would peak at about 7\% of GDP in 2045 (Figure 31 ). This change will be driven mainly by demographic factors. In particular, the old-age dependency ratio will more than double by 2045 (Figure 16) as a result of the increased life expectancy and the dramatic reduction in fertility rates experienced in Spain since 1975 (Figure 8).

In our calculations for the baseline scenario discussed above, it was assumed that the unemployment was progressively reduced during this decade until it reaches $5 \%$ and then stays stable at that level. It also includes a significant increase in the labor force participation, particularly for women (Figure 23). We must conclude that the elimination of unemployment and increased LFPR will not in and by themselves guarantee the financial viability of the PAYGO system. We take them as a given following the trends of the last few years. Should unemployment and LFPR remain at current levels, the outlook for the system would be even worse.

Regarding the impact of demographic factors, the baseline projection includes a continued improvement in the life expectancy (Figure 5) and a rebound in fertility rates from the current level of about 1.2 children per woman to 1.56 (Figure 8). The immigration level is maintained at 35,000 individuals below age 65 per year throughout the period. Should the recovery in fertility rates be slower that the baseline scenario, the financial outlook would deteriorate (Figure 32) significantly, with deficits exceeding $8 \%$ 
of GDP toward the end of the projection period estimated for our low fertility scenario. Only the combination of high recovery in fertility and much higher immigration rates (up to 150,000 individuals per year) shows a significant improvement on the financial outlook starting around 2015. However, the trend towards large deficits in the PAYGO system remains unchanged beyond 2025 even with high fertility and immigration as seen in Figure 32. Furthermore, such a large immigration flow is not a very plausible scenario as it is not compatible with current immigration policy and may create a number of other social problems. Therefore, our conclusions agree with those of Herce (11): demographic factors are the main drivers behind the expected deterioration in the finances of Social Security and cannot be expected to be the solution.

Regarding the macroeconomic outlook, our baseline scenario up to 2004 is the one forecasted by the government in reference 13. Essentially, it includes growth in the range of $3 \%$ mainly driven by job creation. The increase in productivity is $1.1 \%$ per year. Beyond 2004, we assumed a more modest rate of output growth of $2.5 \%$ starting in 2005 . Productivity growth is taken initially as $1.1 \%$, the same figure used for the short run outlook. The rest of the growth stems from job creation. As the labor supply becomes tighter (decreasing unemployment), the rate of productivity growth increases up to a maximum of $1.5 \%$ /year. When $5 \%$ unemployment is reached, the output growth is restricted by the labor supply. For our baseline demographic scenario, job growth will be negative from 2013 onwards. Sustaining high output growth in these circumstances would require very high levels of sustained productivity growth. Figure 33 shows the sensitivity of the finances of the Social security system to the levels of output growth, which in turn are driven by the sustainable levels of productivity growth. If productivity grows at $2 \%$ /year the peak current deficit would be reduced by about $1 \%$ of GDP. However, Social Security is still bound to run into a financial crisis in the decade of the 20 s. In turn, if productivity growth drops to $0.85 \%$ per year, the current deficits would approach $8.5 \%$ of GDP by 2050 . Based on the calculations presented in section 4 , we conclude that no reasonable rate of growth in productivity would avert the large current deficits expected beyond 2025 .

In summary, we estimate that, left unchanged, the contributive portion of the Spanish Social Security system would see an alarming deterioration of its finances beyond 2020 , driven by demographic factors. The restriction on fiscal deficits imposed by the European Monetary Union would make financing deficit of 7\% of GDP a very difficult endeavor. Should nothing be done before then, the most likely consequence would be a reduction in benefits or an increase in the payroll tax. Given the already high payroll-tax, the most likely adjustment mechanism would be a reduction in benefits to the pensioner population, clearly an undesirable scenario, particularly for Spaniards under 40 .

Despite this somewhat gloomy outlook, Spain is in a relatively advantageous position compared to other Western European countries in that its baby boom occurred later. Therefore, the deterioration in the old-age dependency ratio will happen later. This is the key behind the expected surpluses in Social Security over the next two decades, which in turn open a window of opportunity for Social Security reform as described next. 
Based on the simulations described in section 5, a permanent solution for the prospective Spanish Social Security financial problems could be supported on three pillars:

- The creation of a Pension Fund with an investment policy such as that recommended by Modigliani et al. (reference 17). The current and future surpluses of Social Security will be transferred to the fund. These include the complements for minimum pensions currently paid out of contributions. The return on this fund would complement the payroll tax as a second main source of income for Social Security.

- The contribution of the prospective surpluses from INEM to the fund, at least for a transitory period. For these to be significant, unemployment must fall from its current levels of around $15 \%$ to a more reasonable number of around 5\%. Labor market reforms and the expected shortage of working age people in upcoming cohorts should contribute to the reduction in the unemployment rate.

- Reforms in the pension calculating procedures that will foster participation in the labor force, reduce the pension costs and eliminate some of the distortions introduced by the current system. Two candidates are the implementation of a more flexible retirement age policy aimed at promoting later, not earlier, retirement and extending the years used to calculate the base pension from 15 to 35 . The latter would result in a larger decrease in pension expenses, but entails effectively a decrease in retirement pension benefits of over $20 \%$. Our simulations suggest that this latter reform is not needed if the other three are implemented. Alternatively, if implemented, the reduction in benefits could be partially compensated by changing the rules used to calculate the pension. Should an extension in the calculation years be introduced, it could be accompanied by a further reduction in the payroll tax.

This reform would effectively turn the public pension system in Spain into a mixed PAYGO-funded system that would combine several advantages of PAYGO and funded systems:

- Lower payroll tax for the same benefits. Our estimations suggest a long term reduction in the payroll tax of about 30 to $40 \%$ relative to current levels. This in turn is expected to reduce some of the labor market distortions induced by high payroll taxes.

- Increase the savings rate and can thus result in higher output per capita and economic welfare (consumption per capita).

- The financial health of the pension system will become less sensitive to demographic and productivity changes.

- Maintain the redistribution mechanisms currently existent under the PAYGO scheme.

- Maintain the "defined benefit" character, thus limiting individual risk.

- Low administration costs compared to systems based on individual accounts.

- Strengthen the local financial markets

The transition cost will be born by current workers and it is limited to delaying the reductions in the payroll tax that could be implemented now and in the near future to bring the social security and INEM budgets back to balance. The benefits of the transition 
will accrue also to current workers in the form of a guarantee that their retirement benefits will not be reduced, a fact that seems highly likely unless a reform is undertaken. Future generations will also benefit from the reform, as they will get equivalent pension benefits with a lower payroll tax.

One of the key parameters yet to be determined is the optimum size of the fund. Too large a fund could reduce the return on capital and increase the marginal product of labor and thus wages. This in turn would decrease the welfare enhancement to be derived from the funded system and favor a PAYGO scheme. Our recommendation would be to create the fund and assess, as it grows, its effect on the Spanish economy, return on capital, financial markets, wages and corporate governance. Depending on this impact, the decision on the "right size" of the fund can be better taken. The two general options are:

- Target a large fund, of the order of $150 \%$ of GDP so as to permit a large cut in payroll taxes. These would come at the expense of a delay in the potential cuts made possible by declining unemployment. This means creating a mixed system with a larger funded component.

- To limit the fund to about $100 \%$ of GDP or lower, mainly a means to get past the peak in pension expenses (expected around 2045 as a result of the peculiar demographics of Spain) without raising the payroll-tax or decreasing the benefits. This means creating a mixed system with a larger PAYGO component.

Should the creation of a large fund reduce the return on capital in Spain to a significant extent, the option remains open to invest the funds' capital abroad. Some investment abroad is recommendable from a portfolio-optimization point of view. It would also make sense to secure future pensions through claims on assets located in geographical areas that have the potential (labor) to see higher rates of growth than Spain, where labor shortages may restrict output growth in the next decade. However, investing a large portion of the fund in foreign assets would forfeit the opportunity to deepen the local capital stock, which would be welfare enhancing in Spain. It would also prevent the government from collecting the extra tax income presented by Modigliani et al. (ref. 17) as an additional contribution to the spread the government would attain to compensate for its guaranteeing a given real rate of return. Investing large portions of the fund in foreign assets is therefore not recommended for the initial phases of the fund. This may be reevaluated as the fund grows.

Finally, it is worth noting that although the forecasts presented in this work foresee no financial problems with Social Security in the next two decades, the window of opportunity to implement these permanent solutions will close soon. The current surpluses, and those expected in the near future, are needed as the foundation for the pension fund in order to generate the second source of income (besides contributions) that will make the system financially viable without increasing payroll taxes or cutting benefits. 


\section{References.}

1. Aprobación por el Pleno del Congreso de los Diputados del texto aprovado por la Comisión de Presupuestos en relación con el informe de la ponencia para el análisis de los problemas estructurales del sistema de la Seguridad Social y de las principales reformas que deberán acometerse. Boletin Oficial de la Cortes Generales. Congreso de los Diputados. Serie E: Otros Textos. Num. 134, April 12, 1995.

2. Ley 24/1997 de 15 de Julio de Consolidación y Regularización del Sistema de Seguridad Social. July 1997.

3. "Presupuestos de la Seguridad Social. Año 2000", Ministerio de Trabajo y Asuntos Sociales.

4. Guía Laboral 2000. Ministerio de Trabajo y Asuntos Sociales.

5. Proyecciones de la Población de España Calculadas a Partir del Censo de 1991. Instituto Nacional de Estadística, Madrid 1995

6. Renovación del Padrón Municipal de Habitantes a 1-5-1996. Instituto Nacional de Estadística, (www.ine.es)

7. Revisión del Padrón Municipal de Habitantes a 1-1-1998. Instituto Nacional de Estadística, Madrid 2000.

8. Proyección de la Población Española. Juan Antonio Fernández Cordón. FEDEA Documento de Trabajo 98-11, July 1998.

9. El futuro de la Población Española. Juan Antonio Fernández Cordón. Appendix to reference 11 Barcelona, 2000.

10. El Sistema de Pensiones Contributivas en España: Cuestiones Básicas y Perspectivas a Medio Plazo. Juan F. Jimeno FEDEA Documento de Trabajo 2000-15, May 2000.

11. La Reforma de las Pensiones ante la Revisión del Pacto de Toledo. José A. Herce, Javier Alonso Meseguer. La Caixa; Colección de Estudios económicos, Num. 19. Barcelona, 2000.

12. Spain: Selected Issues. IMF Staff Country Report No. 00/156. November 2000

13. Actualización del Programa de Estabilidad del Reino de España. 2000-2004. Ministerio de Economía. Madrid January 2001.

14. On the Fiscal Balance of the Spanish Social Security System. Roman Arjona. FEDEA, Estudios Sobre la Economía Española EEE 78. September 2000.

15. The future of pension systems in Europe A reappraisal. Michele Boldrin, Juan J. Dolado, Juan A. Jimeno, Franco Peracchi. FEDEA Documento de Trabajo 99-08, June 1999. 
16. Labor Force Participation and Retirement of Spanish Older Men: Trends and Prospects. Namkee Ahn, Pedro Mira. FEDEA Documento de Trabajo 2000-25, December 2000.

17. A Better Solution to the Social Security Crisis: Funding with a Common Portfolio. Franco Modigliani, Marialuisa Ceprini, Arun S. Muralidhar. December 2000. Submitted for publication to The Social Security Administration Bulletin.

18. Reforming pensions: Myths, Truths and Policy Choices. Nicholas Barr. IMF Working Paper WP/00/139. August 2000.

19. El sistema de seguridad social español en el año 2000. Miguel Angel García. Confederación Sindical de Comisiones Obreras. Madrid, June 2000. 
Appendix 1. Mortality Projections 


\section{Appendix 1. Mortality projections.}

The projections for future life expectancy in Spain as well as the probabilities of death (POD) at each age were carried out by extrapolating existing data out to 2050 .

This appendix provides more detailed information about this process.

Infant mortality

Infant mortality has been declining steadily in Spain in recent years. The projections call for continued decreases although at a slower pace of about $2 \%$ per year down to about 1.5 per thousand females and 1.8 per thousand males in 2050. Figure A1.1 shows the trend and the projections.

Infant Mortality

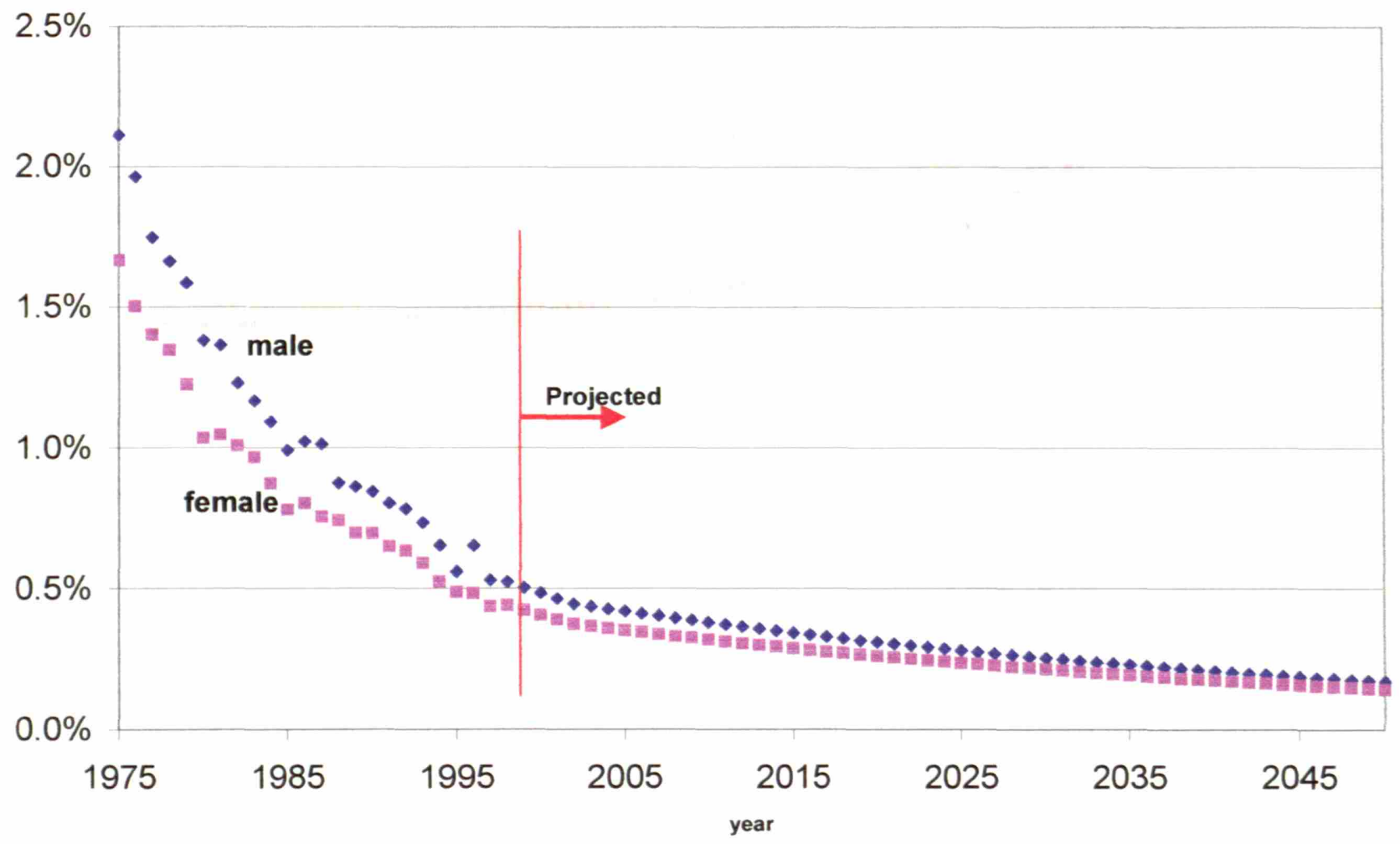

Figure A1.1. Recent trends and projections for infant mortality in Spain. 


\section{Ages 1-15}

As with infant mortality, the probabilities of death in this age range have seen a steady decrease in recent years. The projections moving forward call for further improvements although at a lower pace. Figures A1.2 through A1.7 illustrate the recent trends and projections used in this analysis

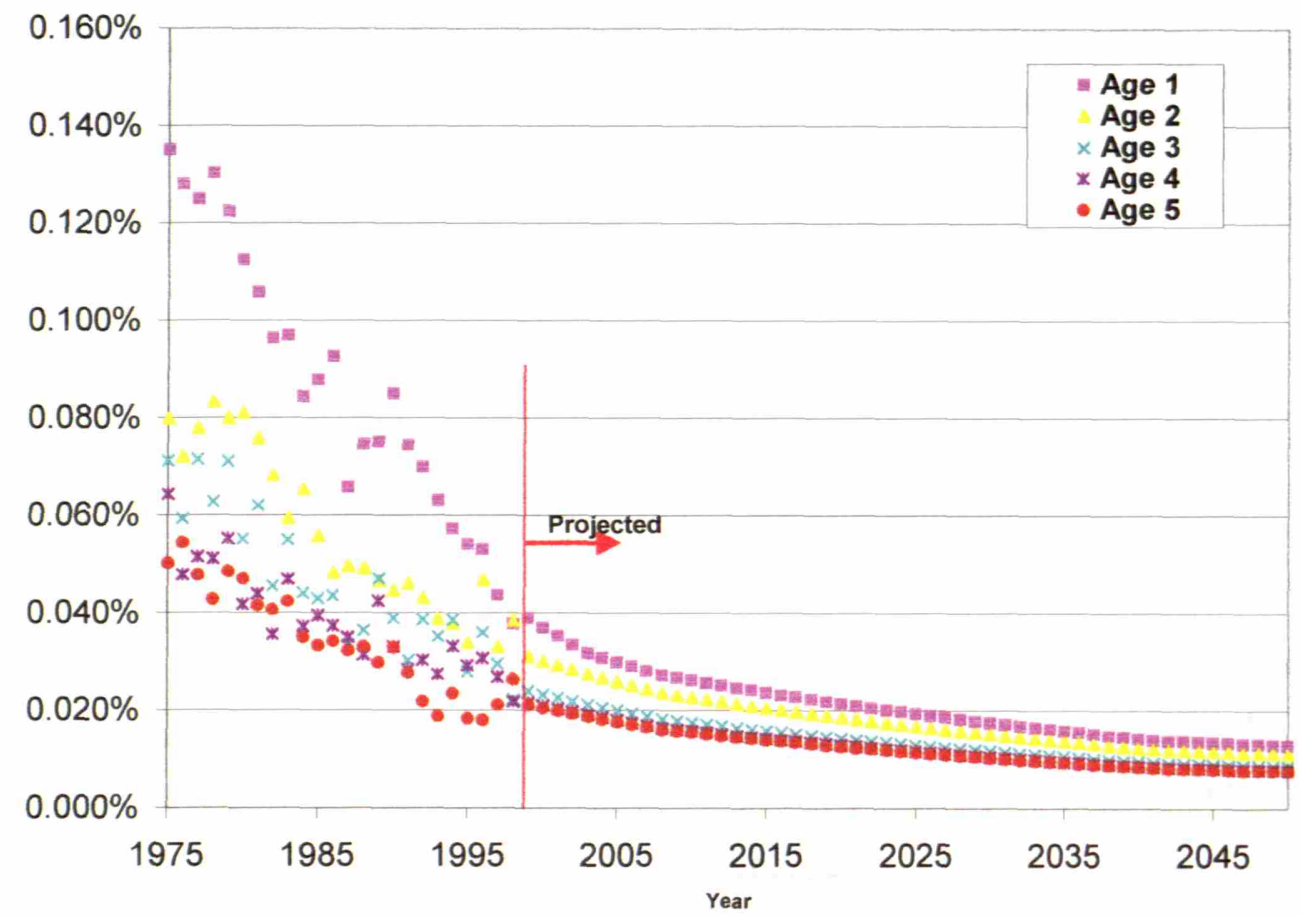

Figure A1.2. Recent trends and projections for POD in males ages 1-5 in Spain.

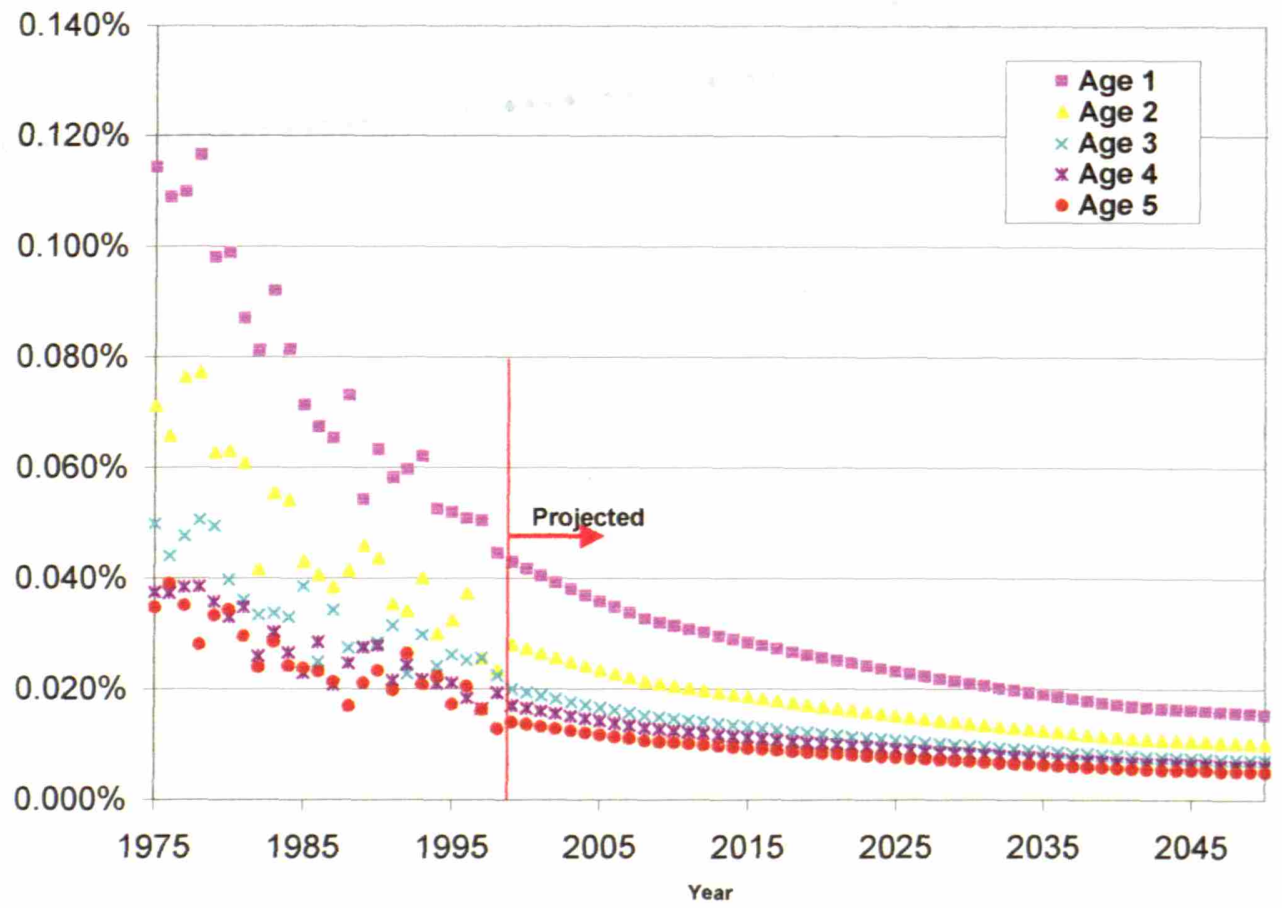

Figure A1.3. Recent trends and projections for POD in females ages 1-5 in Spain. 


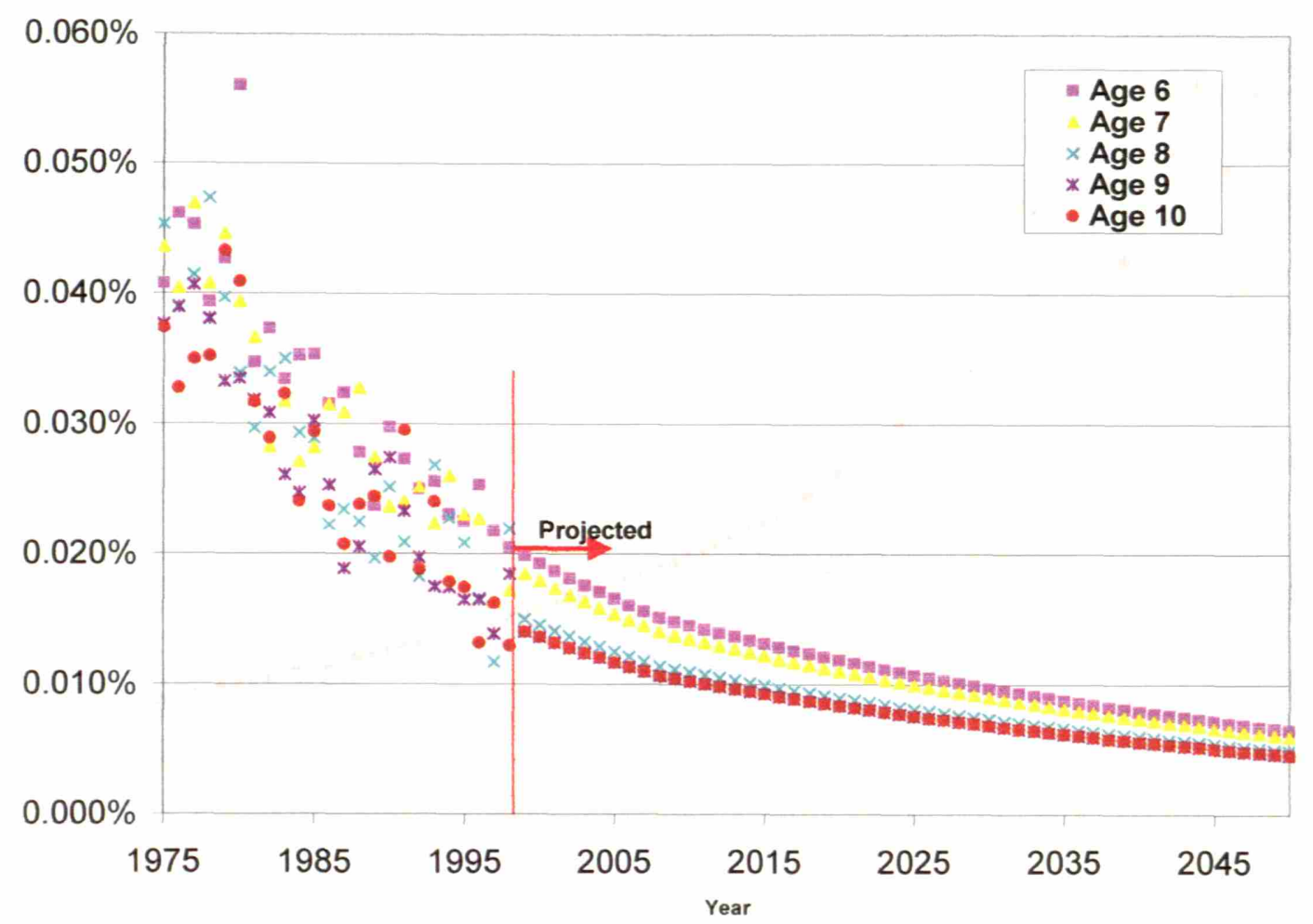

Figure A1.4. Recent trends and projections for POD in males ages 6-10 in Spain.

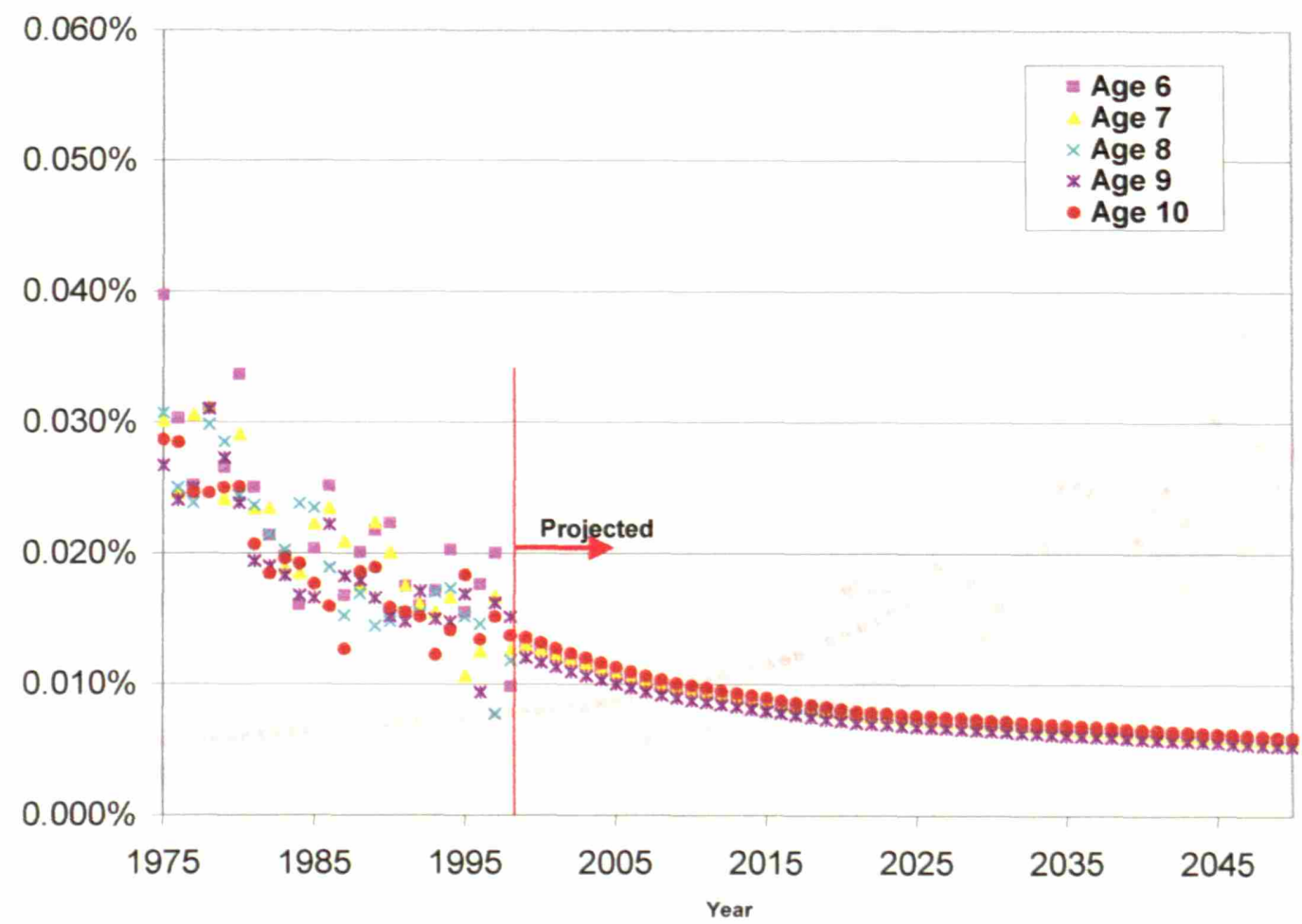

Figure A1.5. Recent trends and projections for POD in females ages 6-10 in Spain. 


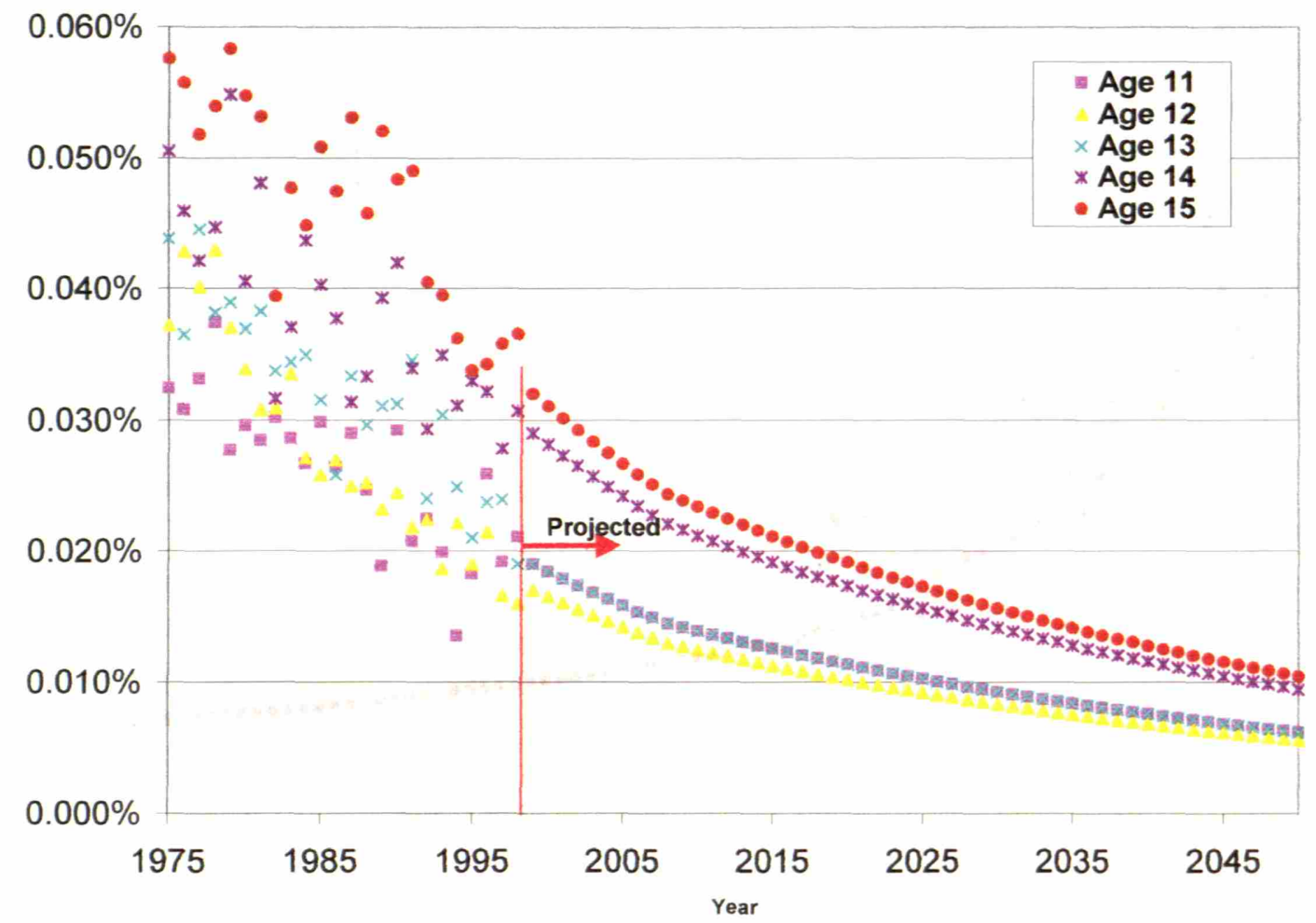

Figure A1.6. Recent trends and projections for POD in males ages 11-15 in Spain.

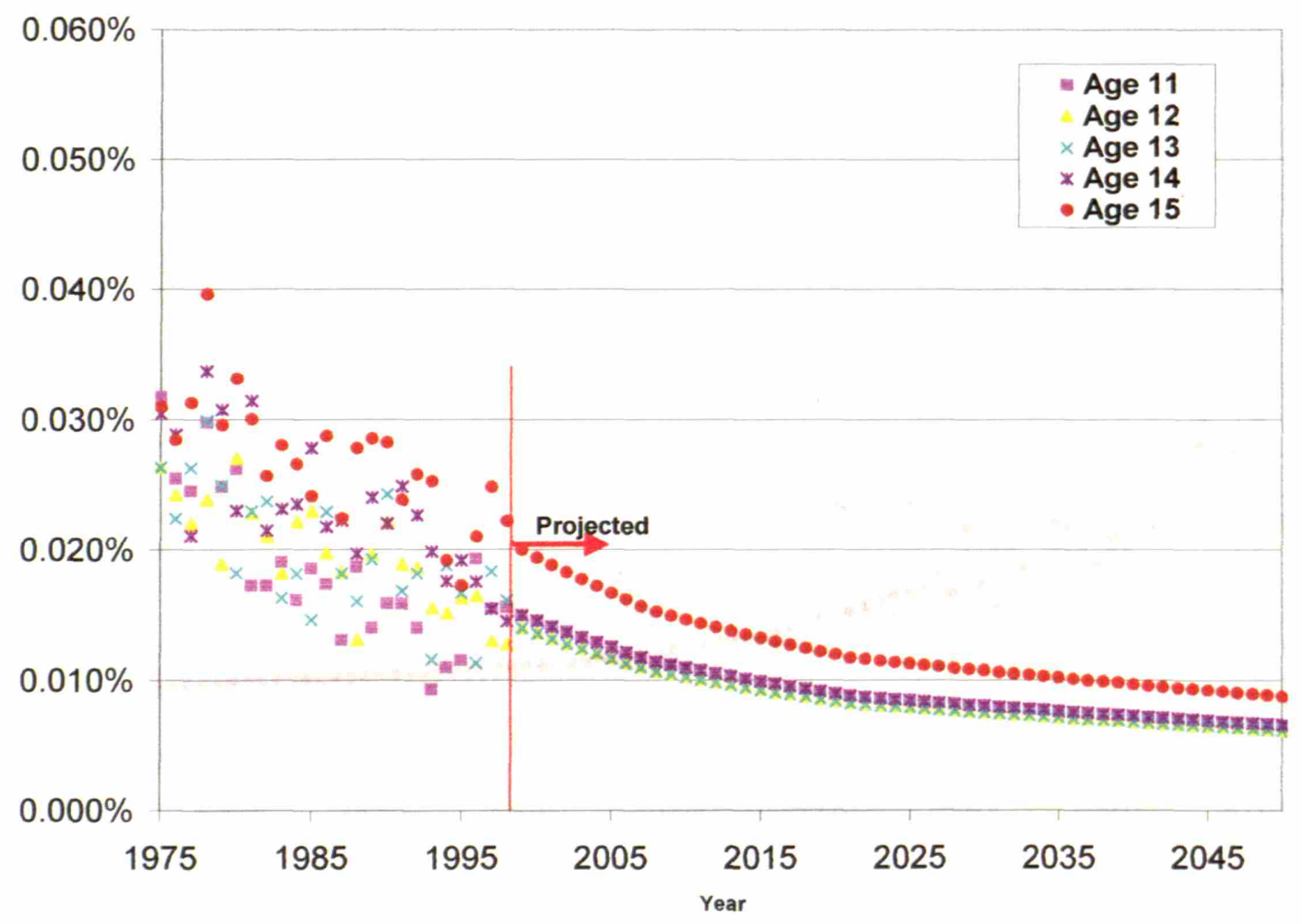

Figure A1.7. Recent trends and projections for POD in females ages 11-15 in Spain. 


\section{Ages 16-40}

This age group had seen increasing probabilities of death develop in the late $80 \mathrm{~s}$ and early 90s. These were attributed to traffic accidents, AIDS and drug addiction and affected mainly the male population. The projections moving forward call for a confirmation of the recovery in the POD suggested by the data from the late nineties. Further improvements take place up to 2050, at a higher pace for males than for females. Nevertheless, the female POD in this age range remains lower for females for the forecasted period. Figures A1.8 through A1.17 illustrate the recent trends and projections used in this analysis

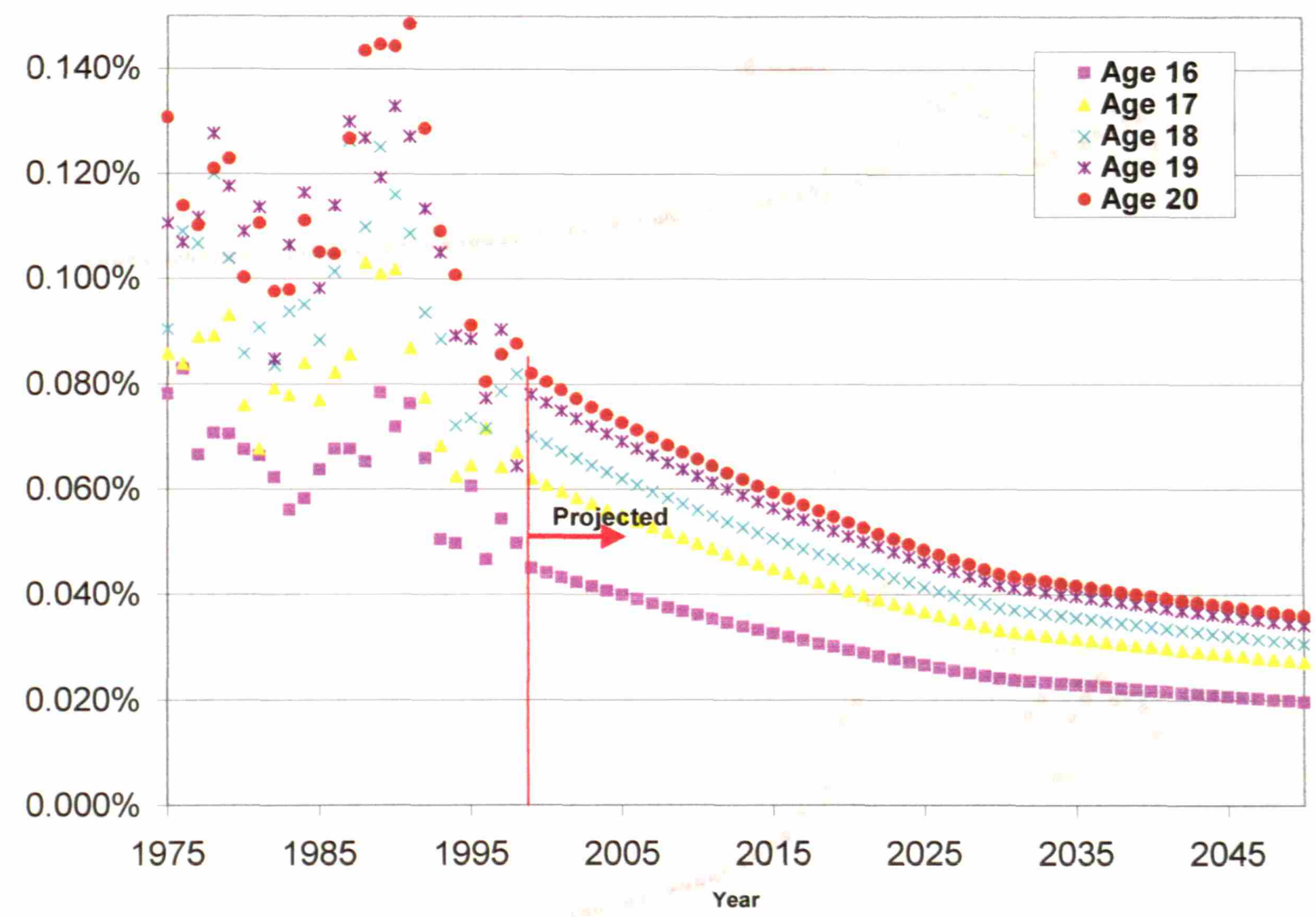

Figure A1.8. Recent trends and projections for POD in males ages 16-20 in Spain. 


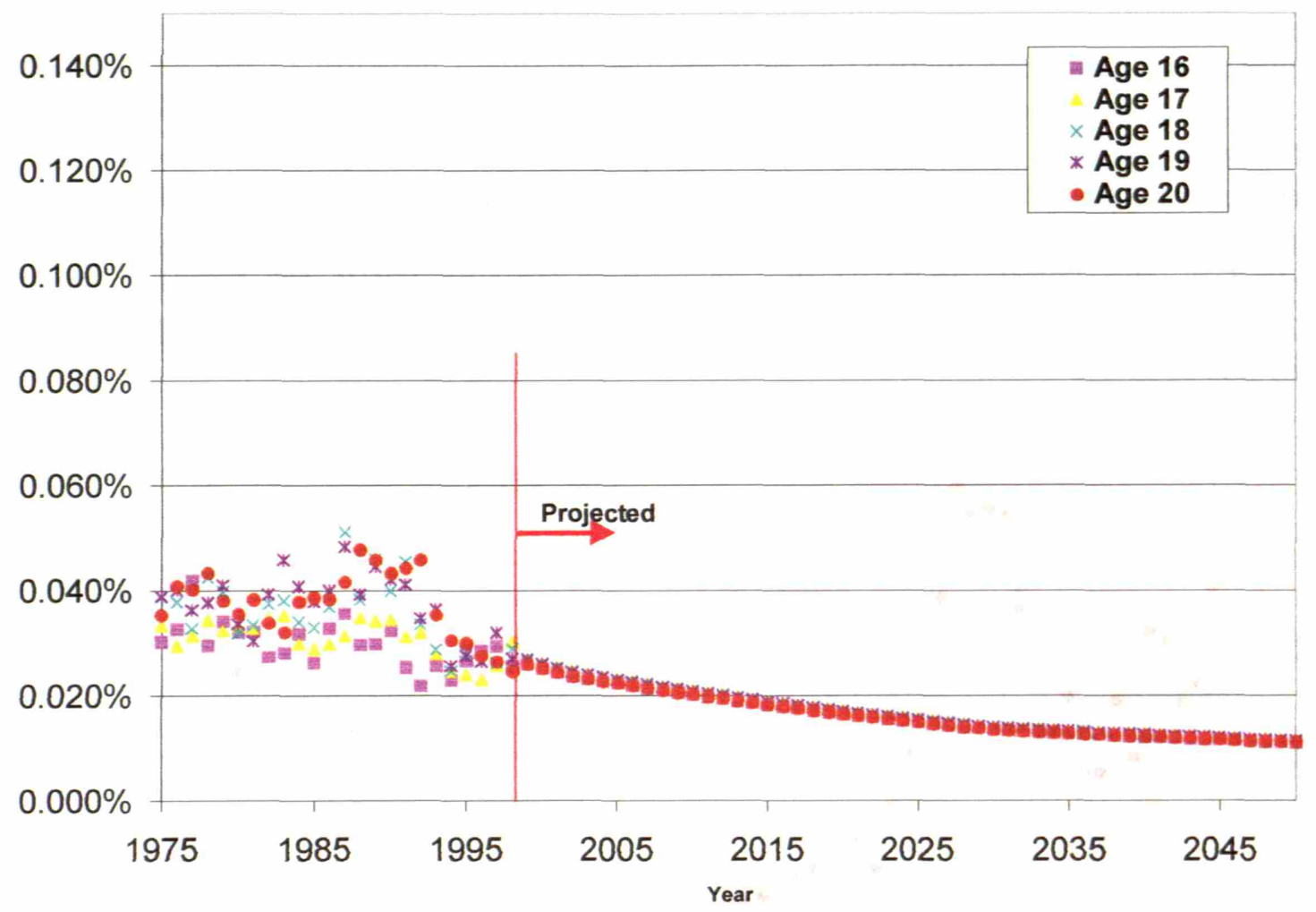

Figure A1.9. Recent trends and projections for POD in females ages 16-20 in Spain.

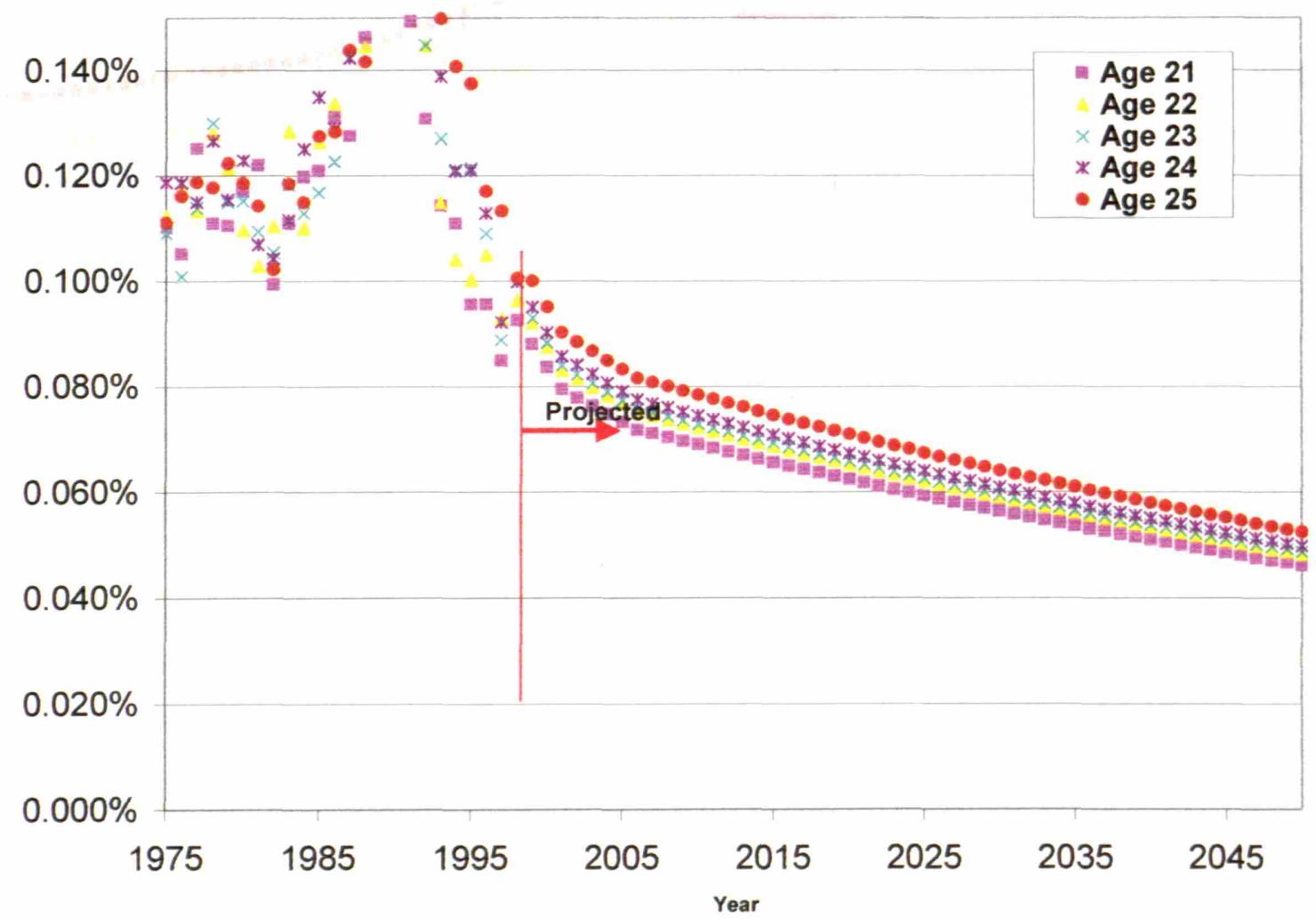

Figure A1.10. Recent trends and projections for POD in males ages 21-25. 


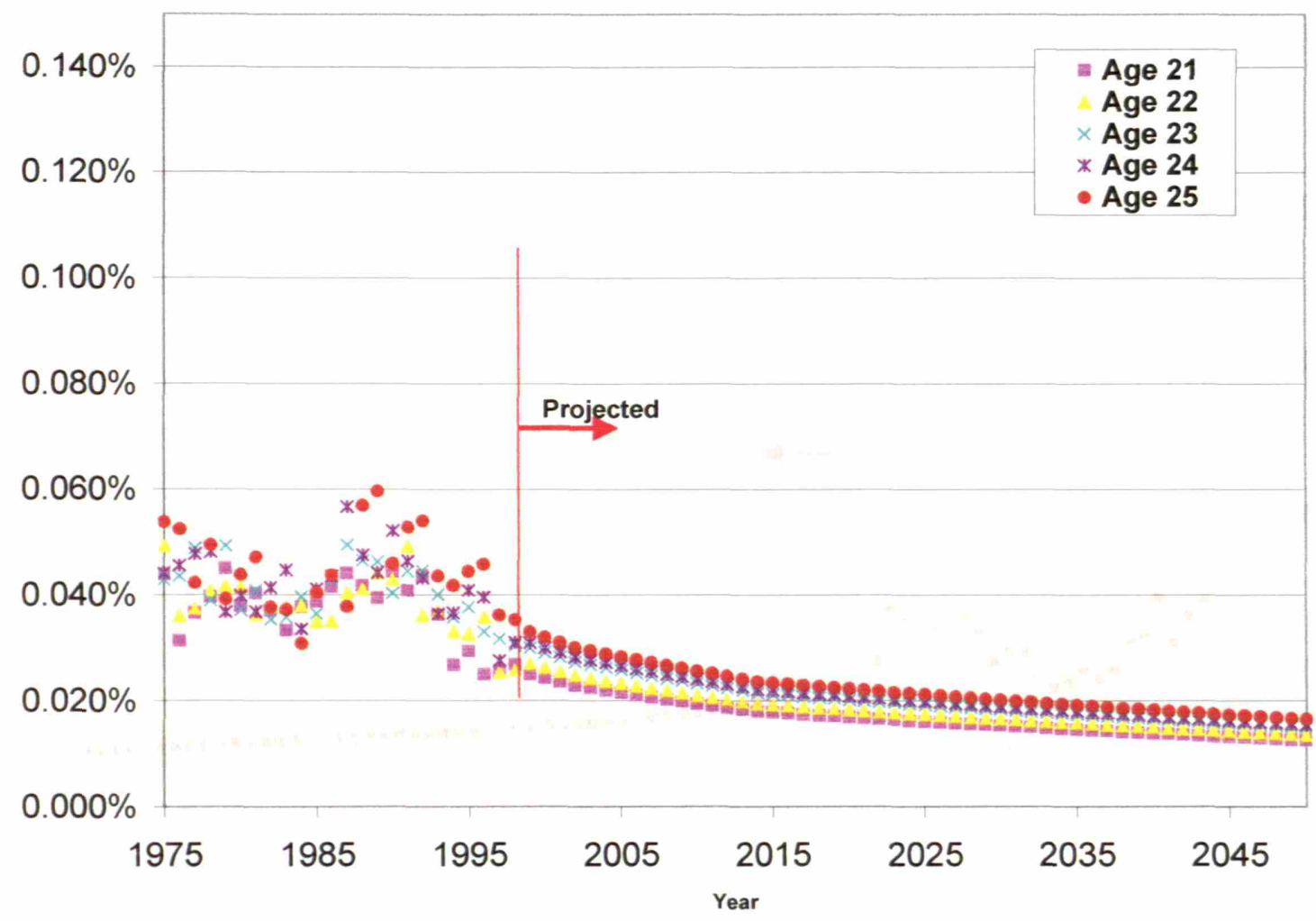

Figure A1.11. Recent trends and projections for POD in females ages 21-25 in

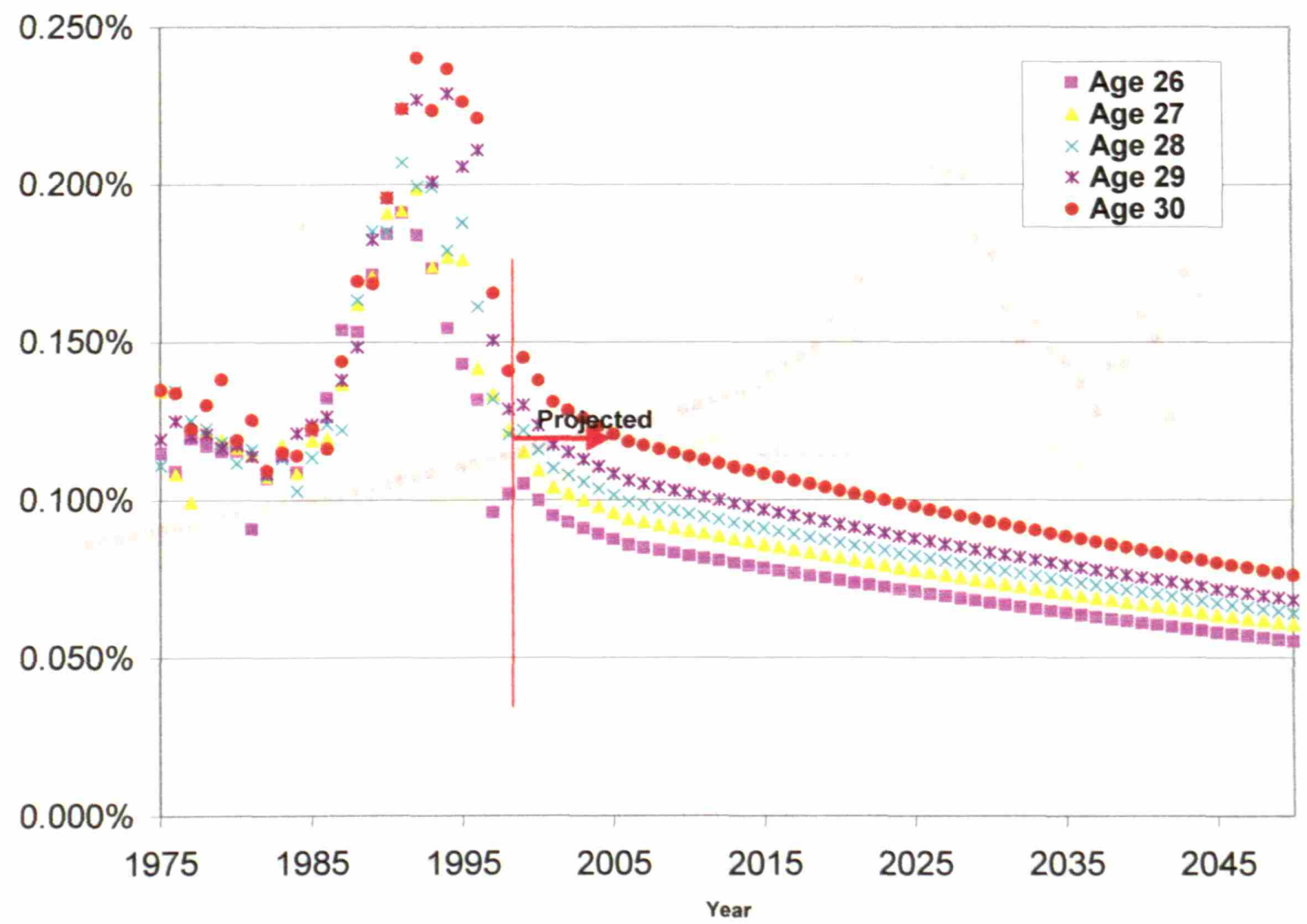

Spain.Figure A1.12. Recent trends and projections for POD in males ages 26-30. 


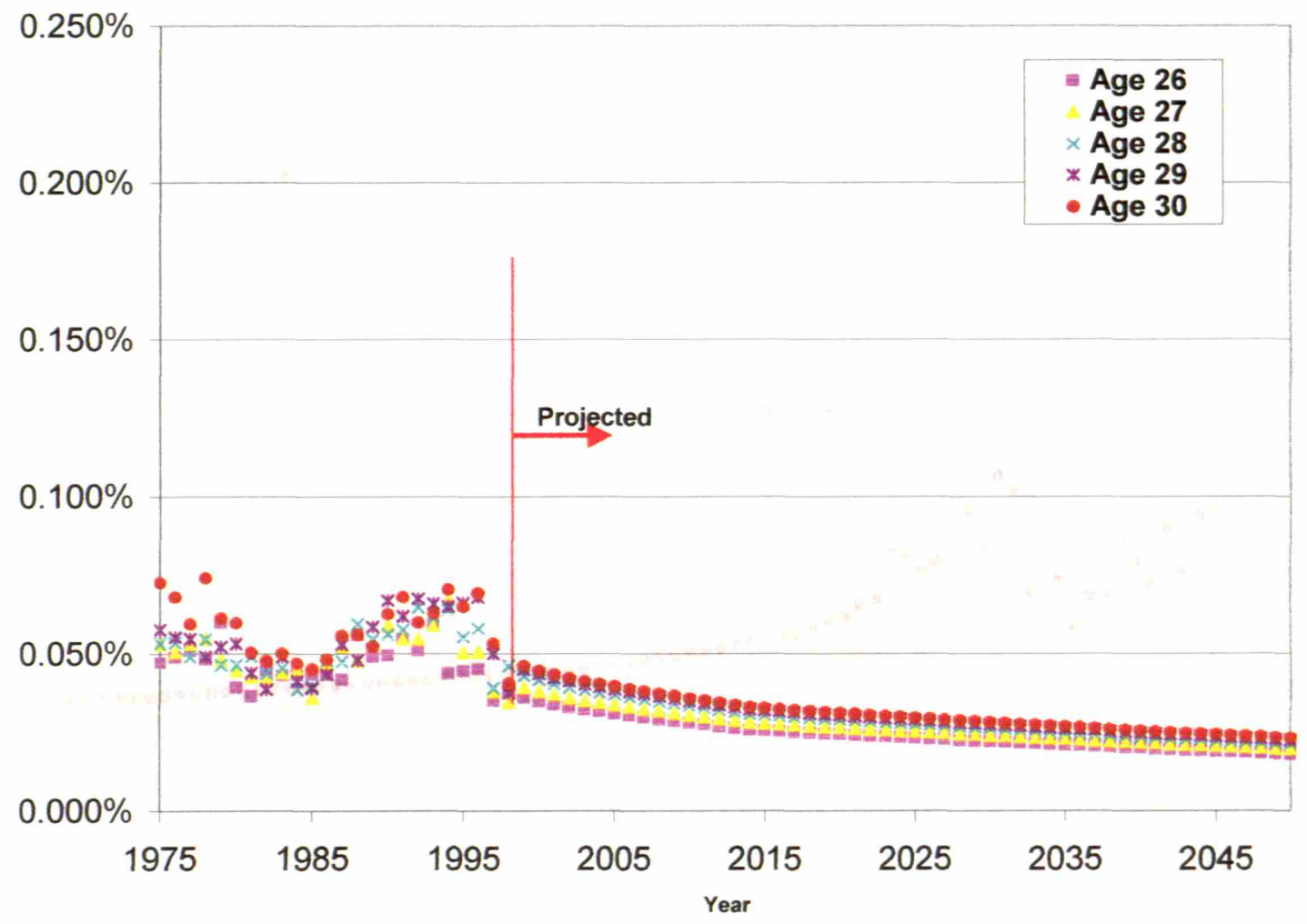

Figure A1.13. Recent trends and projections for POD in females ages 26-30 in Spain.

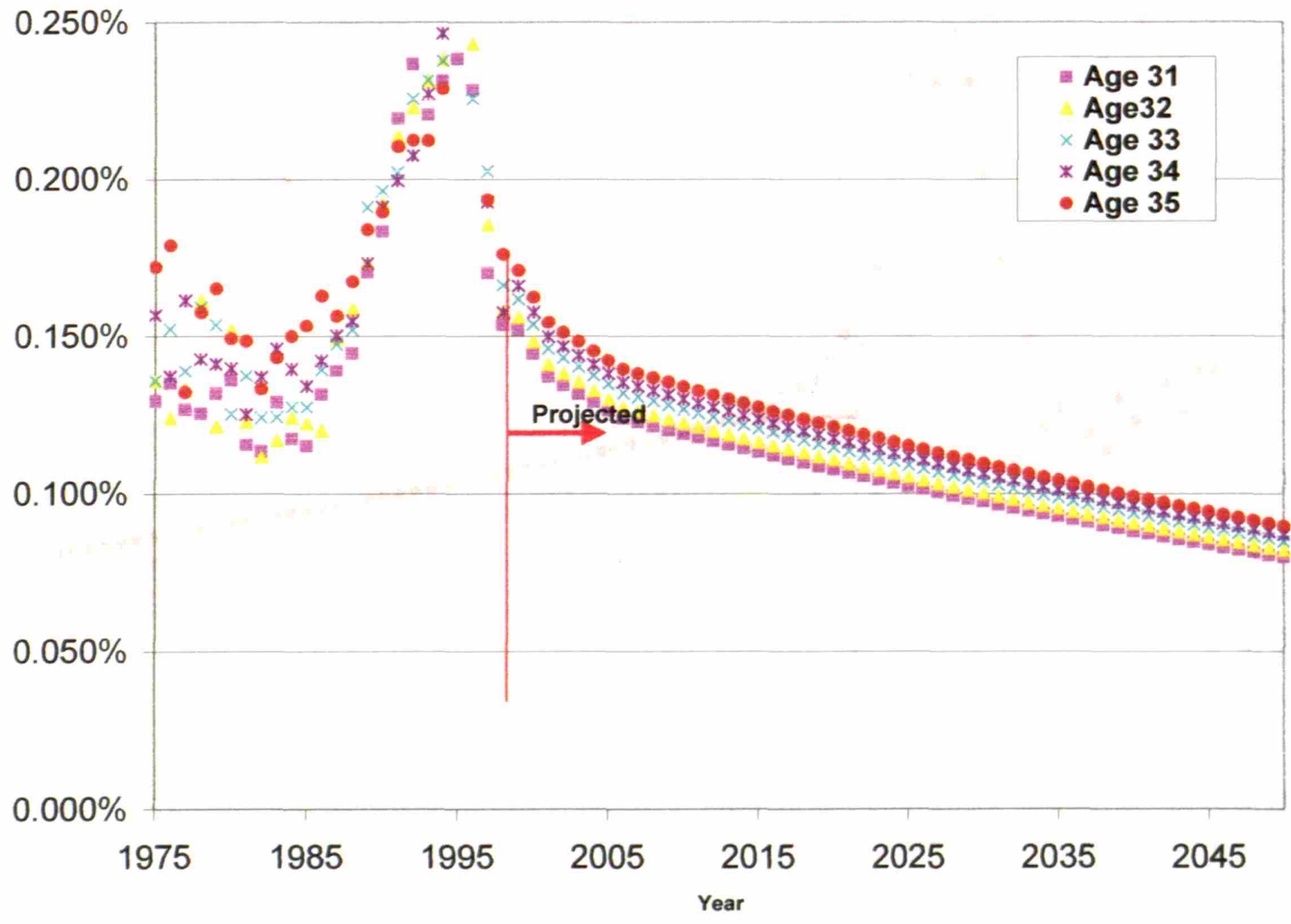

Figure A1.14. Recent trends and projections for POD in males ages 31-35 in Spain. 


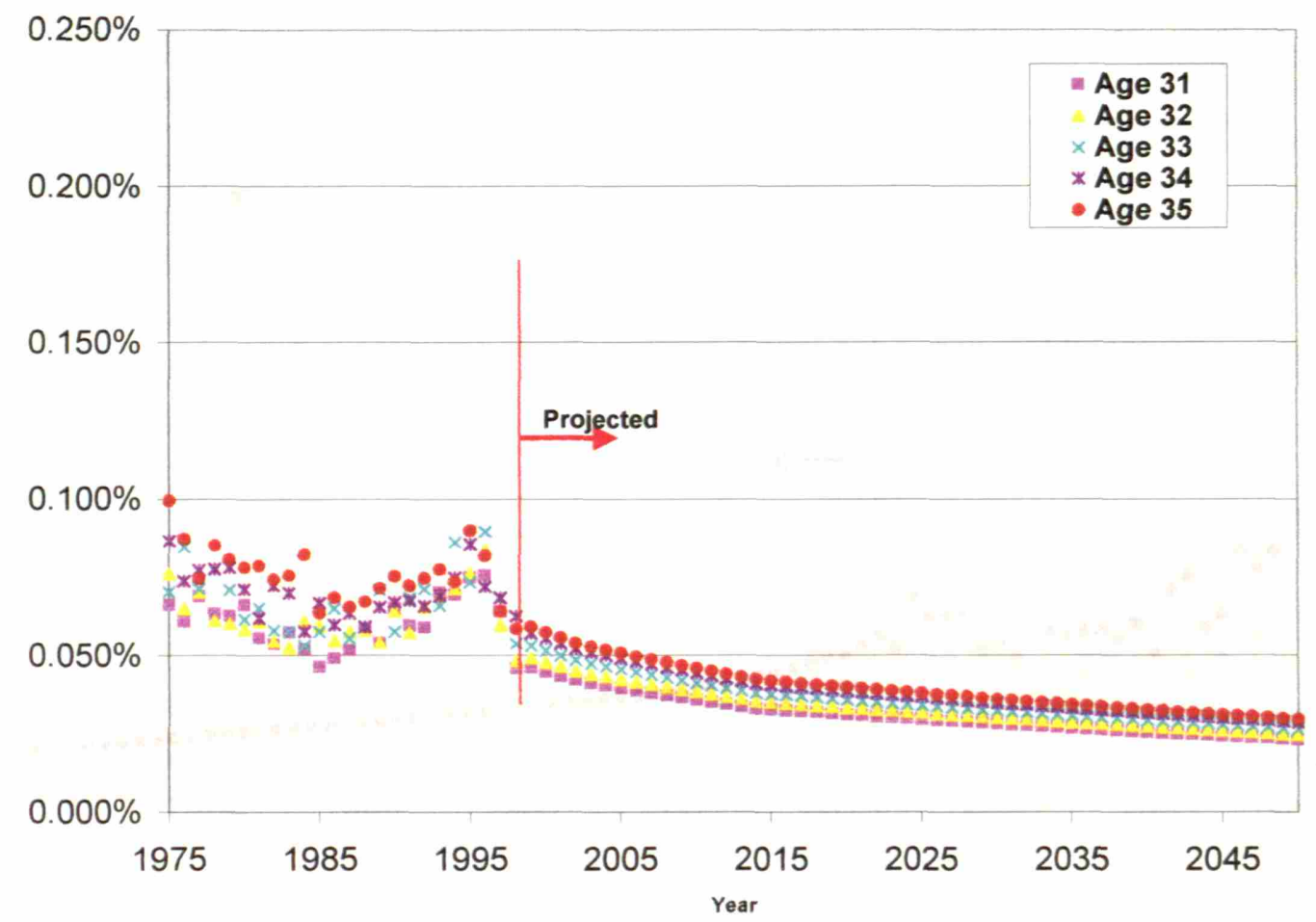

Figure A1.15. Recent trends and projections for POD in females ages 31-35 in Spain.

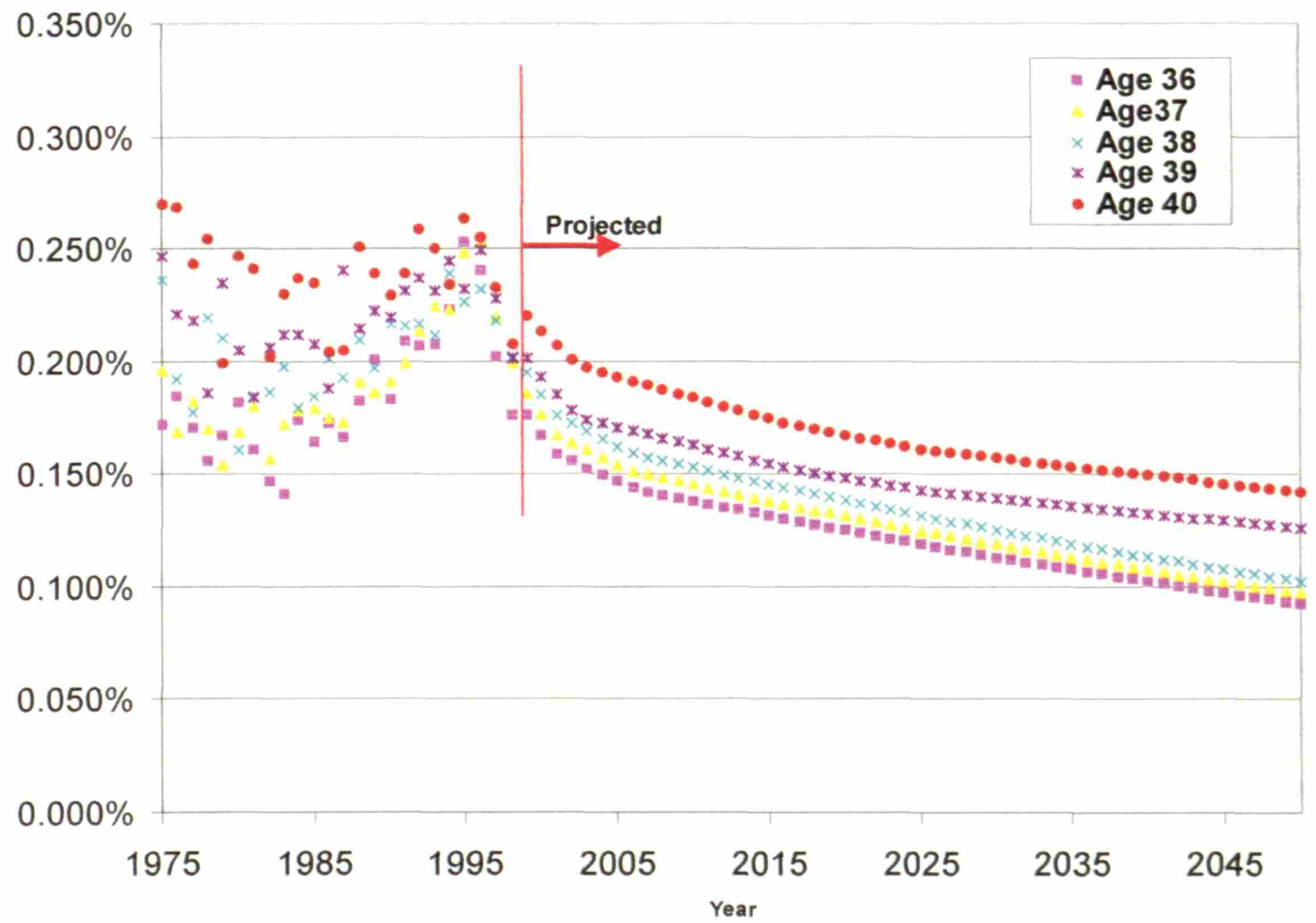

Figure A1.16. Recent trends and projections for POD in males ages 36-40 in Spain. 


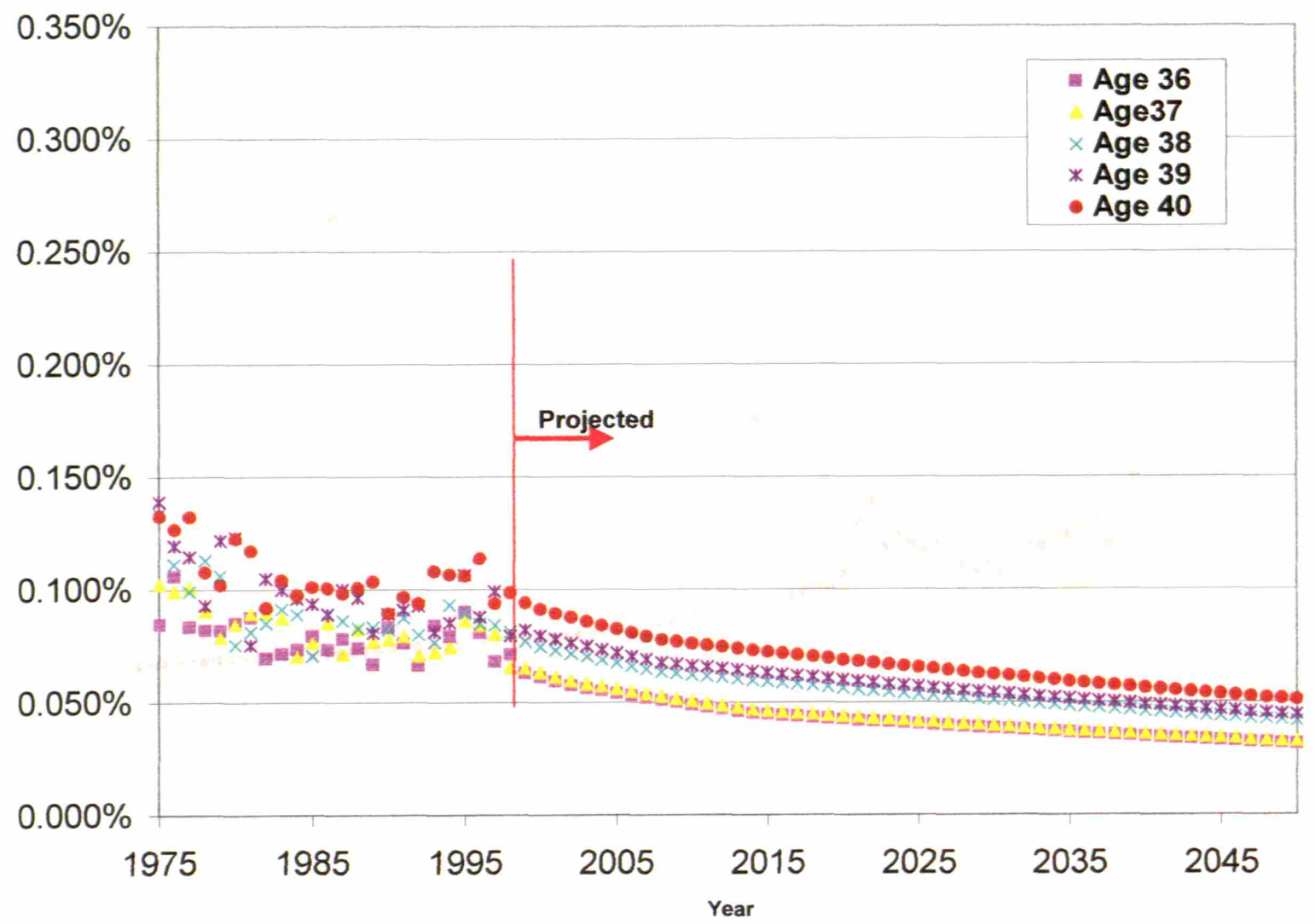

Figure A1.17. Recent trends and projections for POD in females ages 36-40 in Spain.

\section{Ages 41-90}

For this age group the probabilities of death were projected forward assuming there would be a continuing improvement albeit at a slowing pace relative to the recent past. Figures A1.18 through A1.21 illustrate the recent trends and projections used in this analysis 


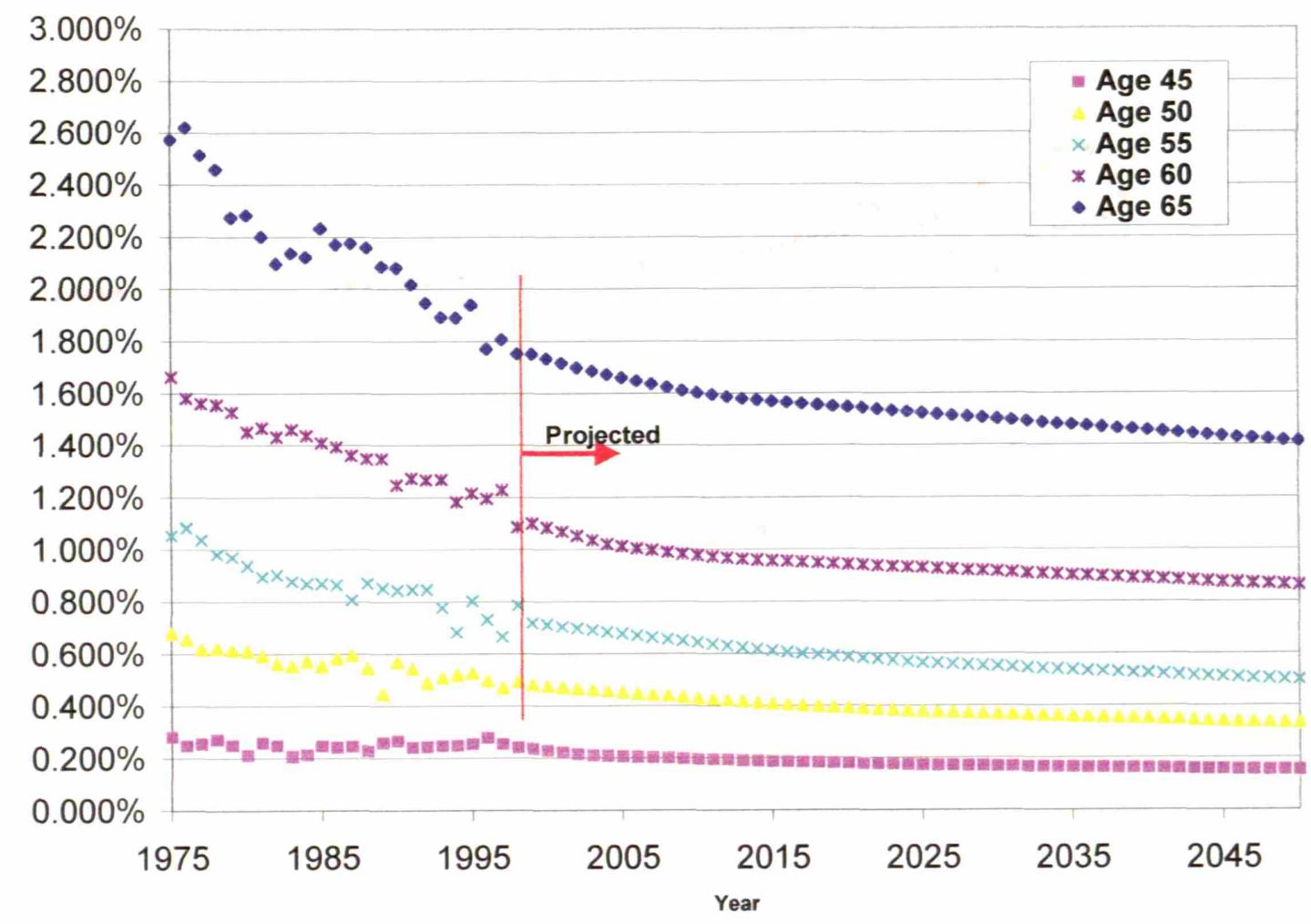

Figure A1.18. Recent trends and projections for POD in males ages 45-65 in Spain.

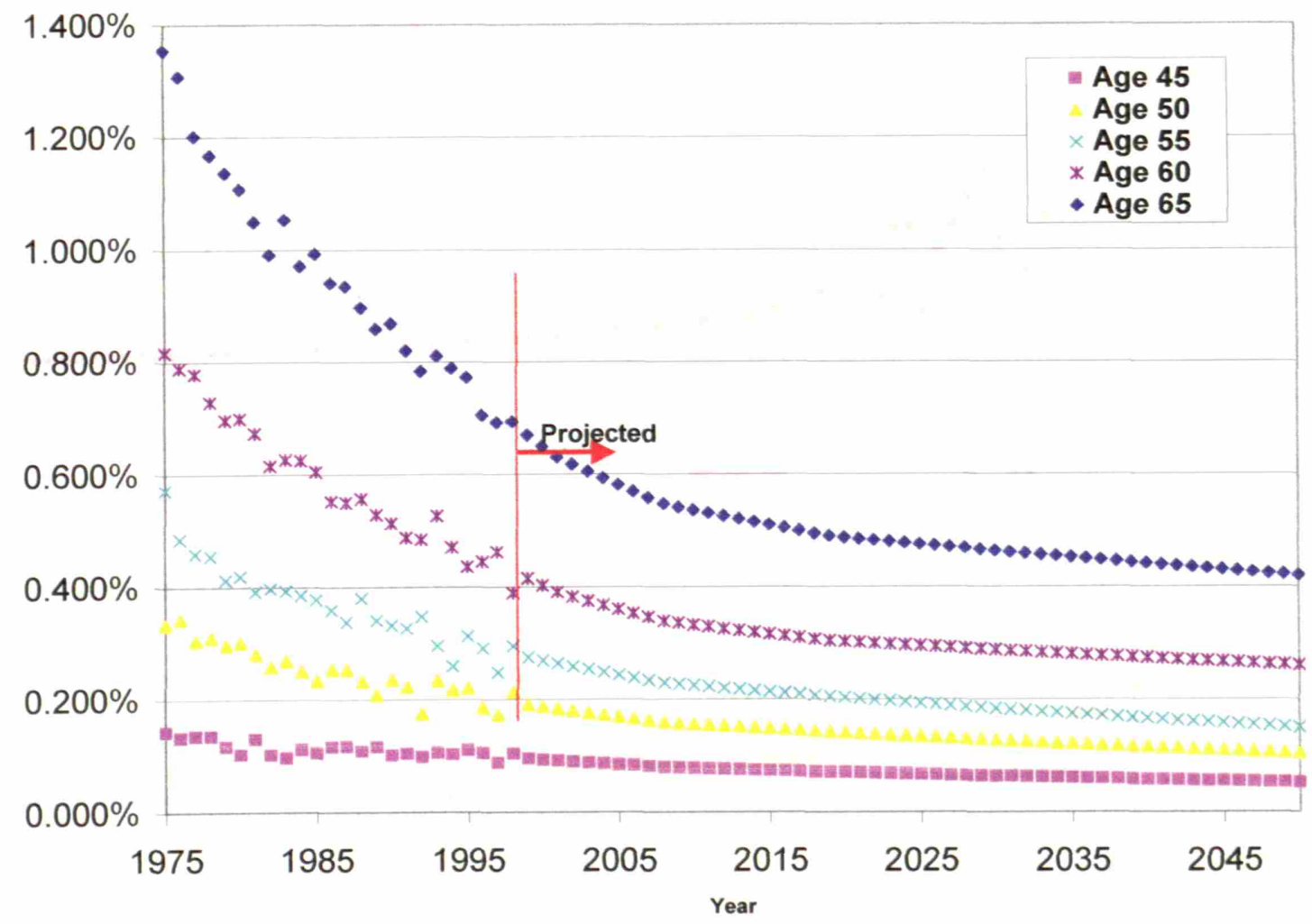

Figure A1.19. Recent trends and projections for POD in females ages 45-65 in Spain. 


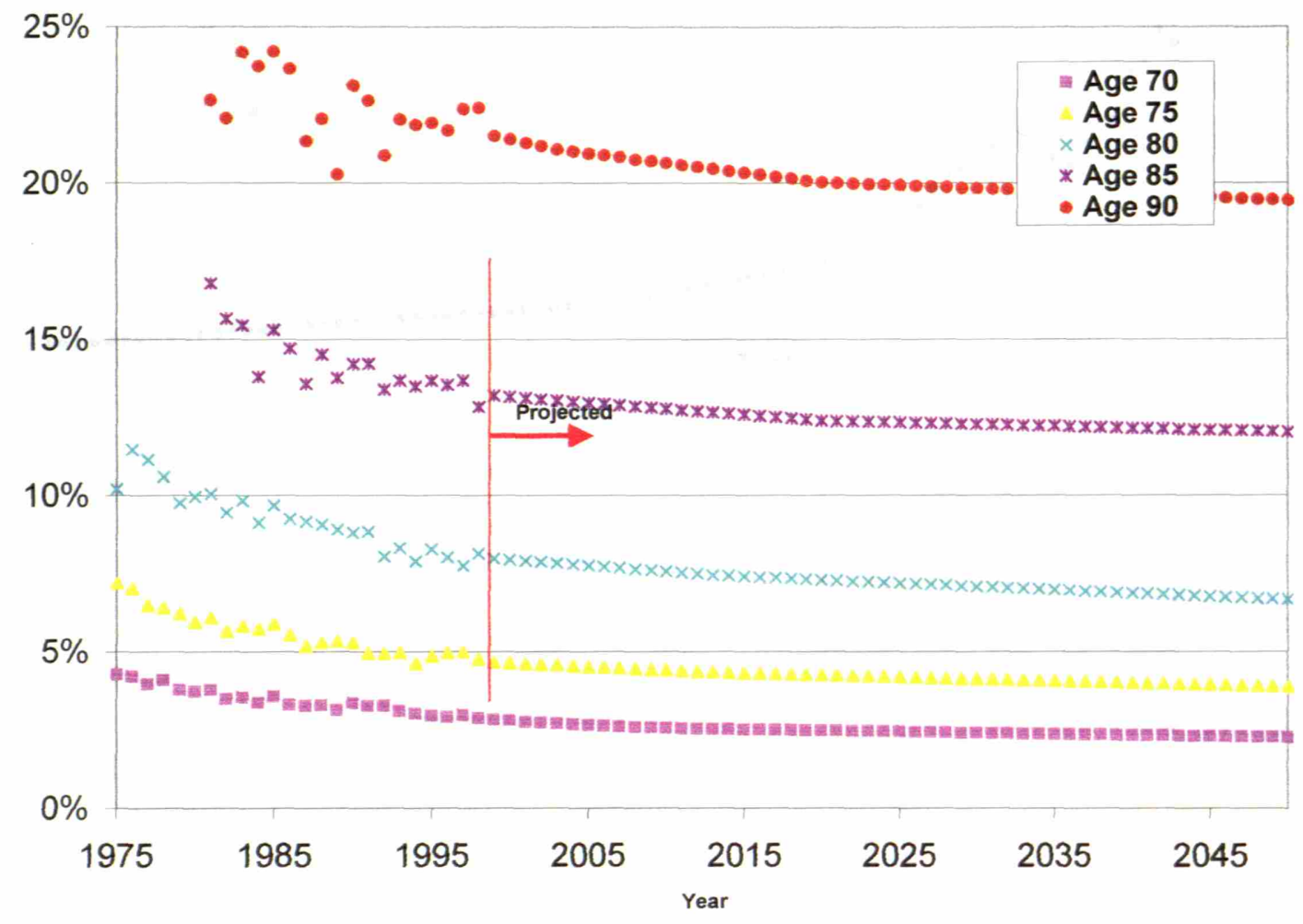

Figure A1.20. Recent trends and projections for POD in males ages 70-90 in Spain.

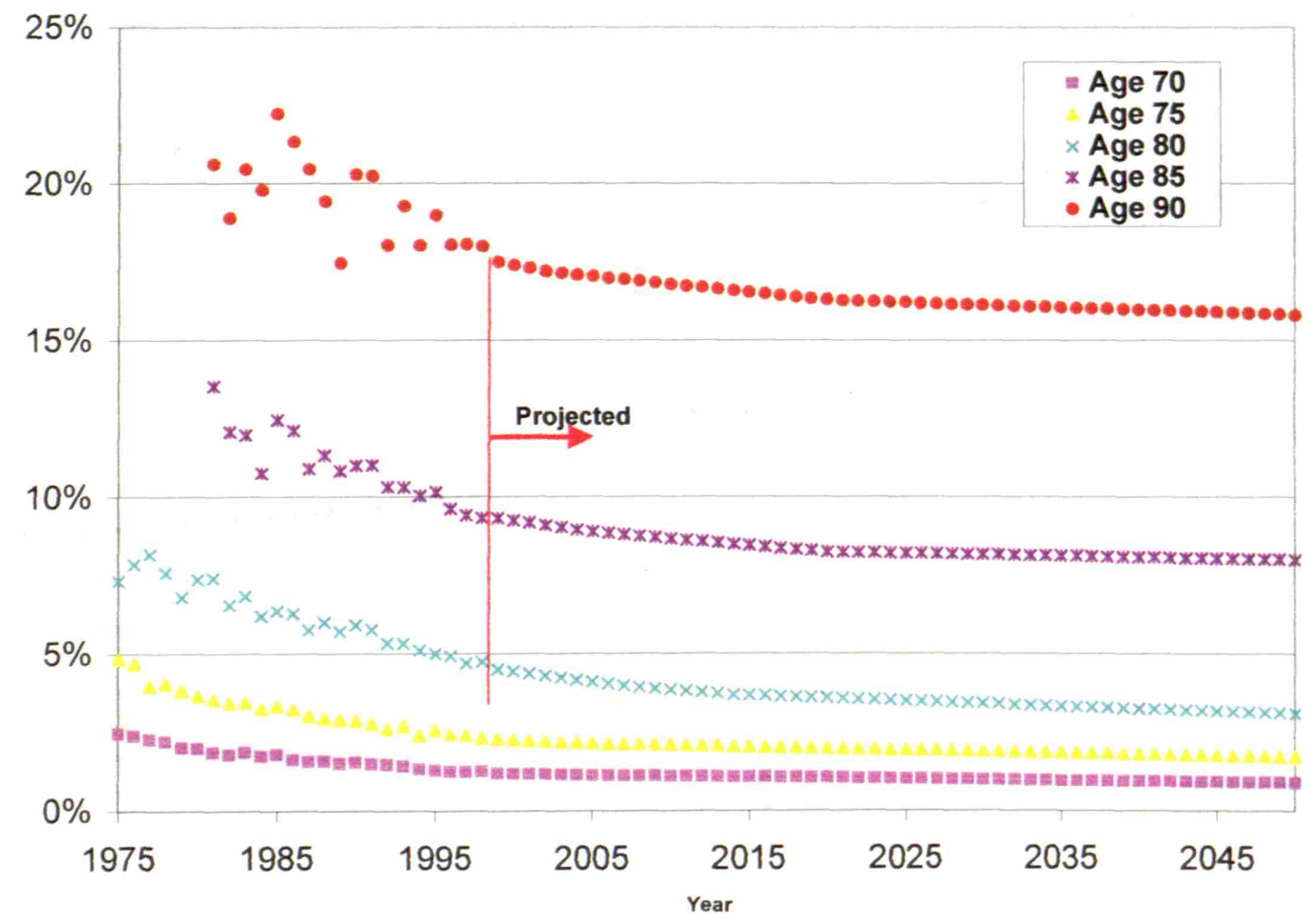

Figure A1.21. Recent trends and projections for POD in females ages 70-90 in Spain. 


\section{Ages 90 and over.}

The data of POD for this age group showed less clear trends. For males, the data showed a slight increasing trend. In these cases, the POD was projected to continue increasing in the short run, but to stabilize and start decreasing farther out in the future, as medical sciences will tend to extend the life span of this older group. Were the data showed improving POD, the probabilities of death were projected forward assuming there would be a continuing improvement albeit at a slowing pace.

Figures A1.22 and A1.23 shows some data and projections for this age group.

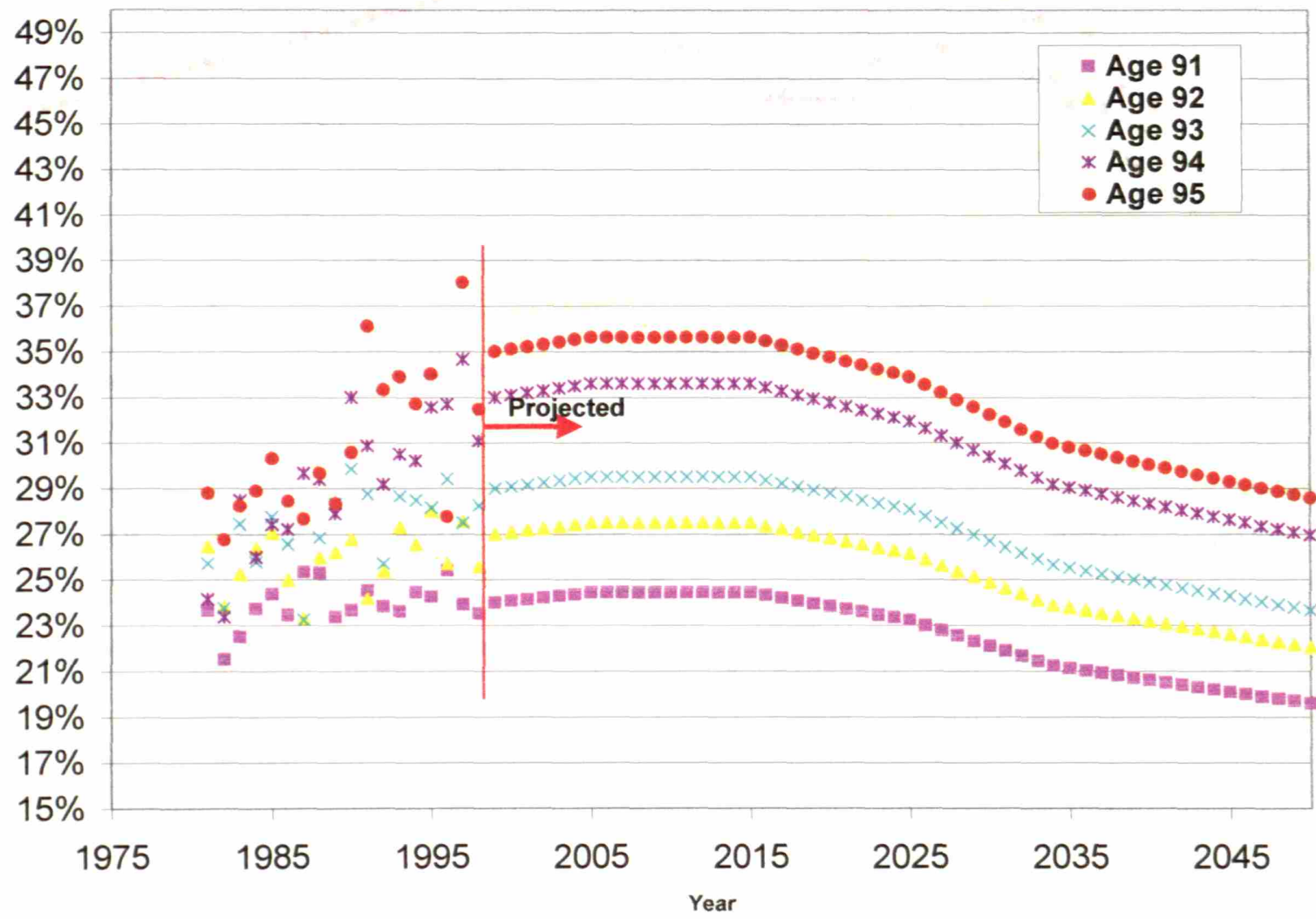

Figure A1.22. Recent trends and projections for POD in males above 90 in Spain. 


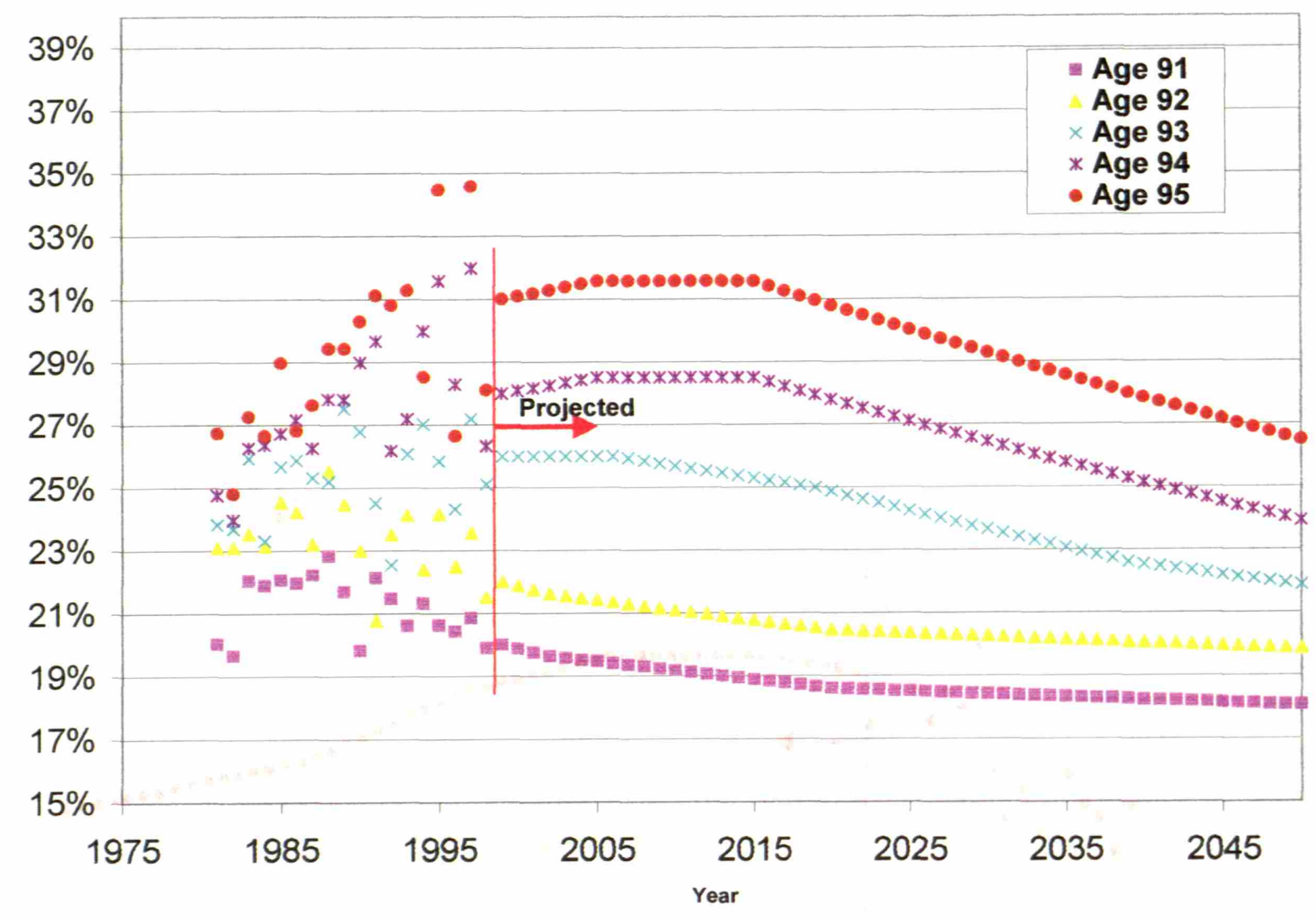

Figure A1.23. Recent trends and projections for POD in females above 90 in Spain. 
Appendix 2. Fertility Projections 


\section{Appendix 2. Fertility projections.}

The projections of future fertility rates for Spanish women at each age were carried out by extrapolating existing data taking into consideration recent trends, past behavior in some other European countries and some social trends.

This appendix summarizes this process for the baseline projection.

Figures A2.1 through A2.7 show the recent trends and baseline projections for each fertile age.

The general guidelines followed were:

f) Teenage fertility rates, as well as fertility rates for women 42 and older have shown a clear decrease in the recent past and are projected to continue at their current low levels. Better education and contraceptive methods, will help move pregnancies away from ages that are either socially (teenagers) or health-wise undesirable.

g) Fertility rates for women 23 to 30 had been steadily declining in recent years. The projection moving forward is that these rates will see a recovery in the decade of 2000-2010 as a result of the better economic and labor conditions. This recovery is more significant for the older segment in this group.

h) The fertility rates for women 31 to 41 had increased in the nineties. The projection moving forward is that this trend will continue for the next decade.

i) Beyond 2020, the rates are assumed constant.

j) The net effect is that the average motherhood age is projected to remain between 30 and 31 for the complete period.

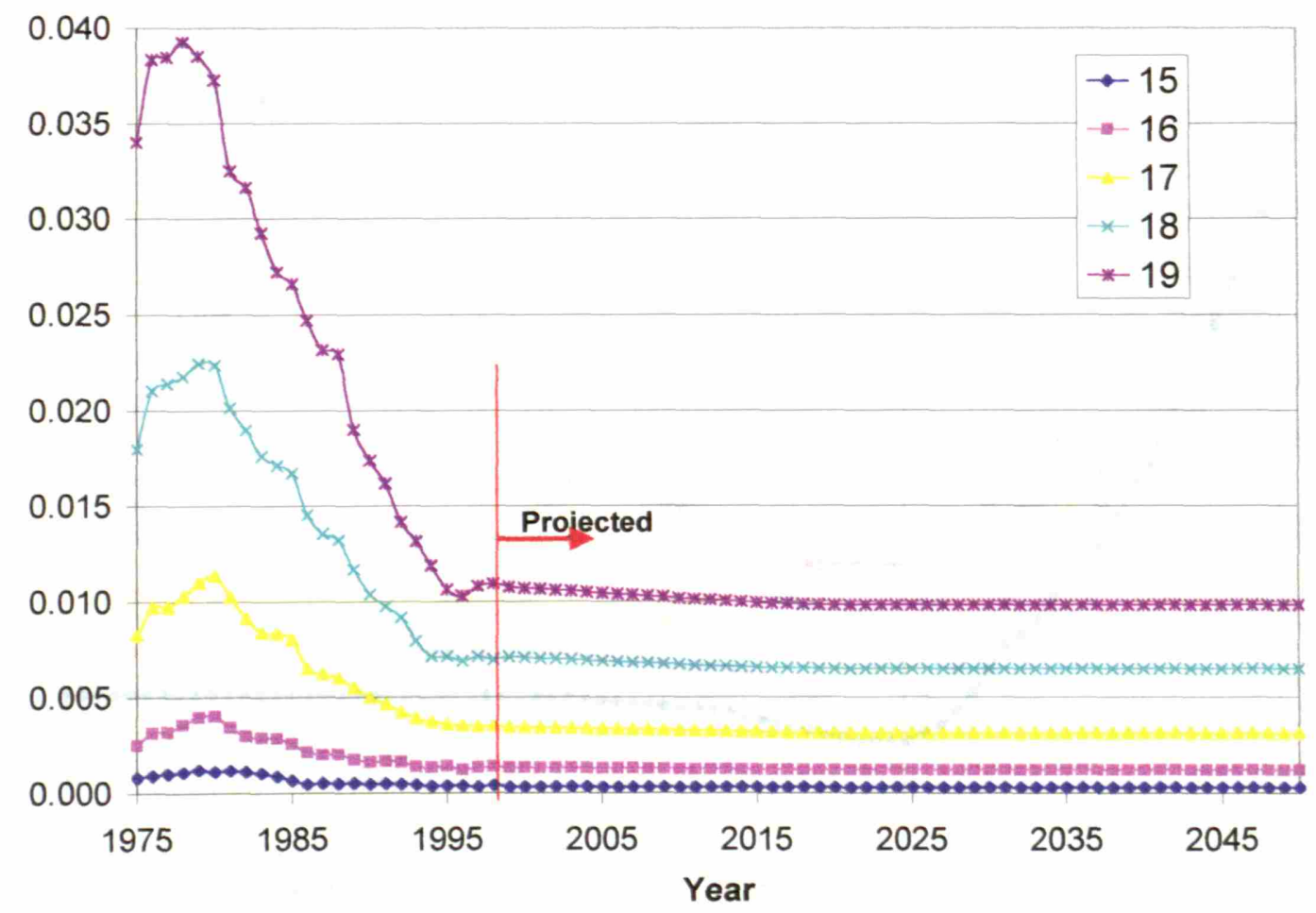

Figure A2.1. Recent trends and projections for fertility rates in women 15-19. 


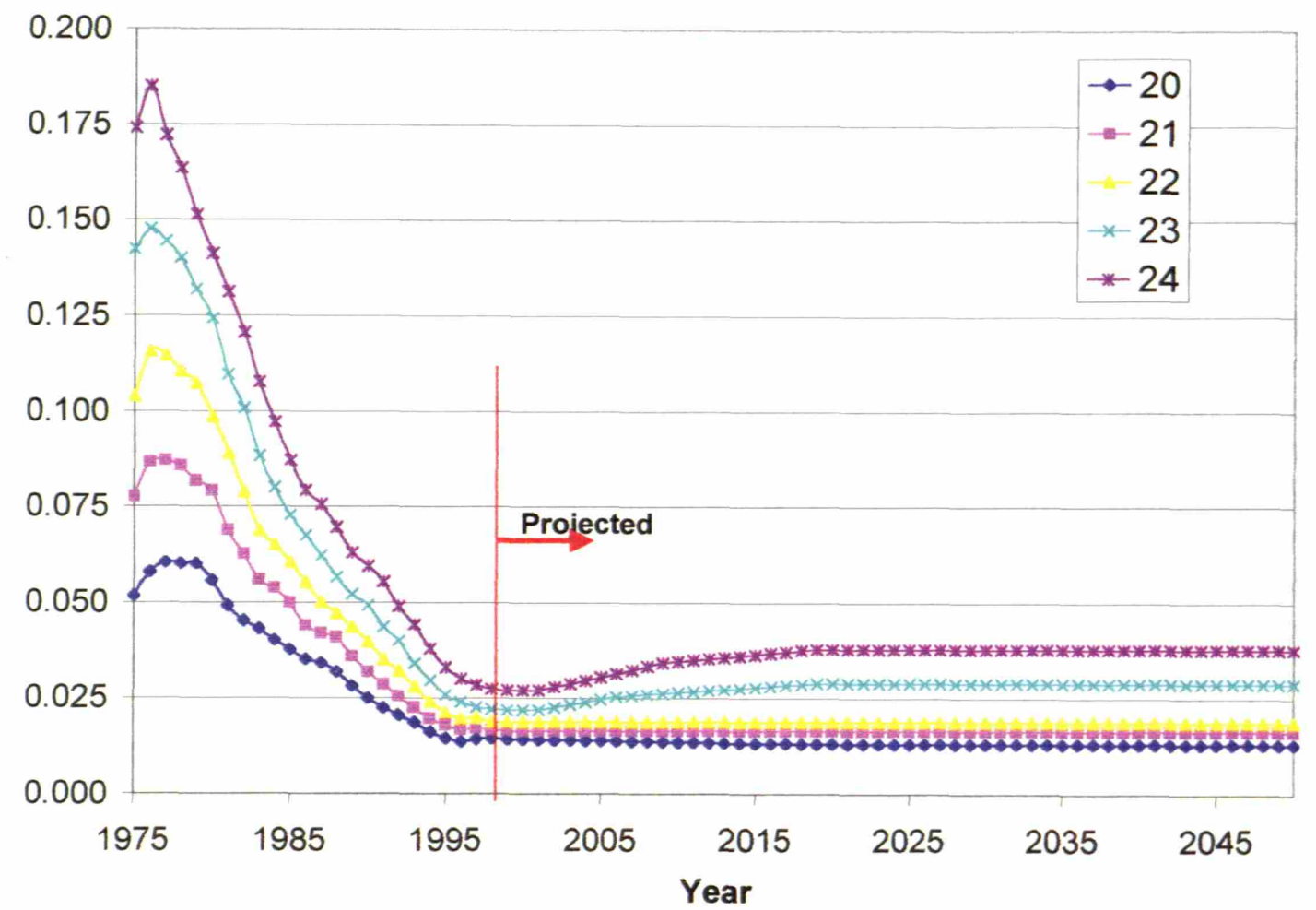

Figure A2.2. Recent trends and projections for fertility rates in women 20-24.

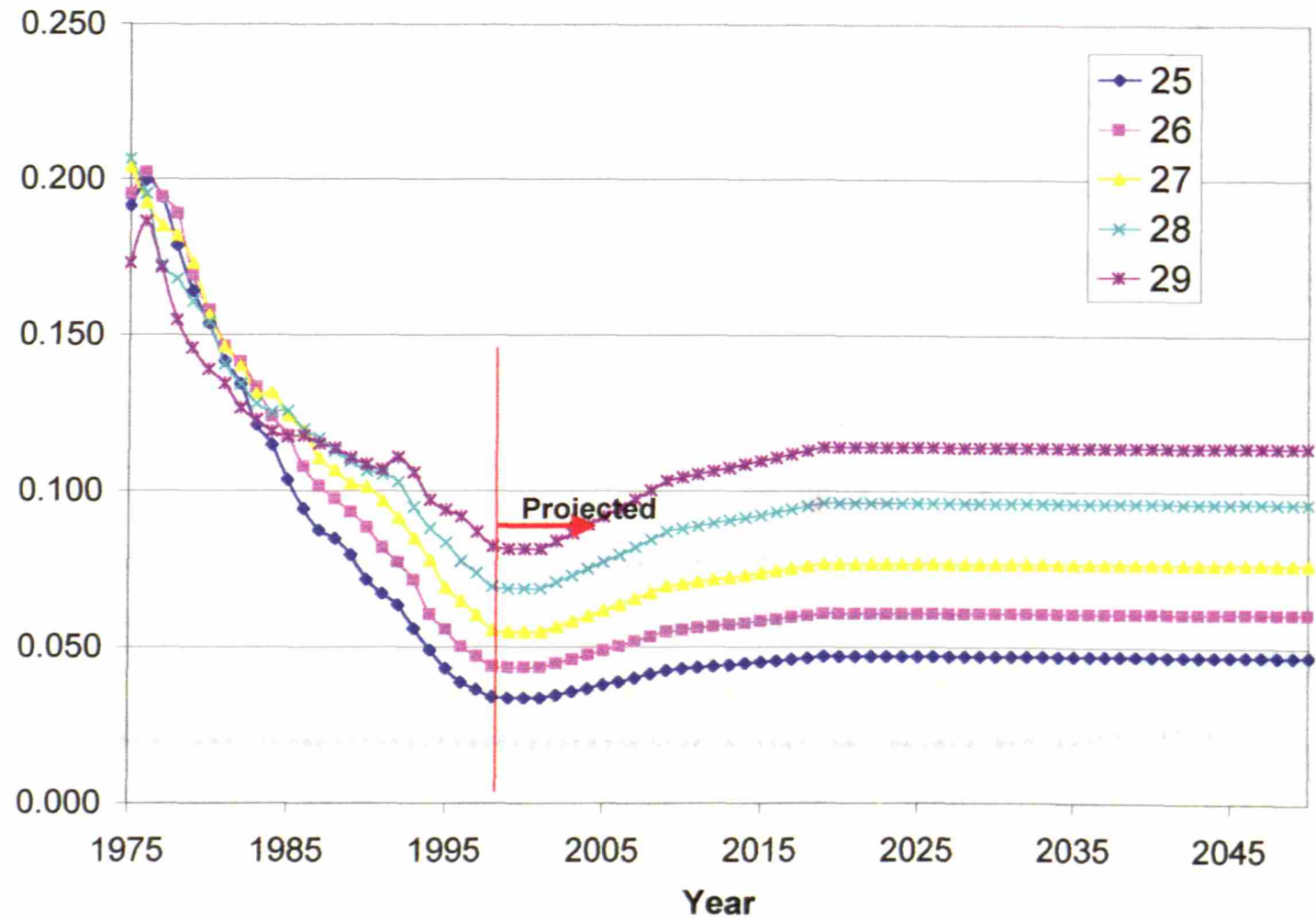

Figure A2.3. Recent trends and projections for fertility rates in women 25-29. 


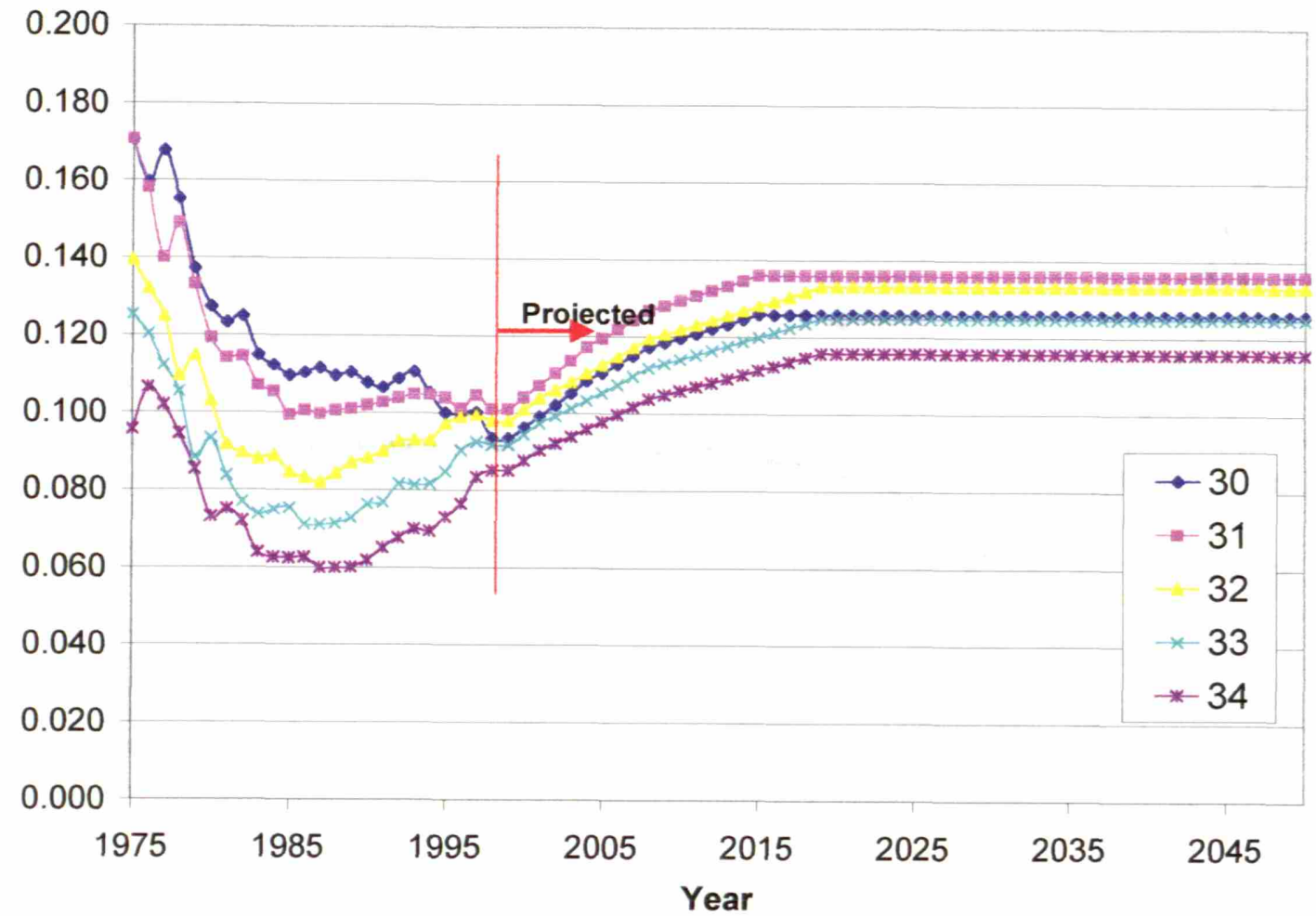

Figure A2.4. Recent trends and projections for fertility rates in women 30-34.

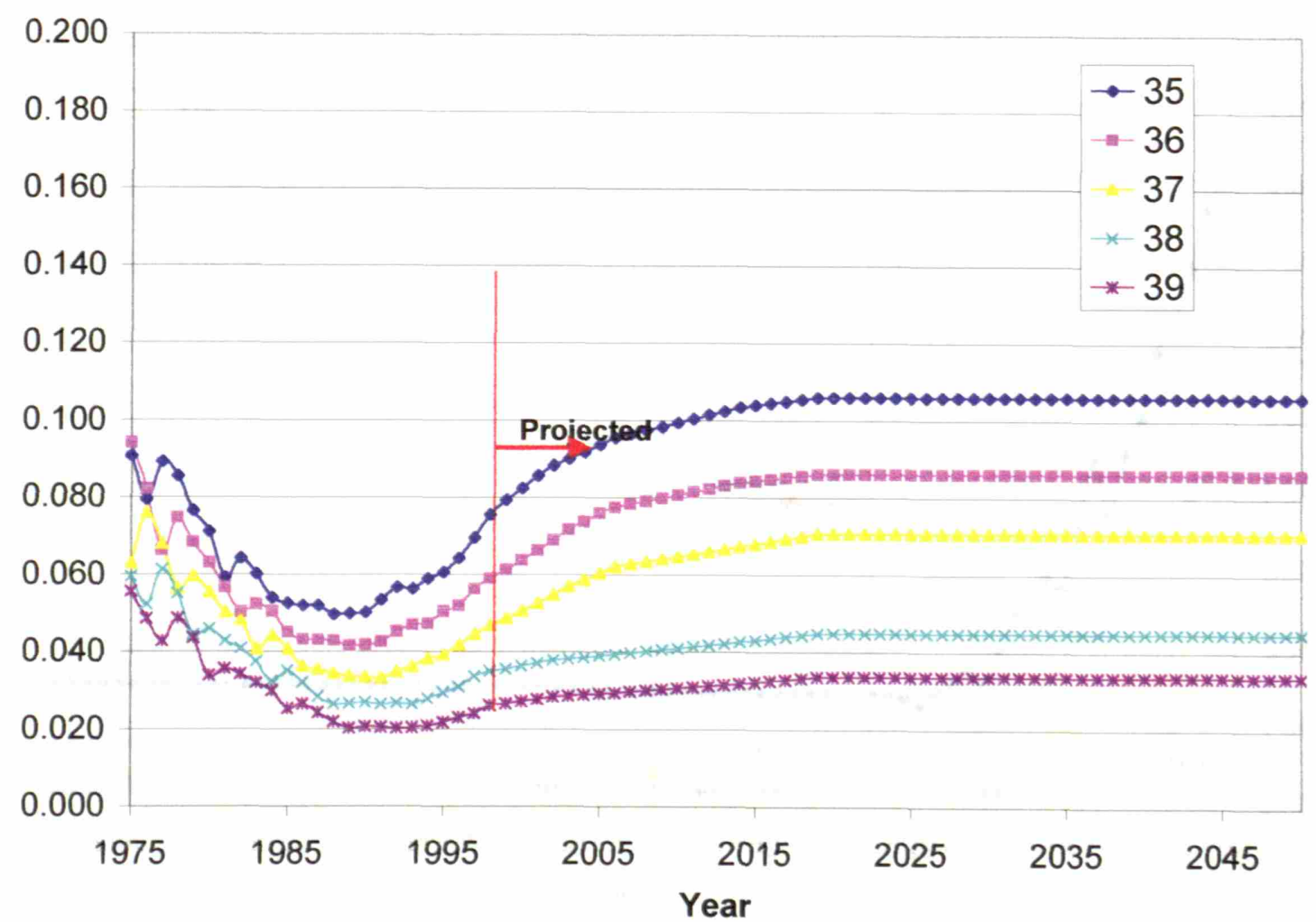

Figure A2.5. Recent trends and projections for fertility rates in women 35-39. 


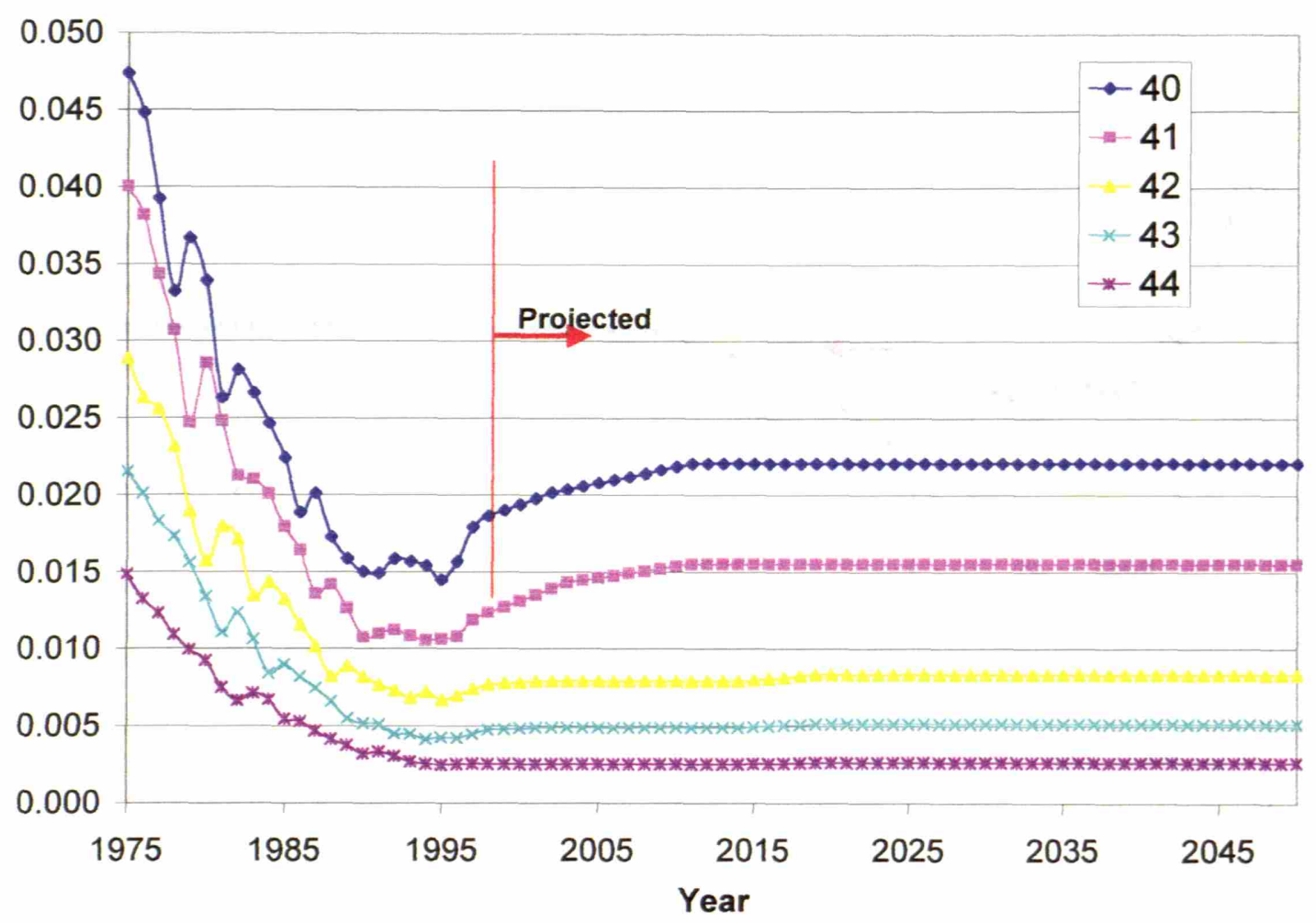

Figure A2.6. Recent trends and projections for fertility rates in women 40-44.

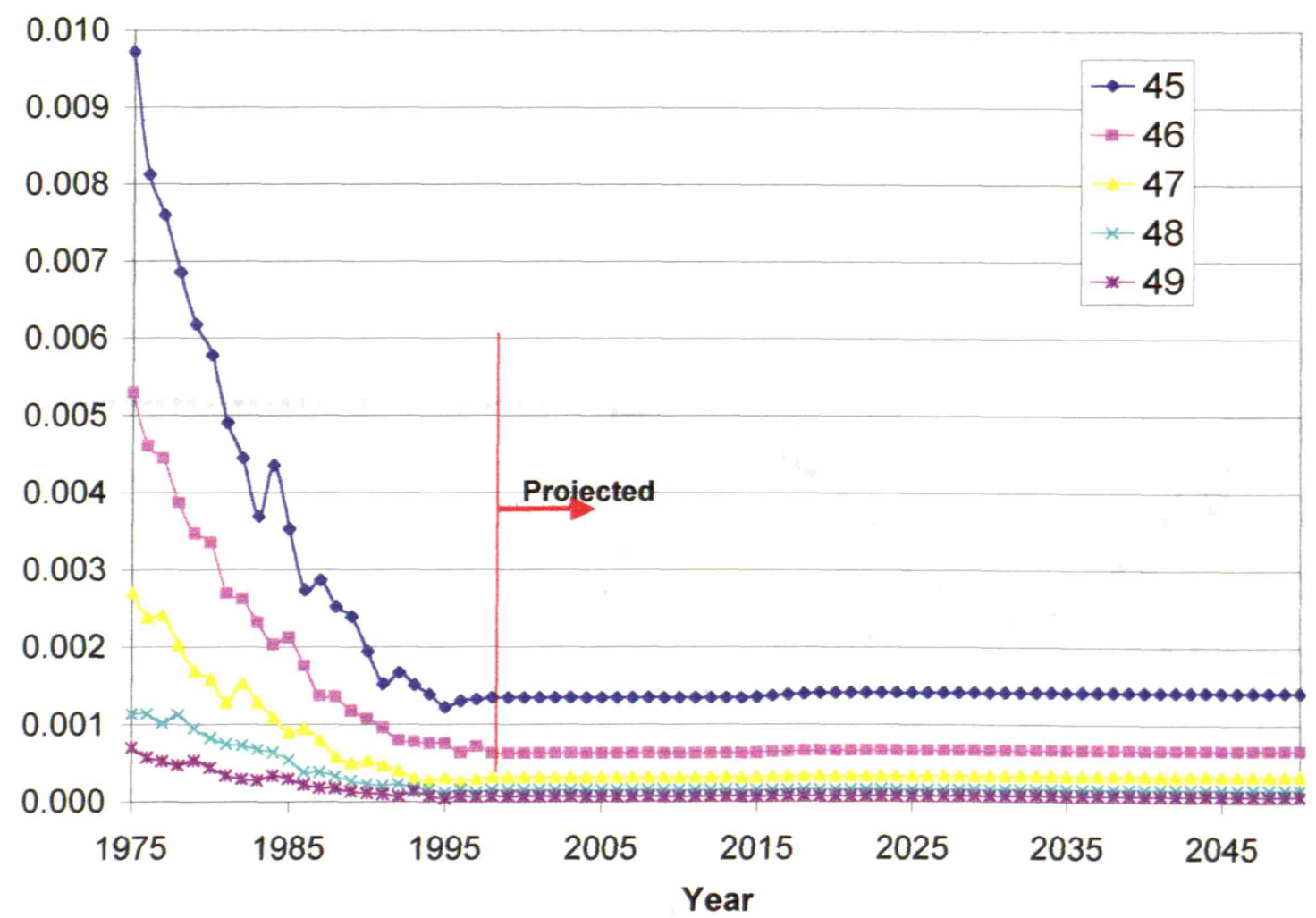

Figure A2.7. Recent trends and projections for fertility rates in women 45-49. 
Appendix 3. Estimating the effect of the non-linearity introduced by the maximum contribution and the maximum pensions. 


\section{Appendix 3. The effect of the maxima for contributions and pensions.}

\section{A3.1 Income Projections.}

To estimate the future contribution income, it will be assumed that contributions increase with real wages (productivity), inflation and total jobs in the economy as:

$$
C_{l}{ }^{y}=C_{l}{ }^{y-1}\left(1+q^{y}\right)\left(1+n^{y}\right)\left(1+\pi^{y}\right) ; C^{y}=C_{l}{ }^{y} f(s)
$$

Where: $C^{y}$ is the contribution (nominal) collected in year y. $C_{l}{ }^{y}$ is a dummy variable that represents the contribution calculated as if $f(s)=1 ; q^{y}, n^{y}, \pi^{y}$ are the productivity growth, job growth and inflation for year y. $f(s)$ is a function of the real salary level to account for the non-linear relation between salary and contributions introduced by the maximum CRB.

To estimate $f(s)$, the distribution of salaries must be known, with particular emphasis on the ratio that exceeds the maximum $\mathrm{CRB}$. If the $\mathrm{CRB}$ grew as the wages, this factor would be 1 for all the projection period. In this case contributions would remain a constant fraction of GDP, about $9.8 \%$. However, the CRB is set to grow with inflation and wages are projected to increase (in real terms) as productivity, in this scenario, $f(s)$ factor will be less than unity and decreasing with increasing level of real wages.

Data from INE for the structure of salaries in 1995 (Figure A3.1) is used with the assumption that the shape of the distribution will not be affected by the real salary increases (all salaries rise in similar proportions). The data does not include selfemployed workers or agricultural workers. These two segments typically have contribution levels far away from the maximum.

Figure A3.2 shows the calculated values for $f(s)$ as a function of the salary levels (in real terms) relative to the starting point for the projections, that is, the year 2000. For the projections, we assume that at the starting point, there is a segment of contributions (from self-employed, agrarian, unemployed) that grow in real terms as productivity (unaffected by the non-linearity introduced by the maximum). This segment was about $20 \%$ of contributions in 2000 . The other $80 \%$ of contributions came from workers with a salary structure as depicted in Figure 2 and thus would be significantly affected by the nonlinearity.

The $f(s)$ plot indicates that unless the rules for calculating the maximum CRB change, the real tax on earnings will decrease as real wages increase as a result of the higher percentage of workers earning salaries in excess of the maximum CRB. 


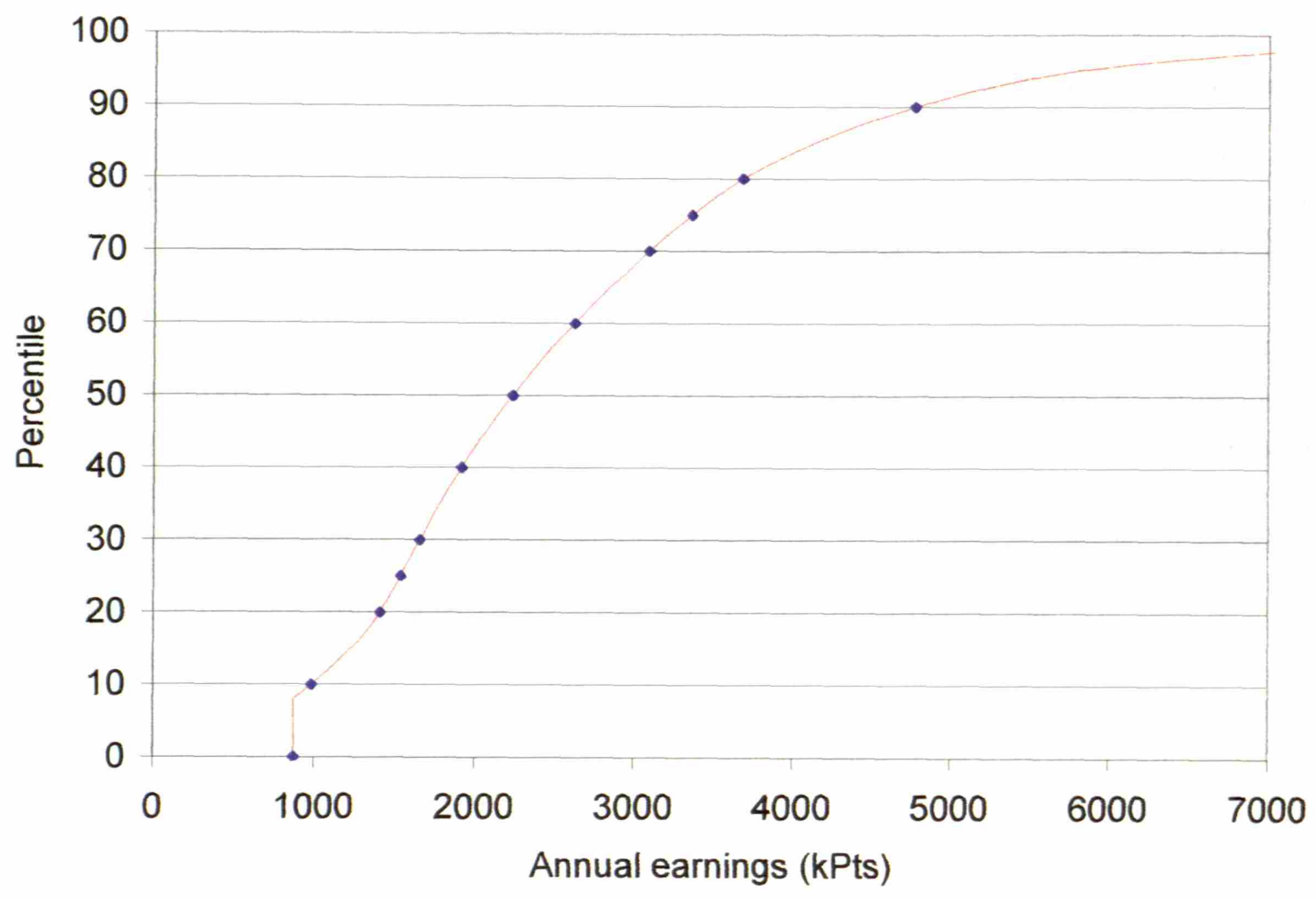

Figure A3.1. Salary structure in Spain, 1995. (Based on data from INE)

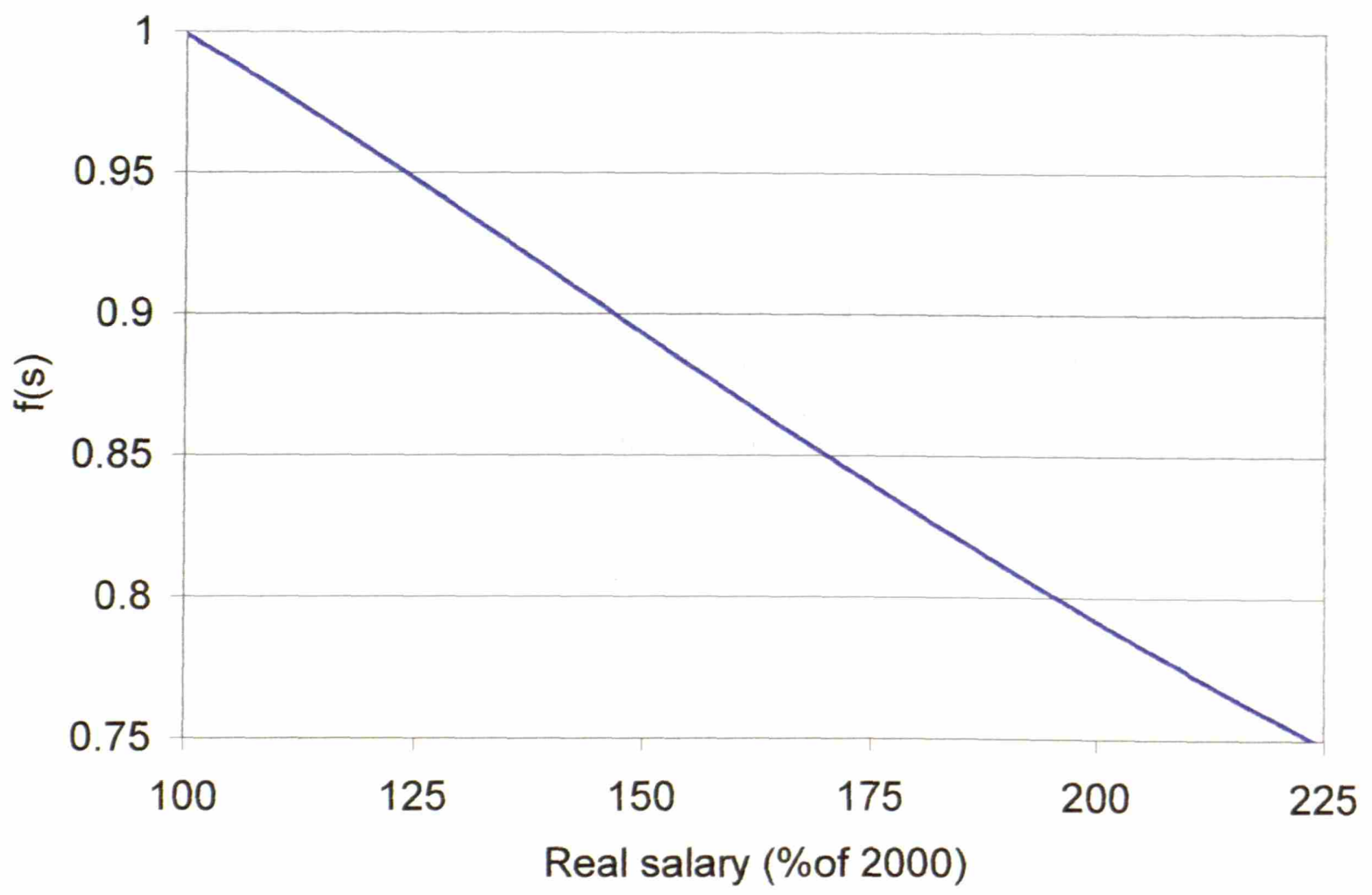

Figure A3.2. Calculation of $f(s)$ as a function of real wages (using the distribution in fig. A3.1) 


\section{A3.2 Expense Projections.}

\section{A3.2.1 Retirement Pensions.}

To take into consideration the effect of the non-linearity between salary increase and pension increase, the new pensions should be calculated by:

$$
A N_{l}(R)_{i}^{y}=A N_{l}(R)_{i-1}^{y-1}\left(1+\pi^{y}\right)\left(1+q^{y}\right) \text { and } A N(R)_{i}^{y}=A N_{l}(R)_{i}^{y} g(s)
$$

Where $A N_{l}(R)_{i}^{y}$ is a dummy variable that represents the contribution calculated disregarding non-linearity and $\mathrm{g}(\mathrm{s})$ is the function to account for the non-linearity. This function was estimated using a maximum pension on $4.25 \mathrm{mPts}$ for 2000 and assuming that $80 \%$ of the new pensions stem from a salary profile as in Figure A3.1. The other $20 \%$ grow as productivity $(\mathrm{g}(\mathrm{s})=1)$ to account for the self-employed, agricultural and other workers not included in the salary profile of Figure A3.1 that tend to generate significantly lower pensions. The function $g(s)$ was very similar to $f(s)$ shown in Figure A3.2.

\section{A3.2.1 Other Programs.}

The effect of the non-linearities on other programs was captured in this approximation as follows:

\begin{tabular}{|l|l|l|}
\hline \multicolumn{1}{|c|}{ Program } & \multicolumn{1}{|c|}{ New pensions grow as: } & \multicolumn{1}{c|}{ Reason } \\
\hline $\begin{array}{l}\text { Surviving } \\
\text { Spouse }\end{array}$ & Average retirement pension & $\begin{array}{l}\text { Most surviving spouse pensions derive } \\
\text { from the death of a pensioner, not an } \\
\text { active worker. }\end{array}$ \\
\hline $\begin{array}{l}\text { Surviving } \\
\text { Children }\end{array}$ & Average contribution & $\begin{array}{l}\text { Don't reach the maximum, but are } \\
\text { affected by the non-linearity because } \\
\text { the regulatory base grows as the CRB } \\
\text { with is not linear with salaries }\end{array}$ \\
\hline Family support & Average contribution & As above \\
\hline Temp. disability & Average contribution & As above \\
\hline Maternity Leave & Average contribution & As above \\
\hline Perm. disability & Average new retirement pension & $\begin{array}{l}\text { Affected by the maximum in a similar } \\
\text { way as retirement pensions }\end{array}$ \\
\hline
\end{tabular}


Appendix 4. The real rate on return. 


\section{Appendix 4. The real rate of return.}

A key factor in the success of the reforms proposed in sections 5 and 6 is to achieve a "good" return on the investment of the fund's assets. We have used a real rate of return of $5 \%$ for most of the simulations described in section 5 . This is slightly lower than the rate of $5.2 \%$ used in reference 17 for the US. This appendix offers some data about the historical performance of the Spanish stock exchange as well as the returns on government and corporate debt.

a) Stock market.

Figure A4.1 shows the monthly changes for Spain's broad index, the Indice General de la Bolsa de Madrid (IGBM) adjusted for changes in the CPI over the same month. The average return in the last fourteen years has been $0.62 \%$ per month. $0.62 \%$ monthly returns would compound to a yearly return of $7.71 \%$.

b) Government debt.

Figure A4.2 shows the return on the ten-year "risk-free" government bond. He real returns have fallen from levels typically between 4 and $6 \%$ prior to 1997 to below $2 \%$ last year. The low returns last year may be a result of the increase in inflation experience in 2000. This rate is unlikely sustainable within the EMU. Figure A4.3 compares the real return on Spanish 10-year bonds and German long-term public debt. The real return on the German bond is higher (about 3\%). This supports the hypothesis of the real returns on the Spanish bond in 2000 being abnormally low, as the spread in government securities has typically favored Germany. It can be reasonable to expect a real rate of return of about $2.5 \%-3 \%$ in the "risk-free" government debt market.

b) Corporate debt.

As noted in section 4.3.2, the market for corporate fixed income securities is very underdeveloped in Spain. In 1999, less than 10\% of corporate financing took the form of corporate bonds in Spain, compared with 30\% in the United States.

Figure A4.4 shows the available data on Spanish corporate bond returns (from Www.ine.es), The real returns follow a pattern somewhat similar to that of public debt, declining significantly in recent years. It is hard to get a good reading on the trends of corporate bond returns from the data in Figure A4.4, however, it is reasonable to expect a spread over the "risk-free" government bonds. Therefore, a real return of $3 \%$ on fixed income securities is not unreasonable.

A real return of $7 \%$ on equities and $3 \%$ on debt is precisely what was used in reference 17 to conclude that the pre-tax return on capital in the US is 8 to $8.5 \%$. This would leave a spread of 3 to $3.5 \%$ to reward the guarantor of a real return of $5 \%$. 


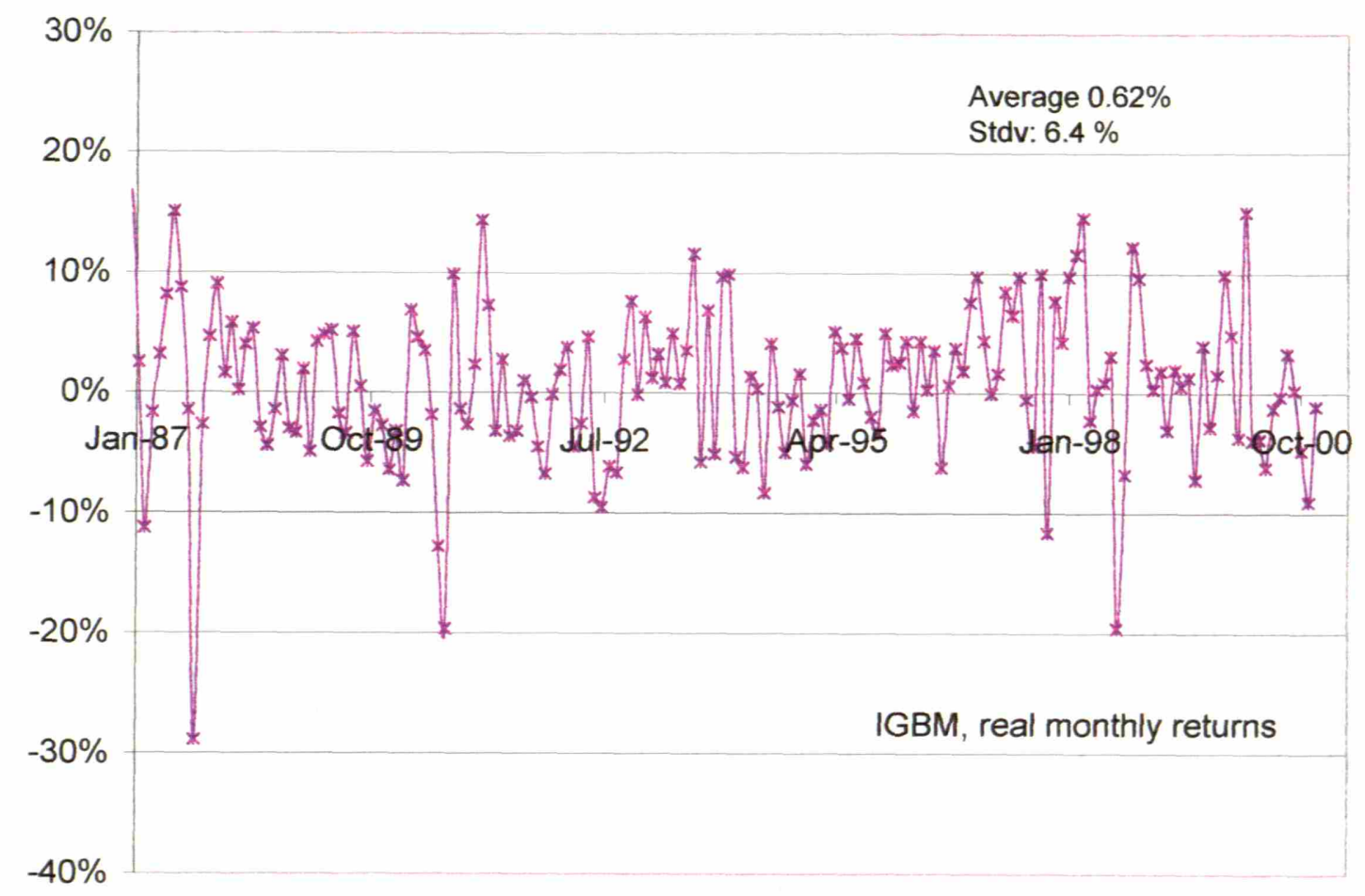

Figure A4.1. Monthly returns in the Spanish stock exchange adjusted by the CPI change. (Data from INE)

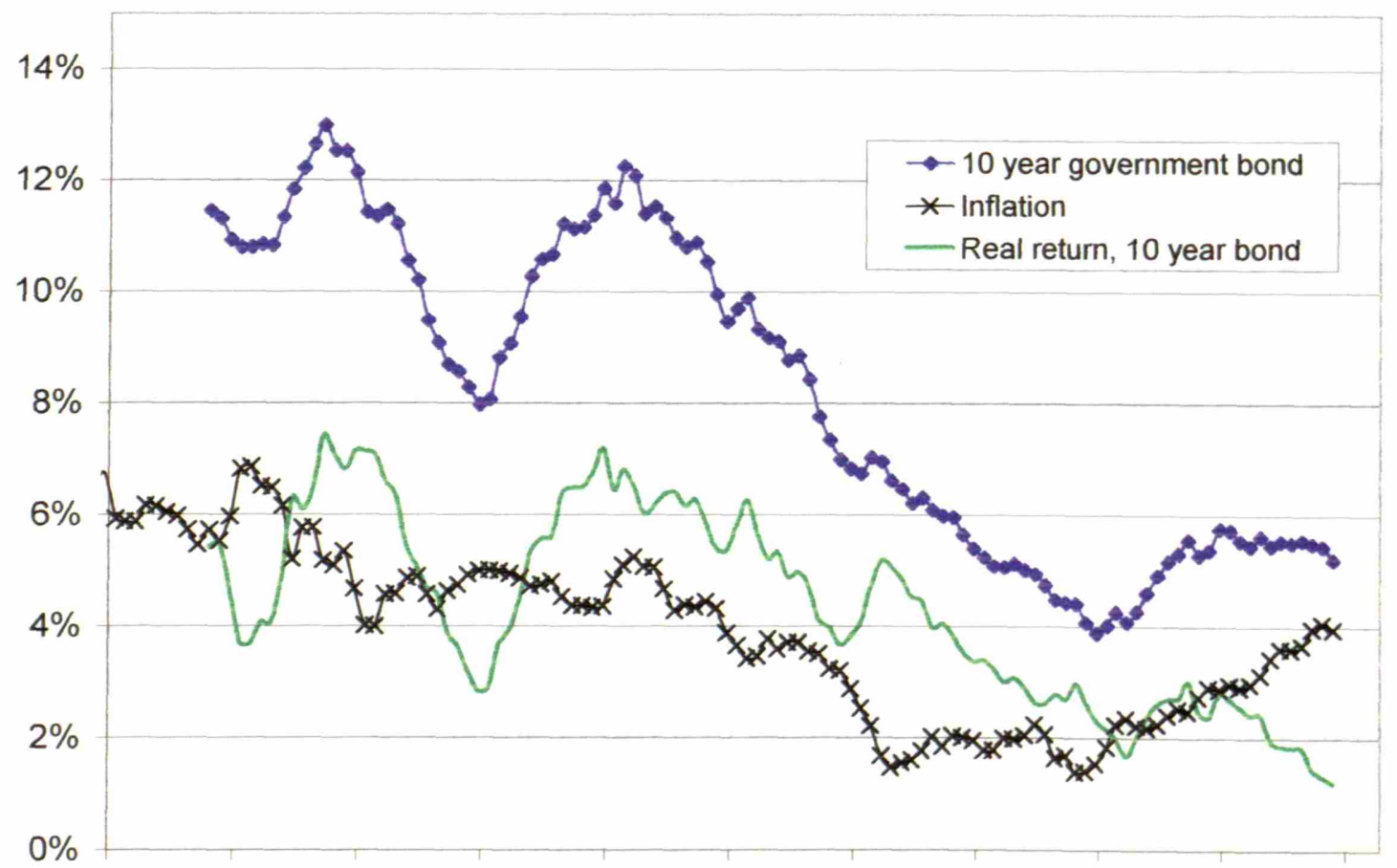

Jan-91 Jan-92 Jan-93 Jan-94 Jan-95 Jan-96 Jan-97 Jan-98 Jan-99 Jan-00 Jan-01

Figure A4.2. Return on government debt in the secondary markets (data from INE) 


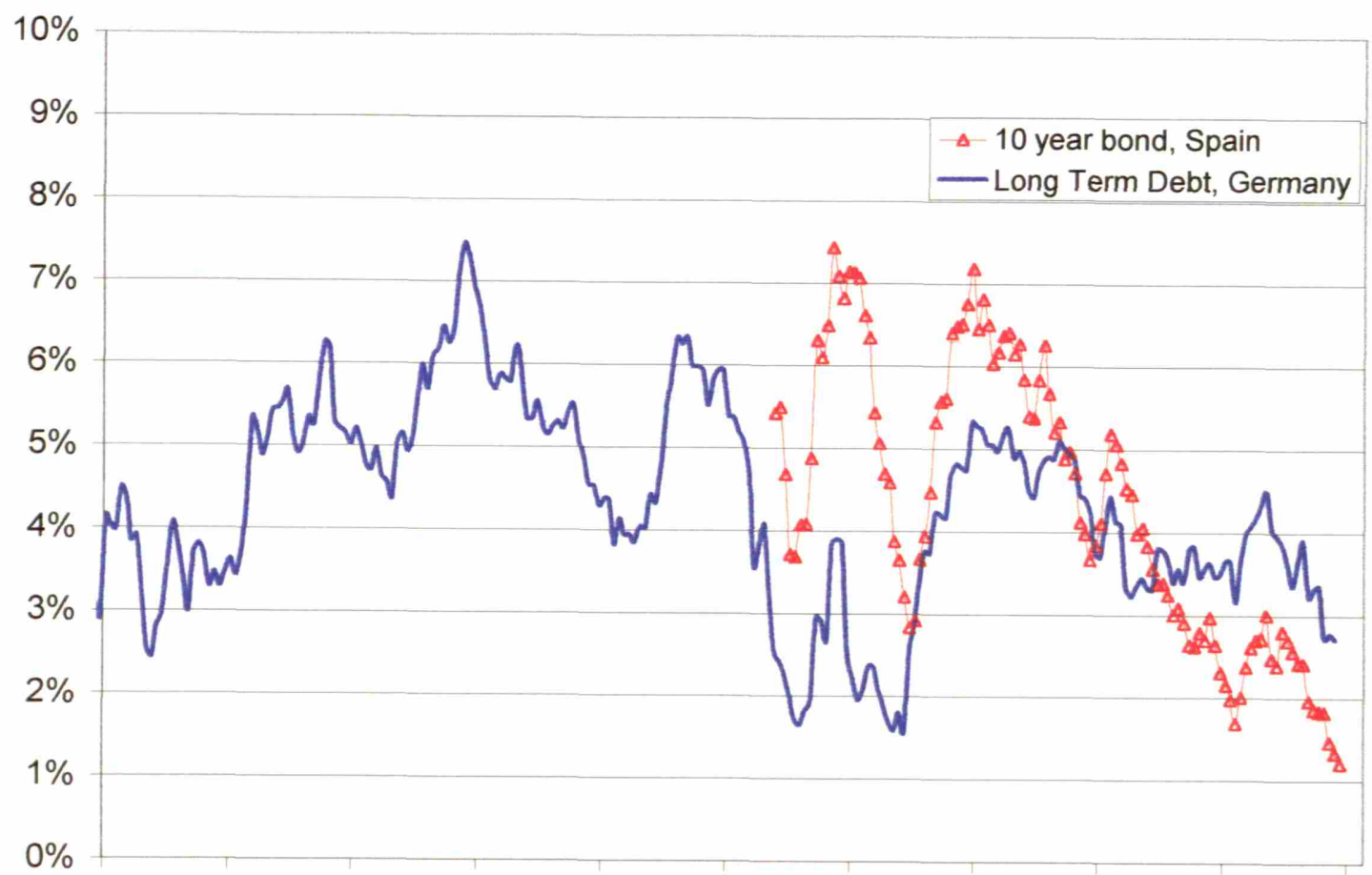

Jan-81 Jan-83 Jan-85 Jan-87 Jan-89 Jan-91 Jan-93 Jan-95 Jan-97 Jan-99 Jan-01

Figure A4.3. Real returns for Spanish and German government bonds. (Data from INE)

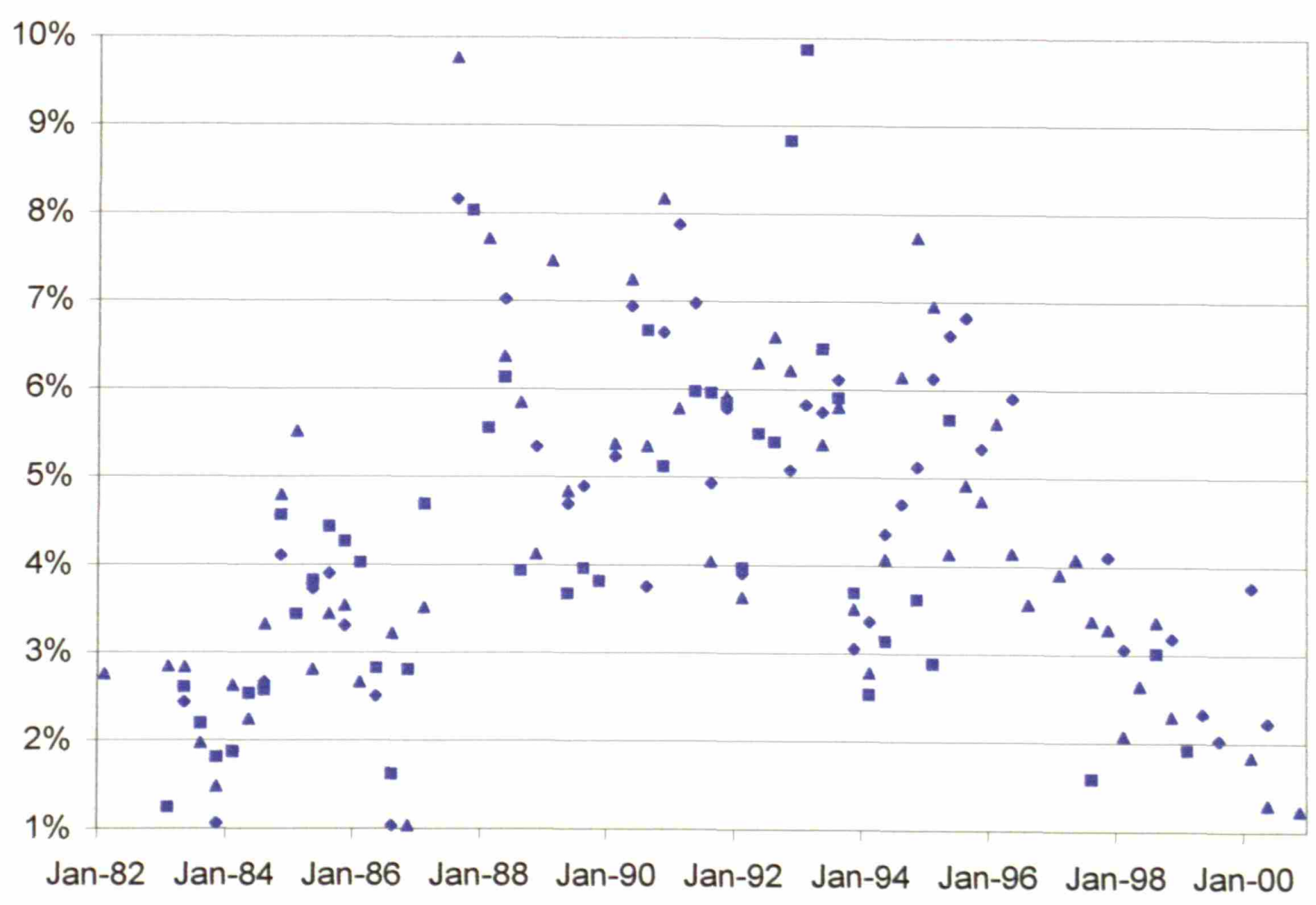

Figure A4.4. Real returns on Spanish corporate bonds (data from INE) 